NUREG/CR-1009

PNL-3040.3

R 1,3,4,5

\title{
REACTOR SAFETY RESEARCH PROGRAMS
}

\author{
Quarterly Report \\ July 1 - September 30, 1979
}

Pacific Northwest Laboratory

Prepared for
U.S. Nuclear Regulatory Commission 


\title{
NOTICE
}

This report was prepared as an account of work sponsored by the United States Government. Neither the United States nor the United States Nuclear Regulatory Commission, nor any of their employees. nor any of their contractors, subcontractors, or their employees, makes any warranty, express or implied, or assumes any legal liability or responsibility for the accuracy, completeness or usefulness of any information, apparatus, product or process disclosed, or represents that its use would not infringe privately owned rights.

\author{
PACIFIC NORTHWEST LABORATORY \\ operated by \\ BATTELLE \\ for the \\ UNITED STATES DEPARTMENT OF ENERGY \\ Under Contract EY-76-C-06-1830
}

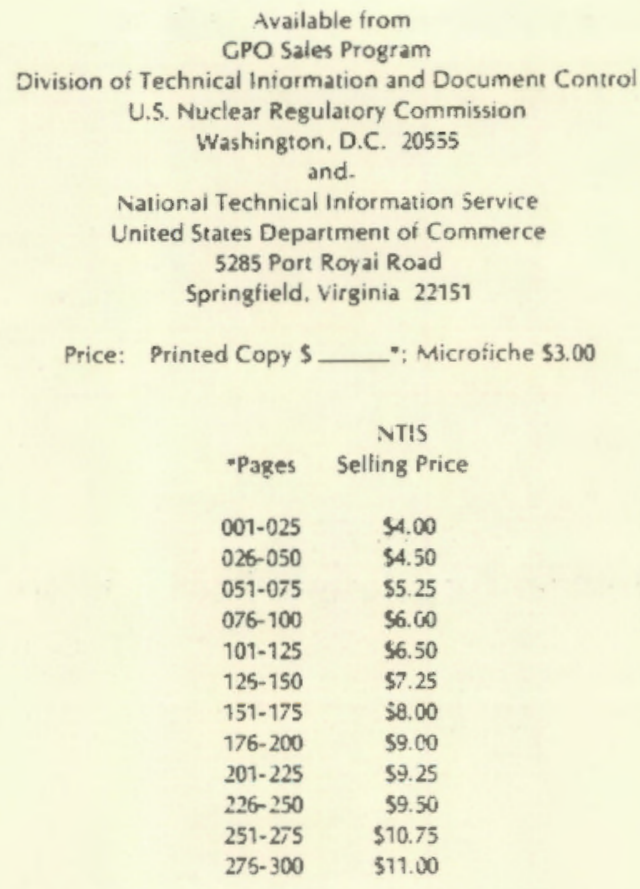


NUREG/CR-1009

PNL-3040-3

R $1,3,4,5$

\title{
REACTOR SAFETY RESEARCH PROGRAMS
}

\author{
Quarterly Report \\ July 1 - September 30, 1979
}

\author{
Compiled and Edited by \\ J. L. Hooper \\ Manuscript Completed: November 1979 \\ Date Published: March 1980
}

Pacific Northwest Laboratory

Richland, Washington 99352

Prepared for

Division of Reactor Safety Research

U.S. Nuclear Regulatory Commission

Under Contract No. EY-76-C-06-1830 


\section{FOREWORD}

This document summarizes the work performed by Pacific Northwest Laboratory from July through September 1979 for the division of Reactor Safety Research within the Nuclear Regulatory Comnission. Each program is considered separately and is discussed according to major tasks or topics, depending on the nature of the project. 


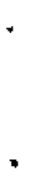




\section{CONTENTS}

FOREWORD
FIGURES 


\section{FIGURES}

EXPERIMENTAL VERIFICATION OF STEADY STATE CODES:

TASK A - IRRADIATION RESULTS

1 Comparison of Model 1 and 2 Calculations to Halden

Scram Data $. \quad . \quad . \quad . \quad . \quad . \quad . \quad . \quad$.

2 Comparison of the Estimated Fission Gas Release Fractions from

IFA-432 to the Predictions of the GASREL, FGASR!, and ANS54 GaS

Release Subroutines. The sinaded areas represent ranges of gas

release inferred from pressure transducer data.

GRAPHITE NONDESTRUCTIVE TESTING

I Eddy Current Response to Graphite Density Variations . . . 20

ACOUSTIC EMISSION-FLAW RELATIONSHIP FOR IN-SERVICE

MONITORING OF NUCLEAR PRESSURE VESSE:S

1 Specimen Geometry and AE Sensor Locations for SEN S.̣ecimen 2W-1B. . . . . . . . . . . . . . . . . 25

2 AE Count/Cycle Versus Fatigue Crack Growtin (FCij) Rate for SEN Specimen $2 W-13 . \quad . \quad . \quad . \quad . \quad . \quad . \quad . \quad . \quad . \quad 29$

3 Normalized Histograms of the AE Signal Energy as a Function of Position on the Load iwaveform. . . . . . . . . 30

4 Normalized Histograns of the AE Signal Energy as a Function of Test Temperature.

5 Correlation Coefficient Versus Sumation AE Signal Energy Range.

6 Correlation Coefficient Versus Incremental AE Signal

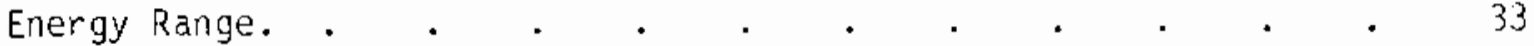

7 Fraction of the Total AE Count Versus Load Position Number . . 34

8 Concept for an On-Reactor AE Monitor for Flaw Detection and Evaluation.

FUEL SUBASSEMBLY PROCUREMENT AND IRRADIATION TEST PROGRAM

1 Lower Inlet Assembly Schematic 
2 Fuel Rod Array Simulating an $8 \times 8$ BWR Lattice . . . . 44

3 OPTRAN 1-3 Fuel Rod Types Showing Instrument Locations . . . 46

4 RIA 1-7 Fuel Rod Types Showing Instrument Locations . . . 46

5 Spacer Design and Bundle Elevations for Both the OPTRAN 1-3 and RIA 1-7 Test Trains . . . . . . . . 47

6 Shroud Side Plates 1 and 2 Showing Instrument Locations . . 49

7 Shroud Side Plates 3 and 4 Showing Instrument Locations . $\quad 50$

8 Core Region Instrument Array . . . . . . . . . . . 51

9 Outlet Flow Region . . . . . . . . . . . . . 54

10 Recombined Flow Region . . . . . . . . . . . . . 56

11 Restrictor Plate Showing the Position of the Four Hardline . . 58

12 Closure Region. . . . . . . . . . . . . . . . . 59

13 Vine-Rod Test Train Elevation Schematic . . . . . . . 60

14 Tost Tube Envelope Dimensions for Nine-Rod Test Train . • • • 61

CORE THERMAL MODEL DEVELOPMENT

1 Hot Wall Flow Regime . . . . . . . . . . . . 69

2 Top Flooding Models . . . . . . . . . . . . . . . 73

3 SCTF System Component Schematic for the COBRA/TRAC Model . $\quad 75$

4 Nodalization Diagram for the Two-Dimensional Vessel Component

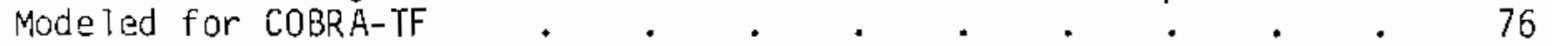

5 Average Liquid Fraction Below the Plane of the 3lockage

6 Average Liquid Fraction of the Center Bund les Compared with the Average Liquid Fraction of the Outer Bundles . . . 80

7 Radial Liquid Volume Fraction Distribution at $30 \mathrm{sec}$ and at $38 \mathrm{sec} . \quad . \quad . \quad . \quad . \quad . \quad . \quad 80$

8 Downcomer Liquid Flow Rate as a Function of Time. . . . . $\quad 81$ 
9 Hot Leg Vapor Flow Rate as a Function of Time. . . . . . 81

10 Hot Leg Entrained Droplet Flow Rate as a Function of Time. . . 82

11 Axial Temperature Profile for Rod 11 at Time

Zero, $20 \mathrm{sec}, 40 \mathrm{sec}, 60 \mathrm{sec}$, and $74 \mathrm{sec} . \quad . \quad . \quad . \quad 82$

INTEGRATION OF NONDESTRUCTIVE EXAMINATION RELIABILITY AND FRACTURE MECHANICS

1 Crack Depth Versus Thermal Cycles . . . . . . . . . . 90

2 Aspect Ratio Versus Crack Depth . . . . . . . . . . 90

3 Crack Propagation of Comparison Specimens . . . . . . . . . 92

4 Thermal Fatigue Fixture for 10-in. Pipe. . . . . . . . 93

5 Utrasonic Response from Angled Slits, 1/2-V Path, 450 Beam. . . . . . . . . . . . . . . . 96

6 UTtrasonic Response from Angled Sitts, Fill-V Path, $45^{\circ}$ Beam. . . . . . . . . . . . . . . . . 96

7 Uitrasonic Response from Angled Sits, 3/2-V Paih, 450 3eam. . 97

8 Ultrasonic Response from Anigied Slits, $1 / 2-V$ Pati, $60^{\circ}$ Beam.

9 Ultrasonic Response from Vertical Slits in Angled Back

Surfaces, 1/2-V Patin, $45^{\circ}$ Beam. . . . . . . . . 98

10 Ulirasonic Response from Vertical Slits in Angled Back

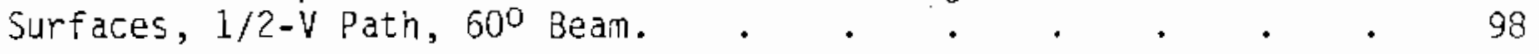

11 Satellite Pulse Technique for Crack Sizing . . . . . . 103

12 Electrical Resistance Gauge Performance in Measurement of
Bending Fatigue Crack Depti . . . . . . . . . . 104

i3 - $6 d$ B Probe Motion in Shadow Technique Inspection of Bending Fatigue Cracks . . . . . . . . . 106

$-20 \mathrm{~dB}$ Probe Motion in Pulse-Echo Inspection of Bending
Fatigue Cracks....
.

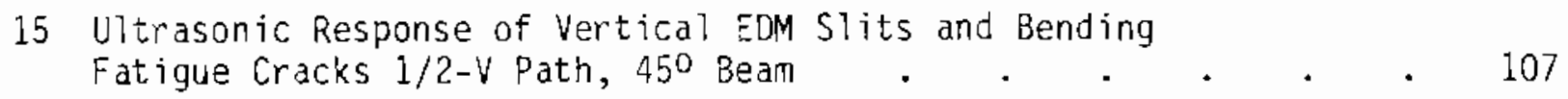


16 Theoretical Ultrasonic Refiection Coefficient of Air and Water Filled Cracks with Varying Crack Tightness, for $2.25 \mathrm{MHz}$ Shear Wave at 450 . $. \quad . \quad . \quad . \quad . \quad . \quad . \quad . \quad . \quad 108$

17 Four-Point Bending Fixture, Ultrasonic Inspection Instrument and Transducer. $\quad . \quad$. . . . . . .

18 U1trasonic Response of Bending Fatigue Crack A153 with Varying Force Applied to Four-Point Bending Fixture . . 111

19 Uitrasonic Response of Bending Fatigue Crack A161 with Varying Force Appliad to Four-Point Bending Fixture . . . . 111

20 U1trasonic Response of Bending Fatigue Crack A141 with Varying Force Applied to Four-Point Bending Fixture . . . . . . 112

21 Change in Ultrasonic Response of Bending Fatigue Crack upon Compression to $75 \%$ of Yield Stress . . . . . . . . 114

22 Ultrasonic Response of Bending Fatigue Cracks Compressed to $75 \%$ of Yieló Stress . . . . . . . . . . . . 114

23 Uitrasonic Response of Bending Fatigue Crack A155 (Annealed) with Varying Force Applied to Four-Point Bending Fixture . . 116

24 Utrasonic Response of Bending Fatigue Crack A156 (Annealed) witn Varying Force Applied to Four-Point Bending Fixture .

25 UTtrasonic Response of Thermal Fatigue Crack B103 with Varying Force Appliad to Four-Point Bending Fjxture. . . . . . . 121

26 Ultrasonic Response of Thermal Fatigue Crack B105 with Varying Force Applied to Four-Point Bending Fixture. . . . . . . 121

27 Uttrasonic Response of Thermal Fatigue Crack B113 (Annealed) with Varying Force Applied to Four-Point Bending Fixture. . $\quad 122$

28 Utrasonic Response of Thermal Fatigue Crack Bl16 (Annealed) with Varying Force Applied to Four-Point Bending Fixture.

\section{STEAM GENERATOR TUBE INTEGRITY}

1 Experimental Configuration of DaedaTeans Internal Friction Device

2 Weld Configuration of $4^{\prime \prime}$ sch 80 Pipe Specimens . . .

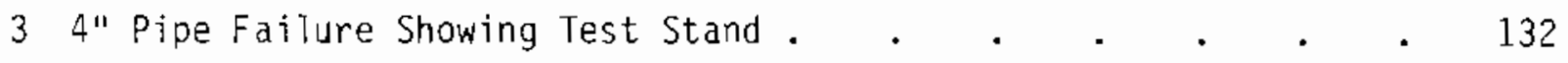

4 Pipe Failure with Loading Ram Detajl . . . . . . . . 133 
5 4" Pipe Exhibiting Fai7ure Mechanism of Several Cracks Growing Together. Also Apparent is the Large Extent of Failure . . . . . . . . . . . 134

6 Details of the Fracture Surface of Specimen Shown in Figure 5. 135

7 Details of Fracture Surface in Figure 5 . Note the Dark Region Showing the Extent of Crack Growth Prior to Final Pipe Failure . 136

8 Typical EDM Notched Tubing Fracture Surfaces used to Evaluate Use of Post Faifure Crack Morphology to Determine Initial Crack Depth . . . . . . . . . . . 137

9 Standard Deviation Plot of Predictive Mathematical Model for Burst Pressure of Tubing with Uniform Thinning Defect . . . 139

10 Standard Deviation Plot of Predictive Mathematical Model for Burst Pressure of Tubing with EDM Slot Defect . . . . 139

11 Standard Deviation Plot of Predictive Mathematical Model for Burst Pressure of Tubing with Elliptical Nastage Defect . . 140

12 Standard Deviation Plot of Predictive Mathematical Model for Collapse Pressure of Tubing with Uniform Thinning Defect . . 140

13 Standard Deviation Plot of Predictive Mathematical Model for Collapse Pressure of Tubing with EDM Slot Defect . . . . 141

14 Standard Deviation Plot of Predictive Matnematical Model fo: Collapse Pressure of Tubing with Elriptical Nastage Defact. . 141

15 Artist's Rendition of Steam Generator Examination Facility,
Based on Conceptual Design . . . . . 143 


\section{TABLES}

EXPERIMENTAL VERIFICATION OF STEADY STATE CODES:

TASK A - IRRADIATION RESULTS

1 Rod Types for Error Anaiysis $\quad$. . . . . . . . . . 12

ACOUSTIC EMISSION-FLAW RELATIONSHIP FOR IN-SERVICE

MONITORING OF NUCLEAR PRESSURE VESSELS

1 Fatigue Loading Conditions for FCG Testing of Specimen 2W-1B $\quad 27$

FUEL SUBASSEMBLY PROCUREMENT AND IRRADIATION TEST PROGRAM

1 Inlet Housing Instrumentation . . . . . . . . . . 42

2 Core Region Instrumentation . . . . . . . . . . . . . . 52

3 Fuel Rod Instrumentation . . . . . . . . . . . . 52

4 outlet Assembly Instrumentation . . . . . . . . . 55

5 Recombined Flow Region Instrumentation . . . . . . . 57

INTEGRATION OF NONDESTRUCTIVE EXAMINATION RELIABILITY AND

FRACTURE MECHANICS

1 Surface Roughness Comparison of the Mechanical Bending and

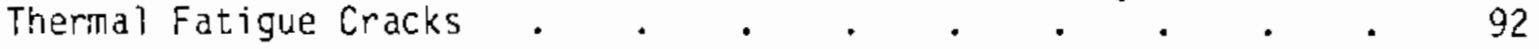

2 Yield Stress of Cold-Rolled and Annealed Samples . . . . . 103

3 ERG Depth Measurement Performance on Thermal Fatigue Cracks . $\quad 119$

STEAM GENERATOR TUBE INTEGRITY

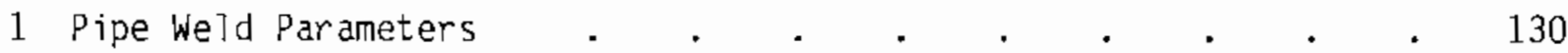





\section{ULTIMATE HEAT SINK PERFORMANCE MEASUREMENT ${ }^{(a)}$}

R. K. Had1ock, Project Manager

\section{SUMMARY}

Four-week-long measurements were initiated at the Department of Energy's Geothermal Component Test Facility, East Mesa, California, in early September. Thermal performance and water utilization data were obtained for several episodes of cooling pond and spray pond cooling from an initially warm temperature in the range of $105^{\circ}$ to $130^{\circ} \mathrm{F}$. These data complement those obtained previously at the Raft River site in southern Idaho. It is anticipated that final measurements wi 11 be conducted for hot pond temperature in July-August 1980, at the East Mesa site.

\section{INTRODUCTION}

The presenty defined scope of the Ultimate Heat Sink Progran at Pacific Nortinwest Laboratory (PNL) includes continuation and completion of cooling pond and spray pond measurements and formulation of data volumes and suggestions for modeling improvements. Measirements were initiated at the Raft River, Idaho, geothermal facility and nave been continued at the East Mesa, California, Geothermal Component Test Facility, managed by WESTEC Services, inc. For the U.S. Departinent of Energy. The geothermal retention basins have provided analogs to ultimate heat sinks of emergency core cooling systems, in both cooling pond and spray pond modes. The measurements have produced data of thermal performance and water utilization for various conditions including short-term, worst-case combinations of meteorological influences. Work during the past quartar has enabled the acquisition of comparative data of cooling pond and spray pond performance for warm $\left(105^{\circ}-130^{\circ} \mathrm{F}\right)$ initial pond

(a) RSP Fin. Budget No. B2081-8; RSR Contact: R. F. Abbey, Jr. 
temperature. The same facility is expected to be used for a final measurement program in the sumer of 1980 designed to study performance for hot initial pond temperature.

\section{IECHNICAL PROGRESS}

With the primary exceptions of data acquisition for the case of the hot pond in the spray mode and the complementary common-site cooling pond data, measurements and data collection are complete. With input from the U.S. Nuclear Regulatory Commission during an East Mesa site visit, plans are to report the Raft River data in useable format soon. It is expected that the 1979 East Mesa data, in useable format, will be reported shortly after that.

\section{FUTURE PLANS}

PNL expects to contract with WESTEC Services, Inc., for a sufficient availability of not water to enable hot pond studies during the sumner of 1980. These measurements are expected to complete the data required for production of comprehensive published data volumes prior to January 1, 1981. The data will be provided in useable, but not publishable, format at timely intervals much prior to the project termination date. The data will be assessed to provide input for suggestions on modeling improvement to be submitted with the data volumes. 


\section{EXPERIMENTAL VERIFICATION OF STEADY STATE CODES:}

TASK A - IRRADIATION RESULTS (a)

C. R. Hann, Program Manager

D. D. Lanning, Program Manager

E. R. Bradley

M. E. Cunningham

R. E. Williford

\section{SUMMARY}

Two heavily instrumented six-rod assemblies, IFA-431 and IfA-432, have been irradiated at Halden, Norway. A third assembly, IFA-513, jointly sponsored by the Nuclear Regulatory Commission (NRC) and the Halden Project, began irradiation in late Novenber, 1978, and construction on a fourth assembly began this quarter. Analys is of IFA-432 and IF̈A-513 data has proceeded as planned. The work is now divided into four subtasks: 1) project management, 2) coordination of irradiation tests, 3) data processing and Jata reporting, and 4) data analysis. Several Pacific Northwest Laboratory and NRC docunents have been completed so far this year.

\section{INTRODUCTION}

The objectives of the Experimental Verification Program are to obtain we 11-characterized data on fuel temperatures, pellet-clad interaction, and gas release for typical light water reactor (LWR) fuel. These data are to be ised by NRC to verify steady-state fuel perforinance computer codes.

Two heavily instrumented six-rod assemblies, IFA-431 and -432 , have been irradiated under the program. The rods contain fuel pellets of U.S. boiling water reactor (BWR) size and fuel type with some variations. The variations include 1) gap size (range to include instantaneous relocation to instantaneous densification), 2) fill gas (a xenon-filled rod was included), and

(a) RSR Fin. Budget No. B2043; RSR Contact: H. H. Scott 
3) fuel density type ( $92 \%$ dense pellets with stable and unstable fuel relative to densification). The instrumentation included fuel centerline thermocouples in each end of each rod, one cobalt and six vanadium neutron detectors, cladding elongation detectors on 211 six rods, and pressure transducers on three of the six rods.

A third assemb 1y, IFA-513, began irradiation in November, 1978. The fuel lengths of the six IFA-513 rods are each $0.78 \mathrm{~m}$ versus $0.57 \mathrm{~m}$ for IFA-431 and -432. There are thermocouples in each end of each rod and bellows-type pressure transducers and cladding extensometers on each rod. The assembiy includes four replicate rods of BWR design (one with pressurized fill gas) and two rods with Xe-He gas mixtures. The latter have provided data, at known gas composition, on the degradation effect of fission gas on rod thermal performance. Some data on the possiblitity of gas segregation in a typical fuel rod have also been gained. The replicate rods will provide statistical information on the behavior of identical rods that are operating identically. The assembly has now attained peak burnup of approximately $6000 \mathrm{MWd} / \mathrm{MTM}$.

Construction began at Halden this quarter on the 4th and last assembly to be irradiated under this program. This assembly, IFA-527, features 6 rods, a 11 containing $\mathrm{UO}_{2}$ fuel pellets of the $95 \%$ theoretical density, stable fuel type, $9.90 \%$ enriched. The rod design and assembly instrumentation will be identical to that for IFA-513, with two exceptions: a11 rods will be filled with xenon gas and one rod will have a 50-um diametral gap as opposed to the standard 230- $\mu \mathrm{m}$ gap. The purpose of IFA-527 is to measure the speed, extent and variability of ficel relocation. The xenon gas will both magnify the thermal effect of relocation and prevent fission gas release from masking those effects.

The scope of Task A (Irradiation Results) has been to attempt to collate and anaiyze these data, which are normally taken every 15 min while the reactor is running. The activities related to data reporting and analysis are described below. 


\section{SUBTASK A-3 - DATA PROCESSING}

A startup data report for IFA-513 was prepared and published. This report (Lanning and Cunningham 1979) presents data on assembly power calibration, compares observed behavior to predicted response, and provides an analysis of beginning-of-life transient thermal data. The startup data was highly consistent with that from IFA-431/432. Five instruments failed on or before startup: two upper center line thermocouples, two gas pressure transducers, and one cladding elongation sensor. No additional instruments have since failed.

A report on the post-irradiation examination of IFA-431 was written (Neally et a1. 1979). Th is report has received review comments and will be published next quarter.

A precharacterization report for IFA-513 was drafted this quarter and will be reviewed and published next quarter.

Further data tapes for IFA-432 and IFA-513 were translated, corrected, and placed onto disk storage for future use.

\section{SUBTASK A-4 - DATA ANALYSIS}

Activities of Subtask A-4 have included 1) estimation of fuel relocation from fuel thermocouple data, 2) analysis of transient data, 3) analysis of fission gas release (pressure transducer) data, 4) analys is of xenon rod data, and 5) error analysis of code applications.

\section{FUEL RELOCATION ANALYSIS}

A thorough discussion of the basic concepts we will use in fuel ralocation modeling and fuel rod mechanics appeared in the last quarterly report (Hann et al. 1979). A document on this subject is under preparation. A synopsis of the major results is given below.

Most fuel performance codes model tuel rods by using concentric solid cylinders. We have proposed and quantified an alternate modeling concept for 
cracked fuel and have constructed a method by which to apply this model to inpile data. The primary variable of the model is the available void (free volume) within the fue 1 rod and its distribution between fue 1 cracks and pellet-cladding gap. The void distribution is in turn dependent on three primary model parameters: effective crack roughness, effective gap roughness, and crack pattern. The model yields internally consistent thermal-mechanica? results when applied to power/temperature/cladding elongation data sets.

Beginning-of-life data for the above assemblias was analyzed because of its freedom from confusion by fission gas release and the relatively rapid fuel structural changes due to progressive cracking. We have found that the effective thermal conductivity of cracked pellets is $10 \%$ to $30 \%$ less than that of solit $\mathrm{UO}_{2}$ for a typical 3WR rod under normal operating conditions. This is accompanied by a reduction in elastic modulus of at least one order of inagnitude. The cracked fuel column also exhibits anisotropy, the axial elastic modulus being about one half an order of magnitude less than the radial modulus. Out-of-pile experiments have verified these results. The prediction of pelletized fuel system evolution was found to be sensitive to the three prinary model parameters.

Since the cracked fuel column cannot remain erect without the cladding, there is always pellet cladding contact, and finite stress levels were found to exist within the rod at all times. Thus, the solid concentric cylinders approach to fuel modeling was found to be inadequate for the prediction of integrated thermal-mechancal fuel rod behavior. Recommendations are made that will contribute to the correction of this situation.

\section{TRANSIENT DATA ANALYSIS}

In previous quarterly reports we have proposed two extreme models for heat transfer in the fuel rod:

Model 1: In this model there are no fuel cracks so there is no impediment to radial heat flow caused by fuel cracks. The changes in gap conductance with power are assumed to be dominated by the thermal expansion of the fuel and cladding, which in turn is related to their respective temperatures. Since, over the range of the power 
decrease, the change in temperature with power is fairly uniform across the entire rod, a linear dependence of gap conductance on the volume-averaged fuel temperature will be assumed.

Model 2: In this model the fuel has many small and randomly oriented cracks, causing crack impediment to the radial flow of heat, which can be accounted for by a temperature-dependent multiplier on the fuel thermal conductivity. The fuel is envisioned to be fully relocated to the cladding, so that over the range of the power decrease there is little change in the gap conductance. The change in resistance with power is presumed to be totally due to the change in effective conductivity, dominated by the crack factor. The multiplier on conductivity is assumed to be linearly dependent on the volume-averaged fuel temperature (presuming this to be a guide to pellet-cladding mechanical interaction that could close the fuel cracks upon increasing power).

Both mode ls have been applied to data from $20 \%$ step power decreases in IFA-432 and IFA-513 and Model 2 has consistently matched that data more closely (Lanning and Cunningham 1979). However, it is not clear that this would be the case for a full scram ( $96 \%$ sudden power decrease). One would expect some fuel shrinkage with a full scram, such that Model 1 or some model intermediate between 2 and 1 would best match the data. On the contrary, scram data received from Halden upholds Mode1 2. An example of these data and comparative Model 1/Model 2 predictions are shown in Figure 1.

\section{PRESSURE DATA ANALYSIS}

The draft IFA-431/432 report has been written, reviewed internal7y, and is in the final stages of preparation. The report analyzes the internal fuel rod pressure data from these assemblies and thereby estimates the fission gas release. Finally, the est imated gas release as a function of burnup is compared to the calculated releases from models currently being considered for the FRAPCON series of computer codes. Nameiy, the GASREL (Beyer et al. 1975), FGASRL (Reymann 1978), and the ANS54 (Rausch and Panisko 1979) subroutines were used for the comparisons. 


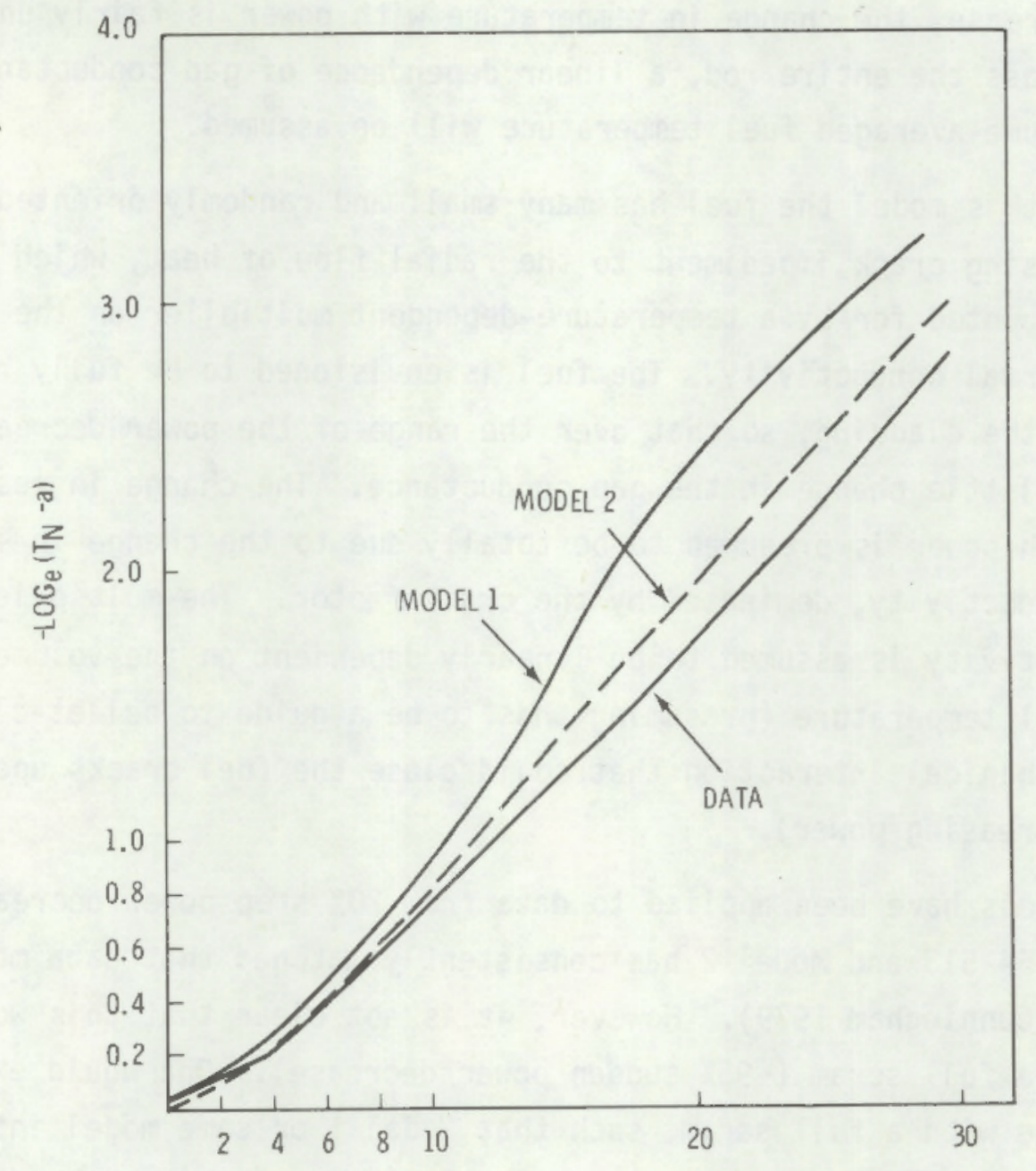

TIME, seconds

FIGURE 1. Comparison of Model 1 and 2 Calculations to Halden Scram Data

Figure 2 shows the comparison between the predictions from the three models and est imated gas release from the fuel rods that exhibited fission gas release, i.e. the rods from IFA-432. As can be seen, differences exist between the models with regard to both the manitude and burnup dependence of fission gas release. The subroutine GASREL calculates lower release fractions than FGASRL at all burnups. The release fractions from ANS54 approach the values from GASREL at burnups below $<400 \mathrm{GJ} / \mathrm{kgU}$ ( $5 \mathrm{GWd} / \mathrm{MTM}$ ) and approach or exceed the FGHSRL values at higher burnups because of the imposed burnup dependence. 
The calculations were based on the measured temperature/power $h$ istories of the fuel rods. Burnup increments of either 86 or $172 \mathrm{GJ} / \mathrm{kgU}$ (1 or 2 GWd/MTM) were used and the fuel column was divided into four axial segments, each about $150 \mathrm{~mm}$ long. The measured centerline temperatures were used for the end segments, and the axial power distribution was used to estimate the temperatures at the inner segments. After the upper thermocouples failed, the temperature difference between end segments was estimated from the difference in local power levels assuming a constant thermal resistence of $0.036 \mathrm{~m}-\mathrm{K} / \mathrm{W}$.

The radial temperature distributions were calculated by the integral conductivity equation using the centerline temperature as the reference point. The experimentally determined thermal conductivities for each fuel type (Hann et al. 1977) were used for the calculations shown in Figure 2. However, the effective fuel conductivity during irradiation is expected to be up to $25 \%$ lower than the preirradiated value because of fuel cracking. Therefore, the preirradiated conductivities were decreased by $25 \%$ and the fission gas release fractions were recalculated.

Decreasing the assumed fuel conductivities lowered the fuel surface temperature inferred from the measured centerline temperature, which in turn led to reduced gas release. The magnitude of the decreases in the fission gas release fractions was about $10 \%$ for GASREL, whereas $20 \%$ - $25 \%$ reductions were observed for the FGASRL and ANS54 calculations. The large reductions in the FGASRL and ANS54 calculations reflect the strong temperature sensitivity of these models. The primary conclusions of the report are as follows:

- Fuel temperature is the predominant factor influencing fission gas release.

- Fuel density has only a minor influence on fission gas release.

- Burnup enhancement of fission gas release is not significant to 1700 GJ $/ \mathrm{kgU}$ (20 GWd/MTM) in stable fuel types.

\section{XENON ROD ANALYSIS}

The report examining the beginning of life behavior of Rod 4, IFA-432 was publ ished (Cunningham, Williford, and Hann 1979). 

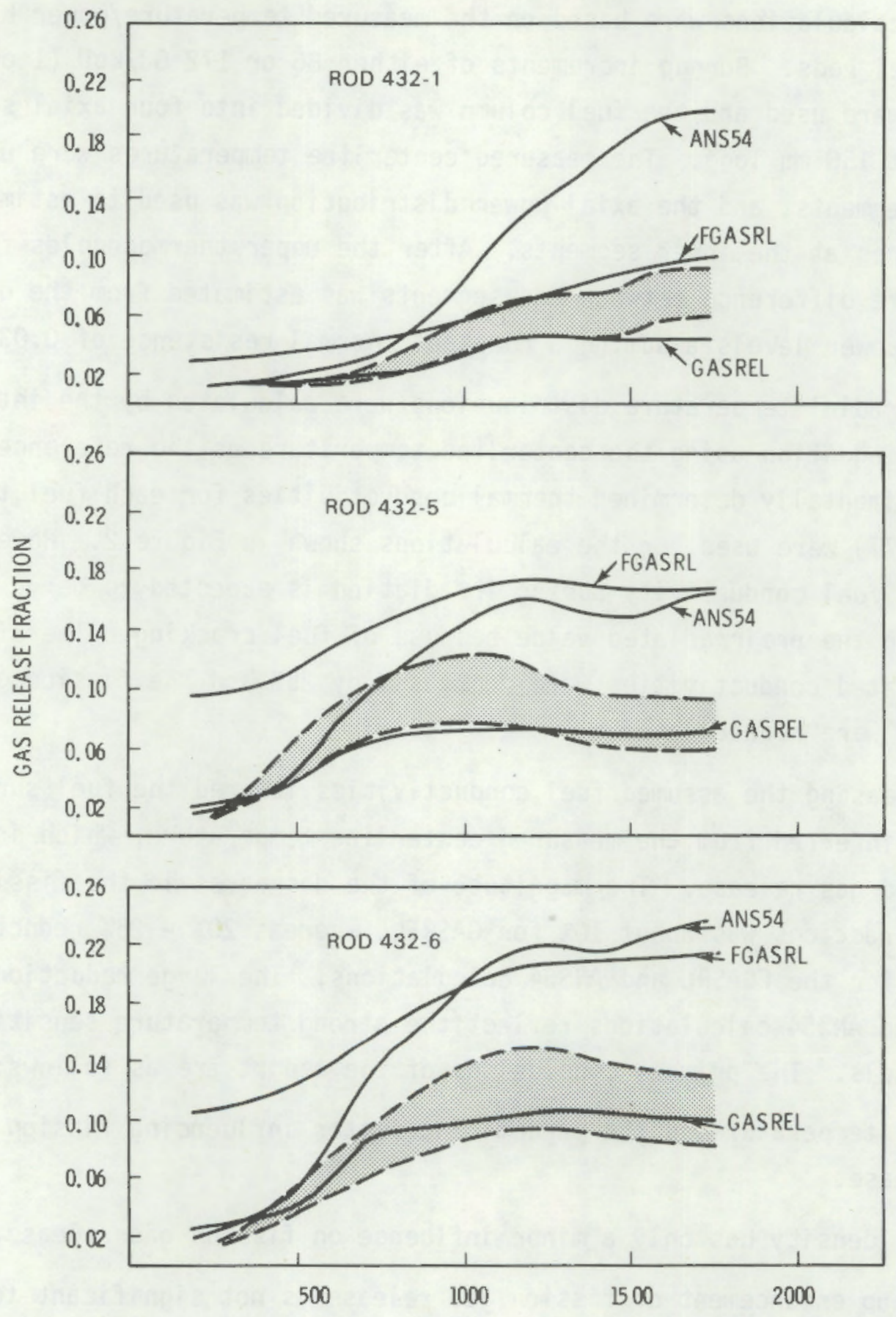

AVERAGE BURNUP, GJ/kgU

FIGURE 2. Comparison of the Estimated Fission Gas Release Fractions from IFA-432 to the Predictions of the GASREL, FGASRL, and ANS54 Gas Release Subroutines. The shaded areas represent ranges of gas release inferred from pressure transducer data. 
The report on the life history behavior of Rod 4, IFA-431 (Cunningham, Lanning, and Hann 1979) completed review and will be published next quarter.

\section{ERROR ANALYSIS}

The error analysis currently being undertaken for this task has three main objectives. They are 1) uncertainty analys is of pressurized water reactor (PWR) stored energy calculations, 2) an analysis of bias between data and code predictions, and 3) an attempt to evaluate possible changes in uncertainty for predicted temperatures when using a fuel pellet model that is no longer a solid right-circular cylinder.

The work done this quarter has concentrated on the first objective-evaluation of PWR uncertainty. This evaluation is using the linear propagation technique previously applied to BWR fuel rods (Cunningham et al. 1978). Five fuel rod types, including BWR rods, have been selected for comparison. The BWR rods are included because of some analysis changes, and a different assumed operating history. Table 1 lists the rod types and their design parameters. The assumed operating history consists of two cycles of 10,000 MWd/MTM burnup each. Each cycle begins with a peak power of $33 \mathrm{~kW} / \mathrm{m}$, with the time per cycle being dependent upon the burnup accumulation rate for each rod type.

Some initial calculations have been made. GAPCON-THERMAL-3 (G-T-3) (Lanning et al. 1978) runs were made for the five rod types. These runs form the base of the uncertainty analys is by providing history-dependent parameters to the uncertainty code STORE. (Cunningham et al. 1978). Two user convenience changes have been made to STORE. First, gas composition and uncertainty, rather than gas thermal conductivity, is now input; the thermal conductivity is calculated internally. Second, an iterative scheme for matching temperatures between STORE and G-T-3 has been automated. Initial STORE runs have been made for the rod designs, but the results have not been evaluated. 
TABLE 1. Rod Types for Error Analysis

Design Parameter

\section{Fuel Diameter, mm}

Cladding ID, mm

$C l$ adding $O D, m$

Density, \%TD

Enrichment, \%

Fill Gas Pressure, MPa

Coolant Inlet Temperature, $\mathrm{K}$

Coolant Pressure, MPa

\begin{tabular}{ccc} 
PWR $15 \times 15$ & PWR $17 \times 17$ \\
\cline { 1 - 1 } 9.31 & & 8.19 \\
9.50 & & 9.36 \\
10.77 & & 9.50 \\
94 & 95 \\
2.8 & 2.6 \\
2.38 & 2.03 \\
561 & 561 \\
228 & 228
\end{tabular}

BWR $7 \times$

12.37

12.67

14.30

94

2.2

0.10

551

105
BWR $8 \times 8$

10.57

10.80

12.52

95

2.2

0.30

551

107 


\section{REFERENCES}

Beyer, C. E. et al. 1975. GAPCON-THERMAL-2:A Computer Program for Calculating the Thermal Behavior of an Oxide Fuel Rod. BNWL-1898, Pacific Northwest Laboratory, Richland, WA.

Cunningham, M. E. et al. 1978. Stored Energy Calculation: The-State-of-theArt. PNL-2581, Pacific Northwest Laboratory, Richland, WA.

Cunningham, M. E., D. D. Lanning, and R. E. Williford. 1979 (In Press). The Thermal and Mechanical Behavior of a Xenon Filled Fuel Rod as a Function of Burnup. NUREG/CR-0749, PNL-3075, Pac ific Northwest Laboratory, Richland, WA (to be published).

Cunningham, M. E., R. E. Williford, and C. R. Hann. 1979. Effects of Fill Gas Composition and Pellet Eccentricity: Comparison Between Instrumented Fuel Assemblies IFA-431 and IFA-432. NUREG/CR-0331, PNL-2720, Pac if ic Northwest Laboratory, Richland, WA.

Hann, C. R. et al. 1979. "Experimental Verification of Steady State Codes: Task A-Irradiation Results." In Reactor Safety Research Programs Quarterly Report, April 1-June 30, 1979, NUREG/CR-0962, PNL-3040-2, ed. J. L. Hooper, pp. 3-12, Pacific Northwest Laboratory, Richland WA.

Hann, C. R. et al. 1977. Test Design Precharacterization and Fuel Assembly Fabrication for Instrumented Fuel Assemblies IFA-431 and IFA-432. NUREG/ CR-0032, BNWL-1988, Pac if ic Northwest Laboratory, WA.

Lanning D. D. and M. E. Cunningham. 1979. Startup Data Report for NRC/PNL Halden Assembly IFA-513. NUREG/CR-0862, PNL-2948, Pac if ic Northwest Laboratory, Richland, WA.

Lanning, D. D., C. L. Mohr, F. E. Panisko, and K. B. Stewart. 1978. GAPCONTHERMAL-3 Code Description. PNL-2434, Pac ific Northwest Laboratory, Richland, WA.

Nealley C., D.D. Lanning, M.E. Cunningham, and C.R. Hann. 1979. Postirradiation Data Analys is for NRC/PNL Haiden Assembly IFA-431. TUREG/ CR-0797, PNL-2975, Pacific Northwest Laboratory, Richland, WA.

Rausch, W. N. and F. E. Panisko. 1979. ANS54: A Computer Subroutine for Predicting Fission Gas Release. NUREG/CR-0497, PNL 3077, U S. Nuclear Regulatory Commission, Bethesda, MD.

Reymann, G. A. ed. 1978. MATPRO-Version 101: A Handbook of Materials Properties for Use in the Analys is of Light Water Reactor Fuel Rod Behavior. TREE-NUREG-1180, EG\&G Idaho, Inc., Idaho FatTs, ID. 

EXPERIMENTAL VERIFICATION OF STEADY STATE CODES

TASK $C$ - CODE DEVELOPMENT ${ }^{(a)}$

\author{
C. R. Hann, Program Manager \\ C. L. Mohr, Project Manager \\ W. D. Bennett \\ M. E. Cunningham \\ D. D. Lanning \\ F. E. Panisko \\ W. N. Rausch \\ R. E. Williford
}

\title{
SUMMARY
}

The basic concepts of the fuel relocation model have been developed. A preliminary version of the model is being evaluated against in-reactor data. The model is closely coupled with the PELET mechanics analys is package and uses the incremental anisotropic techniques that are available in the mechanics formulation.

The ANS 5.4 fission gas release model for both stable and radioactive components has been completed and inserted into FRAPCON. This model work has been funded by the Core Performance Branch of the Division of System Safety.

\section{INTRODUCTION}

The code development effort asociated with the verification of steady state codes has the overall objective of providing analys is models and techniques for FRAPCON, in cooperation with Idaho Nuclear Energy Laboratory (INEL), that can be used in evaluating the experimental results associated with the program. Three subtasks have been defined that include code coordination with INEL, mechanical model development for FRAPCON, and relocation model development for FRAPCON.

(a) RSR Fin. Budget No: B2043; RSR Contact: H. H. Scott 


\section{TECHNICAL PROGRESS}

Intermediate steps toward consolidating the Pacific Northwest Laboratory (PNL) and INEL fuel performance models have been completed and the major concepts associated with the fuel relocation model have been implemented this quarter.

\section{SUBTASK 1 - COOE COORDINATION}

Mr. Gary Berna, programmer from EG\&G Idaho Inc. vis ited PNL for two days this period. During his visit the following was accomplished:

- The GAPRS subroutine, which evaluates gap conductance, was updated from the GAPON-1 model to the GAPCON-2/3 mode 1 .

- The logic for selection of the PNL or EG\&G mechanics models was agreed upon and programmed for FRAPCON-2.

- The format for joint output of thermal and mechanical results from FRAPCON-2 was agreed to.

- Mr. Berna was given supporting documentation for the new GAPRS subroutine. Since Mr. Berna's visit very little has happened on joint code development due to a combination of computer system reorganization and other commitments at EG\&G. The output options were programed and sent to EG\&G. We are convinced that the final prograrming of FRAPCON-2 will have to be accomplished at PNL, with EG\&G personnel working here during that period.

The fuel relocation model developed at PNL last quarter has been implemented in the PNL version of FRAPCON-2. The PNL mechanics package, PELET, was considerably streamlined for FRAPCON-2 application. The extensive changes this entailed have not been programmed into a combined PNL/EG\&G version of the code, emphasizing again the need for cooperative joint pro-graming at a single site. 
SUBTASK 2 - MECHANICAL MODELING

This effort is complete and no further activity is planned until the PNL and INEL models are assembled in FRAPCON-2.

\section{SUBTASK 3- RELOCATION MODEL DEVELOPMENT}

This task also must await the availability of a jointly approved version of FRAPCON-2. Developmental verification will then begin.

\section{FUTURE WORK}

In the next quarter, we expect to fin ish all programming on FRAPCON-2, write the program document, and select 10-20 we 11-characterized, experimental tests to verify the code. 

GRAPHITE NONDESTRUCTIVE TESTING (a)

W. C. Morgan, Project Manager

\section{SUMMARY}

Samples of PGX graphite have been prepared and preoxidation measurements are proceeding. Preliminary measurements on three samples of Stackpole 2020 graphite, having very different oxidation-depth profiles, indicate that a good correlation can be established between density and eddy current measurements. Calculations are underway to determine the range of ultrasonic frequencies required to measure the oxidation-depth profile.

\section{INTRODUCTION}

This is a continuation of previous work, which demonstrated the feasibility of monitoring changes in the compressive strength of oxidized graphite by measuring changes in the velocity of an ultrasonic wave propagated through the graphite. The FY-1979 scope of this project is to:

- continue investigation of sonic velocity technique as applied to PGX and ATJ graphites

- investigate potential for other sonic measurements, such as attenuation data, to provide useful information

- investigate potential of other techniques, such as eddy current devices, for providing interpretable indications of graphite strength.

The objective of this investigation is to demonstrate feasibility of nondestructive testing (NDT) techniques for determination of structural graphite strength.

(a) RSR Fin. Budget No. B2101-9; RSR Contact: R. D. Schamberger 


\section{TECHNICAL PROGRESS}

Approximately one-eighth of a PGX $\log$ (GAC Log. No 7637-57) was received from General Atomic Company in August; samples have been prepared and preoxidation measurements are proceeding.

A preliminary evaluation has established that a strong correlation exists between the density of oxidized Stackpole 2020 graphite and electrical conductivity as measured by eddy current methods. Eddy current measurements were made on one end from each of three cylindrical samples (I-G-4, II-C-2, and II-0-1); (Morgan and Becker 1977); surface layers were machined off in steps. Eddy current measurements were taken prior to each cut. The density of the graphite removed during each cutting process was then compared to the eddy current measurements. These results are plotted in Figure 1.

The conductivity measurements were performed with impedance plane analysis using a conventional eddy current instrument operating at $1 \mathrm{MHz}$. The measurements indicate that a high probability of success exists for performing

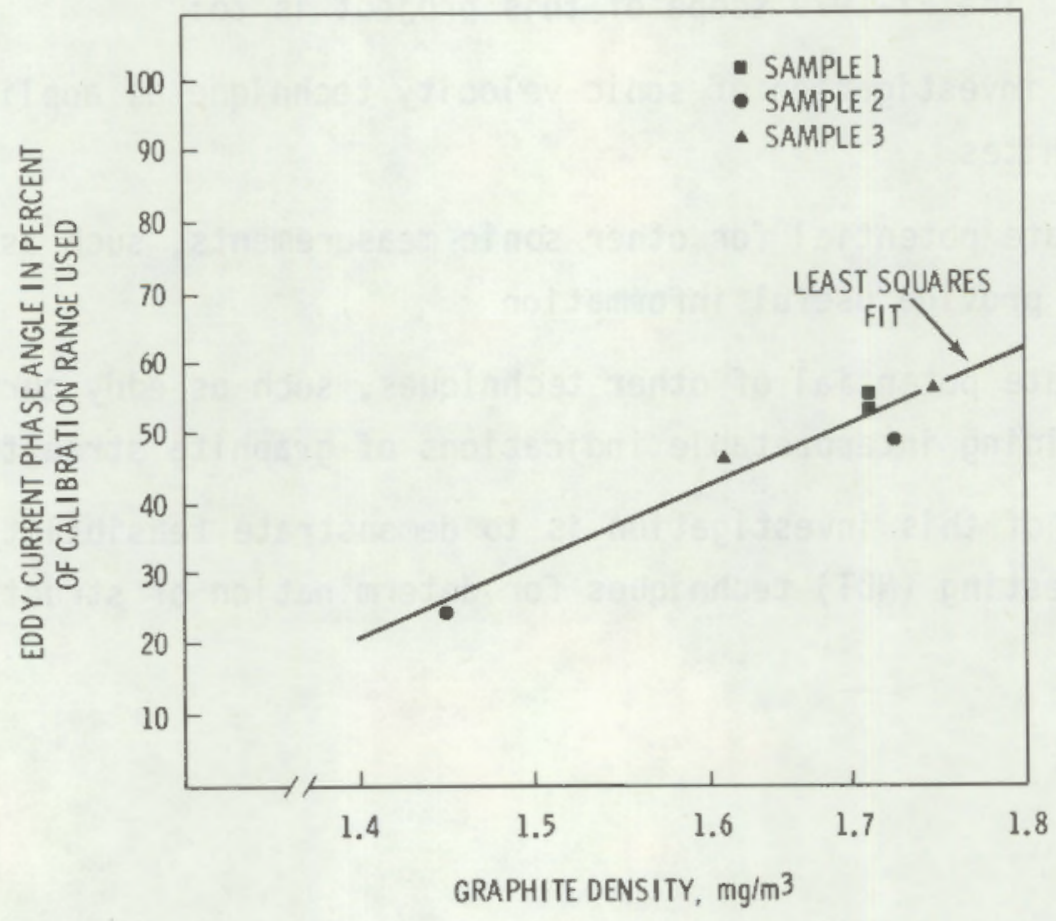

FIGURE 1. Eddy Current Response to Graphite Density Variations 
field assessment of graphite strength if two criteria are attained: 1) if a calibration curve similar to that of Figure 1 can be established for the particular in-service graphite; and 2) if the relationship between density and strength is established.

The development of an ultrasonic surface wave technique for the measurement of oxidation/strength profile is under consideration. This technique is based on the principle of velocity dispersion as a function of frequency in the presence of a surface property gradient. The depth of penetration of a surface wave is approximately one wavelength. As the frequency is increased, the effective depth of penetration decreases and the influence of property gradients can be measured as a function of depth.

The surface wave integrates the influence of property gradients from the surface down to approximately one wavelength. It is a relatively simple calculation to determine the velocity dispersion profile for a given material property gradient. We are calculating velocity dispersion curves for a range of property gradients to determine the effectiveness of the ultrasonic method for oxidation profile measurement.

\section{FUTURE PLANS}

The primary emphasis during the next quarter will be placed on obtaining measurements on oxidized PGX samples. Work has been initiated to determine the ability for profiling graphite oxidation versus depth with eddy current methods. Probes are being fabricated which will provide differing depths of search field in the material. A series of thin $(3$ in. $\times 3$ in. $\times 0.050$ in. thick) graphite coupons have been fabricated and will be oxidized to selected levels in the range of interest. The coupons will then be stacked to simulate various oxidation profiles and subjected to eddy current examination. The depth of the examined volume will be controlled both by using the specialized probes and by varying the test frequency.

The calculations of velocity dispersion curves will be completed during the next quarter, and will be used to define the range of test frequencies 
required and the uncertainty range for property gradient determinations. All preoxidation and most of the post-oxidation measurements should be completed during the quarter.

\section{REFERENCE}

Morgan, W. C. and F. L. Becker. 1977. Feasibility of Monitoring the Strength of HTGR Core Support Graphite--Part 1. BNWL-2239, Pacific Northwest Laboratory, Richland, WA. 


\title{
ACOUSTIC EMISSION-FLAW RELATIONSHIP FOR IN-SERVICE MONITORING OF NUCLEAR PRESSURE VESSELS ${ }^{(a)}$
}

\author{
P. H. Hutton, Project Manager \\ E. B. Schwenk \\ R. J. Kurtz
}

\section{SUMMARY}

Acoustic emission (AE) response during fatigue crack growth testing of a 1-in. thick, single-edge-notch, weld metal specimen was measured at room temperature and $550^{\circ} \mathrm{F}$. The AE results displayed a high degree of scatter, but, in general, the room temperature data compared favorably with data obtained during fatigue crack growth testing of other base and weld metal specimens. In addition, the trend of decreasing $A E$ response with increasing temperature was observed. The AE signal energy as a function of the test temperature and position on the load waveform was analyzed to further characterize the properties of valid AE signals and to attempt to reduce data scatter. Some improvement in the $\mathrm{AE}$ rate versus fatigue crack growth rate correlation was obtained by energy partitioning of the AE data. Evaluation of the AE data with respect to position on the load waveform indicated that approximately two-thirds of the AE data were observed during rising load, and almost onehalf of the total count occured between minimum and mean load.

A concept for a prototypic reactor monitoring AE system has been developed. The initial design of the system allows for longevity testing in the full reactor environment, evaluation of background noise control, and the gathering of various waveform samples for pattern recognition development.

\section{INTRODUCTION}

The purpose of this program is to provide an experimental evaluation of the feasibility of detecting and analyzing flaw growth in reactor pressure

(a) RSR Fin. Budget No. B2088; RSR Contact, J. Muscara 
boundaries on a continuous basis using AE. Type A533B, Class 1 steel is being used in all experimental testing. The objectives of this program are

- characterize AE from defects under material property conditions recognized as being of primary concern to reactor pressure vessel integrity and characterize acoustic signals from representative innocuous sources

- develop criteria for distinguishing significant flaw AE from innocuous acoustic signals

- develop an AE-flaw damage model to serve as a basis for relating inservice $A E$ to pressure vessel integrity

- make available a characterized high-temperature AE sensor

- develop a continuous surveillance AE data acquisition and analys is system.

Progress relative to these objectives is discussed in the following sections. These will include AE/fracture mechanics testing, AE instrumentation, and reports. The final section will describe the work planned for the next quarter.

\section{AE/FRACTURE MECHANICS TESTING}

This section describes the experimental procedure used in the fatigue crack growth testing of a weld metal specimen and is followed by a discussion and analys is of the test results.

\section{PROCEDURE}

A fatigue crack growth (FCG) test of a 1-in. thick, single-edge-notch (SEN), weld metal specimen (2W-1B) was performed at room temperature (RT) and $550^{\circ} \mathrm{F}$. The specimen was fabricated from ASTM A-533, Grade B, Class 1 steel supplied by the Heavy Section Steel Technology (HSST) program of Oak Ridge National Laboratory. Details of the fabrication history have been reported previously (Hutton, Schwenk, and Kurtz 1979). After fabrication of the basic specimen, a notch approximately $0.030 \mathrm{in}$. wide by $1.1 \mathrm{in.}$ long was machined into one edge. The notch was located in the center of the HSST weldment 
material (Figure 1). Next, the specimen surface near the notch was polished to facilitate optical crack length measurements. After polishing, an LVDT was attached to permit measuring the crack opening displacement. Four chromelalumel thermocouples were than spot welded to the specimen for temperature measurement and control. There were two thermocouples on each side of the spec imen and each thermocouple was located a distance of 3 in. from the notch. Acoustic emission sensors were then mounted on the specimen with high-temperature adhesive (HYSOL EA 934) and acoustic couplant (PYROGEL 60). Grit blast calibration of the laboratory AE sensors indicated that the monitoring system's effective sensitivity was about 0.12 bar. During the test, additional checks of the uniformity of sensitivity were applied by using a low-pressure helium gas jet, fracture of Pente $l^{\circledR}$ pencil lead, or a piezoelectric pulser to excite the sensors. This was done to assure that sensor sensitivity did not vary with changes in test temperature. The AE acceptance zone was restricted to a region about $0.5 \mathrm{in}$. wide on each side of the notch.

In order to produce fatigue crack growth, specimen $2 \mathrm{~W}-1 \mathrm{~B}$ was tensiontension fatigue cycled sinusoidally between fixed maximum and minimum loads in a 100-kip, MTS servo-hydraulic test system. The precise fatigue loading conditions employed are 1 isted in Table 1 along with the crack propagation data. Initially, the fatigue crack was grown in air at RT. Then,

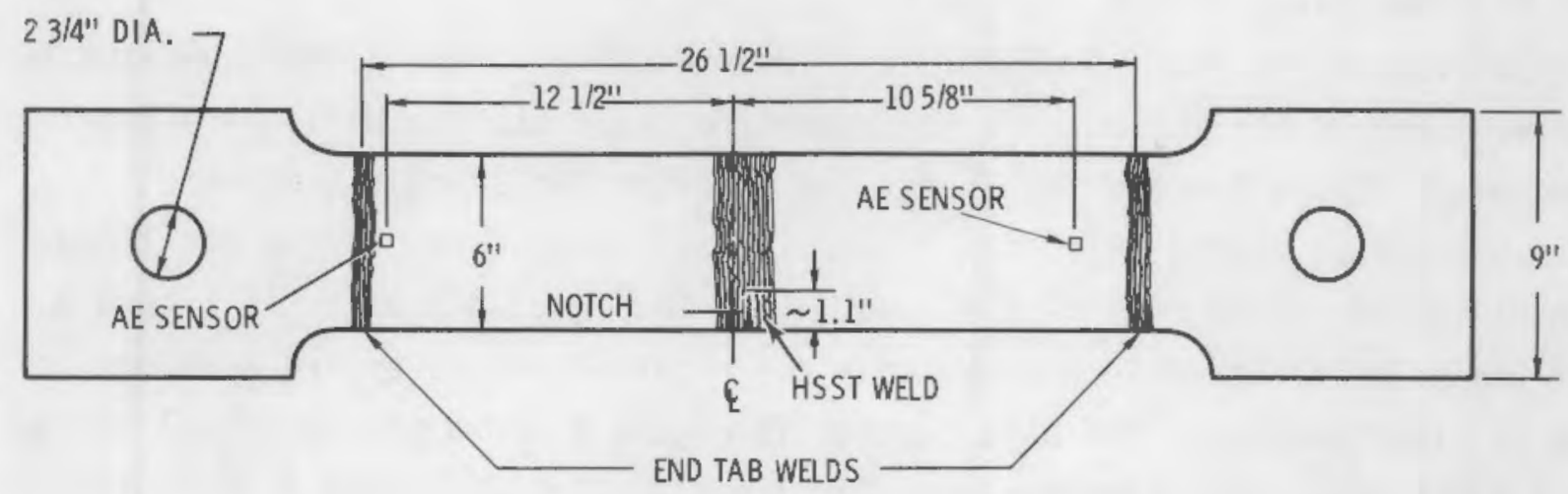

FIGURE 1. Spec imen Geometry and AE Sensor Locations for SEN Specimen $2 \mathrm{~W}-1 \mathrm{~B}$.

${ }^{8}$ Registered trademark of Pentel of America, Ltd. 
when the crack length was 2.2357 in., the maximum and minimum loads were reduced (maintaining the same $\mathrm{R}$-ratio). The objective was to grow the fatigue crack at $550^{\circ} \mathrm{F}$ over the same range in stress intensity factor that was used for the RT-FCG.

\section{RESULTS AND ANALYSIS}

Figure 2 shows a plot of the AE count per cycle as a function of the FCG rate for specimen $2 \mathrm{~W}-1 \mathrm{~B}$. The data shown in Figure 2 display a high degree of scatter, but, in general, the RT data compares favorably with the composite curve calculated from data obtained on other FCG specimens. In addition, the trend of decreasing $\mathrm{AE}$ response with increasing temperature, which has been observed previously in base metal specimens, appears to exist.

To further characterize the properties of valid AE signals obtained during FCG and to attempt to reduce the data scatter, additional analyses of the AE signal energy, peak time, and pulse height as functions of the test temperature and position on the load waveform have been performed. Only the results of the $A E$ signal energy analyses shall be reported this quarter.

A total of 84,866 valid $A E$ signals were detected from the flawed region of the test specimen during the course of the FCG experiment. From this data set, normalized histograms of the AE signal energy were constructed (Figure 3 and 4 ). The data plotted in Figure 3 show the AE signal energy as a function of position on the load waveform. The lower portion of the graph shows the AE signal energy distribution with no attempt to segregate the data. The upper portion of Figure 3 shows the energy distribution for signals that were detected during rising load only. Approximately two-thirds of the total count were observed during $r$ ising load. Note that the results plotted in Figure 3 show no significant difference between the rising load and entire waveform energy distributions. The data plotted in Figure 4 shows the $A E$ signal energy as a function of test temperature. The lower portion of Figure 4 shows the $A E$ data obtained at RT, while the upper half of the graph shows the $550^{\circ} \mathrm{F}$ data. The RT data consisted of about $89 \%$ of the total count.

The effect of increasing test temperature appears to cause the energy distribution to shift to lower energies. This result suggests that the 
TABLE 1. Fatigue Loading Conditions for FCG Testing of Specimen 2W-1B

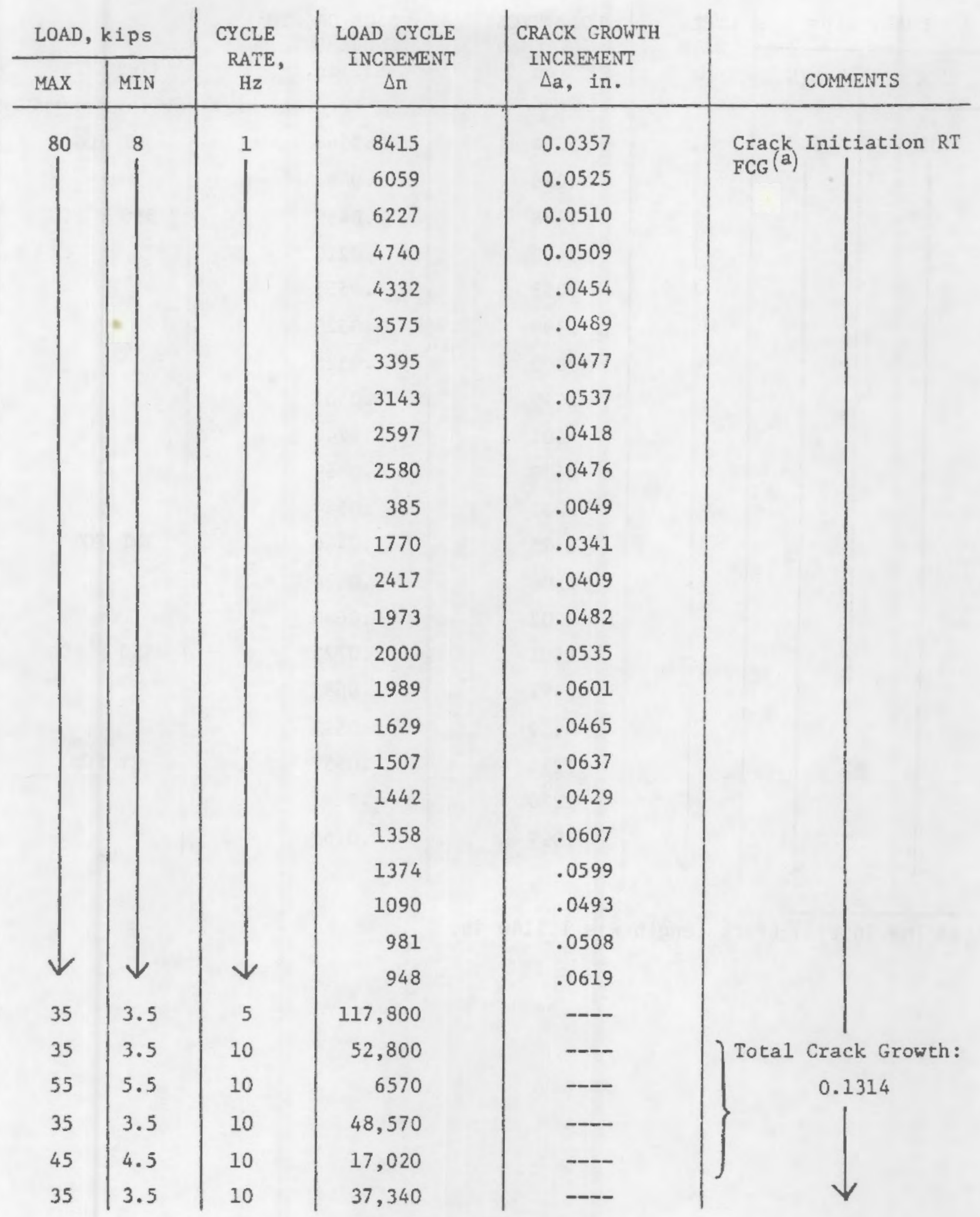


TABLE 1. (contd)

\begin{tabular}{|c|c|c|c|c|c|}
\hline \multicolumn{2}{|c|}{ LOAD, kips } & \multirow{2}{*}{$\begin{array}{l}\text { CYCLE } \\
\text { RATE } \\
\mathrm{Hz}\end{array}$} & \multirow{2}{*}{$\begin{array}{l}\text { LOAD CYCLE } \\
\text { INCREMENT } \\
\qquad n\end{array}$} & \multirow{2}{*}{$\begin{array}{l}\text { CRACK GROWTH } \\
\text { INCREMENT } \\
\triangle \mathrm{a} \text {, in. }\end{array}$} & \multirow[b]{2}{*}{ COMMENTS } \\
\hline $\operatorname{MAX}$ & MIN & & & & \\
\hline 35 & $i^{3.5}$ & 1 & $\begin{array}{r}5084 \\
4028 \\
2488 \\
2460 \\
3053 \\
2999 \\
3002 \\
2999 \\
3001 \\
2499 \\
2032 \\
2525 \\
2506 \\
2202 \\
1501 \\
997 \\
959 \\
1214 \\
1220 \\
1099\end{array}$ & $\begin{array}{l}.0568 \\
.0491 \\
.0459 \\
.0210 \\
.0555 \\
.0520 \\
.0528 \\
.0583 \\
.0740 \\
.0669 \\
.0544 \\
.0440 \\
.0624 \\
.0690 \\
.0722 \\
.0684 \\
.0513 \\
.0557 \\
.0613 \\
.0768\end{array}$ & $\underbrace{\downarrow}_{\downarrow}$ \\
\hline
\end{tabular}

(a) The Initial Crack Length was 1.1140 in. 


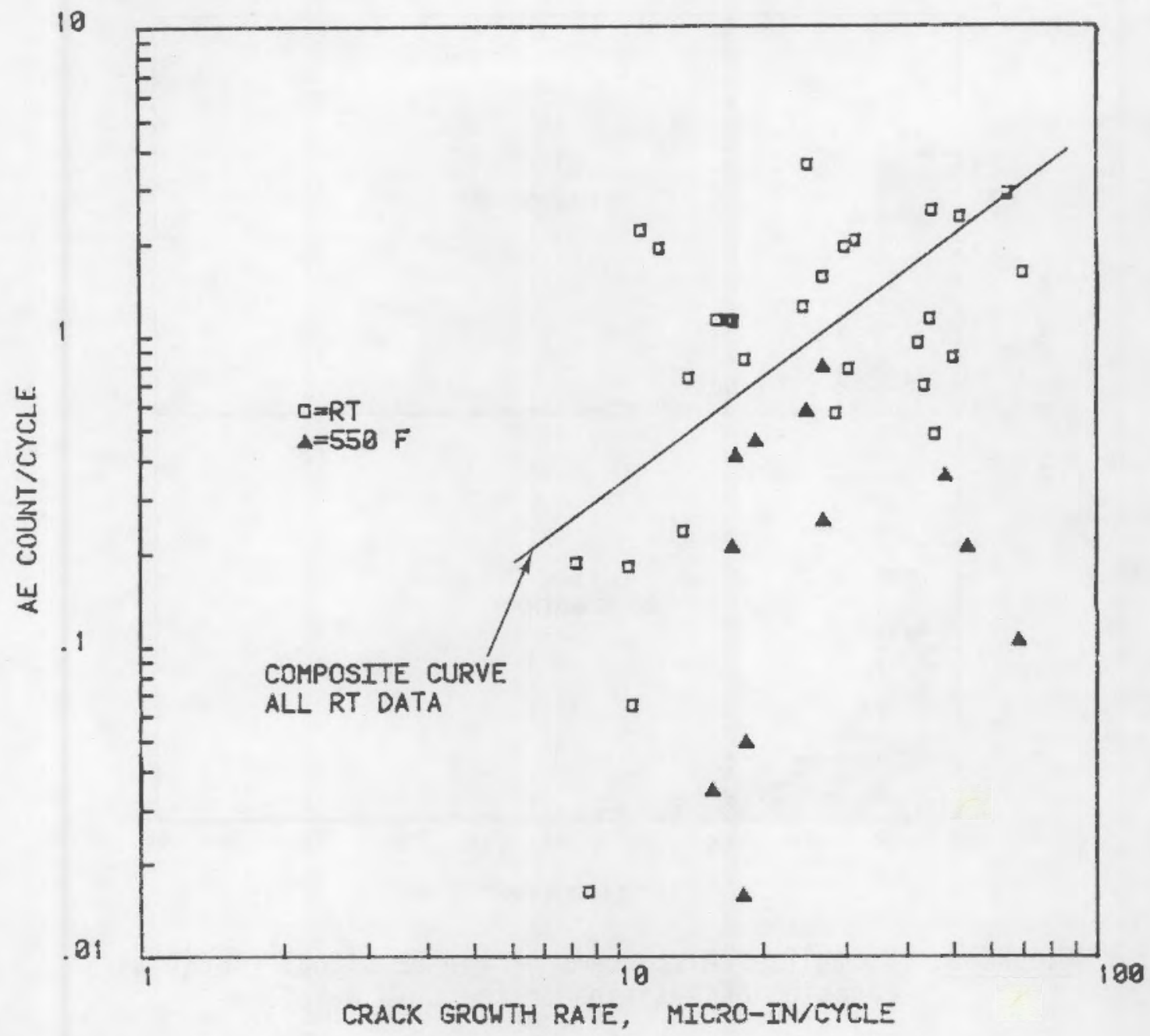

FIGURE 2. AE Count/Cycle Versus Fatigue Crack Growth (FCG) Rate for SEN Specimen 2W-1B.

observed decease in $\mathrm{AE}$ response with increased test temperature may be due to a general decrease in signal amplitudes, which correspond to decreased energy. This could have the effect of dropping some AE signals below the detection theshold.

In all of the histograms, the fraction of the total count with energies greater than 200 energy units is insignificant. This result implies that the AE signals from FCG are of relatively short duration.

One of the objectives in the analys is of the $2 \mathrm{~W}-1 \mathrm{~B}$ test data was to attempt to define a category of AE signals that represent the primary contributor to 


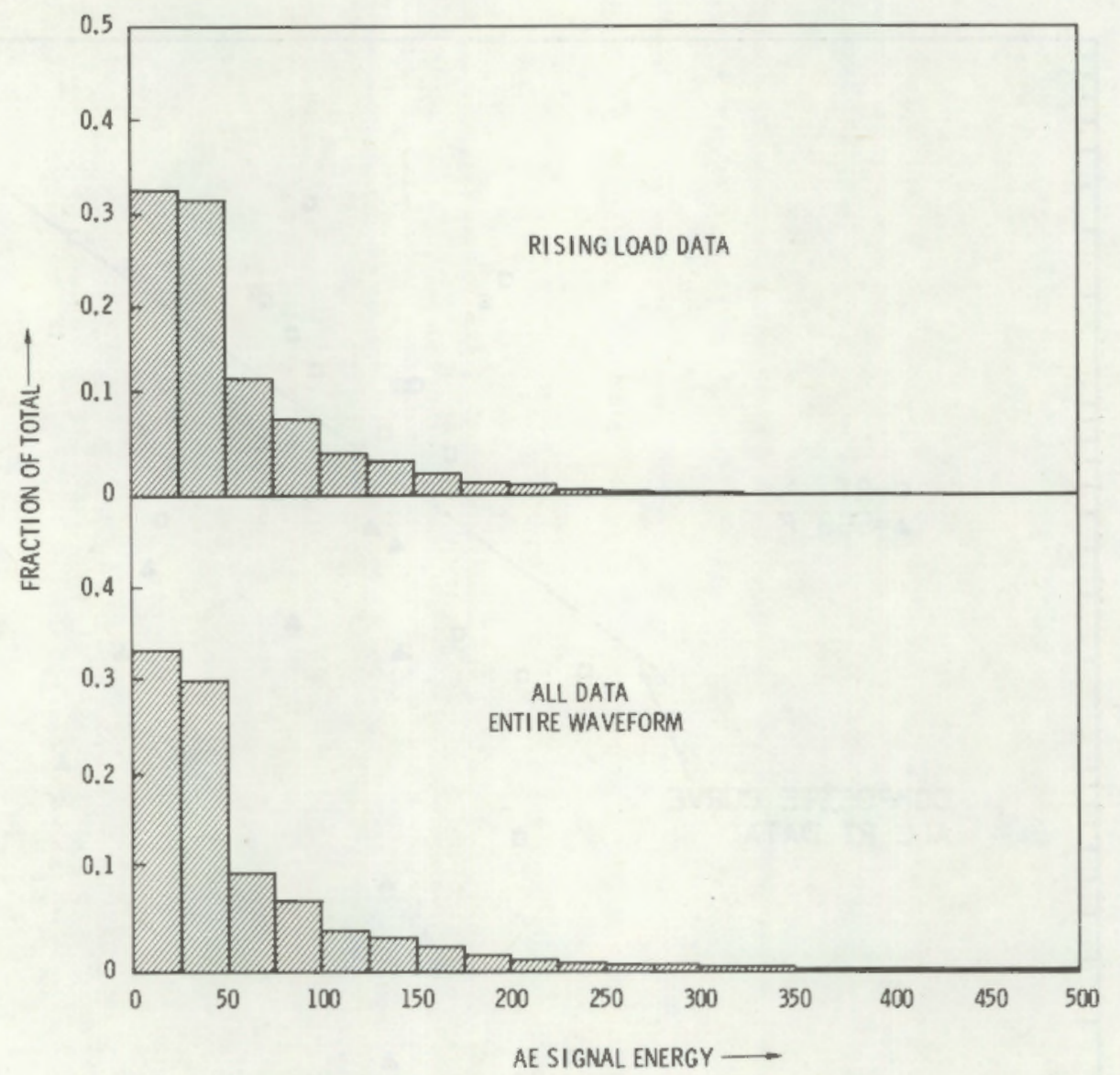

FIGURE 3. Normalized Histograms of the AE Signal Energy as a Function of Position on the Load Waveform.

scatter in the AE-rate versus crack-growth-rate relationship. Although the testing of specimen $2 \mathrm{~W}-1 \mathrm{~B}$ was one of the most carefully controlled tests performed in this work, the data scatter was greater than in most previous tests.

An attempt was made to reduce data scatter by partitioning the AE data from $2 W-1 B$ into 25 energy unit increments. The partitioned $A E$ rate data (in count/cycle) was then fit by a least mean squares curve to an equation of the form

$$
\frac{d N}{d n}=C\left(\frac{d a}{d n}\right)^{m}
$$




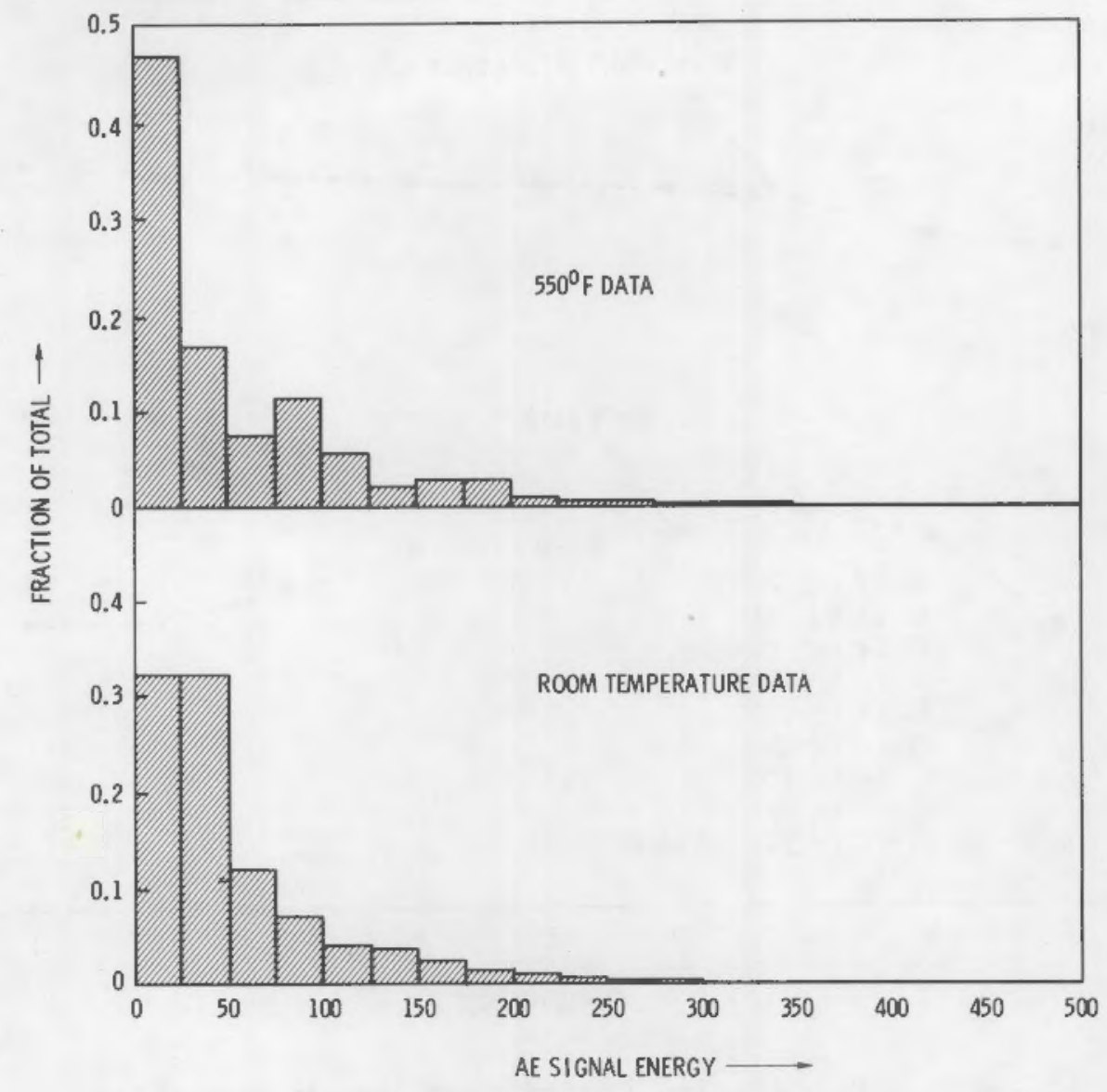

FIGURE 4. Normalized Histograms of the AE Signal Energy as a Function of Test Temperature.

Where $d N / d n$ is the partitioned AE rate data, da/dn is the fatigue crack growth rate, and $C$ and $m$ are constants.

Figures 5 and 6 show plots of the correlation coefficients produced by the regression analyses versus the partitioned $A E$ signal energy range. The data in Figure 5 show the effect of expanding the partitioned energy range by 25 energy unit increments. For the RT data, there was a slight but steady improvement in the correlation coefficient with increasing energy range. The $550^{\circ} \mathrm{F}$ data, on the other hand, showed a peak correlation coefficient of 0.303 for the energy range between 0 and 75 energy units. All other partitioned ranges yielded lower correlation coefficients. In all cases, the RT data produced better correlation coefficients than $550^{\circ} \mathrm{F}$ data. 


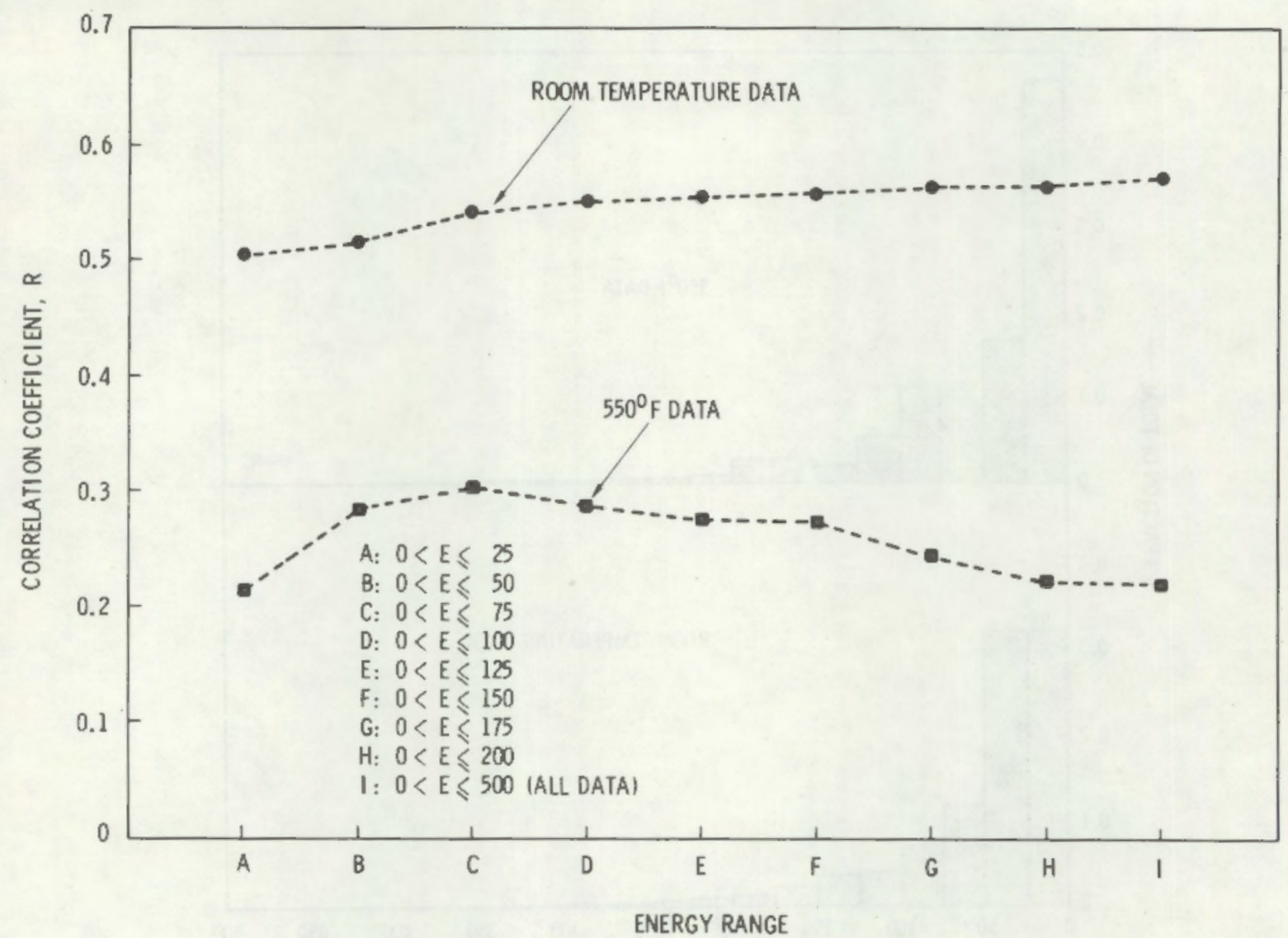

FIGURE 5. Correlation Coefficient Versus Summation AE Signal Energy Range

Another approach used to analyze the same energy partitioned data is illustrated in Figure 6 . The results from regression analyses between individual energy ranges and FCG rate data display significant variations. The $550^{\circ}$ data showed a much improved correlation coefficient when the data set was restricted to those signals with energies ranging between 25 and 50 energy units. For the RT data, the maximum correlation coefficient was obtained with data from the 50-75 energy unit range. These results suggest that energy partitioning of the AE data may be useful for improving the AE rate versus FCG rate correlation.

Further work was performed during this reporting period on partitioning the AE data with respect to the load waveform. The purpose of this analys is was to gain insight into the mechanisms that produce the AE. The histogram 


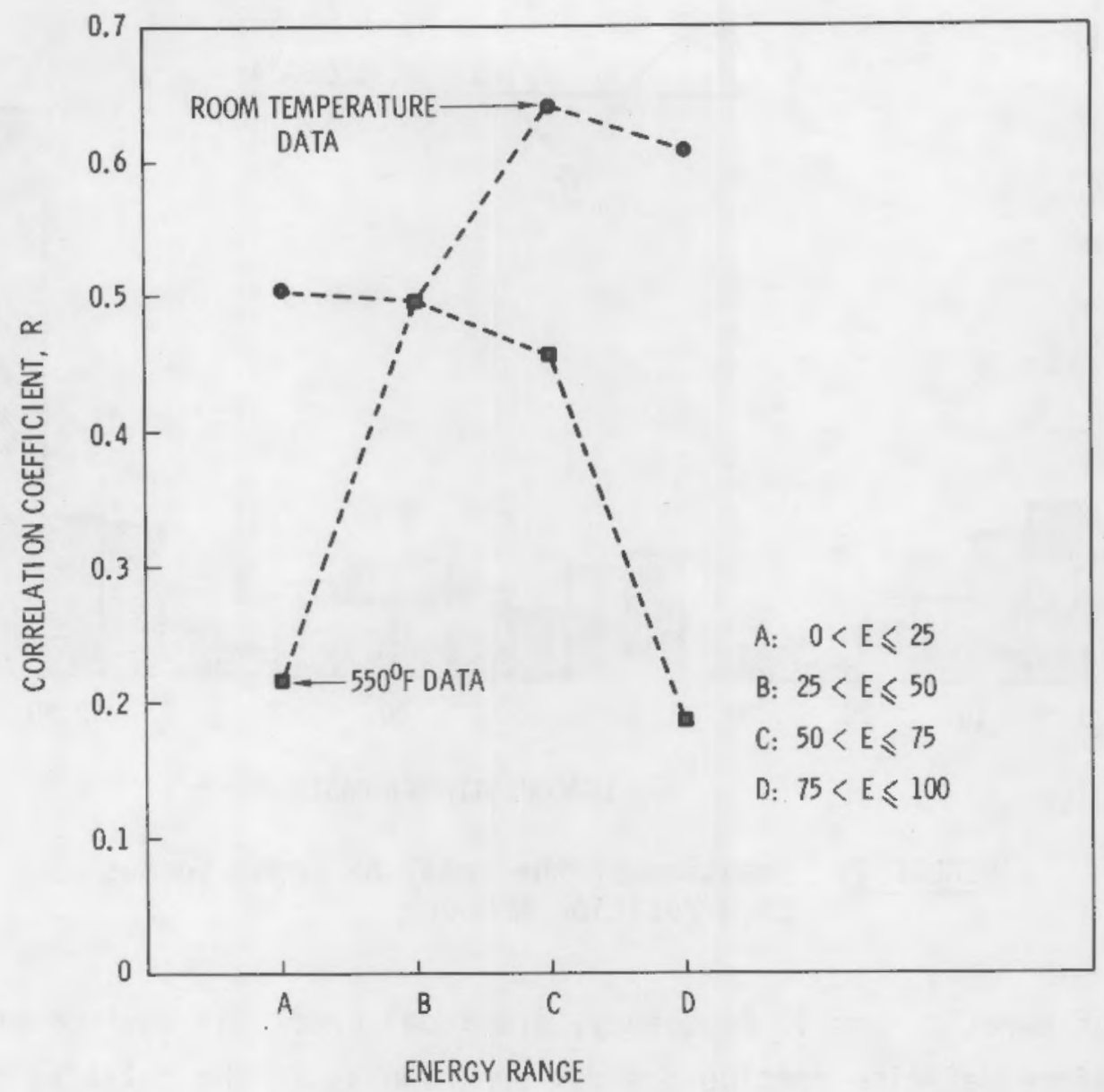

FIGURE 6. Correlation Coefficient Versus Incremental AE Signal Energy Range.

in Figure 7 shows the fraction of the total AE count as a function of the load position number. Load position numbers 25 and 75 represent maximum and minimum load, respectively. Load position number equal to 50 signifies mean load on the descending side of the load cycle, whereas, 0 and 100 represent mean load for the ascending portion of the load waveform. The results shown in Figure 7 were very interesting in that little AE was detected near maximum and minimum loads. The majority of the AE occurred on rising load (two thirds) and almost one-half occurred between minimum and mean load. This result suggests that perhaps an interfacial "unsticking" (i.e., crack tip opening) mechanism may be dominantly contributing to the detected AE. Additional work into the 


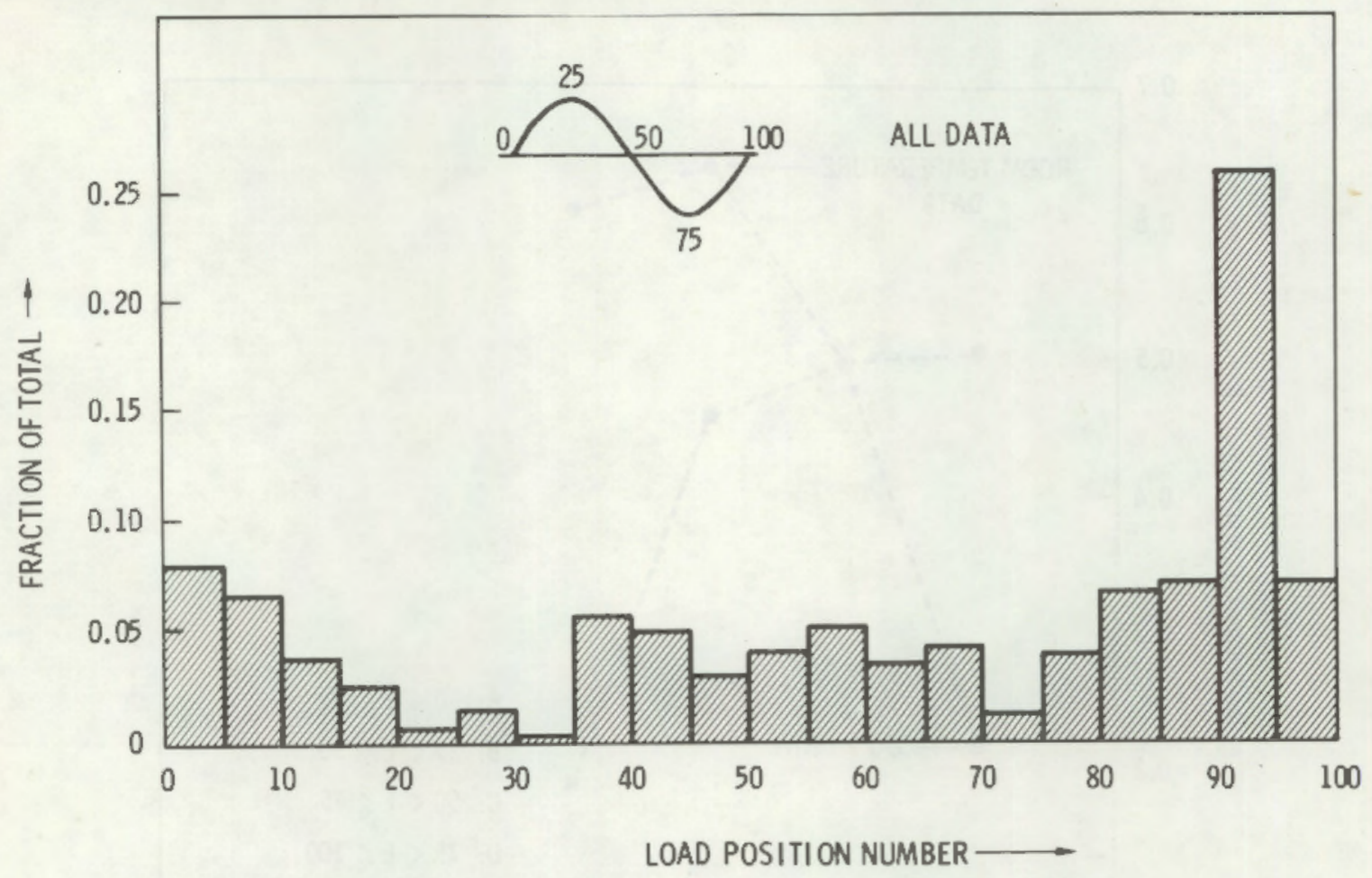

FIGURE 7. Fraction of the Total AE Count Versus Load Position Number

influence of R-ratio, cyclic frequency, and local crack tip environment is required before definite conclusions may be drawn as to the relative significance of crack tip opening and crack growth in producing AE.

\section{INSTRUMENTATION}

The concept for a prototypic reactor monitoring AE system has been developed as shown in Figure 8. It can be defined in two sections: 1) data acquisition and source location and 2) data analysis. The data acquisition section would be acquired, either cormercially or fabricated in-house, and installed on a reactor as soon as possible. This allows initiation of longevity testing in the full reactor environment, evaluation of background noise control, and gathering various waveform samples for pattern recognition development. 


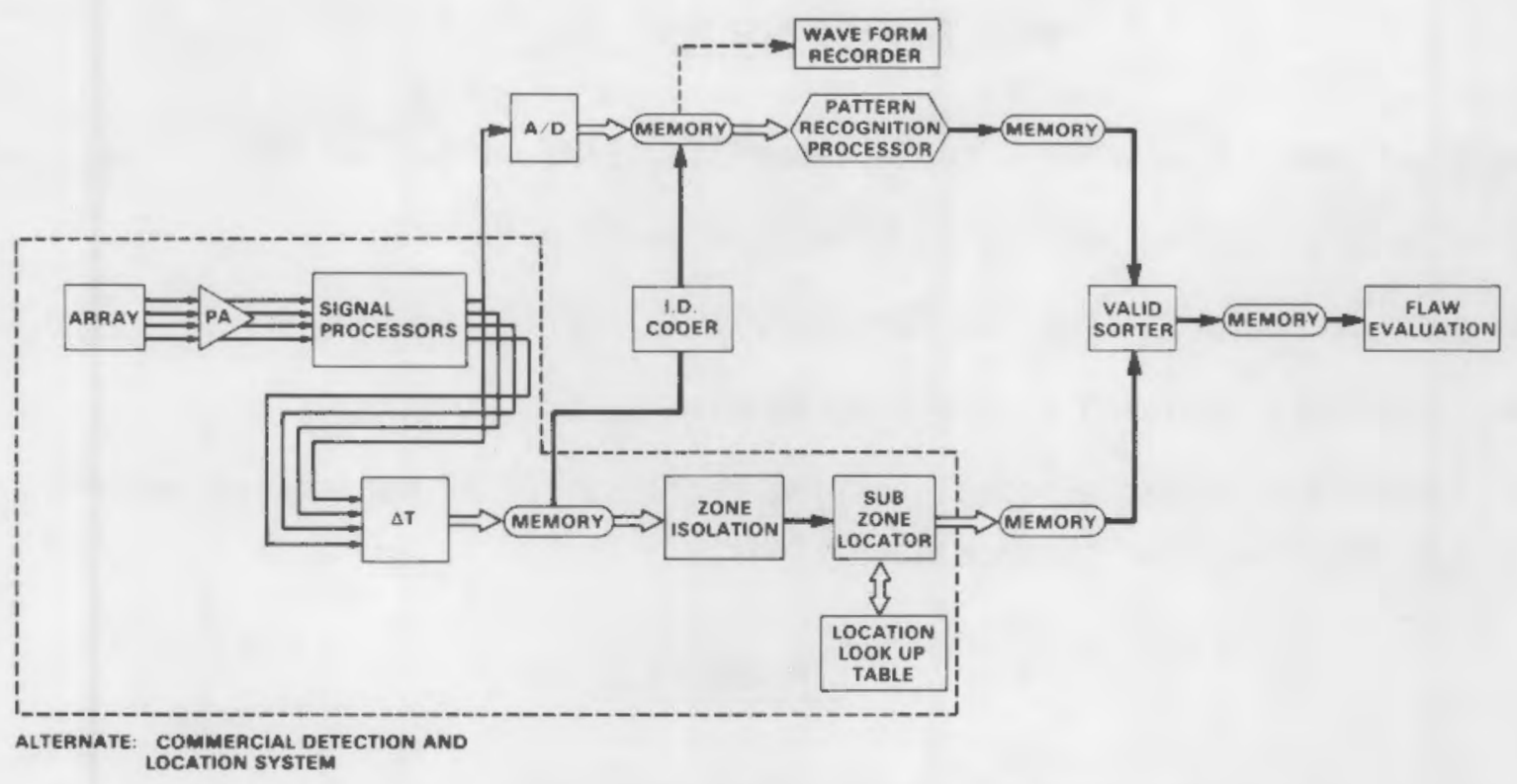

FIGURE 8. Concept for an On-Reactor AE Monitor for Flaw Detection and Evaluation.

The data analysis section as shown is a semi-breadboard system in the sense that it provides for recording pattern recognition waveforms in parallel with pattern recognition processing. This is to allow refinement of the pattern recognition function from initial tests. Subsequently, the waveform recorder would be eliminated and pattern recognition would become a "black box" element. In this concept, the pattern recognition function would operate to determine whether a located signal was a crack growth AE signal or a noise signal. If it was $A E$, the signal would go to the flaw analys is section; if not, it would be rejected. It is necessary to operate the source location and pattern recognition functions in parallel due to timing requirements.

\section{REPORTS}

The following reports were prepared during this period:

- quarterly progress report for the April 1 to June 30, 1979, period.

- paper titled "Progress Toward Acoustic Emission Characterization for Continuous Monitoring of Reactor Pressure Vessels", presented at an international NDT symposium in Saarbrucken, West Germany. 


\section{WORK PLANNED FOR NEXT QUARTER}

Work plans for the October 1 to December 31, 1979, period include

- complete testing and analysis of pipe bend test

- complete material for the November, 1979 , review meeting

- complete a revision of the program plan

- identify a suitable vessel testing facility for AE monitoring under simulated reactor service conditions.

\section{REFERENCES}

Hutton, P. H., E. B. Schwenk, and R. J. Kurtz. 1979. "Acoustic Emission Flaw Relationship for In-service Monitoring of Nuclear Pressure Vessels." In Reactor Safety Research Programs Quarterly Report, April 1 - June 30, 1979, NUREG/CR-0962, PNL-3040-2, ed. J. L. Hooper, pp. 25-38, Pac ific Northwest Laboratory, Richland, WA. 
FUEL SUBASSEMBLY PROCUREMENT AND IRRADIATION TEST PROGRAM(a)

\author{
C. R. Hann, Program Manager \\ E. L. Courtright, Project Manager \\ A. G. Dunbar \\ R. L. Goodman \\ L. L. King \\ R. R. Lewis \\ R. K. Marshall \\ R. F. Klein \\ J. D. Rising \\ R. E. Schreiber
}

\title{
SUMMARY
}

Component fabrication for the $4 X$ quadrant hardware is complete. Final check out and calibration of the instruments have also been completed and several subassembly operations started. The final assembly and shipping will be delayed by approximately two months due to vendor manufacturing problems with the differential, type $T$ thermocouples.

A preliminary nine rod test train design for the RIA 1-7 and OPTRAN 1-3 test programs has been completed. The test assembly was designed to accommodate nine irradiated fuel rods and contains appropriate instrumentation to monitor fuel rod behavior during the course of the proposed transient.

\section{INTRODUCTION}

The Fuel Subassembly Procurement and Irradiation Test Program has been divided into five tasks for FY 1979. The objectives of these are as follows:

- Task A - 4X Test Train Hardware Development. The primary purpose of this task is to develop underwater electrical connector devices for the instrumentation used in fuel rod irradiation experiments. Supplementary or replacement quadrants for Power Burst Facility (PBF) 4X Test Trains will be provided as needed.

(a) RSR Fin. Budget No: 82084; RSR Contact: R. Van Houton 
- Task B - Gap Conductance Test Analys is. This task will be directed at providing the testing methodology for obtaining gap conductance data from a selected test in the PBF series. Post-test analys is and data interpretation of the experimental results will be provided.

- Task C - Dual Purpose Assemblies. This task covers the efforts associated with the experimental design, fuel rod fabrication, precharacterization, and shipping of fuel assemblies irradiated in Halden and subsequently tested in a transient mode in the PBF.

- Task D - Multi-Rod Test Trains. The purpose of this task will be to design and build a multi-rod test assembly based on the generic design concept developed in Task $E$.

- Task E - Generic Test Train Design. The objective of this task will be to provide a conceptual design of a multi-rod irradiation test train for use in conjunction with NRC-sponsored programs. The test assembly will incorporate features designed to support experimental testing in any of the following reactors: PBF, NRU, SGHWR, BR-2, and ESSOR.

\section{X TEST TRAIN HARDWARE DEVELOPMENT}

Five strongback assemblies complete with pads, SPND mounting brackets, and high-pressure connector mounting brackets were completed. The strongback assemblies have been through receiving inspection and are released for assembly and outfitting of the individual quadrants.

Calibration of the turbine flowmeters for the replacement quadrants was completed. The calibration data collected at Pacific Northwest Laboratory show excellent agreement with the calibration curves supplied by the manufacturer. The lower instrument packages were also assembled.

All machined components for the quadrant assemblies have been received from off-site shops and have been through quality assurance receiving inspection and released for final quadrant assembly and outfitting. Fabrication of high-pressure connector components was started with the placement of a purchase 
order to an outside vendor. Completed components for eight complete highpressure connectors of the six-pin type will be delivered to Battelle by October 26, 1979

A preliminary fit up of hardware and strongbacks complete with quadrant hangar tubes was performed. The results of the fit up indicate that there are no major problems in the interchangeability of the quadrants.

The only outstanding items necessary to begin final assembly of the quadrants are the metal-sheathed, ceramic-insulated copper/copper conductor leads, and type T differential thermocouples. Discussions with Control Products indicates that they have had several problems with the metallurgy of the sheath used for the thermocouples. They have indicated that delivery of both conductors and thermocouples cannot be made before November 16, 1979.

\section{MULTI ROD-TEST TRAINS}

The nine-rod test assembly for RIA 1-7 and OPTRAN 1-3 has been designed to provide for a removable and replaceable bundle section. A recombined flow region is also included so that the two-phase steam/water mixture jenerated within the bundle assembly can be combined with bypass flow and a measurement of the combined outlet flow recorded. The bundle has also been designed so that one uninstrumented rod can be removed and replaced following the calibration phase of the proposed experiments.

The test train has been divided into five modular sections, each containing its own package of instrumentation and hardline cabling. The principal features for each of the basic modules are discussed below:

\section{LOWER INLET ASSEMBLY}

The lower inlet assembly (see Figure 1) is designed to divide the inlet flow from the in-pile flow tube into two parts with approximately half of the total flow directed through the bundle portion. This will be accomplished by sizing the orifice plate to equally balance bypass with shroud flow. The in let flow assembly consists of the following components: 
- (1) orifice nut - stainless steel (SST)

- (1) orifice ring - SST

- (1) restrictor plate - SST

- (1) flow straightener

- (1) split thermocouple holder - SST

- (1) adapter fitting to shroud - SST

- (1) shroud to adapter seal - copper

- (1) adapter to flow turbine seal - copper

- (1) flow turbine to flow straightener seal - copper

- (1) high-pressure transducer mounting tube - SST

- (1) tube connector - SST

- (2) band clamps - SST.

\section{Flow Region}

An inlet housing located above the orifice plate guides the inlet flow into a flow straightener before it enters a turbine. Copper gaskets will be used to seal between the inlet housing and the bidirectional ( $90 \mathrm{gpm})$ flow turbine, between the turbine and adaptor, and between adaptor and shroud. The flow straightener is composed of two plates forming a $90^{\circ}$ cross and is held securely in place with the orifice retaining nut.

Instrumentation

Sixteen thermocouples are provided for measurement of the inlet flow. They will be mounted on a split thermocouple holder, which will be clamped to the inlet housing, and distributed at equally spaced circumferential increments. These thermocouples perform the following functions:

- four thermocouples to measure inlet temperatures

- six thermocouples for differential measurement with the shroud flow temperature

- six thermocouples for differential measurement of the temperature in the recombined flow region. 


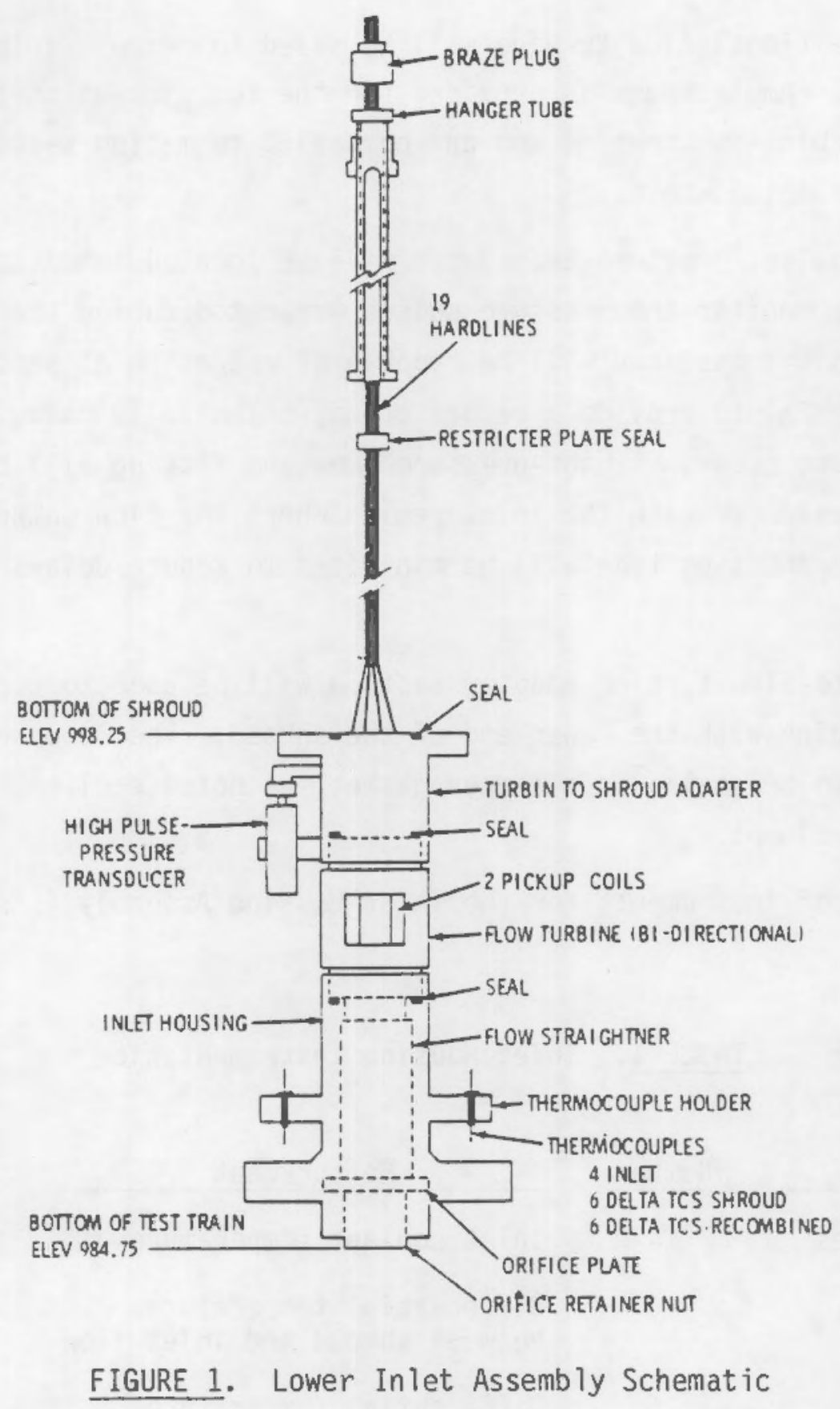

The thermocouples will be held firmly in position with a split holding clamp. Each thermocouple will have a brazed collar and will be clamped to the holder with a cap screw. The split holder sections will also be secured with a band clamp and all clamps and cap screws will be lockwired to prevent disengagement. 
The bidirectional flow turbine will be sized to measure inlet flow in the 9-90 gpm range. Ample space is provided for the two pick-up coils. Each end of the flow turbine is threaded and can be sealed to mating sections with copper gaskets, as noted above.

One high-pulse, pressure transducer will be located immediately above the flow turbine to monitor the pressure pulses generated during the course of the experiment. This transducer will be capable of operating at pressures up to $10,000 \mathrm{psi}(69 \mathrm{MPa})$ to provide a record of any potentially damaging pressure surges that might occur. A high-pressure tube and fitting will be used to connect the transducer with the inlet region where the flow enters the bundle. The length of connecting tube will be minimized to reduce delays in transducer response time.

A shroud-to-flow turbine adapter section will be used to connect the upper end of the turbine with the lower end of the shroud. The lower end of the shroud will also be seated on a copper gasket, as noted earlier, and secured with hold-down clamps.

A listing of instruments for the Inlet Housing Assembly is shown in Table 1.

\section{TABLE 1. Inlet Housing Instrumentation}

\begin{tabular}{|c|c|c|c|}
\hline Sensor & Number & Measurement & Reguirement \\
\hline Thermocoup les & 4 & Inlet coolant temperature & $300^{\circ}-800^{\circ} K$ \\
\hline TC (1 leg) & 6 & $\begin{array}{l}\text { Differential temperature } \\
\text { between shroud and inlet flow }\end{array}$ & $0^{\circ}-20^{\circ} \mathrm{K}$ \\
\hline TC (1 leg) & 6 & $\begin{array}{l}\text { Differential temperature } \\
\text { in the recombined flow region }\end{array}$ & $0^{\circ}-20^{\circ} \mathrm{K}$ \\
\hline $\begin{array}{l}\text { Pressure trans- } \\
\text { ducer }\end{array}$ & 1 & Pressure pulse & $0-69 \mathrm{MPa}$ \\
\hline Flow turbine & 1 & Inlet flow rate & $9-90 \mathrm{gpm}$ \\
\hline
\end{tabular}




\section{Hardline Routing}

The nineteen hardlines, which connect with the thermocouples, pressure transducer, and flow turbine in the lower inlet assembly, will be routed as one group along the outside of the shroud and will be lockwired to a specially designed holding fixture. The hardlines will then pass upward through a seal fitting in the restrictor plate and then through the hanger tube to a single braze plug. This feature allows the entire inlet assembly to be removed and replaced as a module.

\section{FUEL ASSEMBLY}

The fuel bundle assembly will consist of the following components:

- (4) spacer grids - Inconel

- (4) shroud side plates - Zircaloy

- (10) RIA 1-7 fuel rods plus one spare rod

- (10) OPTRAN 1-3 rods plus one spare rod

- (approx 20) shroud clamps

- (4) flux wire holders

- (4) shroud seals - SST

- (2) fuel rod supports

- (2) fuel rod locking mechanisms

- (8) shroud keys

\section{Shroud}

Four Zircaloy side plates will be used to make the shroud. These plates will be dovetailed together and a series of short clamps installed at several locations along the length of the shroud on each corner. A small diameter tube, slit along its length, will be placed in a groove between the corner butt joints as shown in Figure 2. This tube will act as a seal between side plates. A grid support plate is located at the bottom of the shroud. This grid will have a locking mechanism to prevent the rods from shifting. An individual rod can be removed, however, by rotating the keying mechanisms to a release position. The entire bundle assembly is held in place with a shroud keys clamped into both end fittings. 


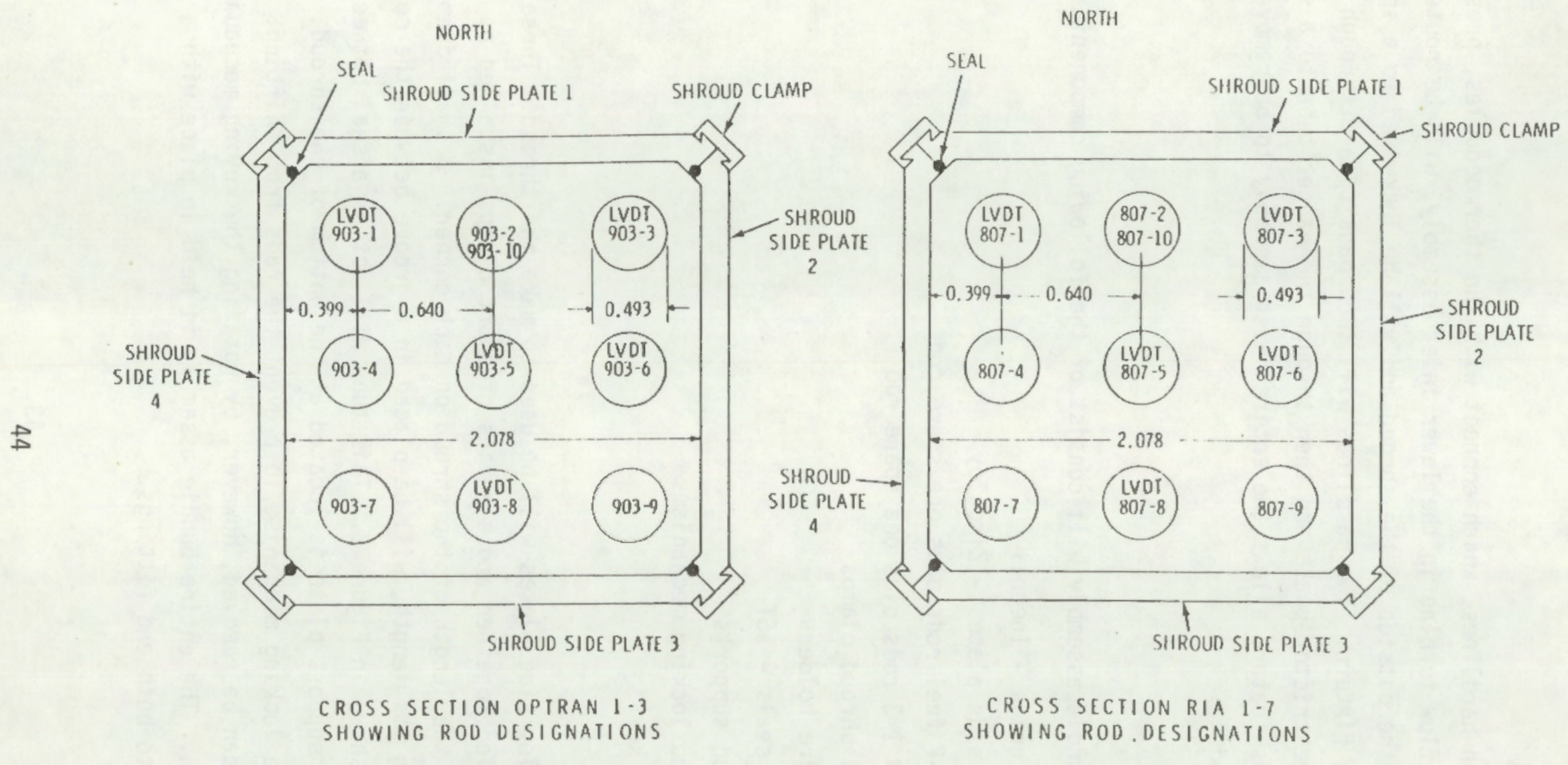

FIGURE 2. Fuel Rod Array Simulating an $8 \times 8$ BWR Lattice 


\section{Lattice Array}

Figure 2 also shows the fuel rod arrays for both the OPTRAN 1-3 and RIA 1-7 bundles based on a standard $8 \times 8$ BWR lattice. The bundle can be redesigned to accommodate a standard $7 \times 7$ BWR lattice if required. Both the OPTRAN 1-3 and RIA 1-7 bundles contain several uninstrumented standard rods, which could be interchanged between bundles if desired. The uninstrumented rod locations for OPTRAN 1-3 are shown in Figure 2 at positions 903-2, 903-4, 903-7, and 903-9. The rod located in position 903-2 can be removed from the bundle following the power calibration phase of the experiment and replaced with an irradiated rod designated as 903-10 for the balance of the experiment. The uninstrumented rod positions for the RIA 1-7 bundle are located at 807-2, $807-3,807-4,807-7$, and 807-8. The replacement rod is designated as 807-10 and is shown in the original $807-2$ position.

\section{Fuel Rod Instrumentation}

The location of pressure transducers, thermocouples, and strain gages for the OPTRAN 1-3 fuel rods are illustrated in Figure 3. New end caps will be mounted at the bottom of each rod type to ensure proper fit up with the lower tie plate. Three of the rods in the OPTRAN 1-3 bundle will contain strain gages mounted at the 1012.27-in. and 1019.75-in. elevations. Rod 903-1 is the only rod fitted with an internal pressure transducer.

Rod types for RIA 1-7 bundle are illustrated in Figure 4 with instrument type and location shown. Three of the rods in the RIA 1-7 bundle will be fitted with internal pressure transducers. Thermocouple locations relative to the $0^{0} \mathrm{~N}$ orientation mark are also illustrated.

The attachment of strain gages and thermocouples to the cladding surface will be done by resistance welding. The hardline cabling for these sensors will be held firmly against the cladding surface by means of a tantalum band that is spot welded to the cladding surface. These bands will be located at 4-in. spacings along the axial length of the fuel rod.

The spacer grid design is illustrated in Figure 5. The spacers will be positioned at four axial locations as shown. These locations will be identical 


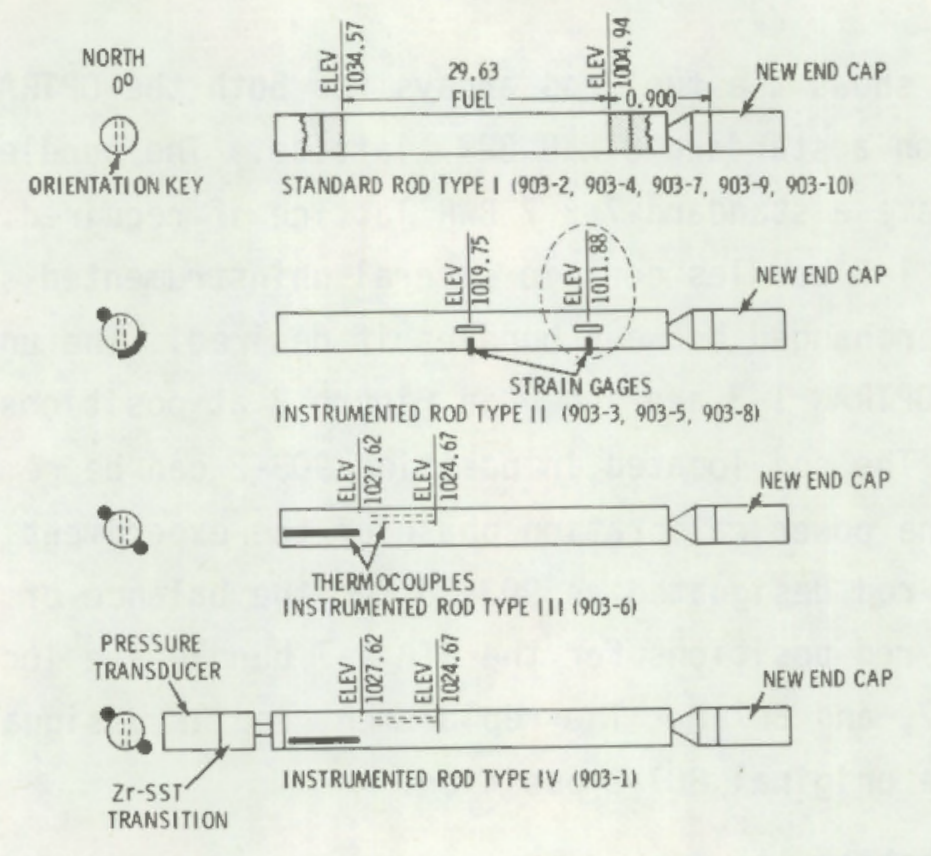

FUEL RODS OPTRAN $1-3$

\section{FIGURE 3. OPTRAN 1-3 Fuel Rod Types Showing Instrument Locations}
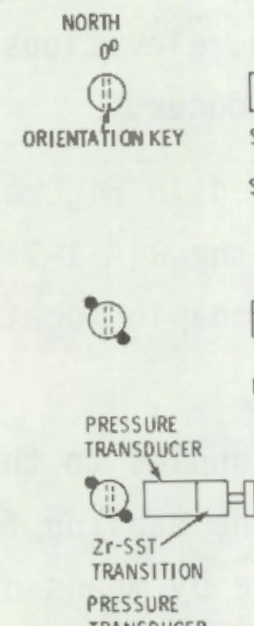

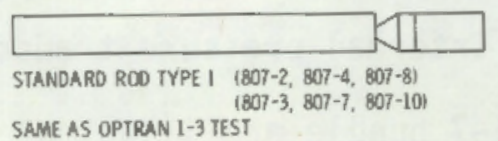
SAME AS OPTRAN 1-3 TEST

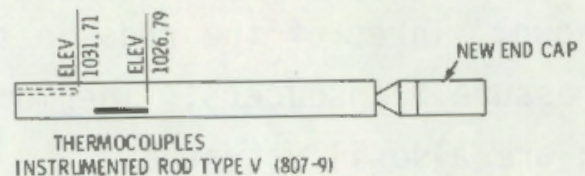

INSTRLIMENTED ROD TYPE V (807-9)

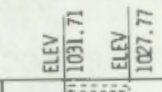

INSTRLMENTED ROD TYPE VI (BO7-1,807-5)
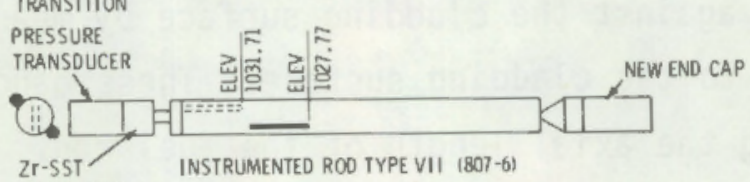

INSTRUMENTED ROO TYPE VII (807-6) IRANSITION

FUEL RODS RIA 1-7

\section{FIGURE 4. RIA 1-7 Fuel Rod Types Showing Instrument Locations}



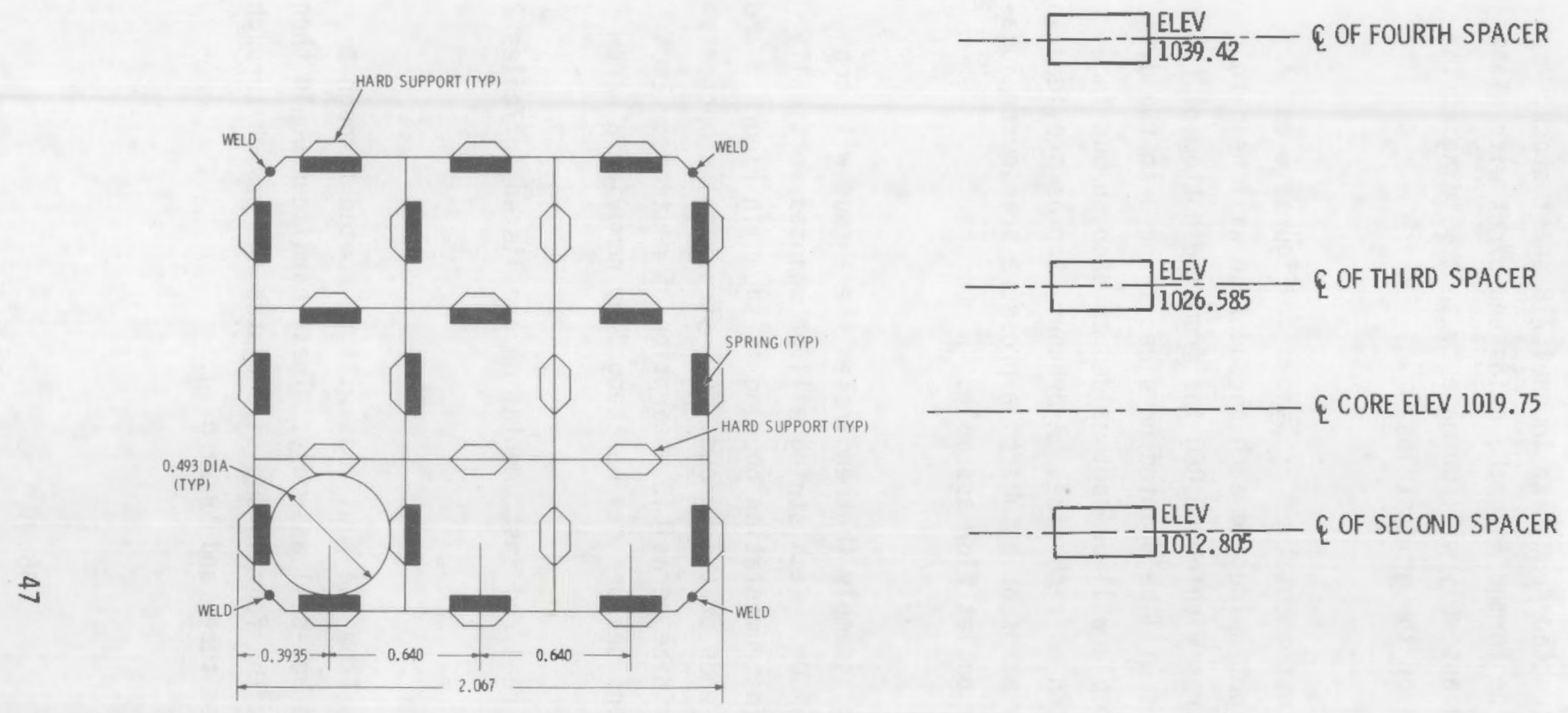
OPTRAN 1-3 and RIA 1-7 Test Trains 
for both the OPTRAN 1-3 and RIA 1-7 bundles. Either pins pressed into the shroud side plates or machined grooves will be used to ensure proper positioning. Each spacer will be constructed from flat Inconel 718 sheet stock. Springs and hard supports will be formed into the grids and bands with blanking or forming dies. The final assembly will be made by spot welding at the corners and at the intersection of the grid strips.

\section{Shroud Instrumentation}

The locations for shroud instrumentation are shown in Figures 6 and 7 . Small-diameter Zircaloy tubes spot welded to each shroud face will help to position the end of the flux wires within \pm 0.050 in. from the bottom of the active fuel stack. Strain gages will be mounted on sides 1 and 3 at two different locations. One thermocouple will be spot welded to each shroud face but at a different axial location on each side. A pressure tap is provided in side 1 and will be connected by means of a tube to a pressure transducer located above the fuel stack on the outlet flow assembly.

\section{Core Instrumentation}

A separate instrumentation assembly that encircles the shroud will contain two strings of SPNDs and SPGDs. Each string will be mounted vertically on Zircaloy tubes. The outer instrumentation housing is shown in Figure 8 and is attached by flanges to both ends of the shroud. All structural components will be made of Zircaloy to minimize parasitic absorption of neutrons. Each of the four strings of instrument sensors can be changed by removing a screw at the upper flange section.

A summary of the core and fuel rod instrumentation are listed in Tables 2 and 3 .

Hardline Routing

Seventeen instrument leads from the fuel rods will be routed through a split outlet housing during the hot-cell assembly. These hardlines would then be combined with six leads from the four shroud side plates and passed through a common restrictor seal, hanger tube, and braze plug. 
$0^{0}$

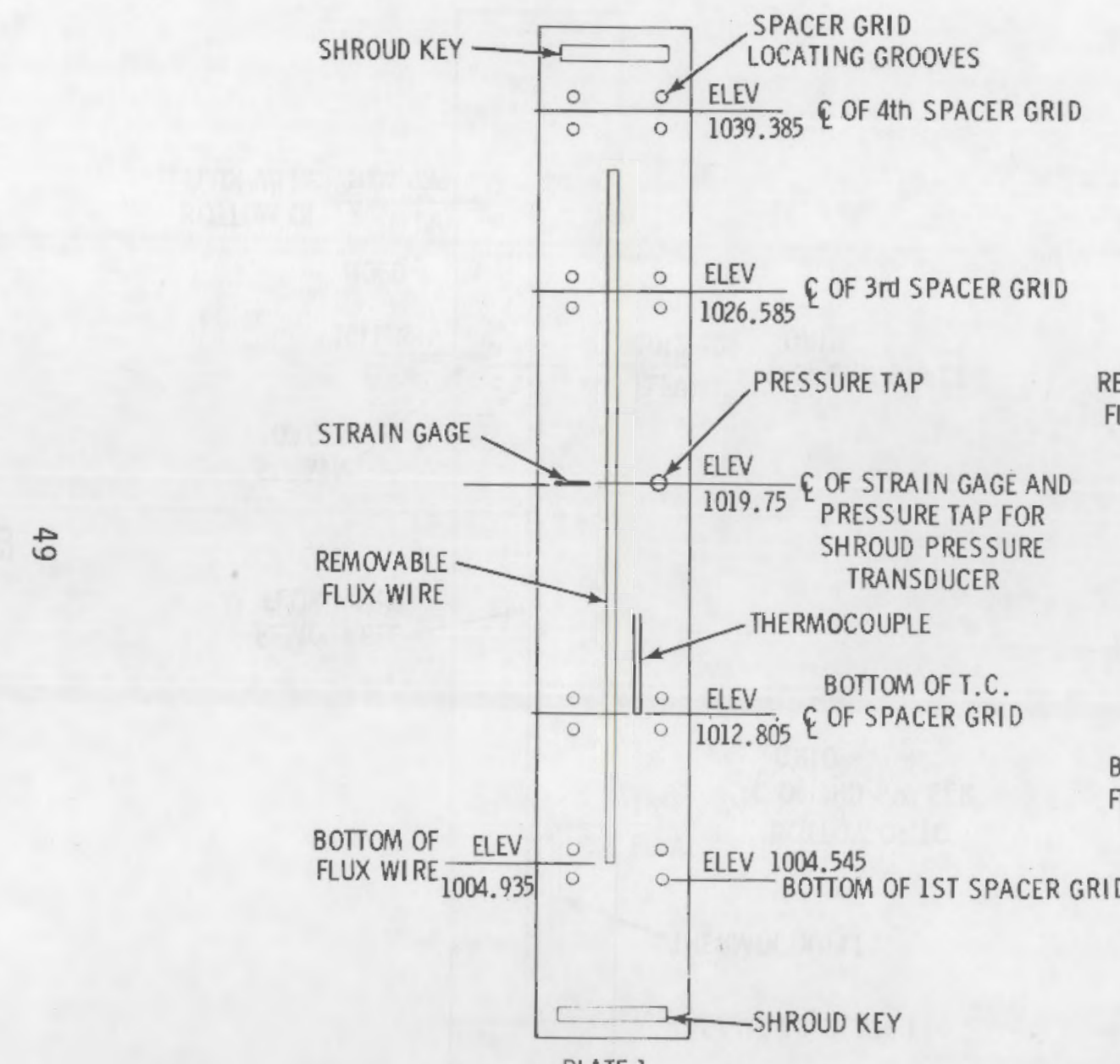

PLATE 1 $90^{\circ}$

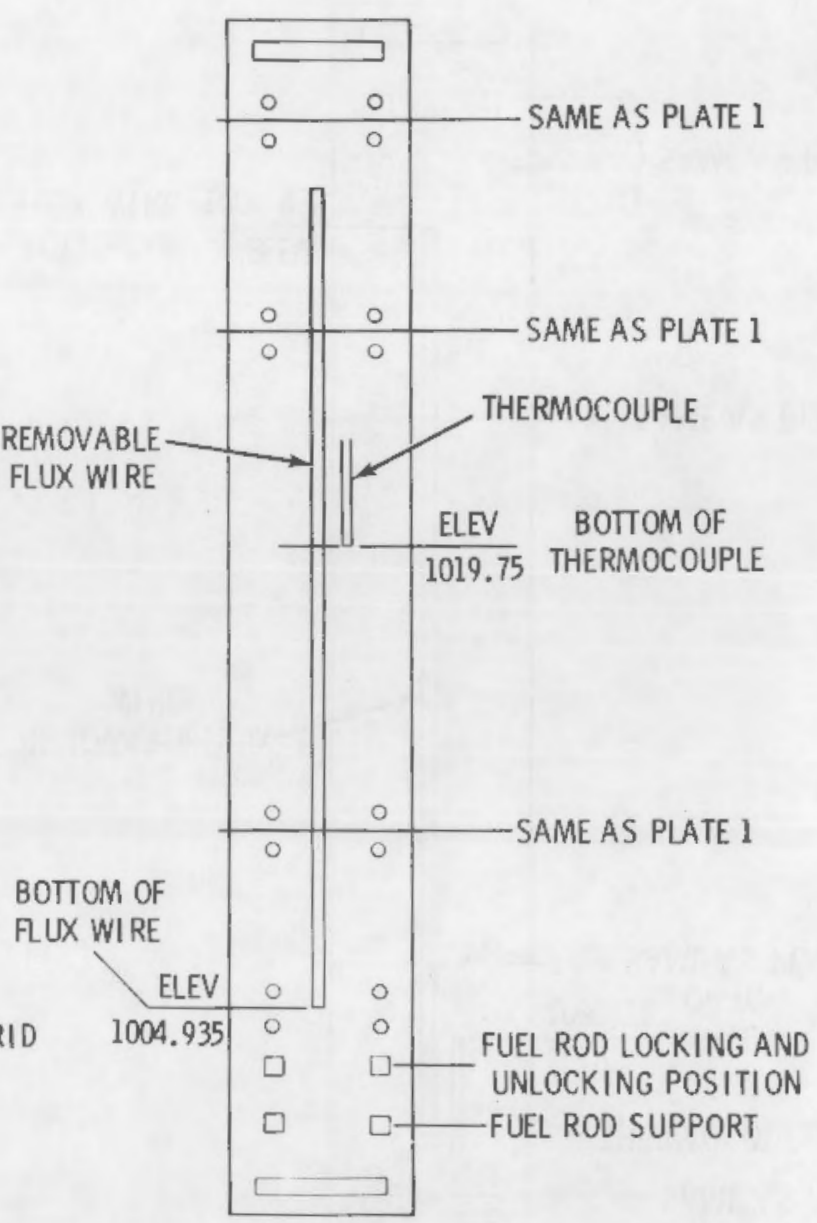

PLATE 2

FIGURE 6. Shroud Side Plates 1 and 2 Showing Instrument Locations 
$180^{\circ}$

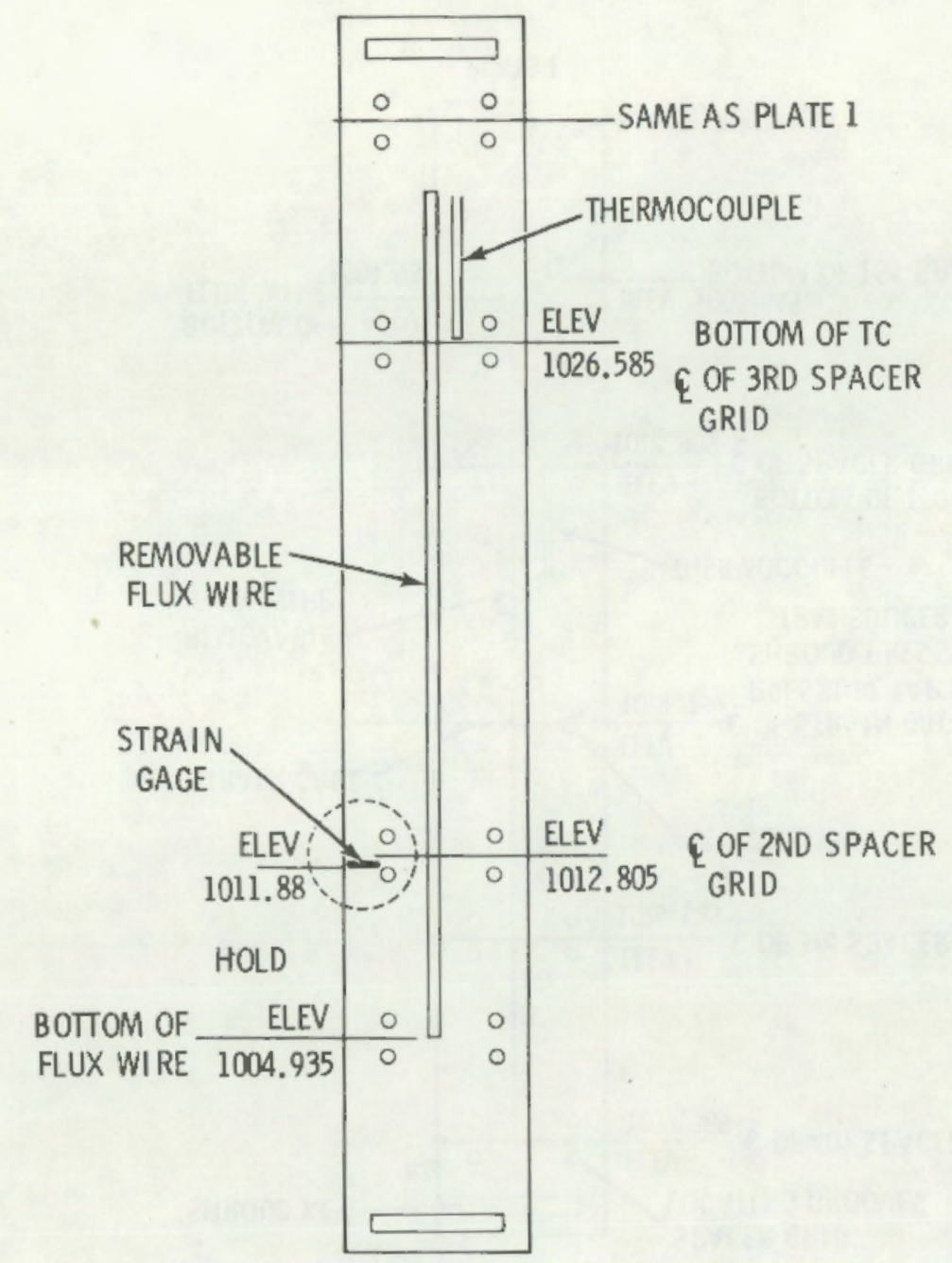

PLATE 3 $270^{\circ}$

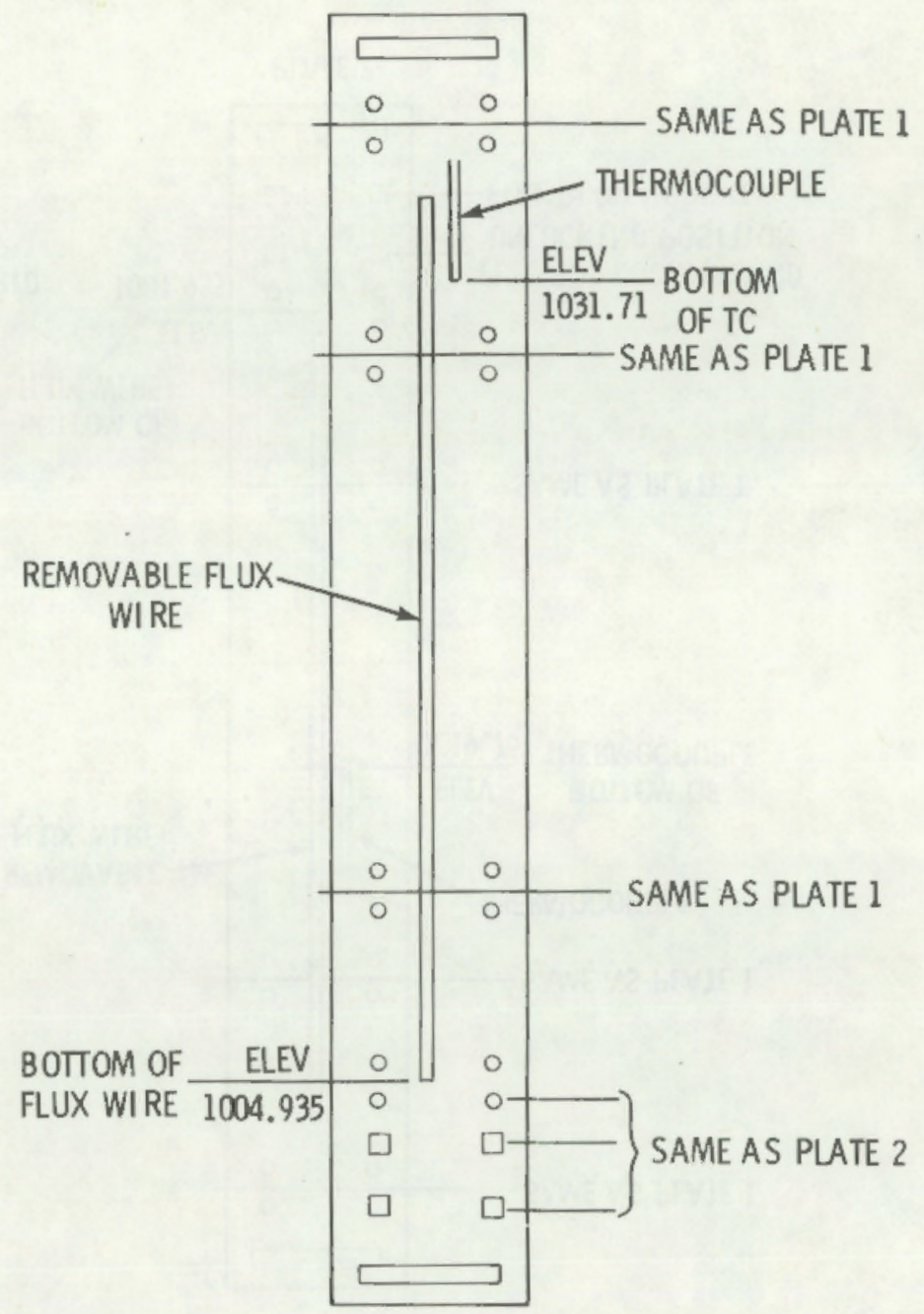

PLATE 4

FIGURE 7. Shroud Side Plates 3 and 4 Showing Instrument Locations 


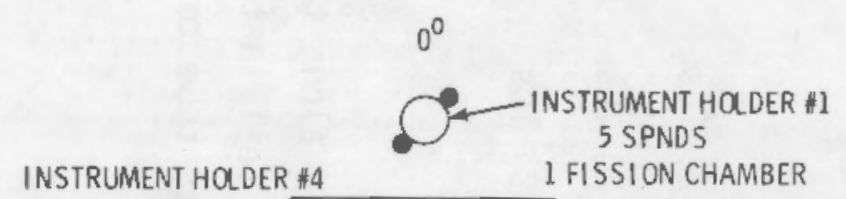

INSTRUMENT HOLDER \#4 I FISSION CHAMBER

$$
30^{\prime \prime} \text { SPND }
$$

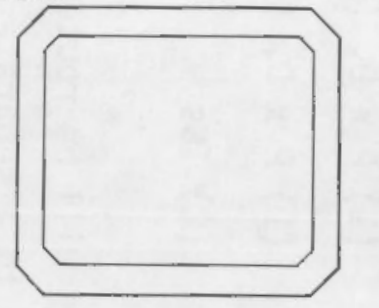

INSTRUMENT HOLDER \#2 SPGD

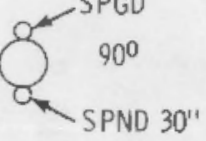

instrument hader *3

5 SPNDS

$180^{\circ}$ IFISSION CHAMBER

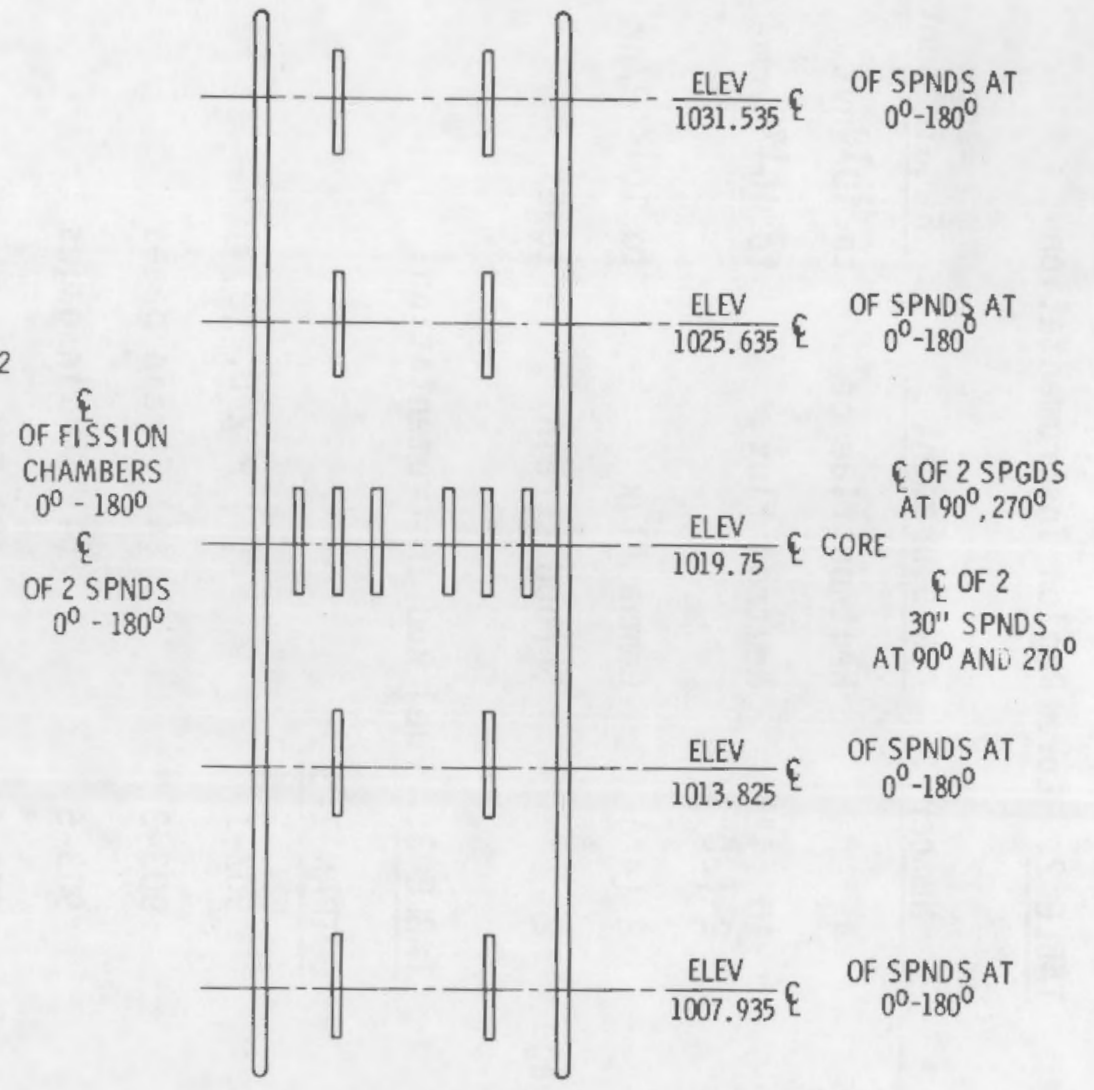

FIGURE 8. Core Region Instrument Array 
TABLE 2. Core Region Instrumentation

\begin{tabular}{|c|c|c|c|}
\hline Sensor & Number & Measurement & $\begin{array}{c}\text { Range } \\
\text { Requirement }\end{array}$ \\
\hline Flux wire & 4 & Neutron fluence & to 1018 nvt \\
\hline SPNDS & $\begin{array}{l}10(4 ") \\
2\left(30^{\prime \prime}\right)\end{array}$ & Neutron flux & to $10^{17} \mathrm{n} / \mathrm{cm}^{2} \mathrm{sec}$ \\
\hline SPGDS & $2\left(4^{\prime \prime}\right)$ & Gamna flux & to $10^{12} \mathrm{R} / \mathrm{hr}$ \\
\hline Strain gage & 2 & Shroud strain & to $5 \%$ \\
\hline
\end{tabular}

TABLE 3. Fuel Rod Instrumentation

$\begin{array}{cl}\frac{\text { OPTRAN 1-3 }}{903-1} & \text { (1) } P \times D, \text { (2) TCS } \\ 903-3 & \text { (4) Strain gages } \\ 903-5 & \text { (4) Strain gages } \\ 903-6 & \text { (2) TCs } \\ 903-8 & \text { (4) Strain gages } \\ \text { RIA 1-7 } & \text { (1) } P \times D, \text { (2) TCS } \\ 807-1 & \text { (1) } P \times D, \text { (2) TCs } \\ 807-5 & \text { (1) } P \times D, \text { (2) TCs } \\ 807-6 & \text { (2) TCS }\end{array}$

The 12 core-region instrument leads will be routed along the outside of the outlet and recombined flow housings to a separate seal in the restrictor plate. They will also continue upward through a hanger tube to a separate braze plug. 


\section{BUNDLE ASSEMBLY}

Since all test rods in the OPTRAN 1-3 and RIA 1-7 experiments will have undergone previous irradiation, the installation of pressure transducers and the attachment of strain gages and thermocouples must be performed in a hot cell. Final bundle assembly involving the insertion of fuel rods into spacers and the installation of shroud side plates and the split outlet housing will also have to be performed in a cell. Fixtures will be designed to aid in these operations. Flux wires can be installed in their special holders during final hot-cell assembly or later at the canal.

The assembled bundle will have to be transferred to the Materials Testing Reactor canal for final installation of the restrictor seal and assembly of the hanger tube and braze plug. This assembly then would be transferred to the PBF canal for final installation with the inlet and outlet hardware.

An option under consideration is to use high-pressure connectors on the hardlines that attach to the fuel rods and shroud side plates. This could be done prior to hot-cell assembly and would allow transfer of the assembled bundle directly to the PBF canal. The total working length would be greatly reduced since the hardlines terminate at each connector. The connectors would be located immediately below the restrictor plate when the test train is inserted into the loop.

\section{OUTLET FLOW ASSEMBLY}

The outlet flow assembly is shown in Figure 9 and consists of the following parts:

- (1) shroud to housing seal - copper

- (1) split outlet housing - 300 series (SST)

- (1) LVDT assembly (housing)

- (2) face seals - copper

- (1) split hardline penetration housing - 300 SST

- (1) flow straightener - 300 series SST

- (1) seal between flow' straightener and turbine - copper

- (1) flange - 300 series SST 


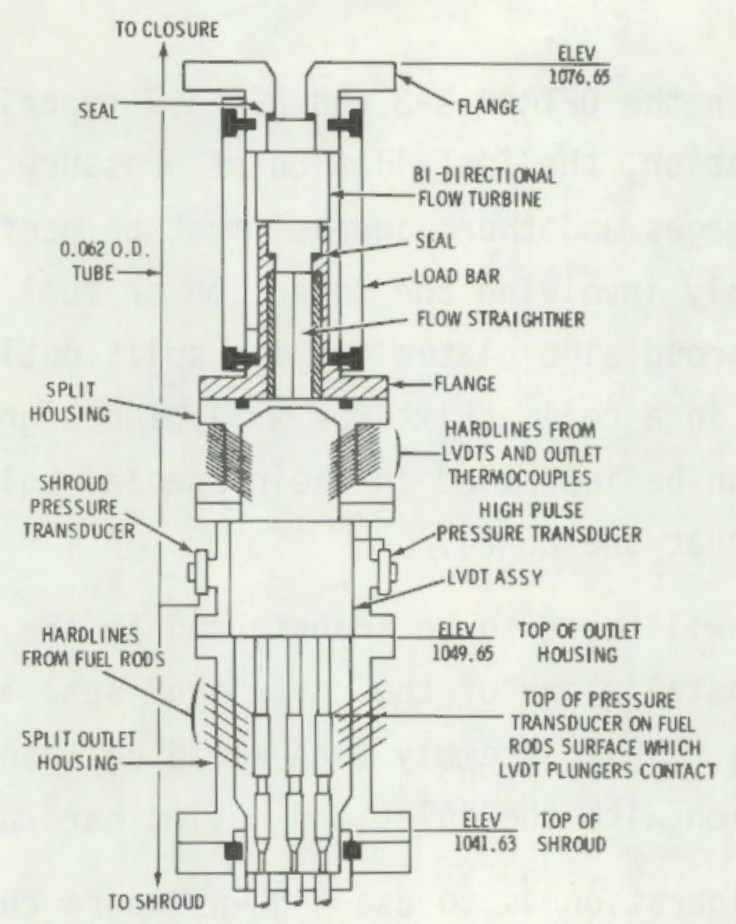

FIGURE 9. Out let Flow Region

- (1) flow turbine extension - 300 series SST

- (1) flow turbine housing

- (2) load bars.

Assembly Instrumentation

The outlet flow assembly will be clamped to the upper shroud flange and sealed with a copper gasket. Space is provided for the mounting of five LVDTS to measure rod elongation of five rods as designated in Figure 2. Two of the five LVDT locations will not be directly above the fuel rod axis because of space limitations. Offset linkages will be used to connect these to other rods. The offset locations will be 903-6 and 903-8 for the OPTRAN 1-3 bundle and 807-6 and 807-8 for the RIA 1-7 bundle.

Six differential outlet thermocouples and two flow outlet temperature sensors will be passed through a split sleeve located just above the LVDT housing. A pressure transducer will be mounted on the outside of the LVDT housing and connected by means of a small diameter tube to a pressure tap in the shroud as discussed previously. 
A flow straightener is located upstream from the LVDT housing and split thermocouple penetration area. This straightener will direct the flow into a bidirectional flow turbine $(9-90 \mathrm{gpm})$ located at the top of the out let flow as sembly.

The outlet assembly instruments are sumarized in Table 4.

Hardline Routing

The 21 hardlines from the flow turbine, LVDTs and thermocouples will be packaged together with the recombined flow region leads (discussed below) and routed through a common seal in the restrictor plate and then upward through the central hanger tube to a braze plug for penetration to the closure head. The outlet flow assembly will be constructed as a modular unit, however, and can be physically separated from other test train modules.

\section{RECOMBINED FLOW REGION}

The recombined flow region consists of the following components:

- flow recombined housing - 300 series SST

- flow straightener - 300 series SST

- flow straightener housing - 300 series SST

- flow turbine extension - 300 series SST

- load bars - 300 series SST

TABLE 4. Out let Assembly Instrumentation

\begin{tabular}{|c|c|c|c|}
\hline Sensor & Number & Measurement & $\begin{array}{c}\begin{array}{c}\text { Range } \\
\text { Requirement }\end{array} \\
\end{array}$ \\
\hline LVDT & 5 & Fuel rod elongation & $0-1$ in. \\
\hline$P \times D$ & 1 & Shroud pressure & $0-17.2 \mathrm{MPa}$ \\
\hline TCs & 2 & Shroud outlet temperature & $300-600^{\circ} \mathrm{K}$ \\
\hline $\mathrm{TCs}$ & 6 & $\begin{array}{l}\text { Differential temperature } \\
\text { shroud (outlet-inlet) }\end{array}$ & $0^{\circ}-20^{\circ} \mathrm{K}$ \\
\hline Flow turbine & 1 & Bidirectional flow & $9-90 \mathrm{gpm}$ \\
\hline
\end{tabular}


- hardline penetration housing

- flow housing

- flow restrictor plate

- clamps

- seals.

A restrictor plate near the top of the upper flow housing forces the bypass flow to recombine with the two-phase mixture exiting the bundle. The steam will be quenched by the subcooled bypass water and the combined mixture passed through a straightener before entering a flow meter (see Figure 10). A catch basket is provided at the top flange of this assembly to prevent large particles stopped by the screen above from falling and clogging the flow turbine. The upper flange also serves as a bracket for attaching the hanger tubes that support the entire test train assembly.

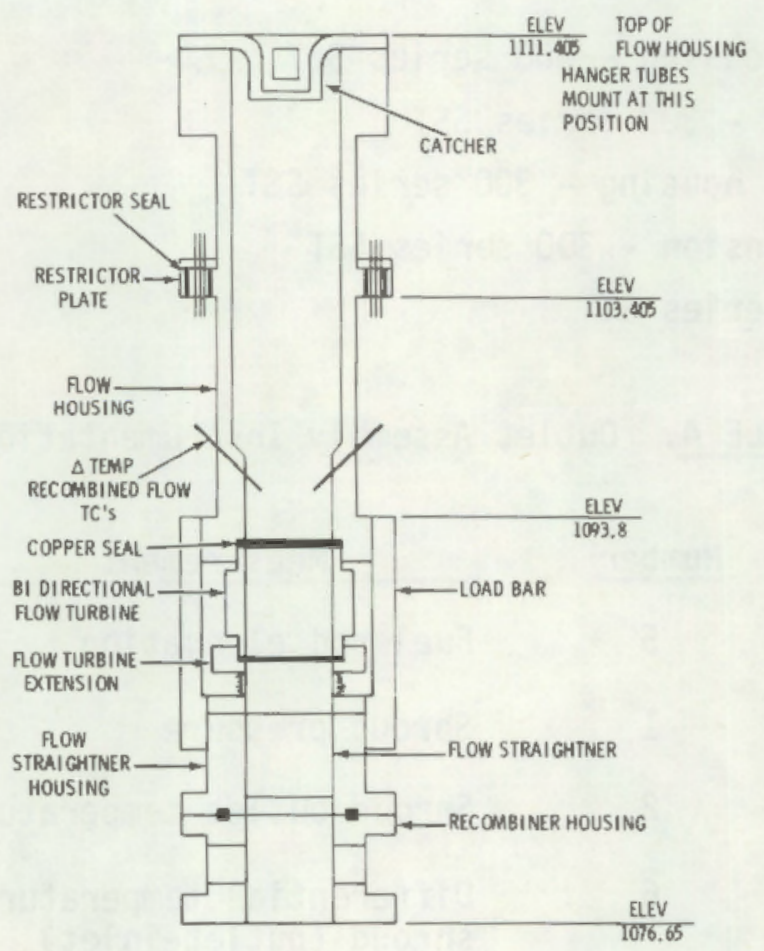

FIGURE 10. Recombined Flow Region 


\section{$\underline{\text { Instrumentation }}$}

The bidirectional flowmeter will be sized to measure the combined flow, which will be approximately twice (18-180 gpm) the flow passing through the bundle. Six differential thermocouple legs penetrate the flow housing immediately above (downstream) the turbine. The thermocouple package will be secured with a mounting ring. These thermocouples are paired with six other legs located in the lower inlet assembly (discussed previously) to provide a combined outlet-inlet differential temperature measurement. A sumary of instrumentation for this section is shown in Table 5 .

TABLE 5. Recombined Flow Region Instrumentation

\begin{tabular}{|c|c|c|c|}
\hline Sensor & Number & Measurement & $\begin{array}{c}\text { Range } \\
\text { Requirement }\end{array}$ \\
\hline Flow turbine & 1 & Recombined flow & $18-180 \mathrm{gpm}$ \\
\hline TCs (1 leg) & 6 & $\begin{array}{l}\text { Differential temp } \\
\text { (recombined flow } \\
\text { - inlet flow) }\end{array}$ & $0^{\circ}-20^{\circ} \mathrm{K}$ \\
\hline
\end{tabular}

\section{RESTRICTOR PLATE}

A plan view of the flow restrictor plate is shown in Figure 11. Four seal regions will be provided to pass the instrument hardlines. Each of these regions are located immediately below a hanger tube to facilitate packaging and routing of the leads. The four seal regions are divided as follows:

1) Lower in let assembly

2) Fuel bundle and shroud

3) Core (region) instrumentation

4) Upper outlet flow and recombined flow assemblies. 


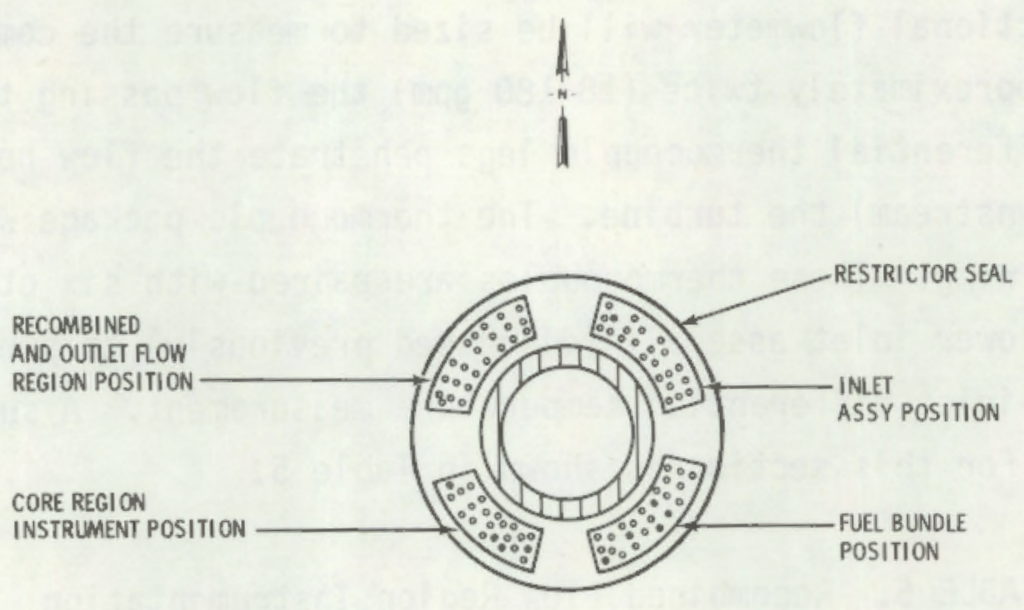

SECTION AT FLOW RESTRICTOR PLATE

FIGURE 11. Restrictor Plate Showing the Position of the Four Hardline (Instrumentation Package) Groups

\section{CLOSURE REGION}

This region will consist of the following components:

- particle screen (Johnson filter)

- closure head

- hanger tubes.

It is anticipated that the established closure head design used for the $4 \mathrm{X}$ test train (PNL Drawing $\mathrm{H}-3-41302$ ) will be used. The instrument line feedthrough configuration will be adjusted to accommodate the different grouping of hardlines required for the nine-rod assembly. Five braze plug penetrations will be used.

Four hanger tubes will support the test train through use of hex-head nuts that thread into the braze plug penetrations in the bottom of the closure head. The hanger tubes will be open on one side to allow access to the hardlines and thereby facilitate removal and repair. 


\section{PARTICLE SCREEN}

A fine mesh particle screen (Johnston filter) will be located immediately above the recombined flow region to trap particles of fuel or debris ejected from the bundle during a test. The upper closure head, hanger assembly, and particle screen is shown in Figure 12.

\section{TEST TRAIN ENVELOPE DIMENSIONS}

An overall elevation schematic of the nine-rod assembly is shown in Figure 13. Envelope dimensions are designed to $f i t$ within the inpile tube and inner flow liner shown in Figure 14.

CLOSURE REGION

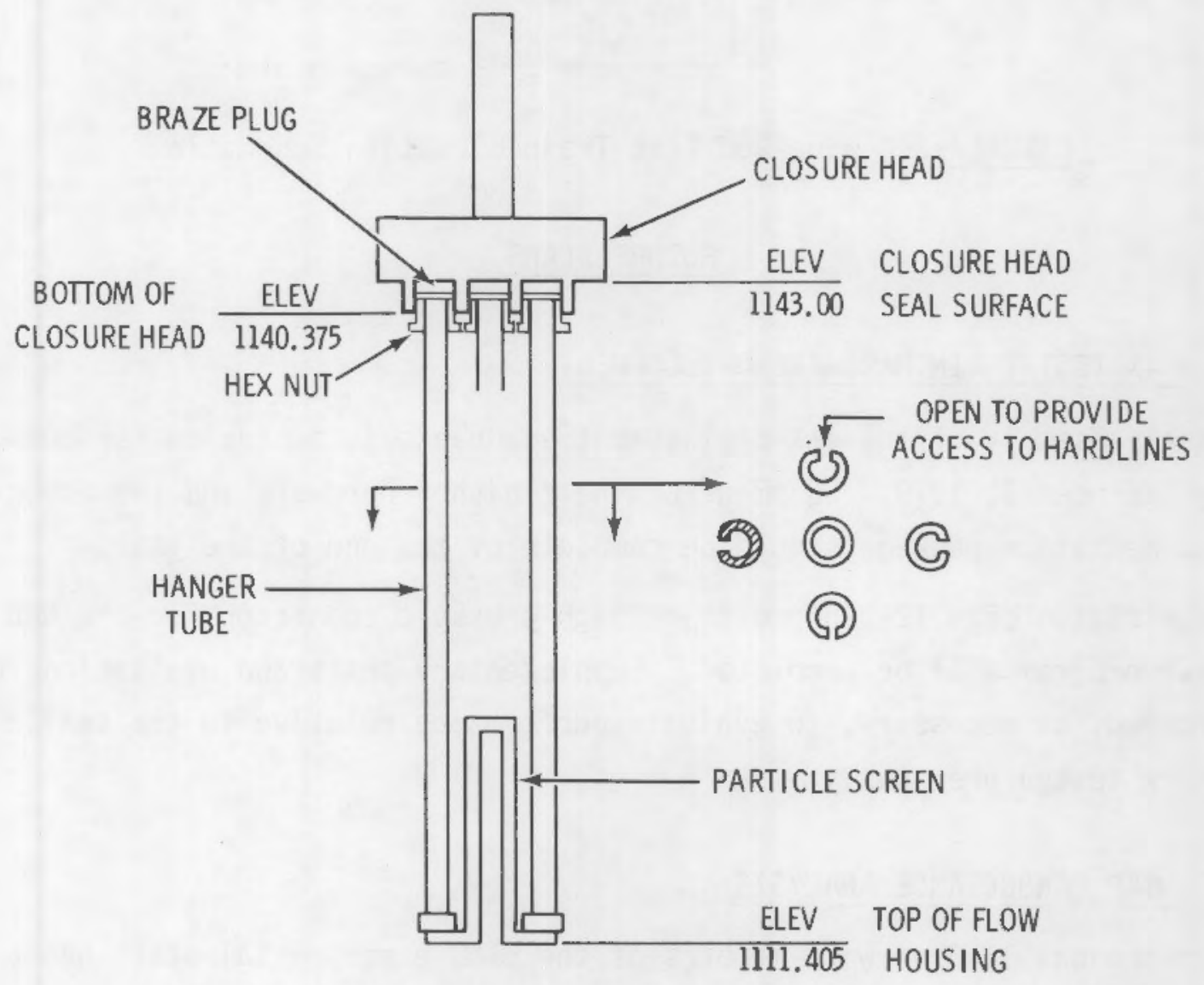

FIGURE 12. Closure Region 


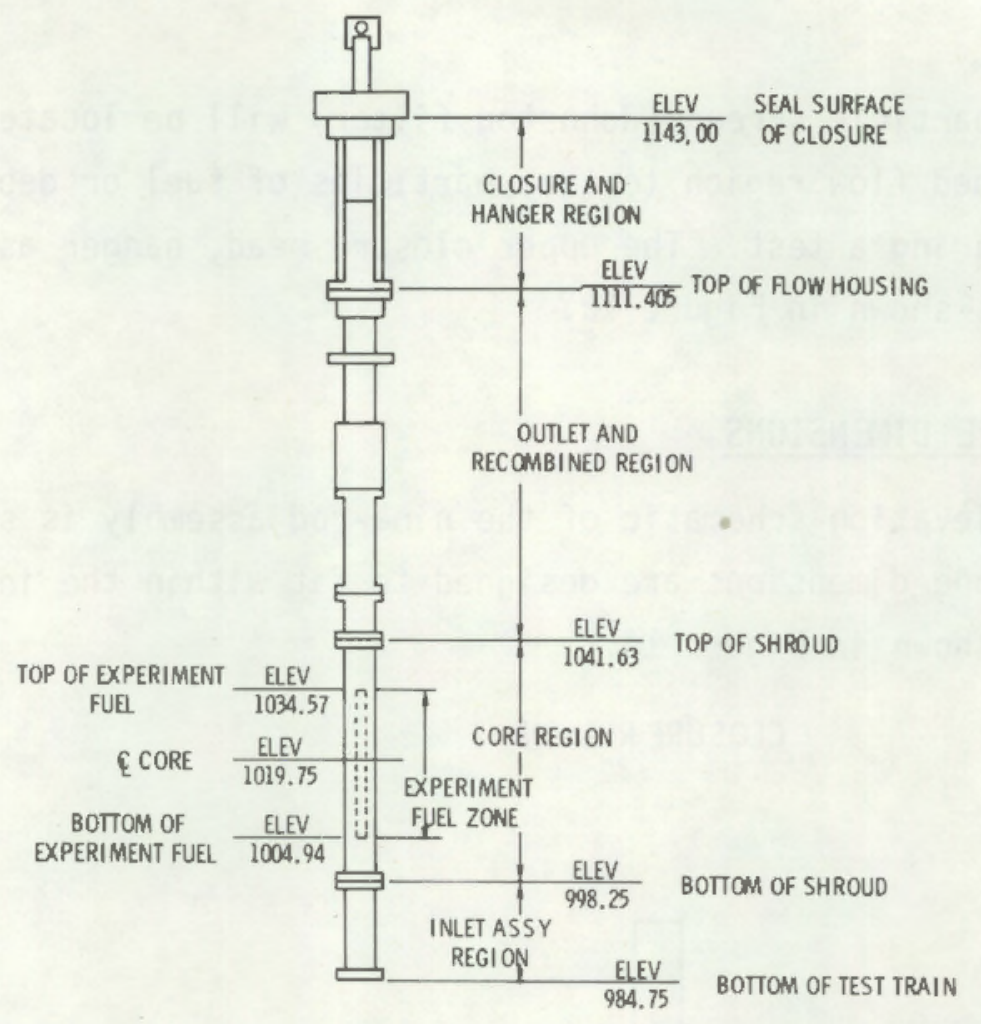

FIGURE 13. Nine-Rod Test Train Elevation Schematic

\section{FUTURE PLANS}

\section{TASK A $-4 X$ TEST TRAIN HARDWARE DEVELOPMENT}

Final assembly of the 4-X replacement quadrants is scheduled for completion by December 1, 1979. Shipment of the finished hardware and the associated documentation package should be complete by the end of the year.

Fabrication of a 12-pin prototype high-pressure connector for the NRU LOCA test program will be completed. Supplementary tests and evaluations will be performed, as necessary, to evaluate performance relative to the smaller connectors tested previously.

\section{TASK B - GAP CONDUCTANCE ANALYSIS}

A technical liaison with members of the EG\&G experimental staff has been established. Analytical support and technical inputs will be supplied as requested. Progress will depend upon PBF test schedules and priorities. 


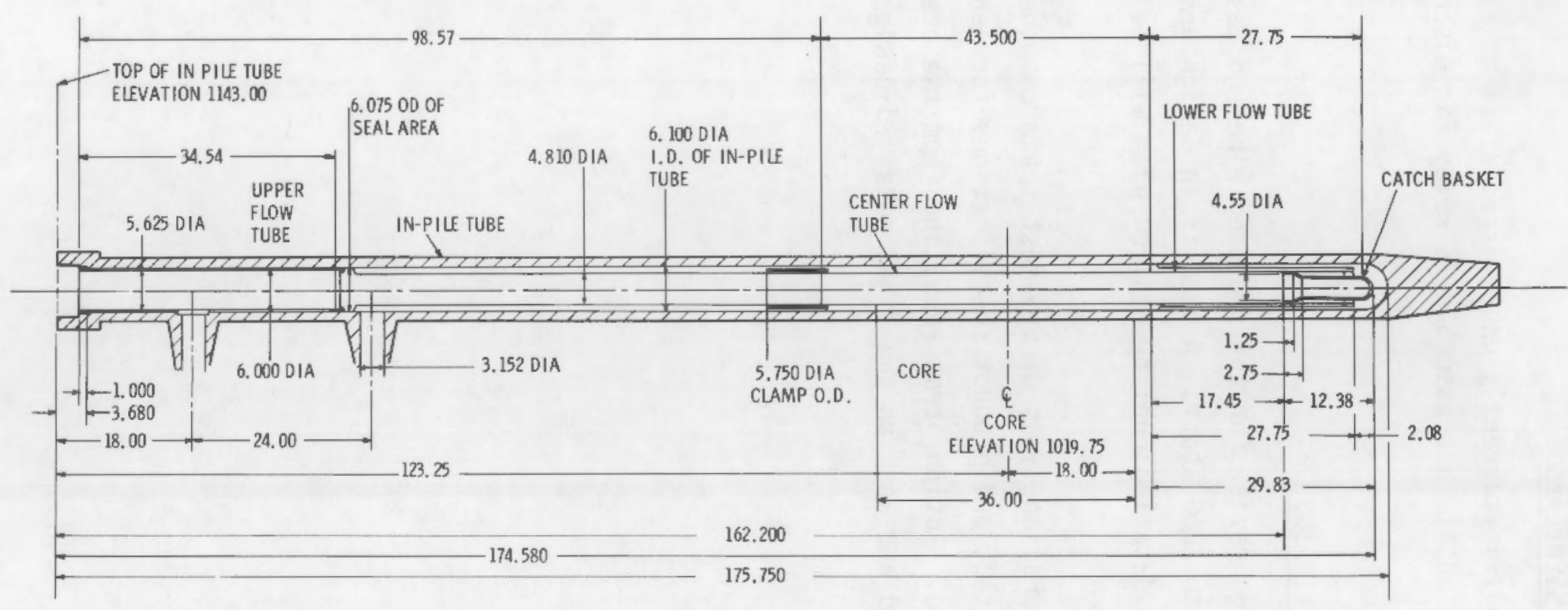

FIGURE 14. Test Tube Envelope Dimensions for Nine-Rod Test Train 


\section{TASK C - DUAL-PURPOSE ASSEMBLIES}

The IFA 513 assembly is currently under irradiation at Halden. No further work is planned until this assembly is ready for discharge near midcalendar year 1981.

TASK D - MULTI-ROD TEST TRAINS

A preliminary design review for the proposed nine-rod test train configuration will be held with EG\&G staff. A test train design and fabrication planning document and a detailed quality control plan will be prepared and issued.

Preliminary structural analys is of key test train components and subassemblies will be initiated, and product specifications for long lead instrumentation items prepared. Action items resulting from the preliminary design review will be addressed and work on the final detailed design will be started. 


\section{RESIDENT ENGINEER AT CADARRACHE, FRANCE ${ }^{(a)}$}

D. S. Trent, Project Manager

C. L. Wheeler

\section{SUMMARY}

All planned hardware modifications were completed and the acceptance testing program for the PHEBUS reactor and test loop continued. The initial shakedown of all reactor and loop components as well as the two adiabatic acceptance blowdown tests were completed.

\section{INTRODUCTION}

The objective of this program is to facilitate the exchange of information between the U.S. and France. To this end, a resident engineer is being supported at the PHEBUS program in France. The PHEBUS experimental program for in-pile studies is operated by the Service D'Essais de Surete (Safety Tests Service) of the French Atomic Energy Commission. The facility, which is located at Cadarache, consists of a closed test loop driven by a pool-type reactor, which develops about $60 \mathrm{MW}$ for a 20-min. test period. The test loop, which passes through the center of the core, contains an $80-\mathrm{cm}$ test section and is capable of operating at power water reactor (PWR) conditions. Current plans call for blowdown and reflood-type testing on rod bundles containing either single-rod or 25-rod assemblies having geometries typical of those found in large PWRs.

\section{CURRENT STATUS}

All planned construction and modifications have been completed and the system is undergoing acceptance testing. As part of the acceptance testing

(a) RSR Fin. Budget No. B2278; RSR Contact: W. V. Johnson 
program, the first and second adiabatic blowdowns have been completed. The first utilized a single-rod assembly and blowdown was made from initial conditions of $275^{\circ} \mathrm{C}$ and 140 bars. In the second, a 25 -rod assembly was used and progressed from initial conditions of $320^{\circ} \mathrm{C}$ and 150 bars. In general, these tests progressed satisfactorily; however, they did illuminate several minor problems, which have subsequently been eliminated.

The fabrication of the two instrumented spool pieces which are to be used to measure flow, density, and pressure in the hot and cold legs is almost complete and a prototypic assembly is currently undergoing calibration at Karlsruhe.

\section{FUTURE WORK}

The two planned nuclear blowdowns which are to be run under the acceptance testing program will be performed early in the next quarter. Then all testing will stop for two months while the two instrumented spool pieces are inserted and evaluated, after which the planned in-pile loss-of-coolantaccident studies will commence. 
CORE THERMAL MODEL DEVELOPMENT ${ }^{(a)}$

D. S. Trent, Program Manager

M. J. Thurgood, Project Manager

T. L. George

J. M. Kelly

J. M. Cuta

K. L. Basehore

\section{$\underline{\text { SUMMARY }}$}

COBRA-TF has been implemented into TRAC as the three-dimensional vessel module. The resultant code, COBRA/TRAC, has been used to perform simulations of tests in the FLECHT and SEMISCALE facilities and has been used to do pretest analysis of the Japanese Slab Core Test Facility (SCTF). A model for liquid entrainment during reflood has been developed and used in reflood simulations.

\section{INTRODUCTION}

The COBRA-TF computer code is being developed as part of the NRC Water Reactor Safety Research Program in the area of analysis development. The purpose of this work is to provide better digital computer codes for computing the behavior of full-scale reactor systems under postulated accident conditions. The resulting codes are presently being used to perform pre-and posttest analysis of light water reactor component and system effects experiments. In particular this project has two main objectives:

1. To develop a hot bundle/hot channel analysis capability that will be used in evaluating the thermal-hydraulic performance of light water reactor fuel bundles during postulated accidents.

(a) RSR Fin. Budget No: B2041; RSR Contact: S. Fabic 
2. To develop a water reactor primary system simulation capability that is readily able to model complex internal vessel geometries such as those encountered in upper head injection-equipped PWRs.

COBRA-TF is formulated to model fully three-dimensional, two-phase flow using a three-field representation: the vapor field, the continuous liquid field, and the droplet field. The model allows thermal nonequilibrium between the liquid and vapor phases and allows each of the three fields to move with different velocities. Thus one can mechanistically treat a continuous liquid core or film moving at a low, or possibly negative velocity, from which liquid drops are stripped off and carried away by the vapor phase. This is an essential feature in the treatment of the hydrodynamics encountered during the reflooding phase of a loss of coolant accident (LOCA). This model has allowed the prediction of liquid carryover in the FLECHT low reflood series of experiments. The treatment of the droplet field is also essential to predict other phenomena such as counter-current flow limiting and upper plenum deentrainment and fallback.

The code also features flexible noding, which allows for modeling complex geometries encountered in reactor vessel internals, such as slotted control rod guide tubes, jet pumps, and core bypass regions. These geometries do not lend themselves easily to modeling in regular cartesian or cylindrical mesh coordinates. Since they have significant impact on the thermal hydraulic response of the system, these geometries must be modeled resonably accurately.

The fuel rod heat transfer model utilizes a rezoning mesh to automatically reduce the rod heat transfer mesh size in regions of high heat flux or steep temperature gradients and increase the mesh size in regions of low heat flux. This model has proven very effective in resolving the boiling curve in the region of the quench front.

COBRA-TF has been implemented into TRAC-P1A as the vessel module, providing a system simulation capability with the above described capabilities in the vessel. The resulting code is referred to as COBRA/TRAC and is being used to simulate several experiments, including FLECHT, SEMISCALE, and JAERI test facilities. 
During the past quarter, a model for the entrainment rate during bottom reflood was developed. Using this model, CDBRA/TRAC was used to perform simulations of experiments in the FLECHT and SEMISCALE MOD3 facilities and of a flow blockage analys is during reflood for the JAERI Slab Core Test Facility. Results of some of this work are presented in this report.

\section{REFLOOD ENTRAINMENT MODEL}

Effective cooling of the core is lost during the blowdown stage of a LOCA in light water reactors. During this period, the core is subjected to a nearly adiabatic heat up. The steam environment surrounding the rods does not provide sufficient heat transfer from the fuel clad to remove heat being added to the clad from stored heat in the fuel pellets and fission-product-decay heat generation. This temperature excursion is halted by the injection of emergency core cooling (ECC) water into the reactor vessel. Examples of sys- tems that have been devised for injecting ECC water into the vessel are cold-leg injection, hot-leg injection, and upper-head injection in PWRs and top spray injection in boiling water reactors (BWRs). Some reactor systems use combinations of various methods of injection. Eventually, the ECC water enters the core from the top or the bottom. As the cooling water enters the core, it comes in contact with the hot rods and the process of re-establishing effective cooling to the core is initiated. This portion of the transient has been termed the reflood phase of the LOCA. It is during this period that the temperature excursion of the fue 1 cladding is turned around.

Complex hydrodynamic and heat transfer processes occur during this phase of the transient as a result of the high-temperature clad being brought into contact with saturated or subcooled water. When the clad temperature is above the surface rewetting temperature, a film boiling heat transfer mechanism will be established. This may correspond to either a dispersed flow or inverted annular two-phase flow regime, depending upon the liquid content of the flow and the vapor velocity. As the clad temperature is reduced as a result of cooling provided by film boiling, the clad will enter a transition boiling and, finally, a nucleate boiling regime; the temperature will fall below the 
surface rewett temperature; and the surface will quench. Heat transfer from the rod will then take place in the form of nucleate boiling or single-phase liquid heat transfer, depending on the subcooling and flow rate of the liquid entering the core. During bottom reflood, the rate at which liquid will enter the core is limited by the balance between the driving head provided by the difference in liquid level of the core and downcomer and the flow resistance through the broken loop hot leg. During top reflood, the flow rate is controlled by counter-current flow limiting. High flows of superheated vapor result from the vapor generated as the rods are quenched. Vapor velocities are sufficiently high to entrain large fractions of the liquid in the form of drops. While droplet entrainment is beneficial in that it enhances heat transfer downstream of the quench front, it can be detrimental since it reduces the liquid inventory in the bindle and retards the propagation of the quench front.

A new flow regime, called the hot wall regime, has been added to COBRA/TRAC to treat the hydrodynamics of the highly nonhomogeneous, thermal nonequilibrium, two-phase flow encountered during reflood. The hot wall regime is assumed in the calculation whenever walls significantly hotter than the fluid are encountered. Figure 1 illustrates how this regime might look during bottom reflood. Also shown is the model used to simulate bottom reflood.

Below the quench front, single-phase liquid or bubbly flow is expected, and the normal COBRA-TF flow regime logic is used to determine which set of models should be used for interfacial drag, interfacial heat transfer, etc. When the wall superheat exceeds a specified value, the inverted annular flow regime is used.

As shown in Figure 1, at high liquid volume fractions the liquid is assumed to consist of a continuous liquid column with vapor flowing around it. The interfacial area is that of a cylinder, and interfacial shear and heat transfer are computed accordingly. Liquid entrainment is assumed to be negligible in this region. When the liquid volume fraction becomes small enough for a given vapor velocity, the liquid column becomes unstable and shatters into droplets of various sizes. For the present, it has been assumed that the top 


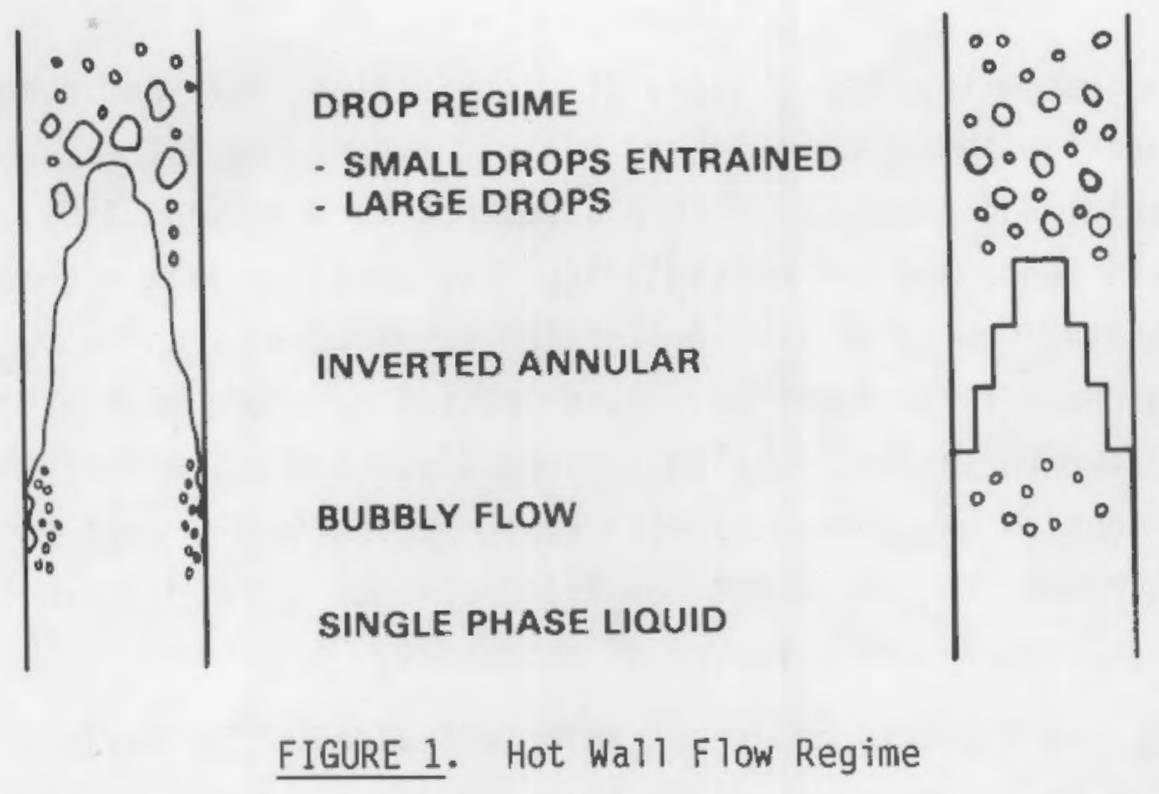

of the liquid column is unstable. (The actual point at which the column shatters is a function of the column length, diameter, and vapor velocity. A model for column breakup based on these parameters could be used, should one become available.) When the column shatters, a population of droplets is formed ranging from large droplets to very small ones. Of these drops, some will be carried away by the vapor flow and the rest will fall back down to the liquid column. The liquid in this region is treated as large drops for the continuous liquid field and small drops for the entrained liquid field.

The maximum stable drop size in this entrainment region can be characterized by the critical Weber number (Andersen 1973, Levy 1979)

$$
D_{0}=13.0 \sigma /\left.\left.\rho_{v}\right|^{V} \bar{v}\right|^{2}
$$

where $V_{\bar{v}}$ is the vapor velocity at the liquid interface.

The droplet size spectrum is determined from the Nukiyama-Tanasawa distribution function in the form; (Wallis 1969, Nukiyama and Tanasawa 1940)

$$
P(D)=32 \frac{D^{2}}{D_{0}^{3}} e^{-4 D / D_{0}}
$$


It has been suggested that other types of distribution functions such as the upper-limit function and the chi-square distributions, match the data better (Levy 1979; Lekic, Bajramovic, and Ford 1976; Mugele and Evans 1951). At the same time, these functions are more difficult to apply or lack a generalized means for obtaining the value for some of the parameters, such as $D_{90}, D_{50}$, and $\mathrm{D}_{10}$ in the upper limit function. Experimental data are most of ten employed to define these distributions accurately. Since the NukiyamaTanasawa distribution has been used with some success in the past (Andersen 1973), we have chosen to use it for our present model. The distribution function may be changed in the future if necessary.

Not all of the droplets produced can be entrained. The maximum size droplet that can be entrained is given by the balance between bouyant and drag forces (Andersen 1973, Levy 1979)

$$
D_{\max }=\frac{3^{C_{D} \rho_{v}}\left(v_{+}\right)^{2}}{4\left(\rho_{\ell}\right.}-\frac{\left.\rho_{v}\right) g}{\rho^{2}}
$$

where the superscript $(+)$ means the vapor velocity above the interface, and $C_{D}=0.45$. All drops smaller than $D_{\max }$ may be assumed to be entrained. The fraction $(n)$ of liquid which can be entrained is then given by (Andersen 1973)

$$
n=\int_{0}^{0} \max D^{3} P(D) d D / \int_{0}^{\infty} D^{3} P(D) d D
$$

where the term in the numerator is the total volume of liquid contained in drops having diameters smaller than $D_{\max }$ and the denominator is the total volume of liquid drops. This model was used with some success by Jens Andersen in REMI/HEAT COOL to model the carryover of drops from the core spray in BWRs and recommended by Richard Lahey of Renselaer Polytechnic Institute for computing entrainment from two-phase interfaces. 
Equation (4) can be used to obtain the source term for entrainment in the COBRA-TF finite difference equations. This term is simply

$$
\mathrm{Se}=\frac{\mathrm{DnM}}{\mathrm{Dt}}
$$

where $n$ is defined by Equation (4), M is the total liquid mass in a computational cell, and $\mathrm{Se}$ is the entrainment rate. The use of the substantial derivative of $\mathrm{nM}$ is required for a correct accounting of the amount of liquid that has been entrained. For example, if a fixed mass of liquid is introduced to a vapor flow field, $V$, and shattered into a spectrum of drops, those small enough to be lifted by the vapor will be carried away, leaving only the larger drops. No further entrainment of drops may occur unless the vapor velocity is increased sufficiently to cause some of the larger drops to be lifted by the vapor or to be shattered into smaller ones. This corresponds to $\stackrel{\mathrm{dn}}{>}>0$. Further entrainment will also occur if new liquid is introduced to the vapor flow $(\stackrel{d M}{>0})$. If the new liquid comes from a region in which it has already been shattered by a vapor velocity, $v^{\prime}$, further entrainment of this liquid will occur only if $V^{\prime}<V$. On the other hand, if the entrained drops enter into a lower velocity region, $V$ ', some of them will "fall out" or become deentrained.

Once the drops are entrained, an average drop diameter must be used to compute the total interfacial drag exerted on the drop population by the vapor phase. Since the ratio between the buoyant force $\left(\infty D^{3}\right)$ and the drag force $\left(\infty D^{2}\right)$ is the most important to maintain, the Sauter mean diameter given by

$$
D_{S E}=\int_{0}^{D_{\max }} D^{3} P(D) d D / \int_{0}^{D_{\max }} D^{2} P(D) d D
$$

is used. Equation 6 gives an average drop diameter that has the same volume to surface area ratio as the entire droplet population. This same diameter is used to compute the interfacial area for heat transfer. Droplets remaining in the continuous liquid phase are assumed to have an average diameter given by 


$$
D_{S C}=\int_{D_{\max }}^{\infty} D^{3} P(D) d D / \int_{D_{\max }}^{\infty} D^{2} P(D) d D
$$

While the size of the drops may change as a result of interfacial mass exchange, the number of drops entrained is maintained and accounted for using a drop number density equation

$$
\frac{\partial N_{d}}{\partial t}=-\frac{\partial}{\partial Z}\left(N_{d} V_{d}\right)+S_{d}
$$

where

$N_{d}$ is the drop number density, drops $/ l^{3}$

$V_{d}$ is the drop velocity computed from the drop momentum equation

$S_{d}$ is the drop source term

Coalesecence and split-up of drops is neglected. The drop source term is given by

$$
S_{d}=\frac{6 S_{e}}{\pi D_{s e}^{3} \rho_{\ell}}
$$

The model for the hot wall flow regime combined with the use of individual momentum equations for each of the three fields (drop, vapor and continuous liquid) allows the direct calculation of carryover in low reflood rate bottom flooding situations, rather than accounting for liquid carryover using numerical diffusion of the liquid phase. In fact, this model completely eliminates the diffusion of the continuous liquid phase in the direction of vapor flow.

In top reflood, the same models described previously are used to determine the fraction of liquid that will be carried over and the fraction that will fall against the vapor velocity. The model for possible top flooding mechanisms is illustrated in Figure 2. The normal flow regime selection logic will select a film model for the cold wall in Figure $2(A)$. 


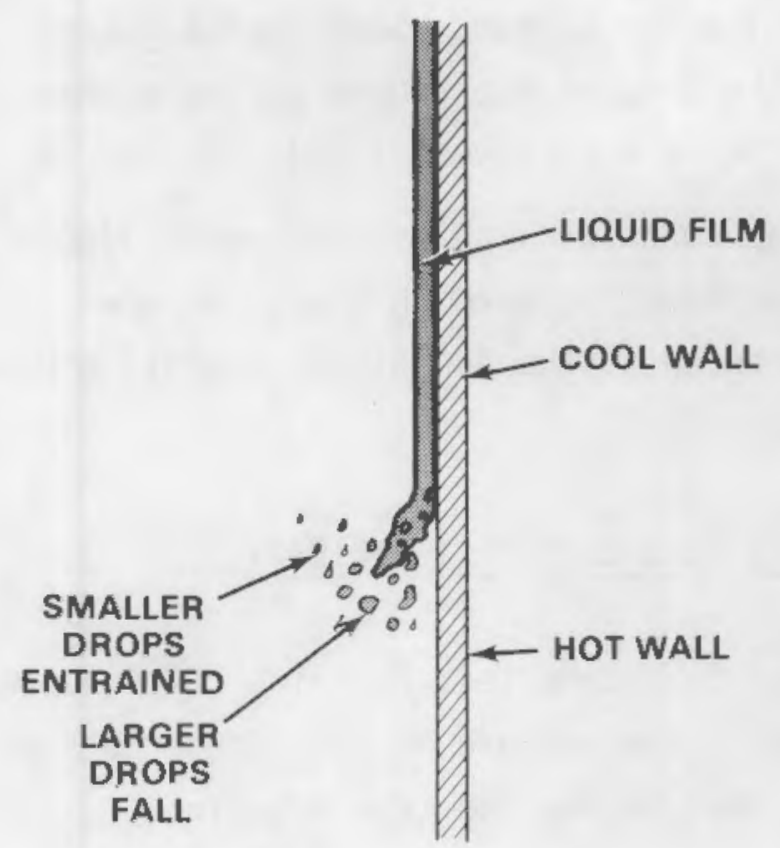

FALLING FILM

(A)

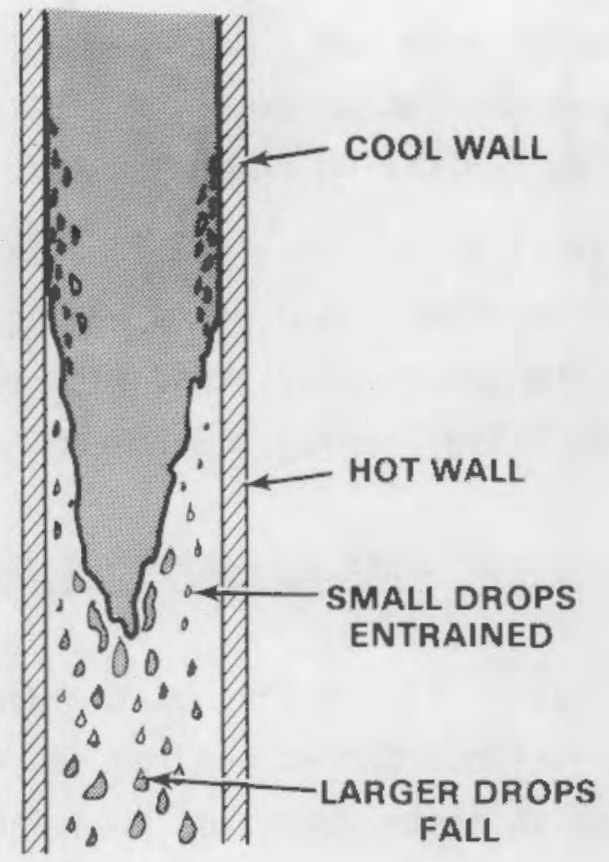

LIQUID DELUGE

(B)

\section{FIGURE 2. Top Flooding Models}

Since the void fraction is generally well above 0.8 for film flow, the hot wall logic will assume a droplet regime below the quench front. The drops that fall provide precooling for the hot surface.

If the rods are deluged from above by a liquid pool, then Figure 2(B) may be more representative of the top flooding process. This regime is also treated with the same logic in the code. In this case, the entrained drops may be carried back up into the liquid region where they may be deentrained or carried by the vapor flow around the liquid plug. The larger drops will fall, providing precooling to the hot surface as does the liquid core. All of these mechanisms are treated by the hot wall regime logic. Further investigation may indicate the need to modify the correlations used in each case. For example, the droplet size distribution for the falling film may be more a function of the processes at the sputtering front than of the vapor velocity near it. If this is the case perhaps Equation (1) may be formulated using the vapor 
generation rate and a different critical Weber number. Some investigators have recommended using a constant for the drop size produced at the quench front by sputtering (Andersen 1973, Duffey and Porthouse 1972).

It is anticipated that a similar approach will be used to model liquid carryover from liquid pools having vapor bubbling through them. We are reviewing other models that were recommended at the NRC Steam Generating Workshop at Silver Springs, Maryland, in July 1979.

\section{REFLOOD ANALYSIS OF JAERI SLAB CORE TEST FACILITY}

Pretest simulations of the Japanese Slab Core Test Facility (SCTF) were begun last quarter at the request of NRC. The purpose of the simulations is to help in instrumentation positioning and ranging and test planning.

The SCTF is an eight-bundle slab vessel one bundle wide with a blockage introduced in the third and fourth bundle from the center. The blockages are co-planar near the center of the axial length covering about $60 \%$ of the available flow area. In addition to the eight-bundle core, the vessel contains a downcomer, lower plenum, core-bypass, and upper plenum with associated internals. The vessel connects via a hot leg and intact cold leg to a streamwater separator, which in turn connects to a containment tank at controlled pressure. A broken cold leg is also included which connects directly to a containment tank.

A COBRA/TRAC system component schematic of the SCTF is shown in Figure 3. The vessel and separator are modeled using the COBRA-TF vessel module (component 8 ) while the hot and cold leg pipes are modeled using TRAC 1-D components. The pipes leading away from the separator and the broken cold leg are connected to break components 3 and 5 , which model the containment back pressure. The intact cold leg connection to the separator is not modeled, as no information was available on the resistance in that line. The intact cold leg was modeled as a short pipe connected to a fill (components 6 and 7 ), which allowed the specified injection of ECC water.

The COBRA-TF nodalization of the vessel is shown in Figure 4. Thirty-one channels were used in the simulation providing a total of 181 mesh cells in 


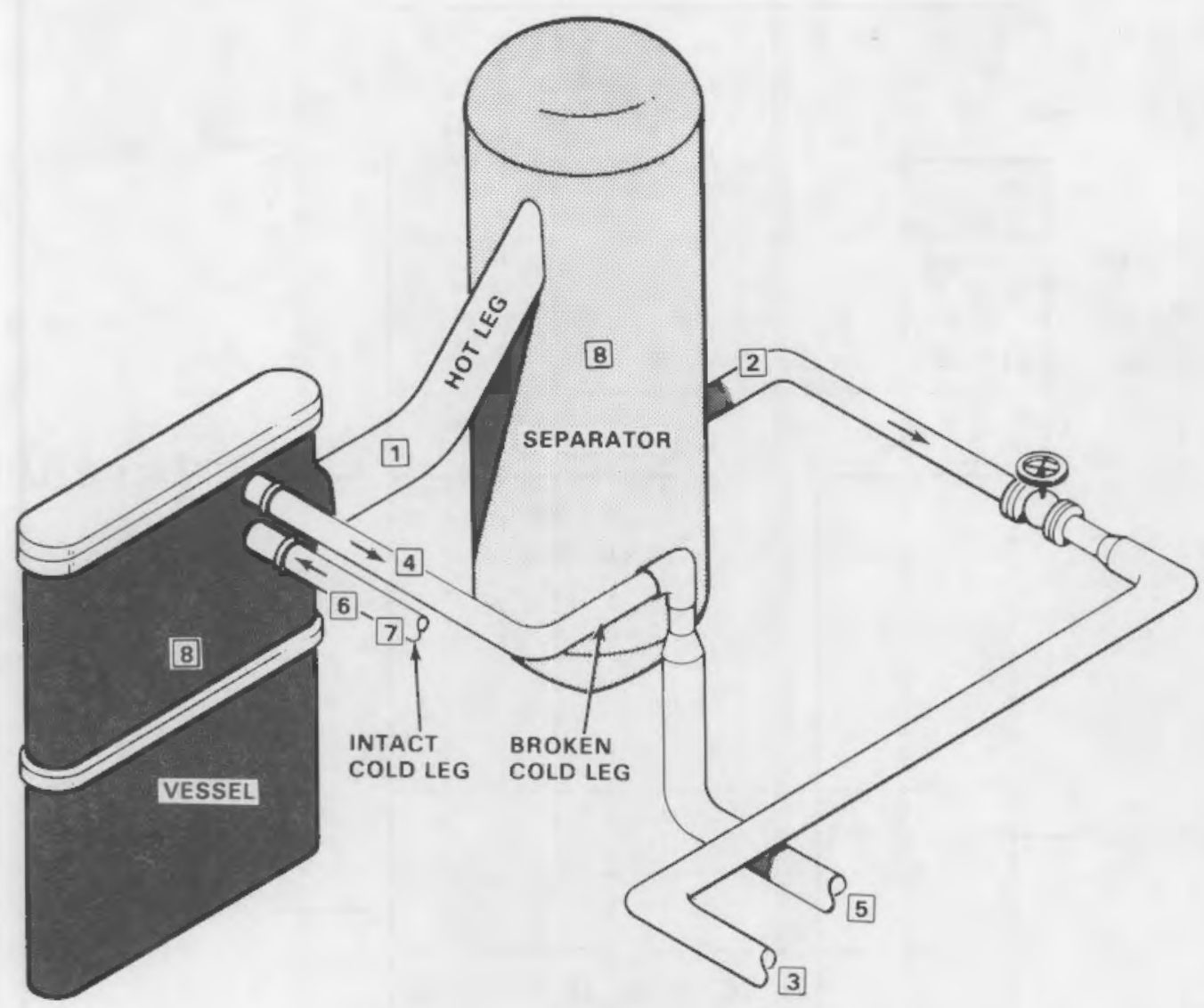

FIGURE 3. SCTF System Component Schematic for the COBRA/TRAC Model

the vessel. A channel was used to model each bundle in the core. Upper plenum injection and injection of extra core steam were ignored in this calculation. All walls and internal structure including the rod bundles were thermally modeled.

The initial conditions for the simulation were representative of beginning of reflood in a LOCA. The rod temperatures were initialized using a temperature profile taken from FLECHT reflood experiment \#00904. The temperature profile for each bundle was corrected for the radial power profile specified for the SCTF. Axial and radial power profiles specified for the facility were used in the simulation and the initial power to each bundle was based on the maximum specified total power of $10 \mathrm{MW}$. The standard ANS $+20 \%$ power decay curve at the beginning of reflood was specified for the transient. The lower plenum was filled with saturated water up to the level of the lower core 


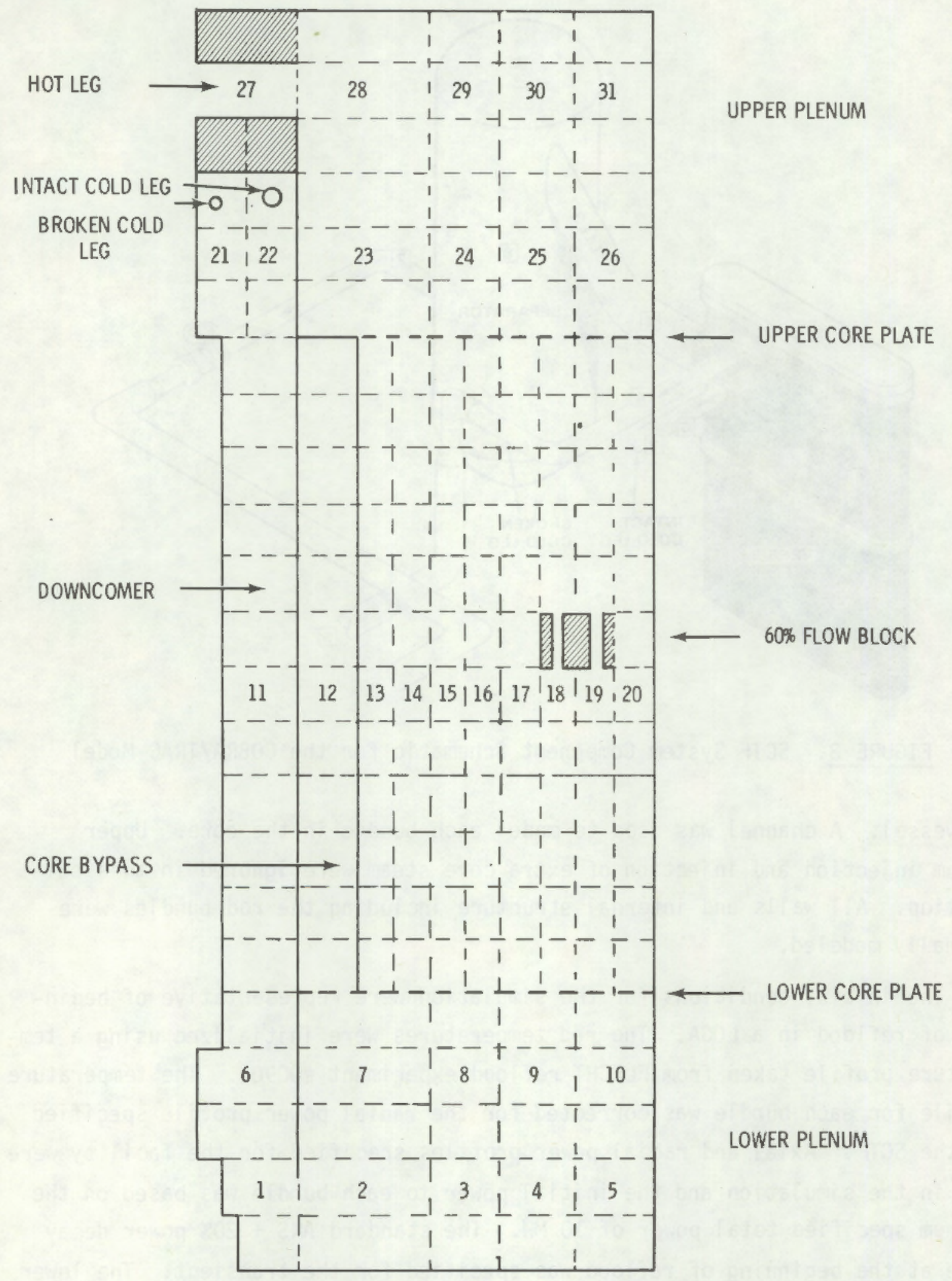

FIGURE 4. Nodalization Diagram for the Two-Dimensional Vessel Component Modeled for COBRA-TF 
plate, with the remainder of the vessel filled with saturated steam. Initial flows in the vessel and piping were zero. The initial vessel pressure was set equal to the specified containment pressure of three bars.

The transient was initiated by injecting ECC water into the downcomer through the intact coid leg. As liquid entered the lower plenum from the downcomer and pushed liquid up into the core, an initial surge of vapor generation caused by liquid coming into contact with the hot rods forced liquid from the core and lower plenum into the downcomer. This initiated a U-tube type downcomer oscillation, which returned the liquid level to the bottom of the core at a higher rate than that provided by ECC injection alone. This resulted in a larger delivery of water into the core and another surge in vapor generation, which again voided the core, filling the downcomer with water and causing ECC water to back-flow through the broken leg.

Water re-entered the core at $10 \mathrm{sec}$ and remained there until about $17 \mathrm{sec}$ when the core was again voided due to vapor generation. Water penetration into the core and its residence time were greater during this oscillation as a result of increased driving head provided by the full downcomer and the lower temperature of the rods at the core inlet -- a result of the two previous oscillations. During this oscillation, the hotter bundles at the center of the core voided slightly ahead of the cooler bundles near the downcomer. As water re-entered the core at approximately $19 \mathrm{sec}$, the hotter center bundles voided at a slightiy higher rate than did the cooler bundles and a rolling wave was established across the bottom of the core. As the hot bundles generated vapor, liquid was forced from these bundles into the lower plenum, which in turn forced water up into the cooler bundles near the downcomer. These bundles voided later in time, reversing the process and forcing liquid from the lower plenum into the hotter bundles on the other side of the core. This oscillatory behavior is apparently due to the radial power profile, which results in the hotter bundles having a higher vapor generation rate than the cooler bundles.

Since the bundles void at different rates, the oscillations are at times in phase and at other times $180^{\circ}$ out of phase. When they are in phase, i.e., the liquid volume fraction in all bundles is decreasing at the same 
time, downcomer flow reversal is observed. A U-tube oscillation is induced between the core and downcomer. When the oscillations are out of phase, the rolling density wave across the bottom of the core described above is observed.

The nature of these oscillations is shown in Figure 5 with a plot of the average liquid fraction below the plane of the blockage in the bundle next to the downcomer as a function of time. At $2 \mathrm{sec}$ and again at $5 \mathrm{sec}$, the initial oscillations are seen as small increases in liquid fraction in the bundle, followed by the period in which a large amount of liquid entered the core. This is followed by the development of regular oscillations that continue throughout the transient and have a fairly regular period of around $2 \mathrm{sec}$.

If a plot of the average liquid fraction for the hotter (center) bundles is overlayed on the outer bundle plot, the phase relationship between the
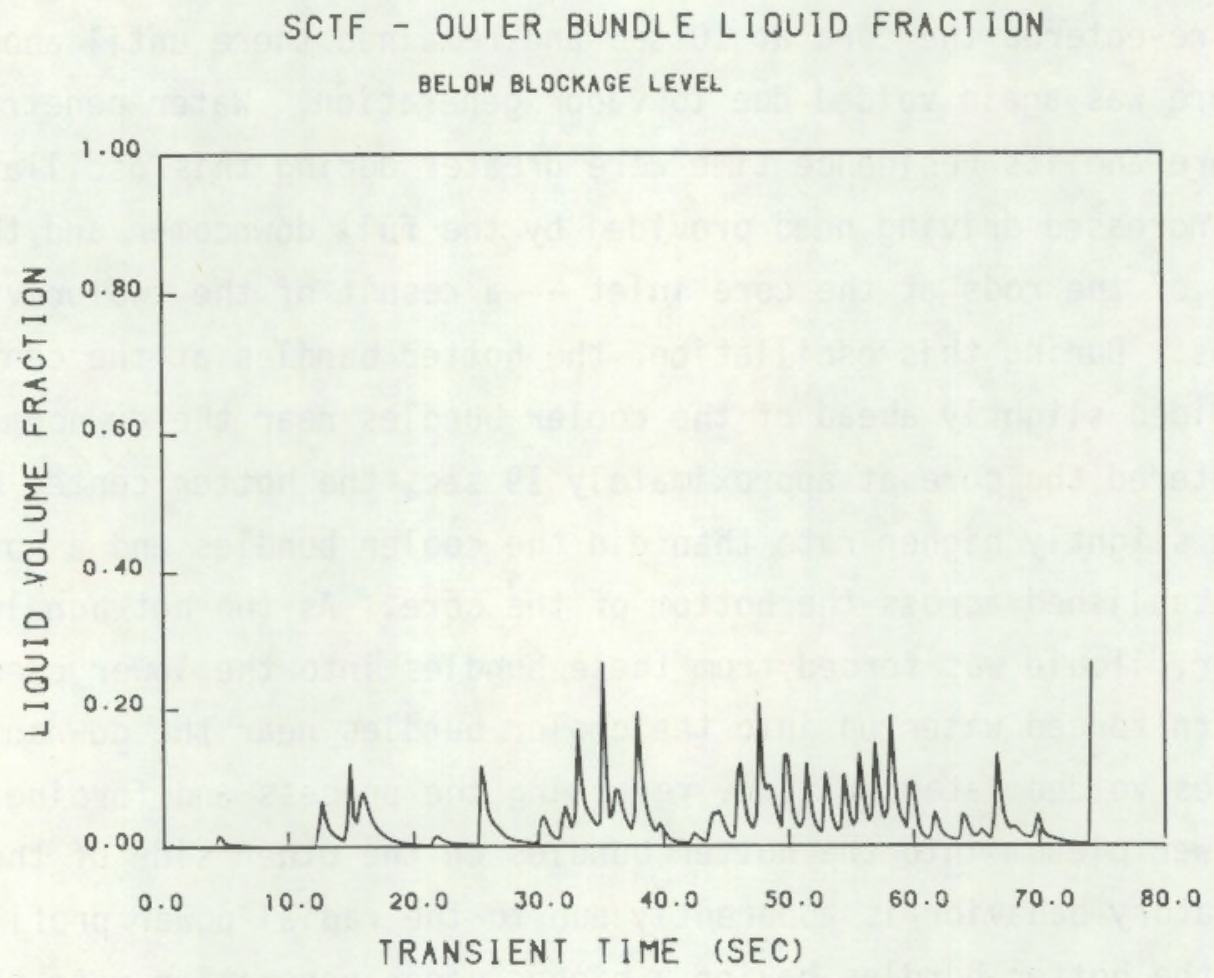

FIGURE 5. Average Liquid Fraction Below the Plane of the Blockage in the Outermost Heated Bundle 
oscillations becomes apparent (Figure 6). The "rolling density wave" established at the bottom of the core $c$ an be seen by plotting the liquid faction across the core at two different instances in time. This is done in Figure 7. At $30 \mathrm{sec}$, the outer bundles nearest the downcomer (bundles 1, 2 and 3) have a high liquid fraction, while those near the center of the core (bundles 6,7 and 8) have low liquid fractions. At $38 \mathrm{sec}$, the picture has reversed with the outer bundles having the lower liquid fraction and the center bundles the higher liquid fraction. The main effect of the flow blockage was to dampen the magnitude of the oscillations in the blocked bundles relative to the surrounding bundles. This is a direct result of the increased flow resistance in the blocked bundles.

The rate at which the core can be reflooded is limited by the flow resistance through the hot leg (steam binding). Of all the ECC water injected, an average of about $15 \mathrm{lbm} / \mathrm{sec}$ flows down the downcomer to the core (Figure 8 ). About $10 \mathrm{lbm} / \mathrm{sec}$ of this is converted into steam (Figure 9 ) and $3 \mathrm{lbm} / \mathrm{sec}$ is carried over in the form of entrained droplets (Figure 10). The remainder goes toward increasing the liquid level in the core. (Note general positive slope of liquid fraction curves in Figures 5 and 6 ).

The net result is a very slow propagation of the quench front. This is shown by plotting the axial rod temperature profile at equal intervals of time (Figure 11). As time advances, the distance the quench front moves diminishes, indicating a slowing of the quench front velocity as it approaches the hotter center portions of the bundle. The quench front velocity will further decrease as the driving head diminishes with increasing liquid level in the core and as higher rod temperatures are encountered at the quench front. As can be seen from Figure 11, the rate at which the peak clad temperature is increasing has also diminished as a result of precooling provided by carryover of liquid in the core.

Since the hot leg flow resistance is such an important parameter, the simulation was terminated at $70 \mathrm{sec}$ in order to review with NRC the operating conditions of the facility to assure that the flow resistance between the 


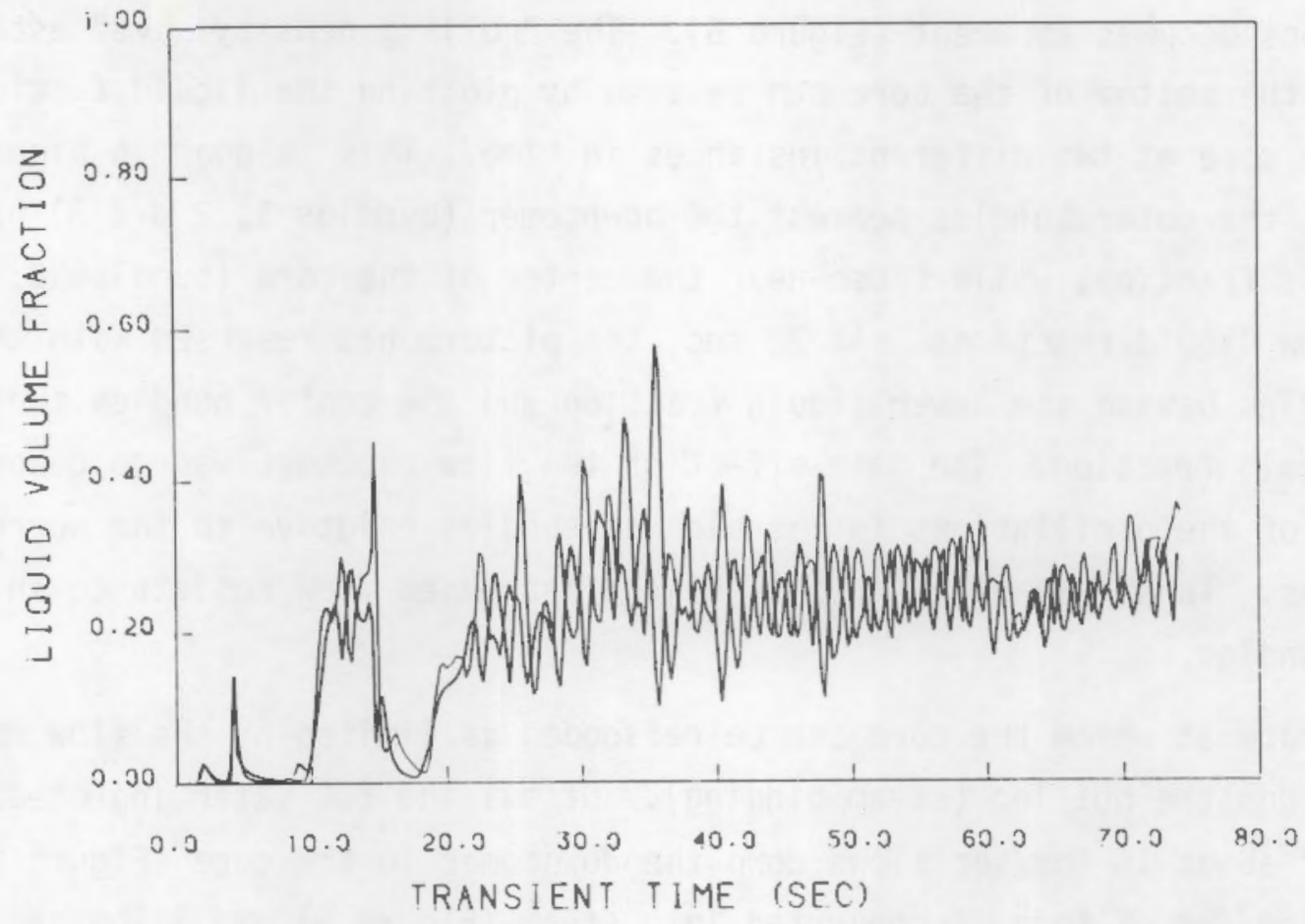

FIGURE 6. Average Liquid Fraction of the Center Bundles Compared with the Average Liquid Fraction of the Outer Bundles

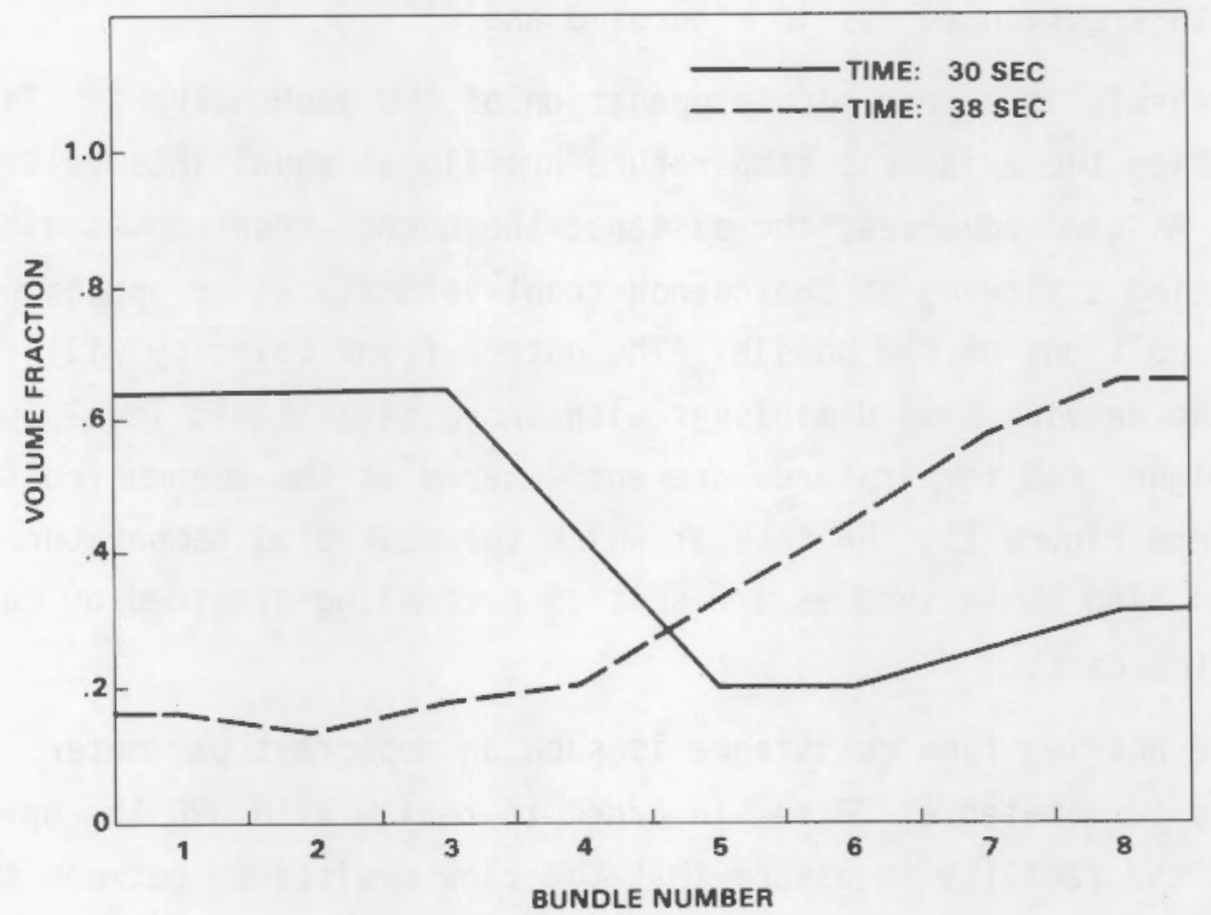

FIGURE 7. Radial Liquid Volume Fraction Distribution at $30 \mathrm{sec}$ and at $38 \mathrm{sec}$ 


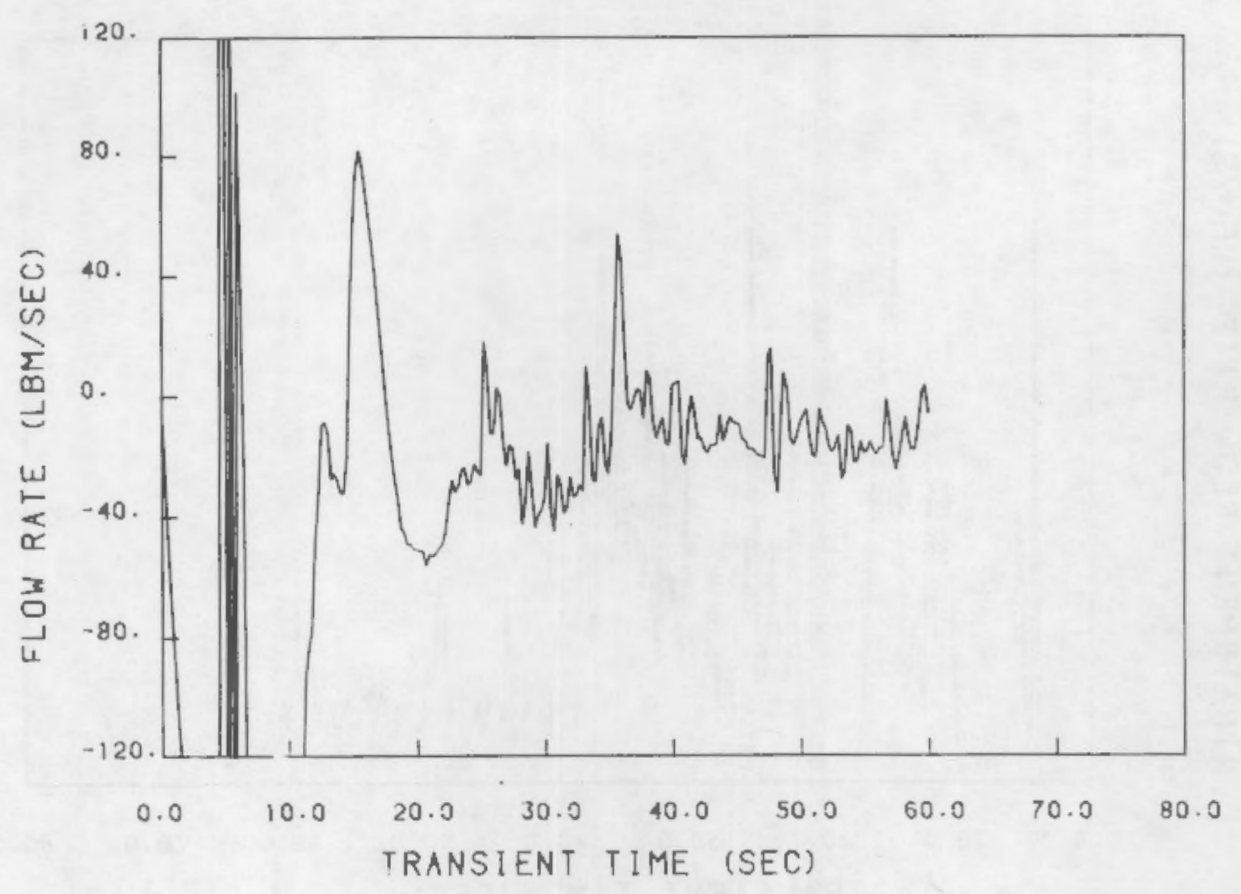

FIGURE 8. Downcomer Liquid Flow Rate as a Function of Time.

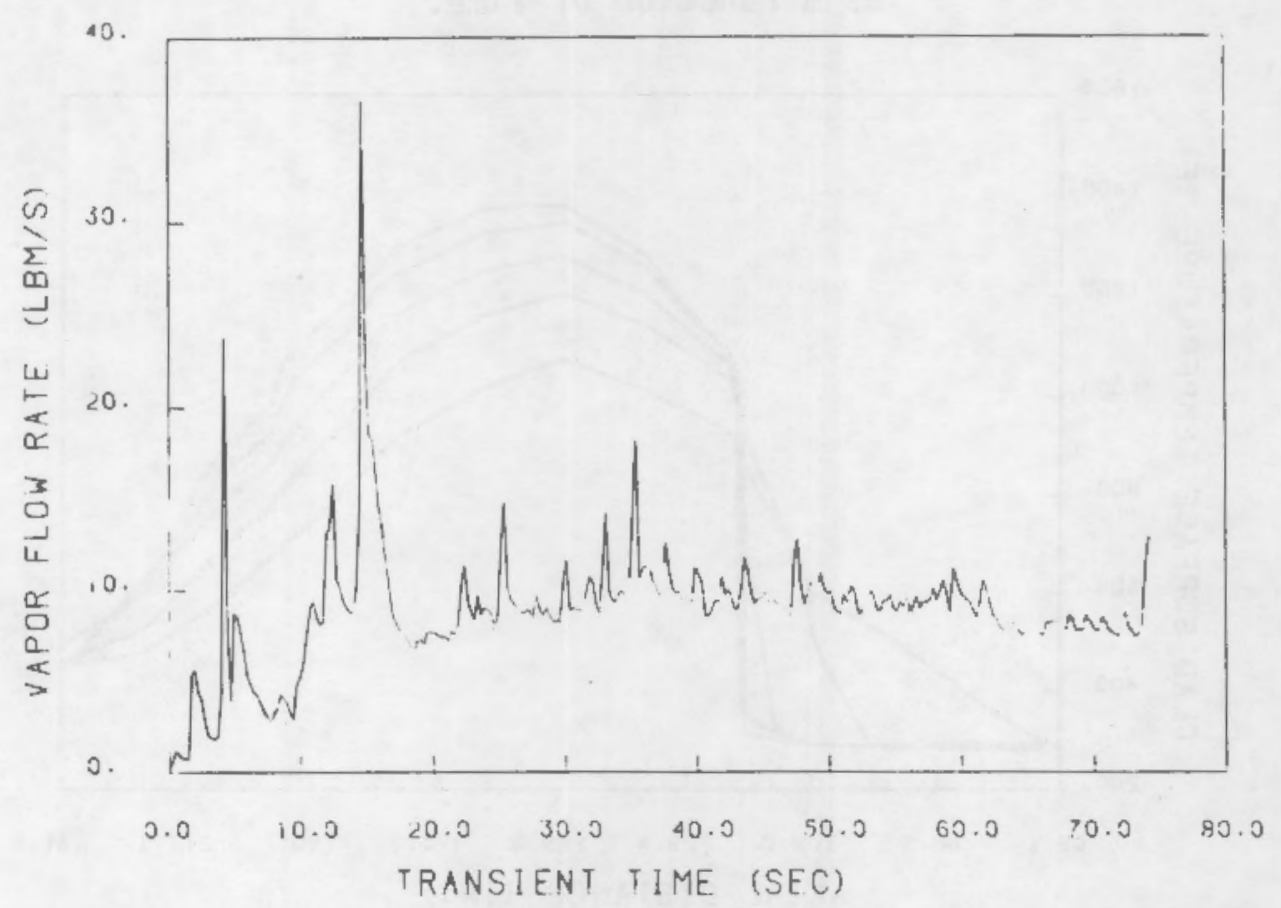

FIGURE 9. Hot Leg Vapor Flow Rate as a Function of Time. 


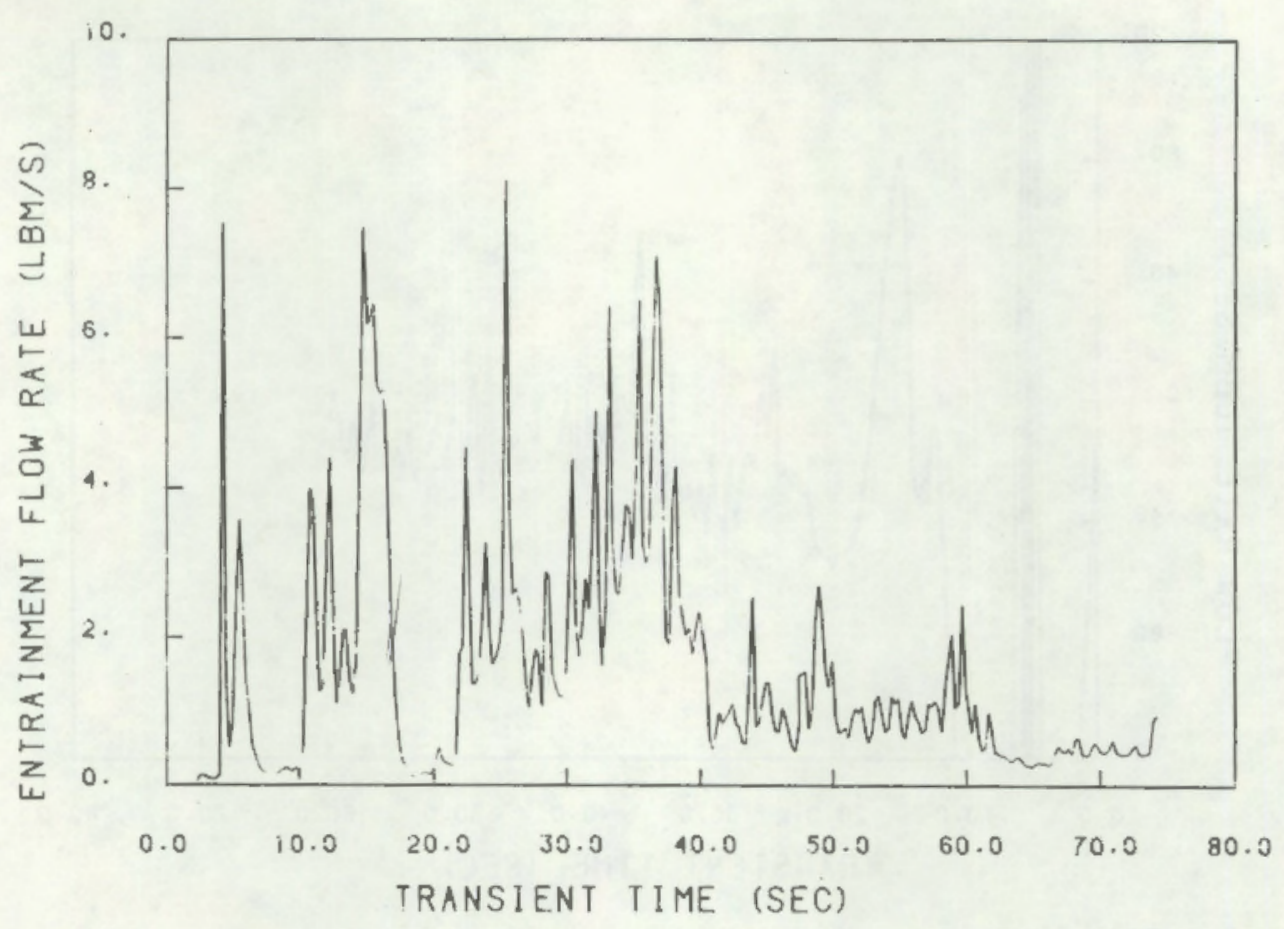

\section{FIGURE 10. Hot Leg Entrained Droplet Flow Rate} as a Function of Time.

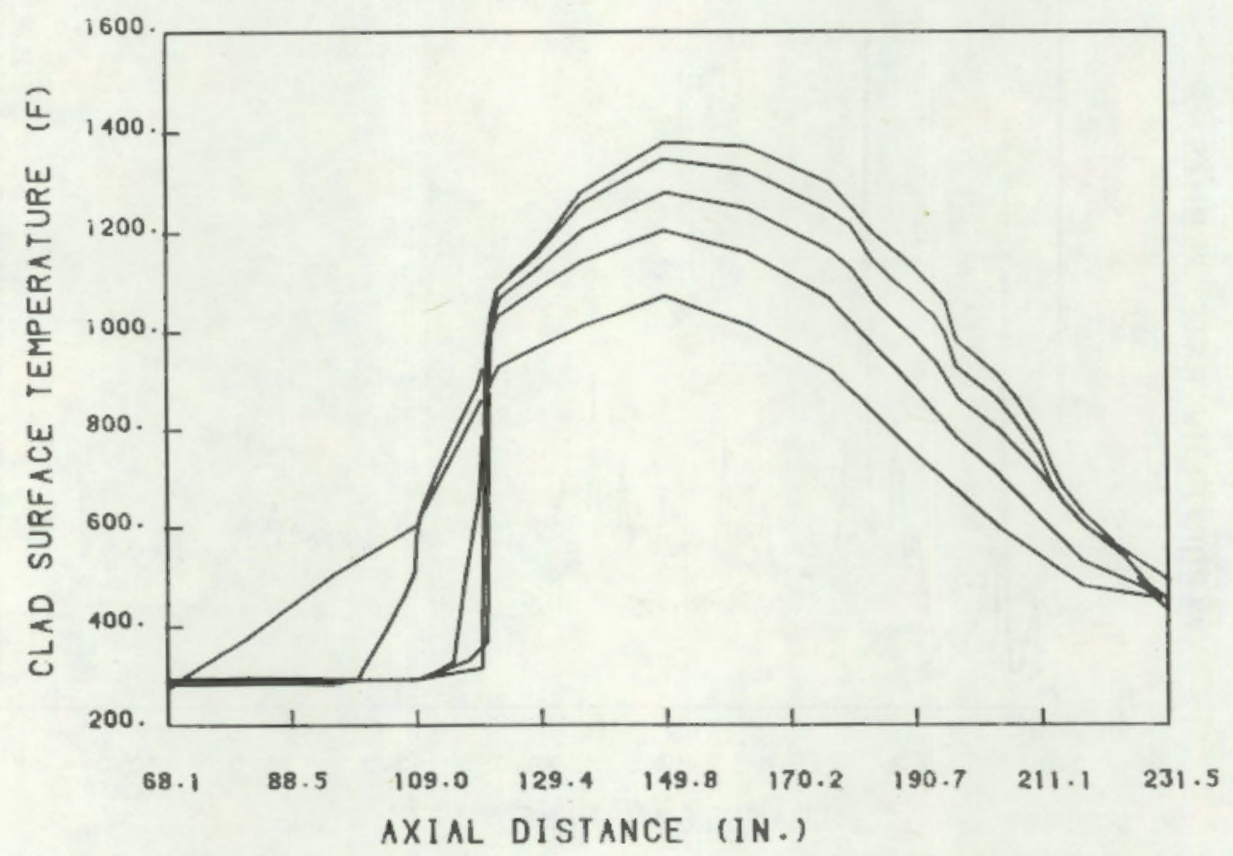

FIGURE 11. Axial Temperature Profile for Rod 11 at Time Zero, $20 \mathrm{sec}, 40 \mathrm{sec}, 60 \mathrm{sec}$, and $74 \mathrm{sec}$. 
broken cold leg and intact hot leg is being modeled correctly. Further simulations will be completed as soon as the correctness of the model of the facility is verified.

During the simulation, some experimenting was done to model deentrainment in the upper plenum. Up until $40 \mathrm{sec}$, essentially no deentrainment was calculated to occur in the upper plenum. At $40 \mathrm{sec}$, a simple deentrainment model for the upper plenum was tried. Th is simple model reduced the entrainment flow out the hot leg by about $60 \%$, as can be seen in Figure 10 . During the next quarter, further work will be done to model upper plenum deentrainment and the possible fallback of liquid onto the top of the core.

\section{FUTURE WORK}

Results of FLECHT and SEMISCALE simulations will be reported next month. Additional simulations of the SCTF will al so be made to further investigate the effects of flow blockages on reflood dynamics. Simulations are also being planned for the Cylindrical Core Test Facility, Dartmouth flooding experiments, RPI phase separation tests, downcomer experiments, and others in an effort to broaden the developmental assessment of the code. 


\section{REFERENCES}

Andersen, J. G. 1973. REMI/HEAT COOL, A Model for Evaluation of Core Heat-Up and Emergency Core Spray Cooling System Performance for Light-Water-Cooled Nuclear Power Reactors. Danish Atomic Energy Commission, RISO No. 296.

Duffey, R. B. and D. T. C. Porthouse. 1972. Experiments on the Cooling of High-Temperature Surfaces by Water Jets and Drops. RD/B/N 2386, Berkeley Nuclear Laboratories, Berkeley, Gloucestershire, U.K.

Lekic, A., R. Bajramovic and J. D. Ford. 1976. "Droplet Size Distribution: An Improved Method for Fitting Experimental Data." C. J. Chem. Eng. Vo1. 51.

Levy, S. 1979. Review of Water Spray Into Steam, WRSR Workshop on Condensation Silver Springs, Maryland.

Mugele, R. A. and H. D. Evans. 1951. "Droplet Size Distribution in Sprays." Ind. Eng. Chem., 43: 1317.

Nuk iyama, S. and Y. Janasawa. 1940. Trans Soc. Mech. Engs. (Japan): No. 14, 86 (1938): No. 15,138 (1939), No. $\overline{18,63,68, ~ № . ~ 22, ~ I I-7, ~ N o . ~ 23, ~}$ II-8 (1940).

Wallis, G. B. 1969. One-Dimensional Two-Phase Flow. McGraw-Hill, New York, New York. 


\title{
INTEGRATION OF NONDESTRUCTIVE EXAMINATION RELIABILITY AND \\ FRACTURE MECHANICS (a)
}

\author{
G. J. Posakony, Program Manager \\ F. L. Becker, Project Manager \\ S. H. Bush Project Manager \\ G. B. Dudder \\ G. P. Selby \\ F. A. Simonen
}

\section{SUMMARY}

Major accomplishments during the past quarter have included:

- A critical fracture mechanics review of the required nondestructive examination (NDE) sensitivity has been completed.

- Thermal fatigue cracking has been completed on one 10-in. diameter pipe and two cast stain Tess pipe segments.

- The Phase I measurements of crack tightness and orientation have been completed.

\section{INTRODUCTION}

The progress and accomplishments of the past quarter are described below by task.

\section{TASK 4: FRACTURE MECHANICS}

Critical flaw size estimates have been performed to establish required sensitivity ranges for NDE. These calculations will be documented in a forthcoming topical report. Only results and conclusions of the calculations are reported below.

(a) RSR Fin. Budget No. B2289-0; RSR Contact: J. Muscara 
By directive from NRC, the critical flaw size estimates in the present research program have been based largely on results of calculations performed at Battelle-Columbus Laboratories ( $B C L$ ). A draft report from the $B C L$ study became available late in the past quarter and evaluation of the results is continuing.

In addition to the $\mathrm{BCL}$ results, a series of independent calculations have been conducted at Pacific Northwest Laboratory (PNL) to supplement the results of the BCL cold-leg integrity evaluations. The calculations have been limited in scope, but provide an independent check on the BCL work. Furthermore, these calculations provide a basis for evaluating the conservatism present in the $\mathrm{BCL}$ study, which was based on deterministic considerations and was intended to establish margins of safety against a large break in the cold-leg piping system of a pressurized water reactor power plant. In contrast, the present research program is to provide results for eventual probabilistic evaluations and is directed to inspection rather than design requirements.

The PNL calculations consisted of the following efforts:

1. Critical flaw sizes were estimated based on ASME code-allowable stresses, and the methodology of ASME Section XI.

2. Critical flaw sizes were estimated based on fatigue crack growth rates by extension of results generated by Combustion Engineering (Combustion Engineering 1977). The sensitivity of predictions to variation in crack growth rates curves (da/dn versus $\Delta K$ ) for reactor piping materials was emphasized.

3. Critical flaw sizes were estimated based on the dual criteria approach (Chel1 1979); linear elastic fracture mechanics and net section plastic collapse provided bounds on critical flaw sizes.

4. Critical flaw sizes were estimated based on the recent work of Paris and associates using the concept of tearing instability (Paris et al. 1979b; Tada et al. 1979; and Par is et al. 1979a). 
5. Piping flexibility calculations were performed to establish bounds on axial loads and moments for upset conditions.

To date, inside diameter (ID) surface defects in relatively large pipes have been considered; ID defects will initiate and grow at faster rates due to environmental effects. In general, smaller pipe sizes will present less demanding inspection requirements. As a rule, critical defect sizes in a small pipe will represent a greater fraction of the pipe wall than the corresponding defect for a large pipe. Hence, flaws of interest in smaller diameter piping should be more easily detected.

\section{CONCLUSIONS OF FLAW SIZE ESTIMATES}

The available analyses of the growth and stability of flaws in large reactor piping have led to the following results and conclusions:

\section{Failure Mode}

1. Evaluations of the consequences of ID surface flaws in piping indicate that flaws will produce a leak before they will cause a pipe break. Therefore, the definition of critical flaw sizes on the basis of unstable crack growth and fracture toughness considerations is of limited usefulness for application to reactor piping systems.

2. The failure mode of concern is an increase in crack growth rate such that an ID surface flaw breaks through the pipe wall within a time span of the inspection interval.

3. In accordance with the leak-before-break condition, critical defect sizes for unstable crack growth have been found to be through wall flaws of significant length. For axial flaws, the length is on the order of half a pipe diameter and, for circumferential flaws, the length is on the order of half the circumference of the pipe.

Variation in Critical Flaw Sizes

1. Evaluations of crack growth rates show significant differences in allowable defect sizes both from pipe to pipe and from location to location with in a given pipe. 
2. Even under the conservative assumptions of the BCL calculations (e.g. levels of vibrational stress, fatigue crack growth rates and threshold $\Delta K$ values), many welds can tolerate quarter-wall defects and achieve a 40-yr design life.

3. Conservative analysis methods indicate a finite probability of failure at certain locations (particularly at dissimilar metal welds) within $1 \%$ or less of design life for flaws of depth as small as one tenth of the pipe wall.

4. Nevertheless, the overall trend of the results suggests a relatively low probability of failure within a 10-yr inspection interval (say less than 1\%) for flaws of depths less than $25 \%$ of the pipe wall.

\section{ASME Code Evaluations}

1. Application of linear elastic fracture mechanics following the procedures of Section XI of the ASME code leads to critical flaw depths on the order of one-fourth of the pipe wall thickness. These flaw size predictions agree qualitatively with the conclusions of fatigue crack growth calculations. This agreenent, however, comes from a prescribed reduction of fracture toughness rather than consideration of the actual mechanisms leading to pipe failure.

Tearing Instability Analysis

1. Elastic plastic fracture mechanics have been applied to predict conditions for unstable crack growth through the concept of tearing instability. The The main concern in the present study has been circumferential flaws that may grow in a relatively uniform manner through the wall of the pipe without breaking through and causing a detectable leak.

2. The tearing instability analyses indicate that unstable crack growth under displacement-controlled bending loads requires pipe lengths much longer than relevant to reactor piping systems.

3. Under pure axial loadings, unstable flaw growth could occur for flaw depths of about $80 \%$ of the pipe wall provided that the pipe length is 
about $20 \mathrm{ft}$ or longer. Further work is needed to establish whether there are credible sources of axial loads of the required magnitude to sustain such unstable fractures.

\section{TASK 6: SAMPLE FABRICATION}

Thermal fatigue is a unique method of controlled crack production, which provides a method for simulating field-service flaws in pressure vessel and piping components. The technique allows flaws to be produced in locations that would not be possible using other techniques. This ability arises from the localized stressing of the component due to temperature gradients rather than bulk loading of the entire part. The fatigue nature of the technique provides a method of reliably predicting crack depths and resultant crack geometries. Therefore, the thermal fatigue technique can produce specimens containing cracks that have controlled depths and geometries in specified locations, making it a very useful technique for NDE studies.

The application of the thermal fatigue technique for producing simulated field service cracks in piping systems has continued this quarter. The parameter development for the 10-in.-diameter, Schedule 80 stainless steel pipe has been completed and the parameters selected. Cracks of 10\%, 25\% and 50\% through wall are desired, corresponding to crack depths of $0.050 \mathrm{in.}(1.27 \mathrm{~mm}), 0.125$ in. $(3.18 \mathrm{~mm})$ and $0.250 \mathrm{in} .(6.35 \mathrm{~mm})$. The relationship between the crack depth and total number of thermal cycles is illustrated in Figure 1 for the parameter development specimens. The number of cycles required to produce the specified crack depths are also indicated. Production of cracks of $10 \%, 20 \%$ and $50 \%$ through wa 11 require 2400,5500 and 16,000 thermal cycles, respectively. The thermal cycle consists of a $5-\mathrm{sec}$. quench, followed by a $25-\mathrm{sec}$. recovery period, which results in a frequency of 2 cycles/min. The time required to produce a $50 \%$ through-wall ( $0.250 \mathrm{in}$.) crack is approximately 5.5 days.

The resultant crack geometries as a function of crack depth are illustrated in Figure 2. The aspect ratios (crack length/crack depth) corresponding to the $10 \%, 25 \%$ and $50 \%$ crack depths are $7.5,4.5$ and 3.5 , respectively. The 


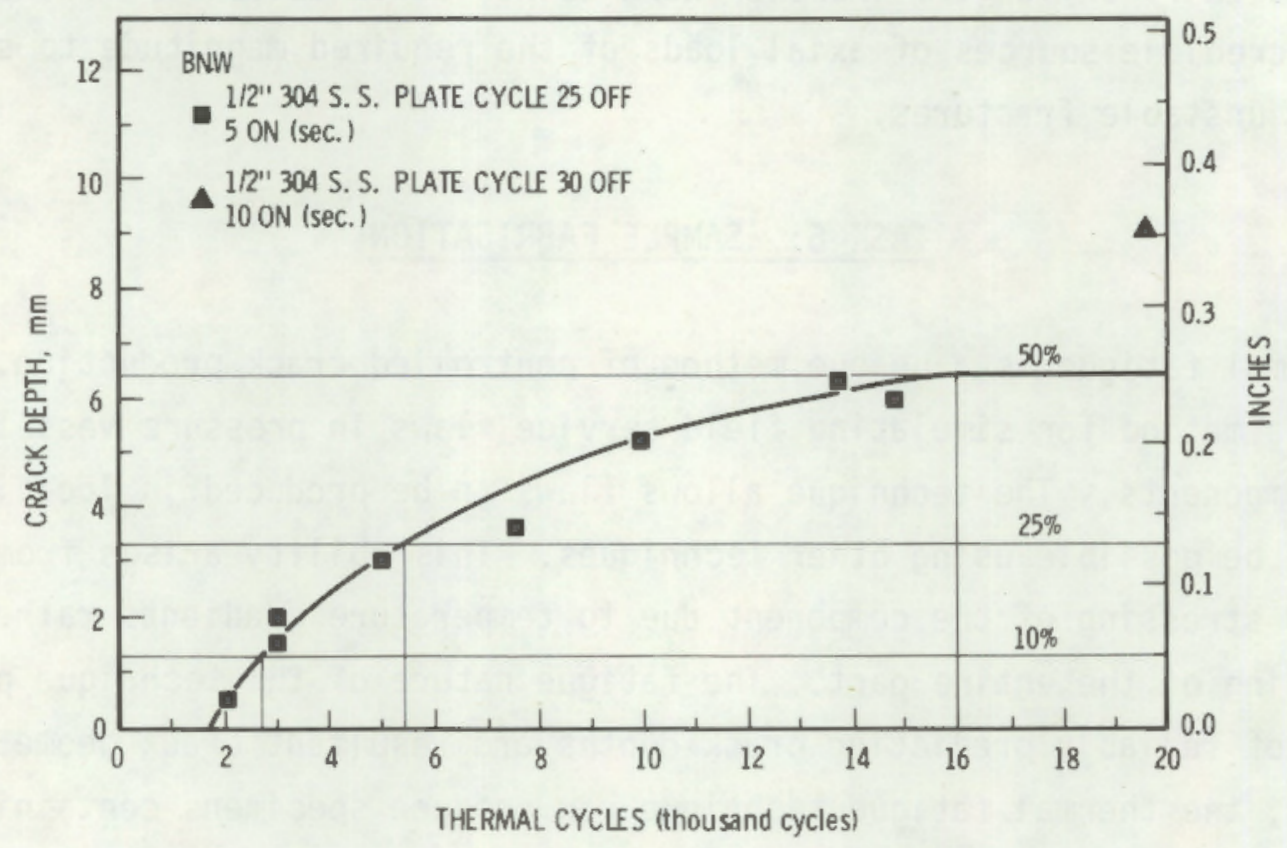

FIGURE 1. Crack Depth Versus Thermal Cycles

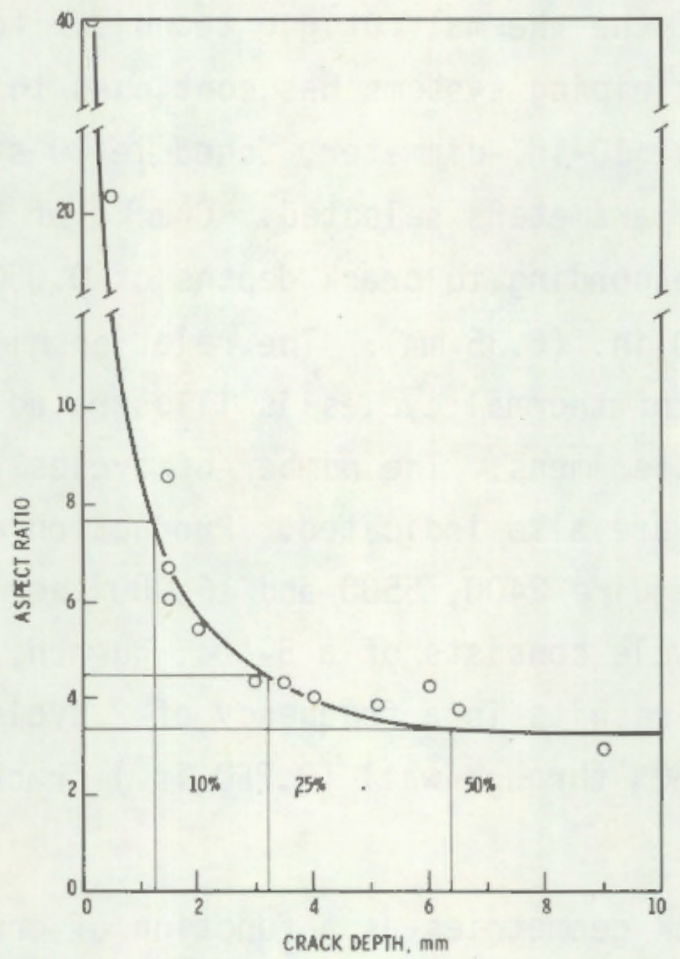

FIGURE 2. Aspect Ratio Versus Crack Depth 
aspect ratio is a function of, among other things, the initiator length, nozzle diameter and the thermal cycle. The maximum crack length is limited by the diameter of the confining nozzle as predicted by theoretical considerations and confirmed by observation. In addition, the minimum aspect ratio has been experimentally determined to be between 2.5 and 3.0 , as illustrated in Figure 2. The thermal cycle has been shown to limit the maximum obtainable crack depth: the more severe the thermal cycle, the deeper the crack. An effort to decrease the aspect ratios of the smallest crack would consist of reducing the nozzle diameter and initiator length and increasing the severity of the therma? cycle. The simplest of these would be to reduce the initiator length.

A series of thermal fatigue specimens were produced this quarter to facilitate a comparison of cracks produced by mechanical bending fatigue and therma? fatigue. Two sets of specimens were produced by thermal fatigue. The first set consisted of 304 stainless steel specimens that had been cold rolled from $1.0 \mathrm{in.}(25.4 \mathrm{~mm})$ to $0.75 \mathrm{in} .(19.1 \mathrm{~mm})$, then thermally fatigued using a cycle of $10 / 40 \mathrm{sec}$. (on/off). The second set of specimens consisted of 304 stainless steel specimens that had been cold rolled to $0.65 \mathrm{in} .(16.5 \mathrm{~mm})$, annealed at $1950^{\circ} \mathrm{F}\left(1065^{\circ} \mathrm{C}\right)$ for $30 \mathrm{~min}$., followed by air quench and then thermally fatigued using a cycle of $10 / 35 \mathrm{sec}$ (on/off). The crack propagation data for both sets of specimens are shown in Figure 3. The crack depths were obtained by electrical resistance gauge (ERG) measurements. The larger crack growth rate demonstrated by the cold-worked specimens can be attributed to the residual stresses from cold rolling and the more severe thermal cycle.

The resultant cracks produced under the two sets of conditions were compared using destructive examination. The cracks in the cold-rolled material were nonplanar, apparently heavily influenced by the residual stress in the material. The cracks in the annealed material were typical of previously encountered thermal fatigue cracks in annealed 304 stainless steel, which are much nearer to being planar cracks.

An important criterion for comparison of the mechanical bending and thermal fatigue cracks is surface roughness. A profilometer with a $0.001-i n$. $(0.0254-\mathrm{mm})$ stylus was used to scan the surface at $0.01 \mathrm{~cm} / \mathrm{min}$. The mechanical bending and thermal fatigue surface roughnesses are compared in Table 1. 


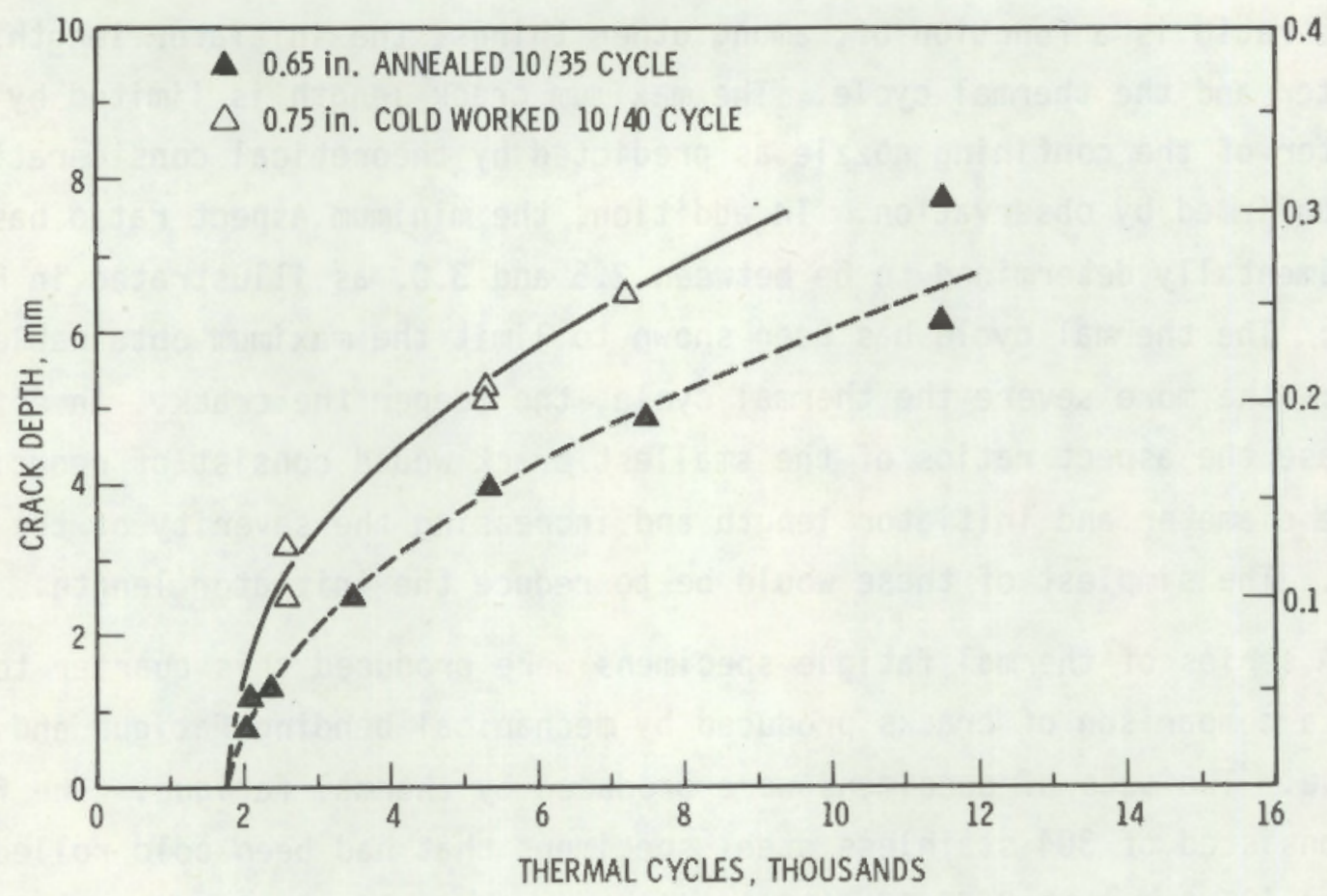

FIGURE 3. Crack Propagation of Comparison Specimens

TABLE 1. Surface Roughness Comparison of the Mechanical Bending and Thermal Fatigue Cracks

\begin{tabular}{|c|c|c|c|}
\hline Specimen & Classification & $\begin{array}{l}\text { Average } \\
(\bar{x}), \mu \mathrm{m}\end{array}$ & $\begin{array}{l}\text { Standard Deviation } \\
(S), \mu \mathrm{m} \\
\end{array}$ \\
\hline $140 \mathrm{~A}$ & Rough Mechanical & 7.9 & 1.4 \\
\hline $141 \mathrm{~A}$ & Rough Mechanical & 9.2 & 3.0 \\
\hline $160 A$ & Smooth Mechanical & 6.7 & 1.8 \\
\hline $161 \mathrm{~A}$ & Smooth Mechanical & 5.0 & 1.2 \\
\hline $101 B$ & Thermal Fatigue & 9.3 & 2.0 \\
\hline $114 \mathrm{~B}$ & Thermal Fatigue & 8.1 & 2.0 \\
\hline
\end{tabular}

The roughness measurements indicate that the rough mechanical bending fatigue cracks have approximately the same roughness as the thermal fatigue cracks. This may be somewhat misleading due to generally larger amplitude contours that were superimposed on the measurements recorded for the thermal 
fatigue cracks. This is to say that although the localized roughness may be the same, it is not superimposed on a flat surface as is the case for the mechanical bend cracks.

Preparation for thermally fatiguing 10-in.-diameter stainless steel pipes has been completed this quarter. A spider assembly which supports three nozzles has been designed and is illustrated in Figure 4. The assembly is located on the interior of the pipe near the centerline of the circumferential weld. The confining nozzles are butted to the pipe by a high-temperature spring to provide a good seal with the pipe and secure the spider assembly. Water is supplied to the system through the center block and then projected through the spray nozzle. The angle between the nozzles can be changed by simply manufacturing a new center block. The first spider assembly has been constructed and successfully tested and crack production begun.

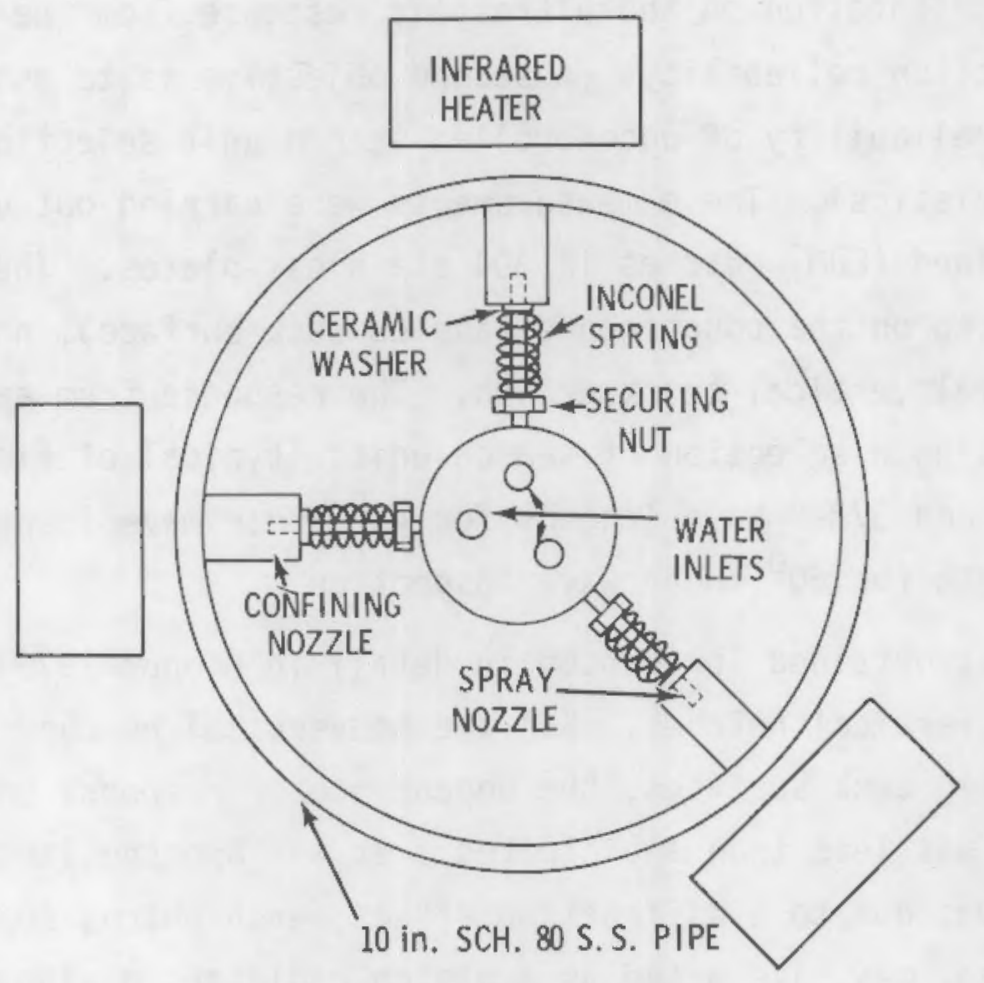

FIGURE 4. Thermal Fatigue Fixture for 10-in. Pipe 
Thermal fatigue cracking of segments of larger diameter pipe has been initiated this quarter. Two stations have been designed for this purpose. Due to the heavy thickness of these materials and the knowledge that the crack depth is limited by the nozzle diameter, 1.5-in. diameter nozzles have been utilized. To date, two cast stainless steel pipe segments have been subjected to 10,000 and 21,000 thermal cycles. Crack measurement by NDE and destructive analyses are yet to be made.

\section{TASK 7: MEASUREMENT AND EVALUATION}

Two major measurement efforts are in progress. These include measurement and evaluation of flaw characteristics and the flaw geometry samples.

\section{FLAW GEOMETRY MEASUREMENTS}

The objective of flaw geometry measurements is to define the influence of flaw size and orientation on the ultrasonic response from the flaw and its impact on detection reliability. A second objective is to assess the impact on inspection reliability of uncontrolled search unit selection (size and operating characteristics). These measurements were carried out using electron discharge machined (EDM) notches in 304 stainless plates. The notches simulated flaws located on the counterbore (angled back surface), nonvertical crack growth and normal vertical crack growth. The response from each of the notches was measured using a selection of search units (typical of field units) at $1 / 2-V$, full-V, and $3 / 2-V$ path lengths for $45^{\circ}$ shear wave inspection and at $1 / 2-V$ path length for $60^{\circ}$ shear wave inspection.

The results obtained (presented in detail in Hooper 1979) were as expected for the normal vertical notches. For the nonvertical notches and vertical notches in angled back surfaces, the dependence of response on flaw (or back surface) angle was less than anticipated. It was hypothesized that this lack of dependence was due to a diffraction effect; each notch, approximately two wavelengths deep, may have acted as a piston radiator, giving the reflected beam more angular spread than a pure reflection would have had. The high angular spread of the reflected wave could result in a received signal of 
greater amplitude than purely geometric considerations would indicate. In order to test this idea, new samples were fabricated and inspected.

Samples

The original notches, producing less than the expected dependence of signal amplitude on flaw orientation, were all 100 mils deep (through wall). The new samples include 200-mil and 300-mil notches of the same orientation and aspect ratio as the 100-mil notches. To save time, these were saw cuts instead of EDM notches. The blade thickness was 20 mils. The difference in fabrication method should not affect reflection amplitude.

The angled notches have these angles from normal: $0^{\circ}, 2.5^{\circ}, 5^{0}, 7.5^{\circ}$, $10^{\circ}, 15^{\circ}, 20^{\circ}, 25^{\circ}$, and $30^{\circ}$. The angled back surfaces are nonparallel by these angles: $5^{\circ}, 10^{\circ}, 15^{\circ}$ and $20^{\circ}$.

As for the 100-mil notches, these samples are 0.600-in.-thick, 304 stainless-steel bars $4 \mathrm{in}$. wide and about $1 \mathrm{ft}$ long, with a similar grade of finish.

As before, the calibration standard is a 0.600-in.-thick, 304 stainless bar with a $10 \%$ (60 mil) end-mill notch 1 in. long, in accordance with ASME Boiler arid Pressure Vessel Code, Section XI, Appendix III.

\section{Measurements}

Since the search units used on the 100-mil notches all exhibited about the same dependence of received signal amplitude on flaw orientation, the measurements were repeated with only one transducer - the 0.5-in.-diameter, 2.25-MHz Aerotech Gamma. Measurements were made at $1 / 2-V$, full $-V$ and $3 / 2-V$ path length with beam angle of $45^{\circ}$ and $1 / 2-V$ path with beam angle of $60^{\circ}$. The ultrasonic instrument was again the Sonic Mark I.

Peak amplitudes are measured in decibels relative to a distance amplitude correction (DAC) established from the calibration sample. This permits comparison with results obtained from the 100-mil notches.

The results of the measurements are presented here in graphic format, with one graph for each combination of beam path and flaw type (see Figures 5-10). 


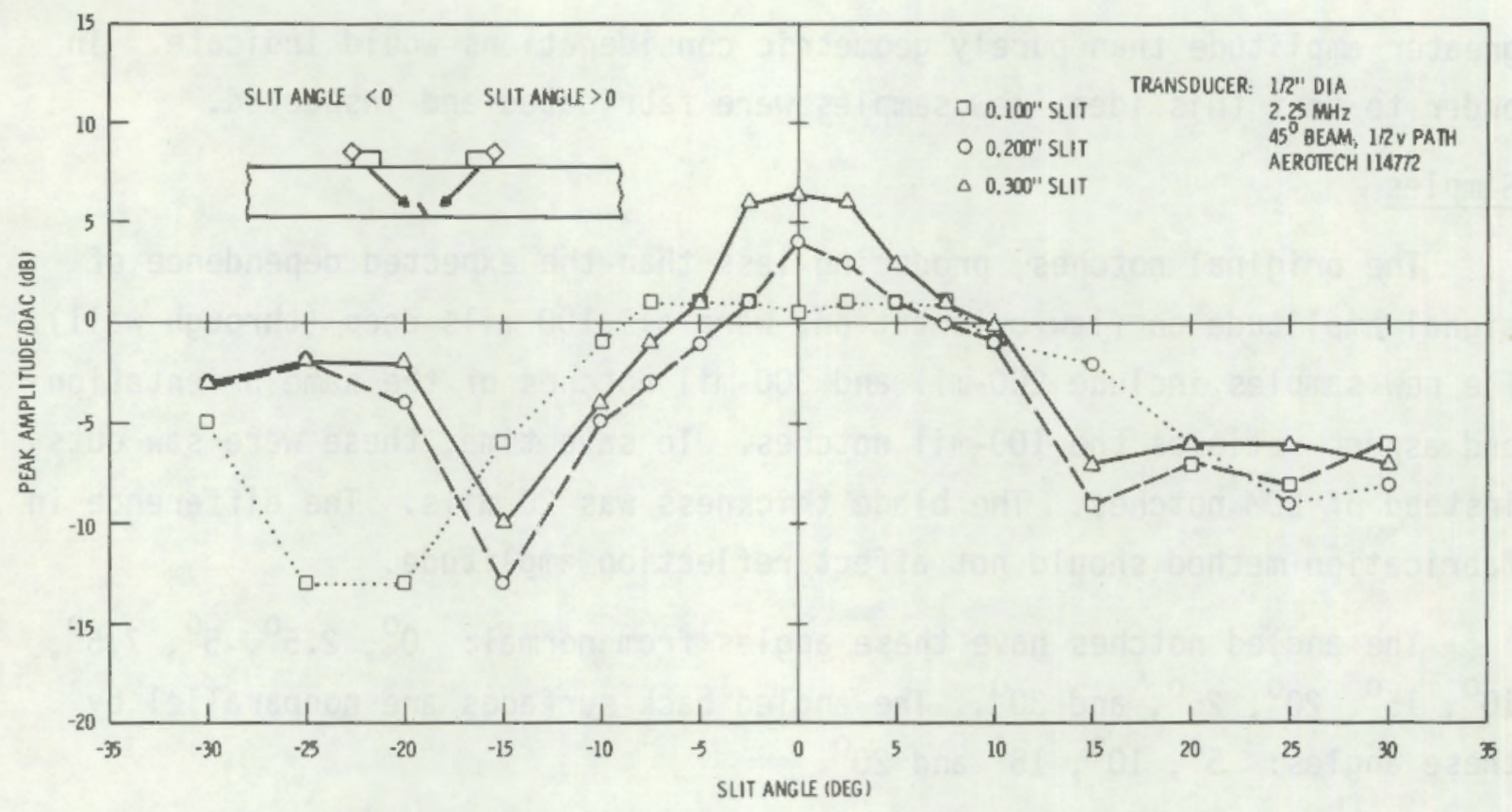

FIGURE 5. UItrasonic Response from Angled Slits, 1/2-V Path, $45^{\circ}$ Beam.

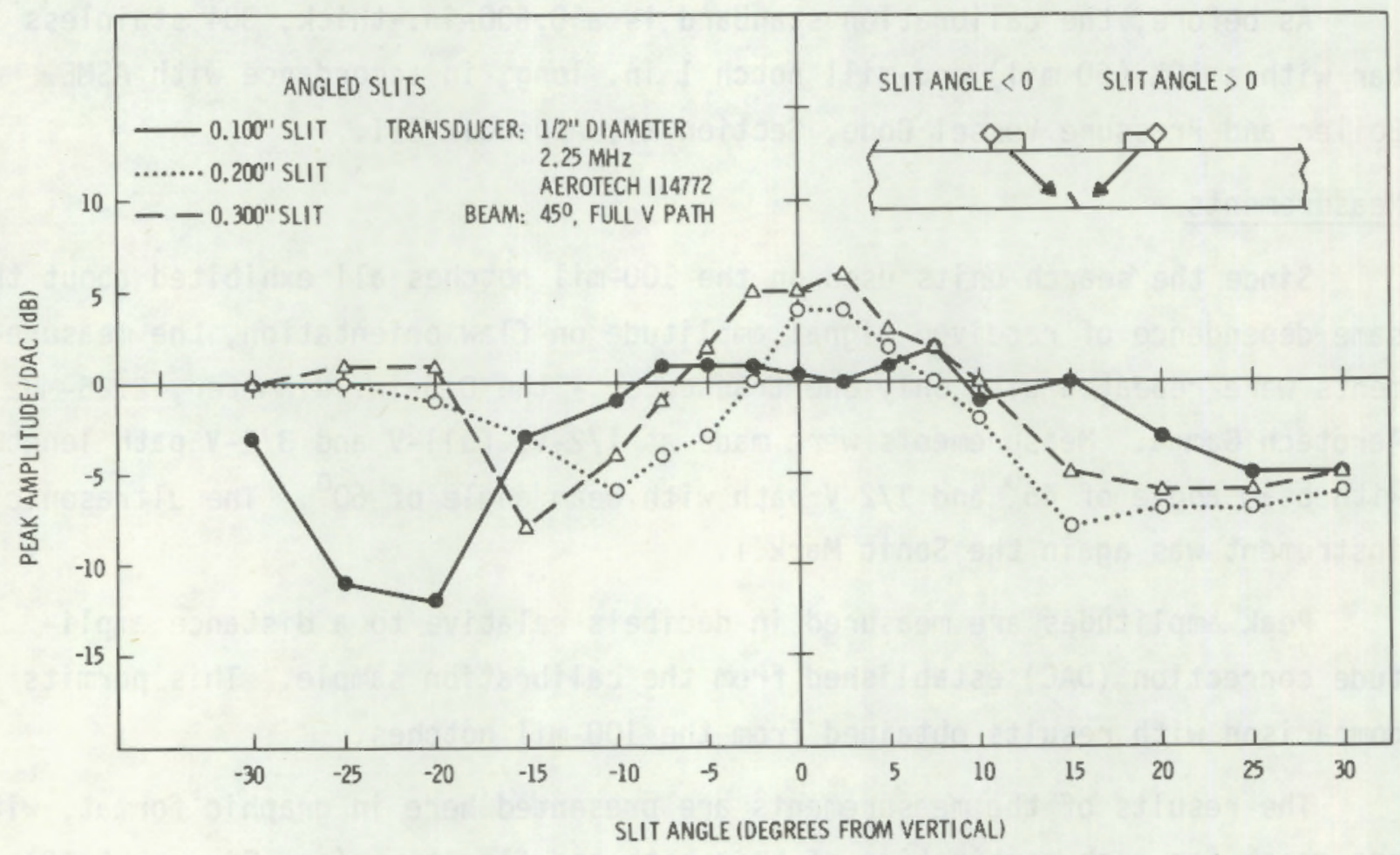

FIGURE 6. U1trasonic Response from Angled Slits, Full-V Path, $45^{\circ}$ Beam. 


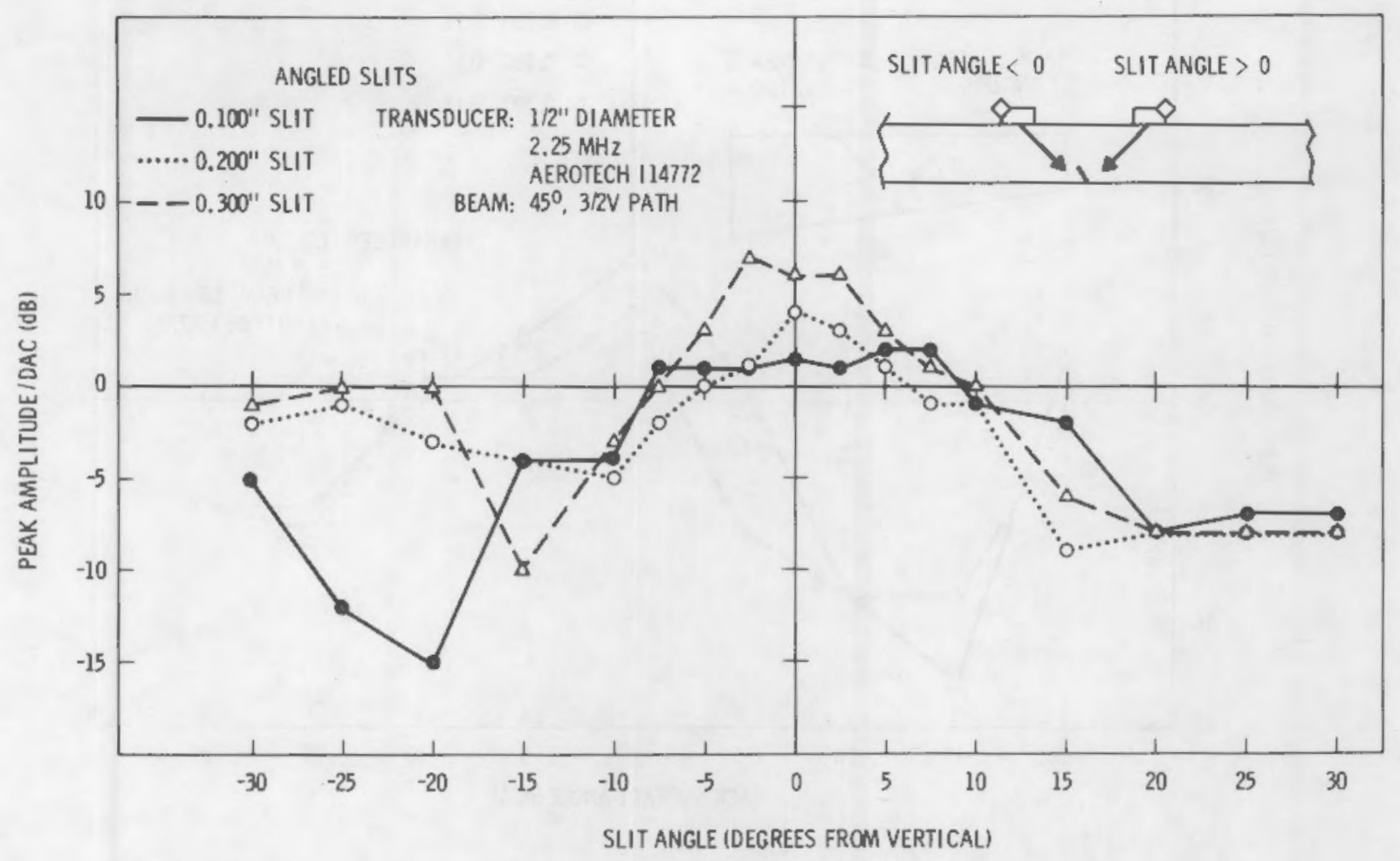

FIGURE 7. Ultrasonic Response from Angled Slits, 3/2-V Path, $45^{\circ}$ Beam.

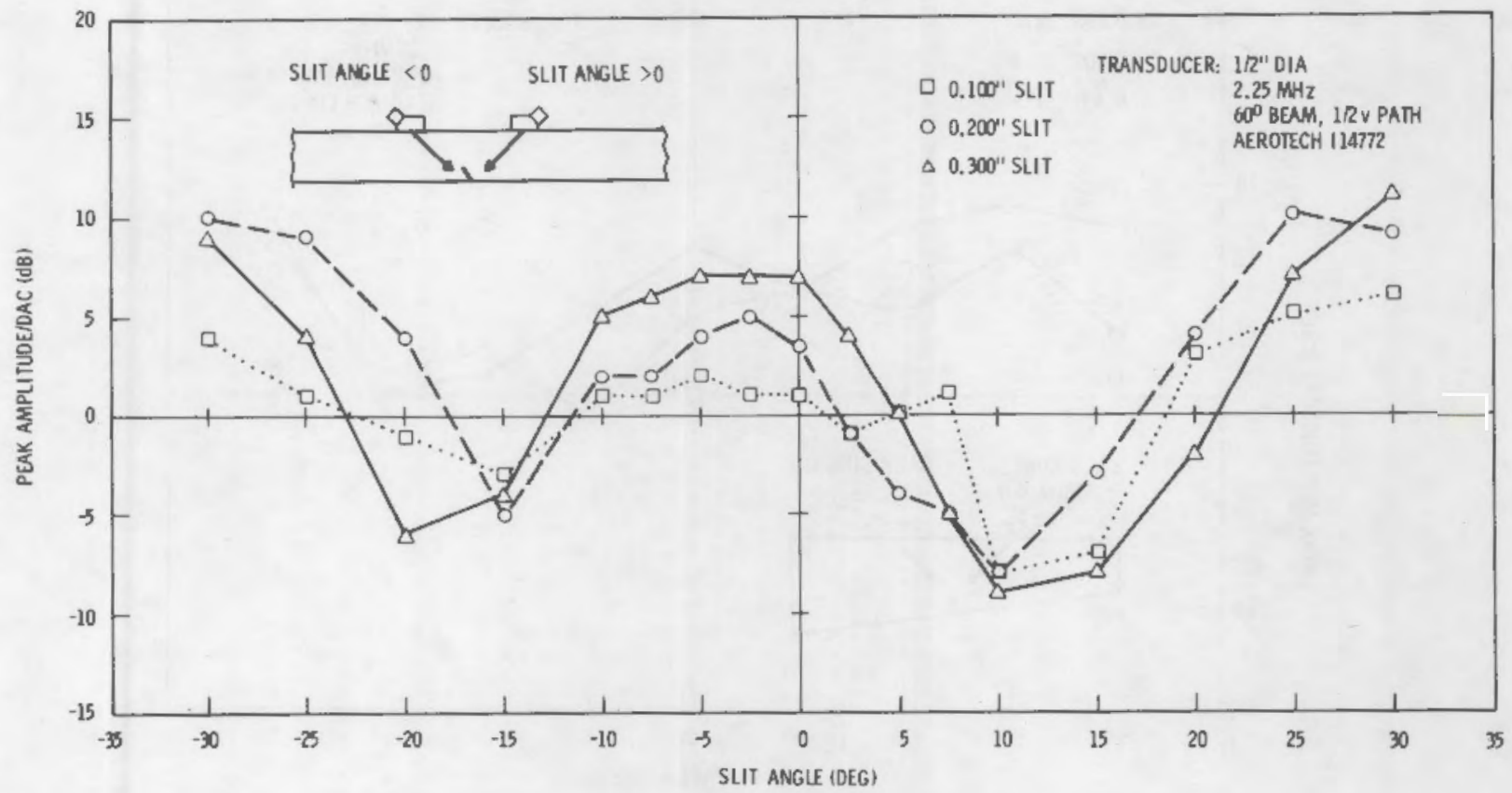

FIGURE 8. UItrasonic Response from Angled Slits, 1/2-V Path, $60^{\circ}$ Beam. 


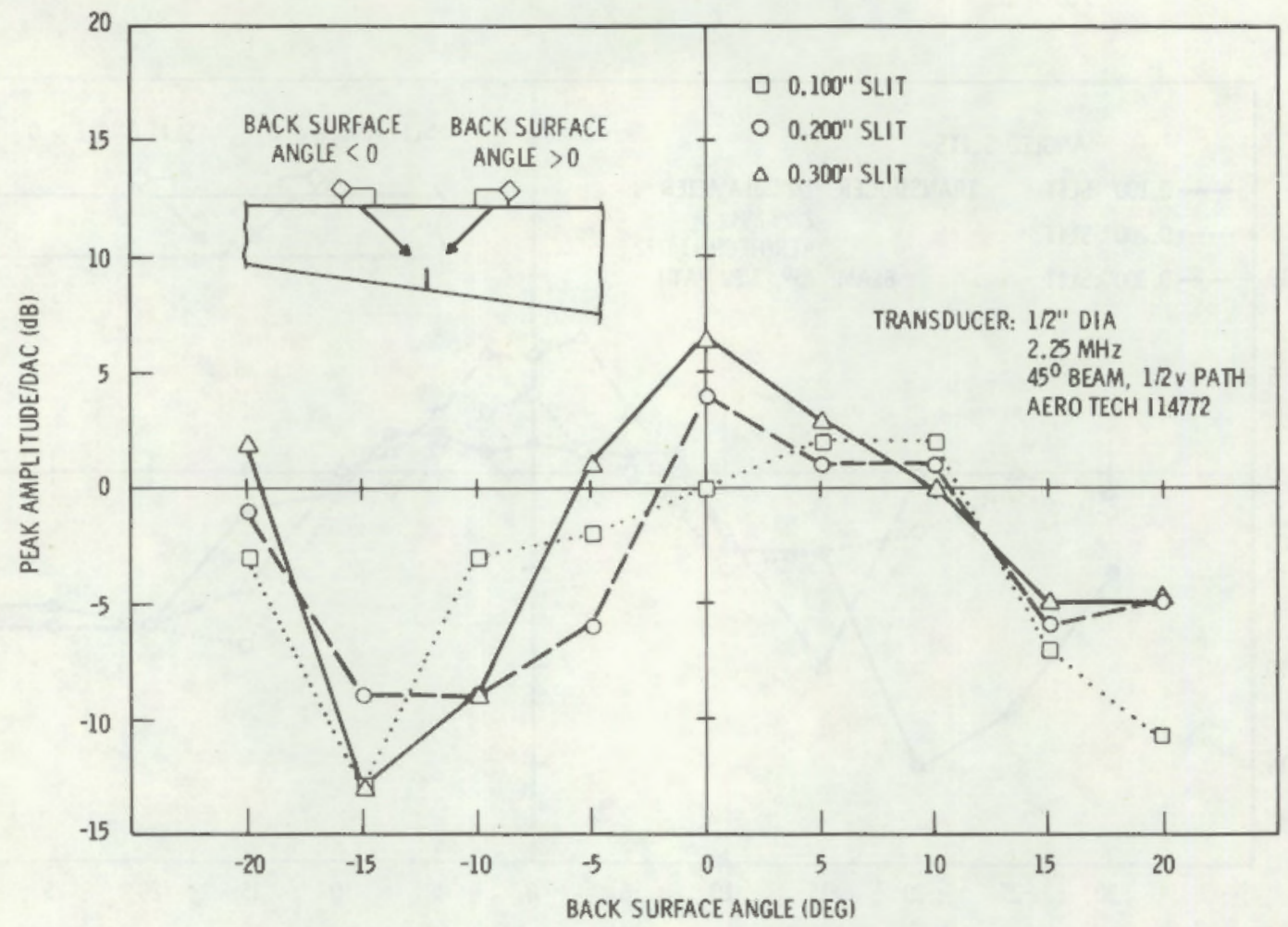

FIGURE 9. Ultrasonic Response from Vertical Slits in Angled Back Surfaces, 1/2-V Path, $45^{\circ}$ Beam.

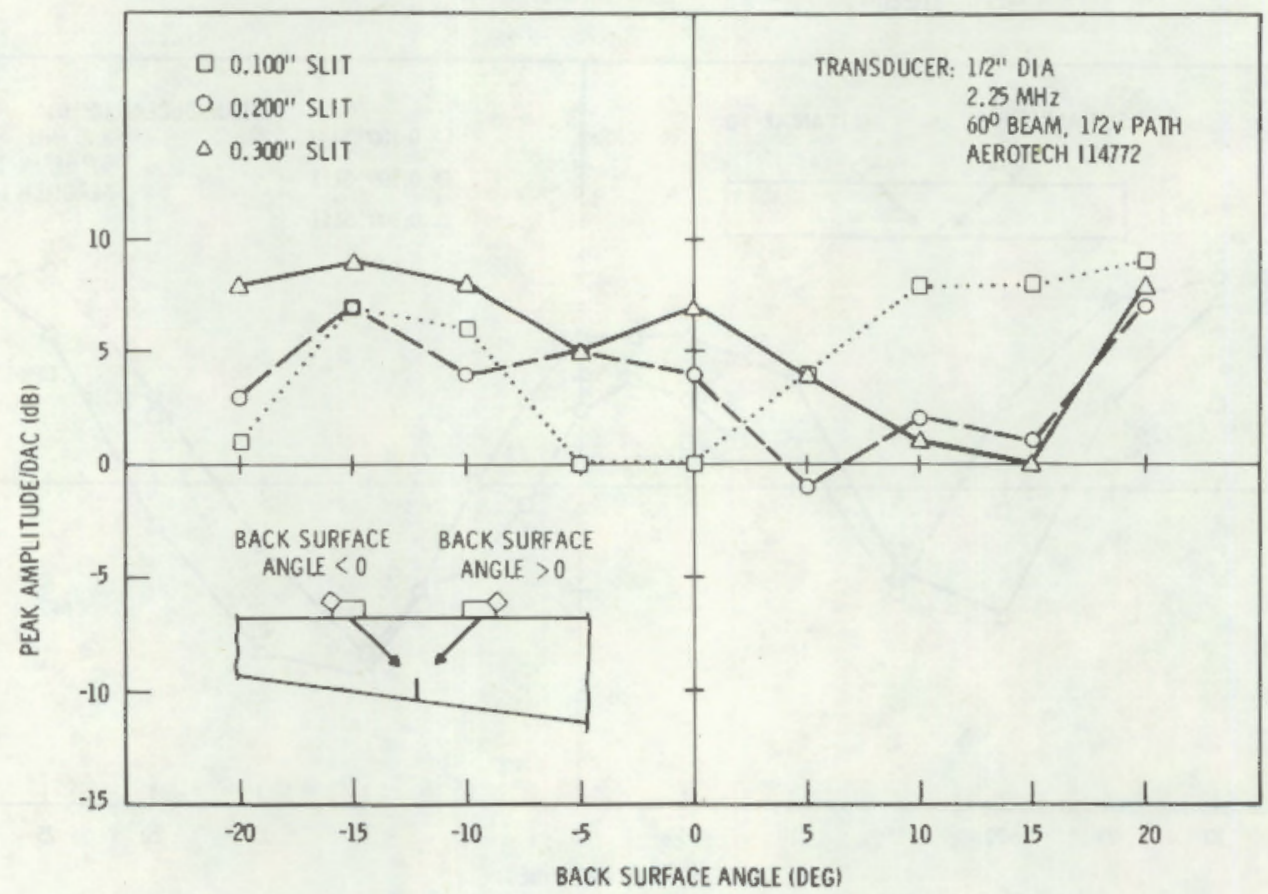

FIGURE 10. U1trasonic Response from Vertical Slits in Angled Back Surfaces, 1/2-V Path, $60^{\circ}$ Beam. 


\section{Angled Notches}

The results previously obtained from the 100-mil angled slits showed some unexpected features, which we attributed to diffraction effects caused by the two-wavelength depth of the slits. Fabrication and measurement of similar, but deeper, flaws were expected to yield more lucid results. It did, in part; however, some aspects of the data remain unexplained.

In the near-vertical range, about $-10^{\circ}$ to $+10^{\circ}$, the 100-mil notches gave almost uniform response the $45^{\circ}$ inspection. The deeper flaws responded with more small-angle sensitivity; the response dropped significantly for flaw angles of $5^{\circ}$ or more from vertical. In the range $-2.5^{\circ}$ to $+2.5^{\circ}$, signal amplitude increased with flaw depth.

The $+15^{\circ}$ and $-15^{\circ}$ slits were expected to have minimal response for a $45^{\circ}$ beam because each involved a $30^{\circ}$ (from normal) incidence angle, and consequently there was a large energy loss through mode conversion. The deeper flaws did show a sharp drop in response at these angles, while the 100-mil flaws did not.

From $+20^{\circ}$ to $+30^{\circ}$, all three slit depths produced approximately the same response amplitude for $45^{\circ}$ inspection, about 5 to $8 \mathrm{~dB}$ below $O A C$. This indicated that, with a 50\% DAC recording criterion, flaws at these angles and with depths up to $50 \%$ through-wall will be, at best, marginally detectable.

The deeper slits at $-20^{\circ}$ to $-30^{\circ}$ angles gave higher responses to $45^{\circ}$ inspection: about two or three $\mathrm{dB}$ below DAC for $1 / 2-\mathrm{V}$ path length and about equal to DAC for full-V and $3 / 2-V$ paths. The $100-m i l$ slits behaved very differently; while the $-30^{\circ}$ response was nearly as high as that of the 200-mil and 300-mil slits, the $-20^{\circ}$ and $-25^{\circ}$ responses were quite low, falling between 10 and $15 \mathrm{~dB}$ below DAC. We do not know why the responses were so $10 \mathrm{w}$; the smaller slit size was not enough to account for such a marked difference in response amplitude.

For $60^{\circ}$ inspection, the only slit angles that were troublesome from the standpoint of a 50\% DAC recording criterion were $+10^{\circ}$ and $+15^{\circ}$. Responses were near or above DAC (for all depths) for the slit angle ranges $-30^{\circ}$ to $-20^{\circ},-10^{\circ}$ 
to $+2.5^{\circ}$ and $+20^{\circ}$ to $+30^{\circ}$. The response dropped rapidly for small positive slit angles because the corresponding reflection angles had low reflection coefficients. However, the angled flaws likely to be encountered in the field (lack of fusion, for example) would be inspected from the negative direction and the only negative angle that might give problems is $-15^{\circ}$. The responses at $-15^{\circ}$ were 3 to $5 \mathrm{~dB}$ below DAC.

Vertical Slits in Angled Back Surfaces

The responses of the deep slits do not vary markedly from that of the 100 -mil slits in $45^{\circ}$ inspection. All depths showed a sharp minimum at $-10^{\circ}$ to $-15^{\circ}$ (mode conversion). Positive angles are most likely to be encountered in field inspection; $+5^{\circ}+10^{\circ}$ responded with signals above DAC, while $-15^{\circ}$ and $+20^{\circ}$ responses were at or below 50\% DAC. ASME Boiler and Pressure Vessel code, Section III specifies counterbore angles of less than $15^{\circ}$. The data indicated that, under high angle counterbore conditions, vertical flaws would be only marginally detectable (for all depths) at the 50\% DAC level when using $45^{\circ}$ inspection.

Inspection with a $60^{\circ}$ beam produced much higher amplitude; nearly every response was at or above DAC. No investigated condition of slit depth and counterbore angle presented detectability problems.

Impact of Flaw Geometry Results on In-Service Inspection Reliability

The ultrasonic responses of three slit depths have been compared under varying conditions of orientation geometry. The depths covered the range 0.1 in. to $0.3 \mathrm{in.,}$ or $17 \%$ to $50 \%$ through wal1. The significant finding of this comparison is that when a flaw does not have the simple geometry of a $90^{\circ}$ corner reflector, echo amplitude is no measure of depth. In some of the geometries we investigated, deeper flaws produced higher responses; in others, deepening the $f l a w$ reduced the response. It is entirely possible that, as certain cracks grow, periodic inspections would show decreasing signal amplitude. Also, the previous finding that $60^{\circ}$ inspection is less sensitive than $45^{\circ}$ to $\mathrm{flaw}$ orientation was verified. 
While the data presented here represent smooth planar reflectors (EDM notches), we expect normal fatigue flaws to be only marginally less sensitive to flaw orientation due to their low roughness as compared to the wavelength. Intergranular stress corrosion cracks (IGSCC), due to their high roughness and nonplanar flaw growth characteristics, may exhibit lower orientation dependence.

\section{FLAW CHARACTERISTICS}

The objective of flaw characteristic measurements is to define the influence of crack roughness and crack tightness on detection reliability. Samples

Two types of $f l a w s$ were produced for study: mechanical fatigue cracks produced by four-point bending and thermal fatigue cracks. In all, 38 samples were fabricated from 304 stainless steel. Twenty-six of these contained one bending fatigue crack each and twelve contained one thermal fatigue crack each.

The bending fatigue samples were $4 \mathrm{in}$. wide and $0.75 \mathrm{in}$. thick, cold rolled from $1 \mathrm{in.}$ thickness. After the cracks were grown, the starter notches were machined off leaving the bars' thicknesses near the cracks slightly over 0.6 in.

To produce aspect ratios of approximately 4 and 10 , drilled holes and sawcut notches, respectively, were used as crack initiators. This approach was unsuccessful because the aspect ratios ranged mainly between 4 and 6 , with no apparent correlation between aspect ratio achieved and type of initiator used.

Crack roughness refers to the load and cycle rate used to grow the cracks. The cracks referred to as "rough" were loaded with $50.4 \mathrm{ksi}$ maximum stress change at a rate of $4 \mathrm{~Hz}$. The "smooth" cracks were loaded with $28.8 \mathrm{ksi}$ maximum stress change at a rate of $7 \mathrm{~Hz}$. Crack growth rates were on the order of $10^{-6} \mathrm{in./}$ cycle for the smooth flaws and $10^{-5}$ to $10^{-4} \mathrm{in./cycle}$ for the rough flaws.

The range of depths of the 12 bending fatigue cracks that were examined destructively was 68 to $235 \mathrm{mils}$. The crack faces were all quite vertical and most were very flat, though a few had step discontinuities. Most of these 
discontinuities were significantly large compared to the wavelength (greater than $1 / 4$ wavelength). The phase interference resulting from these discontinuities caused lower maximum signal amplitudes and the position of maximum amplitude was displaced from the center of the crack.

In depth, aspect ratio and orientation, these bending fatigue cracks were similar to the normal vertical EDM flaws mentioned earlier.

Of the 12 4-in.-wide thermal fatigue samples, 6 were 0.75 in. thick (coldrolled from $1 \mathrm{in}$. thickness), and 6 were $0.6 \mathrm{in}$. thick. The latter samples were annealed before thermal cycling. After crack growth was completed, the starter notches were machined off, but a minimal amount of material was removed and no attempt was made to reduce the thickness of the $0.75 \mathrm{in}$. pieces to $0.6 \mathrm{in}$.

Four of the thermal fatigue cracks were examined destructively. These cracks were extremely tight and rough, and their shapes and orientations varied widely. The crack faces showed ripples, twists and changes in the direction of propagation.

Two specimens were taken from each of four samples for measurement of yield strength. The results are in Table 2. Sample numbers beginning with "A" refer to bending fatigue samples and sample numbers beginning with "B" are thermal fatigue samples. The annealed thermal fatigue sample B114 was annealed before crack growth. The annealed bending fatigue sample A142 was annealed in preparation for further ultrasonic measurement after crack growth and ultrasonic inspection had been done.

\section{BENDING FATIGUE CRACK MEASUREMENTS}

Sizing

Methods investigated for nondestructive determination of crack depth were satellite pulse technique, electrical resistance gauge, probe motion and echo amplitude.

The satellite pulse technique (SPT) determines crack depth by measurement of the difference in time-of-flight between the shear wave reflected from the crack and the shear wave diffracted from the crack tip (Figure 11). Sometimes 
TABLE 2. Yield Stress of Cold-Rolled and Annealed Samples

\section{Sample}

A140

A140

B103

B103

A142

B114

B114
Annealed

No

No

No

No

Yes

Yes

Yes

Yes
Yield Stress, ksi

95.4

114.0

102.4

90.15

$$
\begin{aligned}
& \text { Average cold-rolled yield } \\
& \text { stress }=100.5 \mathrm{ksi}
\end{aligned}
$$

49.9

49.1

47.4

44.6

Average annealed yield stress $=47.8 \mathrm{ksi}$

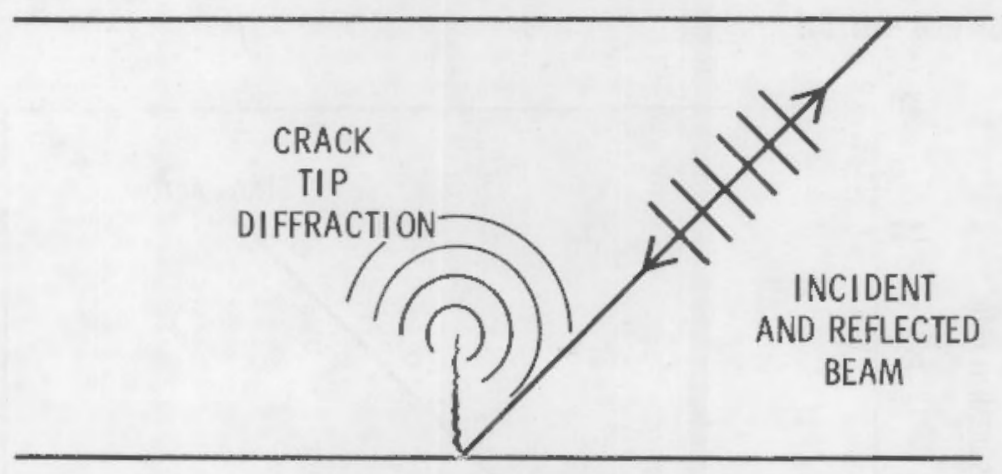

FIGURE 11. Satellite Pulse Technique for Crack Sizing 
this technique works well but, more often, the diffracted signal (satellite pulse) is buried in noise and can be distinguished only with difficulty, if at a]1. Also in some cases, another signal can be mistaken for the satellite, resulting in an erroneous depth determination. This method is insufficiently reliable.

The electrical resistance gauge (ERG), a commercial instrument manufactured by Test Systems International, Inc., measures the electrical resistance resulting from current flow around the crack and can be calibrated using EDM notches as a standard. The major limitations are conduction around the edges of low aspect ratio cracks and conduction through very tight cracks, both of which would cause a low depth reading. These are apparently no problem for the bending fatigue cracks, as this was the best of the sizing methods investigated. The correlation between ERG depth determinations and destructive depth measurements is illustrated graphically in Figure 12. For inservice sizing of reactor piping cracks, the ERG could only be used for cracks opening on the outer diameter of the pipe because use of the ERG involves pressing a probe against the cracked surface.

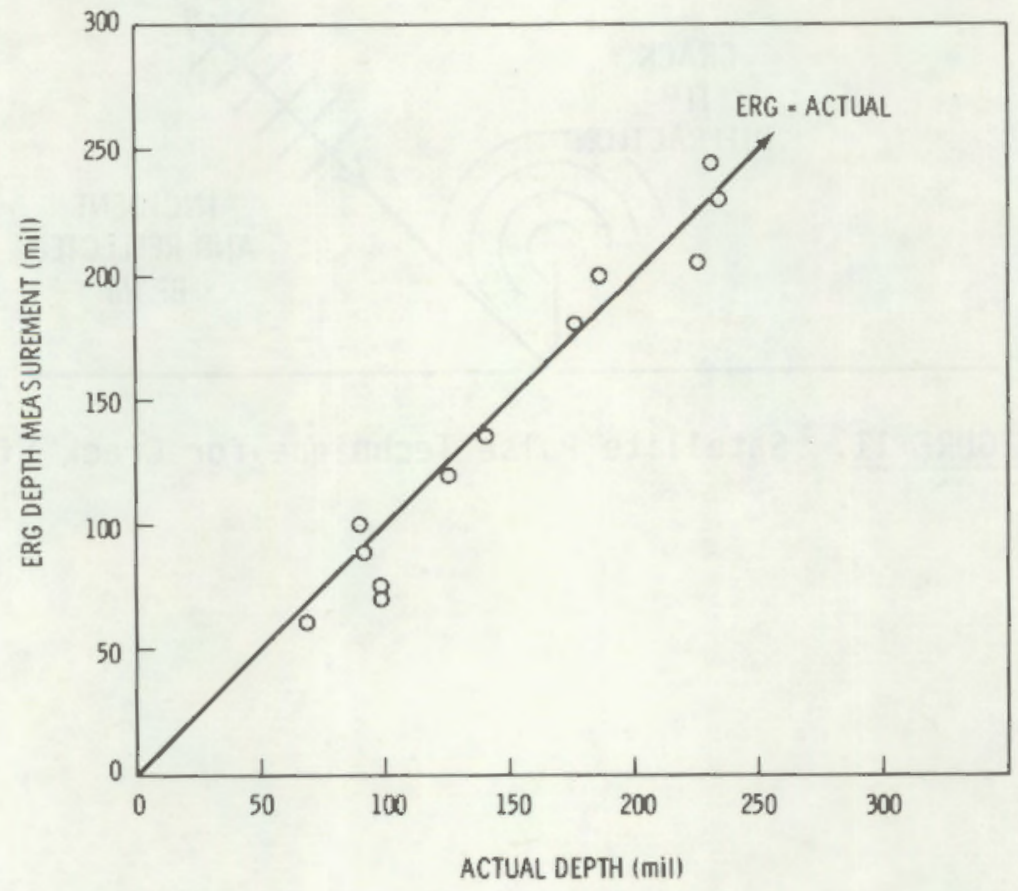

FIGURE 12. Electrical Resistance Gauge Performance in Measurement of Bending Fatigue Crack Depth 
Probe motion involves moving a transducer toward a crack and observing the reflection as it grows and then fades. As an example, one might measure the change in transducer position between the two points that give a signal $6 \mathrm{~dB}$ below maximum. An empirical relation can be developed between probe motion and crack depth. Twelve probe motion measurements were made, that is, four different measuring points ( $-6 \mathrm{~dB}$ points, $-20 \mathrm{~dB}$ points, vanishing points, and two points a fixed voltage from baseline) with three transducer setups $(3 / 4 \mathrm{in}$. 2.25 $\mathrm{MHz}$ unfocused, $1 / 2$ in. $5 \mathrm{MHz}$ focused, and shadow technique with the former sending and the latter receiving) for each crack. Then each of the twe lve resulting data pair sets was given a least-squares fit to linear, exponential, logarithmic and power curves. Using correlation coefficient as the criterion, the best correlations obtained were 1) depth as a linear function of the logarithm of the $-6 \mathrm{~dB}$ probe motion in the shadow technique, resulting in a standard deviation of error in predicting depth of $17.6 \mathrm{mi} 1 \mathrm{~s}$, and 2) depth as an exponential function of the $-20 \mathrm{~dB}$ probe motion of the $0.5-i n ., 5-\mathrm{MHz}$ focused transducer, resulting in a standard deviation of error in predicting depth of 22.7 mils. See Figures 13 and 14 . The method most commonly used in the field, $-6 \mathrm{~dB}$ probe motion in pulse echo mode, produced very poor correlations.

Echo amplitude cannot be relied upon for crack sizing because it is too sensitive to crack tightness, roughness, orientation, and selection of transducer and inspection instrument.

\section{Detectability}

The analysis of ultrasonic inspection sensitivity to flaw orientation was performed using data obtained from EDM slits of known geometry. To predict the ultrasonic behavior of cracks in the same geometry, some direct comparison must be available between responses of cracks and EDM slits of a similar nature. Such a comparison is available; the bending fatigue cracks are closely modeled by the normal vertical EDM slits. They are similar in aspect ratio, range of depths, orientation and flatness of faces. Figure 15 shows ultrasonic reflection amplitude versus depth for both the EDM slits and the bending fatigue cracks. The actual depth is plotted for those cracks examined destructively; for the other cracks, depth was determined from the observed correlation between ERG depth measurement and actual depth, applied to the 


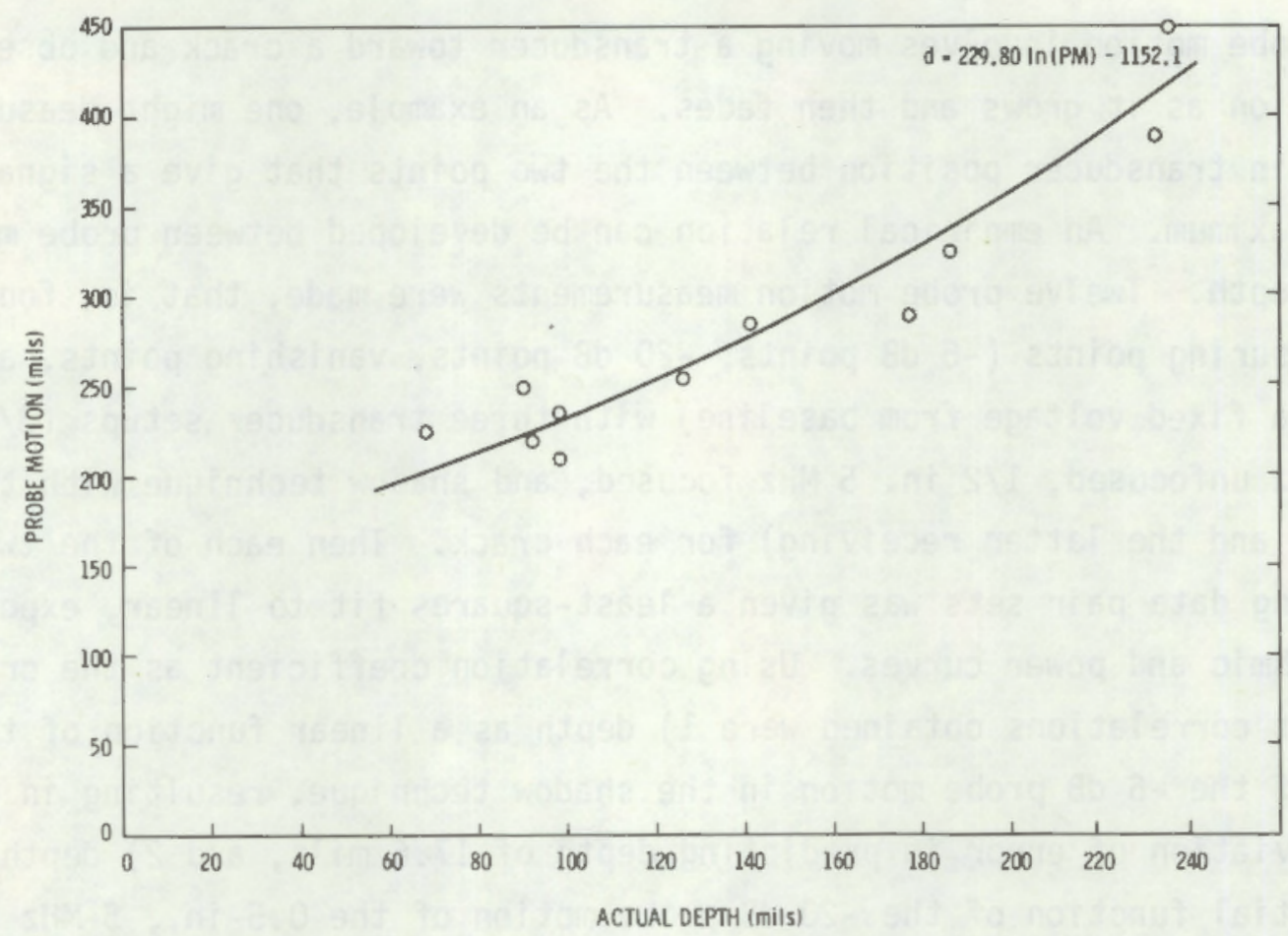

FIGURE 13. $-6 \mathrm{~dB}$ Probe Motion in Shadow Technique Inspection of Bending Fatigue Cracks

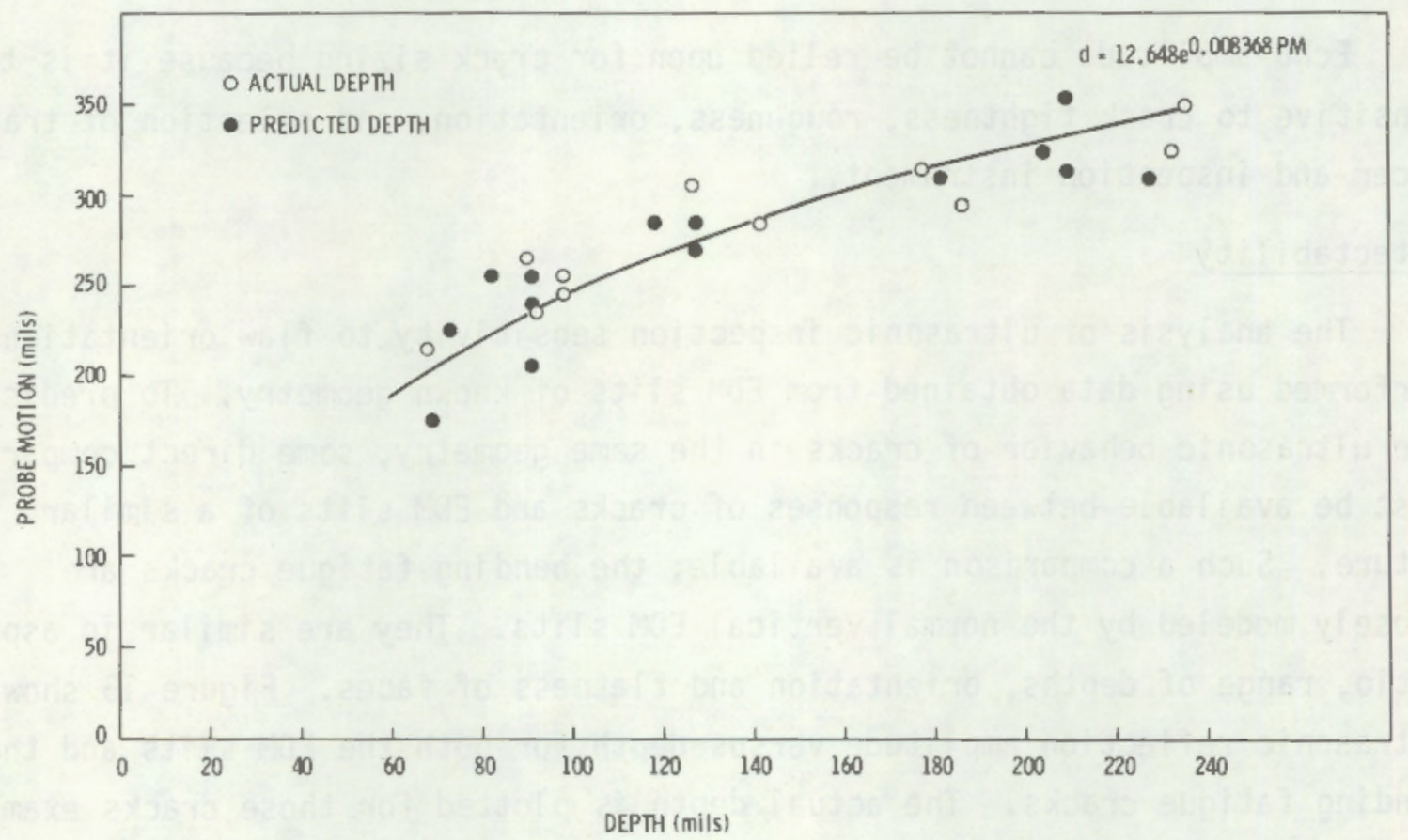

FIGURE 14. $-20 \mathrm{~dB}$ Probe Motion in Pulse-Echo Inspection of Bending Fatigue Cracks 
cracks' ERG depth. The echo amplitudes from most of the cracks fall below the curve established by the EDM standards, thus defining the influence of the flaw characteristics not shared by these two types of flaw. As will be shown later, crack tightness is not a factor in the difference between the cracks and the slits. Note also that Figure 15 shows no significant difference between rough and smooth cracks.

Crack tightness is an important parameter influencing ultrasonic response. A sufficiently tight crack can transmit almost all the energy of an ultrasonic wave, reflecting practically none. As such a crack is made less tight, the fraction reflected increases until it reaches unity. How tight a crack must be to have a certain reflection coefficient depends on what occupies the crack volume (see Figure 16). An air-filled crack must be much tighter than a waterfilled crack in order to allow significant transmission of acoustic waves. No method was available to measure the tightness of the cracks, so the theoretical

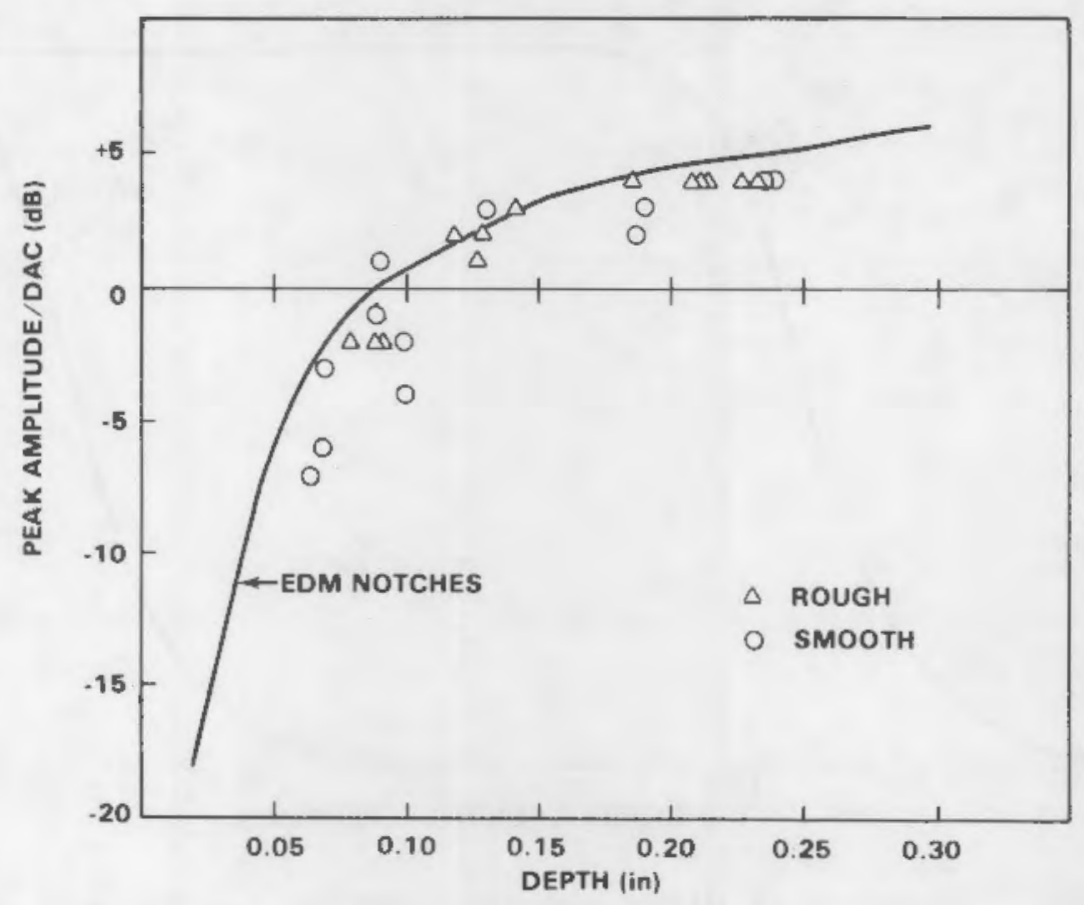

FIGURE 15. Ultrasonic Response of Vertical EDM Slits and Bending Fatigue Cracks $1 / 2-V$ Path, $45^{\circ}$ Beam 
curve could not be verified quantitatively; however, means were available to verify it qualitatively. Of particular interest was the lower limit of achievable reflection coefficient and the consequent impact on detection reliability.

To vary the crack tightness, a four-point bending fixture was used (see Figure 17). This set-up allowed us to put the crack in tension or compression and to position the transducer (0.5-in.-diameter, 2.25-MHz contact unit) by hand for maximum response while under load. Ultrasonic response in $\mathrm{dB}$ relative to OAC was measured as a function of force applied to the bending fixture. This force is not easily relatable to stress at the crack face, but is sufficient for the purpose of establishing the magnitude of the effect of tightness on ultrasonic response. The DAC was established by calibration on a milled $10 \%$ notch according to ASME Section XI specifications.

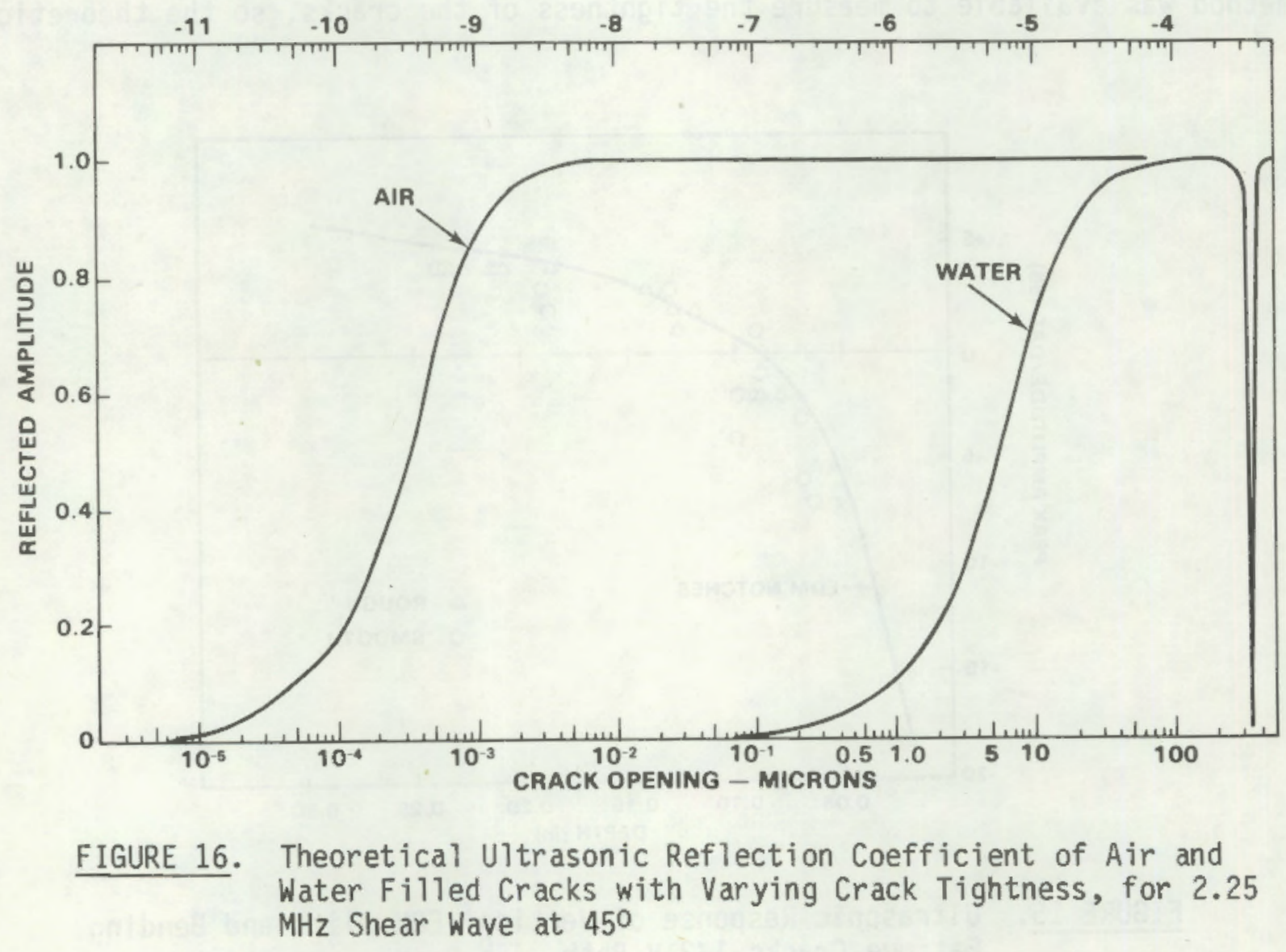




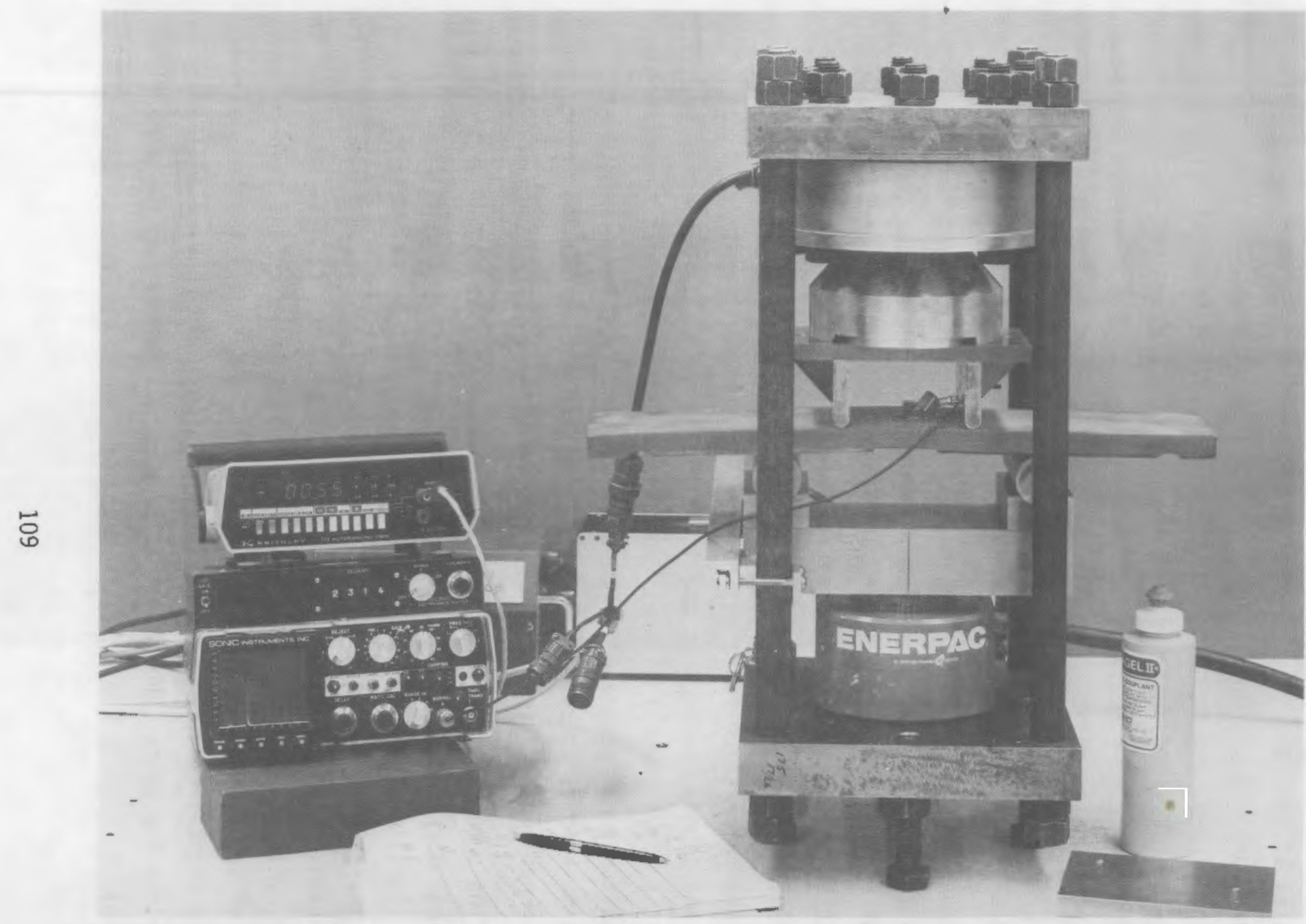

FIGURE 17. Four-Point Bending Fixture, U1trasonic Inspection Instrument and Transducer. 
Putting the cracks in tension and reducing the tightness had no effect. This means that, with no externally applied force, the cracks were already fully open for the purpose of ultrasonic reflection.

When compressive force was applied, the reflection amplitude dropped markedly (Figures 18 and 19). As the force was increased from zero to 50,000 1b, the reflected amplitude dropped slowly as the crack tip closed, then rapidly as the faces closed, and then leveled off at a lower plateau. Further force had no effect. This could mean either that the crack would not get any tighter or that additional force would be expended in plastic flow elsewhere in the sample without increasing the compressive force applied to the crack faces. The latter is possible, because, at 50,000 1b applied, the stress in the sample at the cross-section where the crack was located exceeded the yield stress.

The amount of the signal drop was about the same for all cracks so tested-- 30 to $34 \mathrm{~dB}$ for all depths and roughness. Thus, the major point of interest of the theoretical curve of reflection coefficient versus crack opening has been verified: sufficient tightness can reduce the reflection coefficient of a crack enough to render it effectively undetectable.

When the compressive force was relaxed, a mechanical hysteres is was observed; the signal remained at the lower plateau, finally beginning to increase at a force lower than that required to initially reach the plateau. Once enough force had been applied to close the crack, a lesser force was sufficient to keep it there. Upon full relaxation of the applied force, the signal returned to the level it had before the stressing procedure.

When the same crack was compressed a second time, the signal drop to the lower plateau occurred at a lower applied force than was required the first time. The level of the lower plateau was unchanged. Upon relaxation, the signal increase followed the same path as for the relaxation phase of the first cycle. Subsequent compression-relaxation cycles produced results identical to the second cycle. However, if the crack were put in tension and then relaxed after one of these compression-relaxation cycles, a residual tension would be left in the cracked face, and the next compression would require additional force to close the crack (though not as much as was needed for the very first compression). 


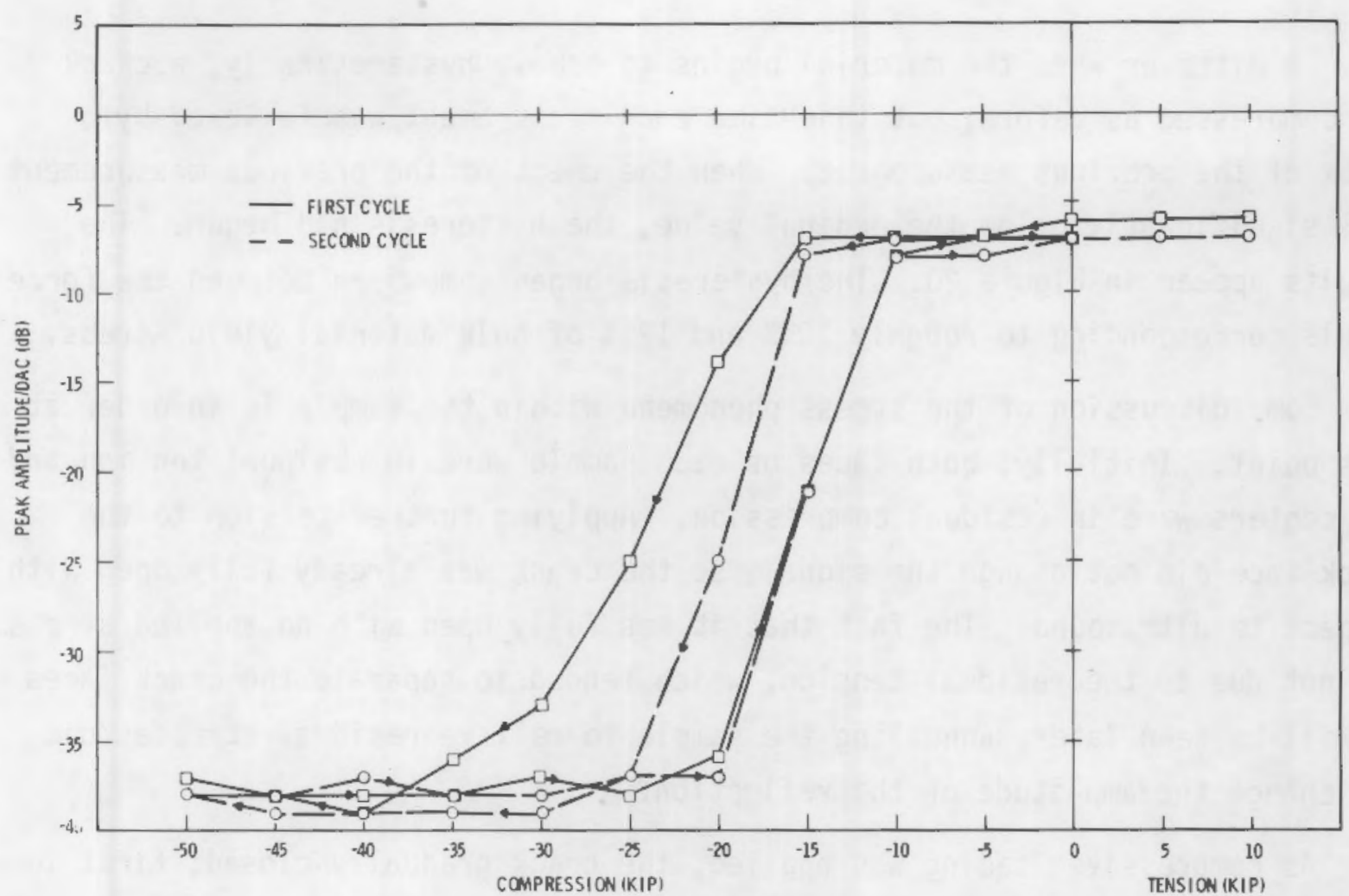

FIGURE 18. U1trasonic Response of Bending Fatigue Crack A153 with Varying Force Applied to Four-Point Bending Fixture

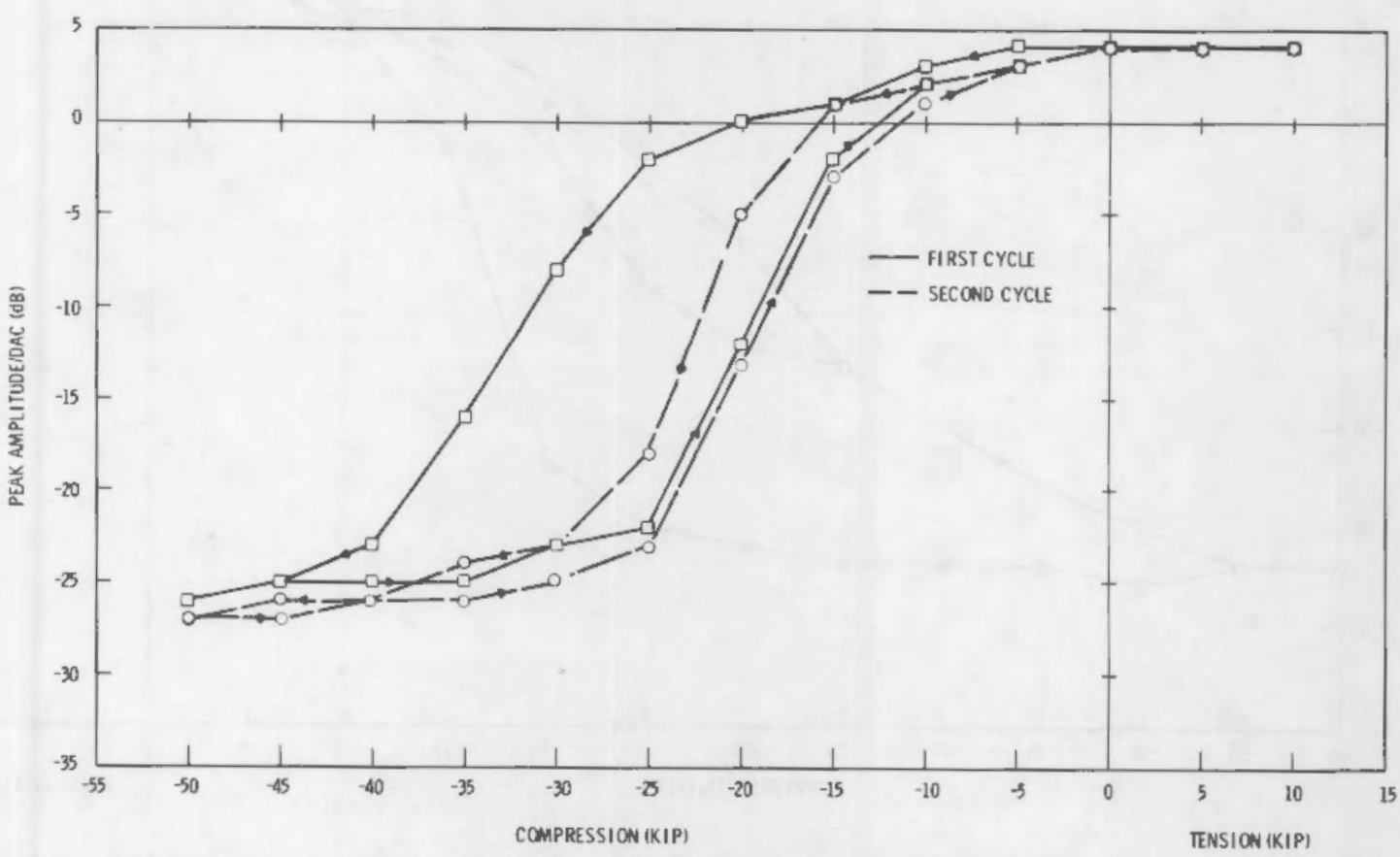

FIGURE 19. Ultrasonic Response of Bending Fatigue Crack A161 with Varying Force Applied to Four-Point Bending Fixture 
To discover when the material begins to behave hysteretically, a crack was compressed as before, but this time each measurement was followed by a check of the previous measurement. When the check of the previous measurement fell significantly below the orginal value, the hysteres is had begun. The results appear in Figure 20 . The hysteres is began somewhere between the force levels corresponding to roughly $105 \%$ and $125 \%$ of bulk material yield stress.

Some discussion of the stress phenomena within the sample is in order at this point. Initially, both faces of each sample were in residual tension and the centers were in residual compression. Applying further tension to the crack face did not change the signal, so the crack was already fully open with respect to ultrasound. The fact that it was fully open with no applied stress was not due to the residual tension, which tended to separate the crack faces. As will be seen later, annealing the sample to relieve residual stresses did not change the amplitude of the reflection.

As compressive loading was applied, the crack gradually closed; first to close was the crack tip, the area under the highest residual compression, and

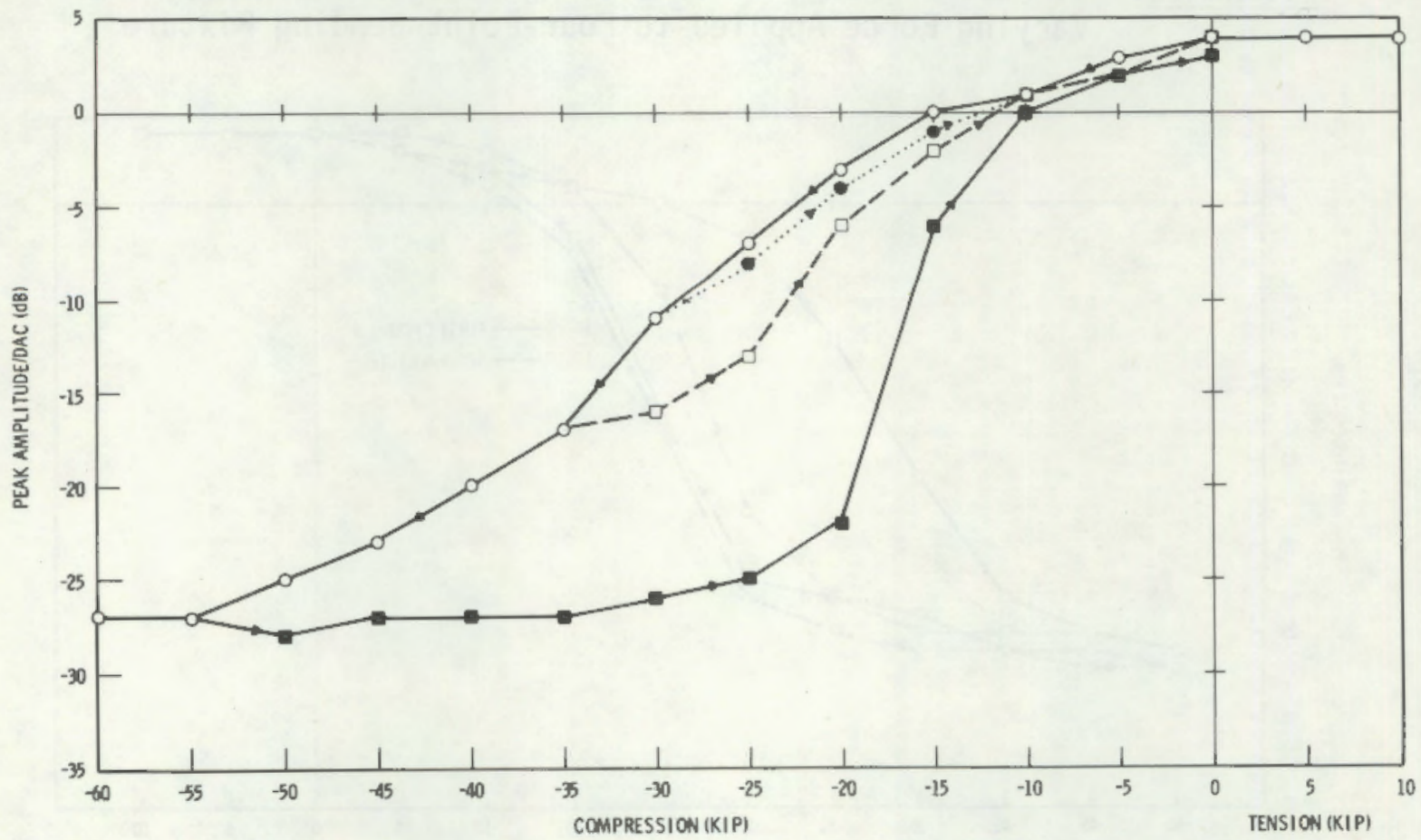

FIGURE 20. U1trasonic Response of Bending Fatigue Crack A141 with Varying Force Applied to Four-Point Bending Fixture 
last to close was the area under highest residual tension or the crack mouth. The signal dropped slowly at first because the first area to close, the tip, had a small reflection area, and the effect on the net crack reflection coefficient was small. The drop accelerated as larger areas of the crack face closed.

It seems likely that the lower plateau is not a manifestation of some limit on crack face deformation; rather, further applied force probably produces plastic yielding eleswhere in the material. The material at the crack faces may be considerably harder due to deformation during crack growth. Also, the fact that the ultrasonic reflection signal returns to its original (maximum) value upon relaxation of external stress contraindicates ultrasonically significant plastic deformation.

Upon unloading, the hysteres is effect was observed, showing that less force is required to keep a crack closed than is needed to close it.

When the specimen was compressively loaded again, the crack began to close at a lower stress. This indicated that the residual tension in the cracked surface had been reduced by the stressing procedure. With less residual tension to overcome, less force was required to achieve the same result.

The stress used to achieve this drastic signal reduction was high, we 11 in excess of the bulk material yield stress. While it is conceivable for such high stresses to occur in practice, stresses below yield will be, by design, far more common. Therefore, it may be more instructive to look at signal drop at some point below the yield stress. Figure 21 is a plot of signal drop at approximately $75 \%$ of yield stress versus crack depth. It shows that the signal drop at this stress ranges between 2 and $10 \mathrm{~dB}$, with one sample dropping $17 \mathrm{~dB}$. The signal drop seems slightly greater at high crack depth, but the data has much scatter; there seems to be no correlation with roughness. Figure 22 plots signal $\mathrm{dB}$ relative to the ASME DAC curve with $75 \%$ yield compression applied, with the zero-stress values (shaded area) drawn in for comparison. It is clear that, while under no applied stress, the amplitudes are nearly all sufficient for detection at 50\% DAC recording level, applied compressive force renders most of the smaller cracks undetectable and some of the deep ones undetectable or only marginally detectable. 


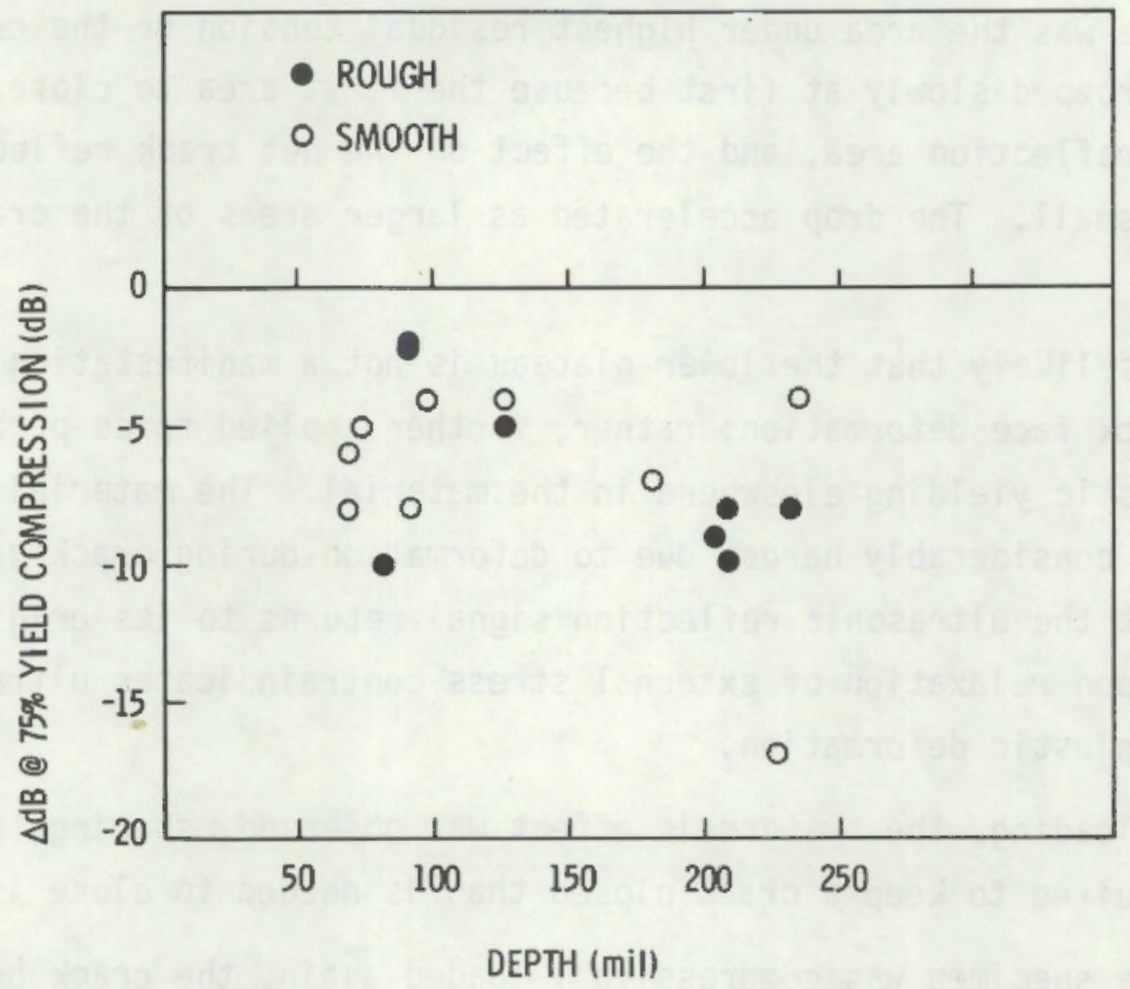

FIGURE 21. Change in UItrasonic Response of Bending Fatigue Cracks Upon Compression to $75 \%$ of Yield Stress

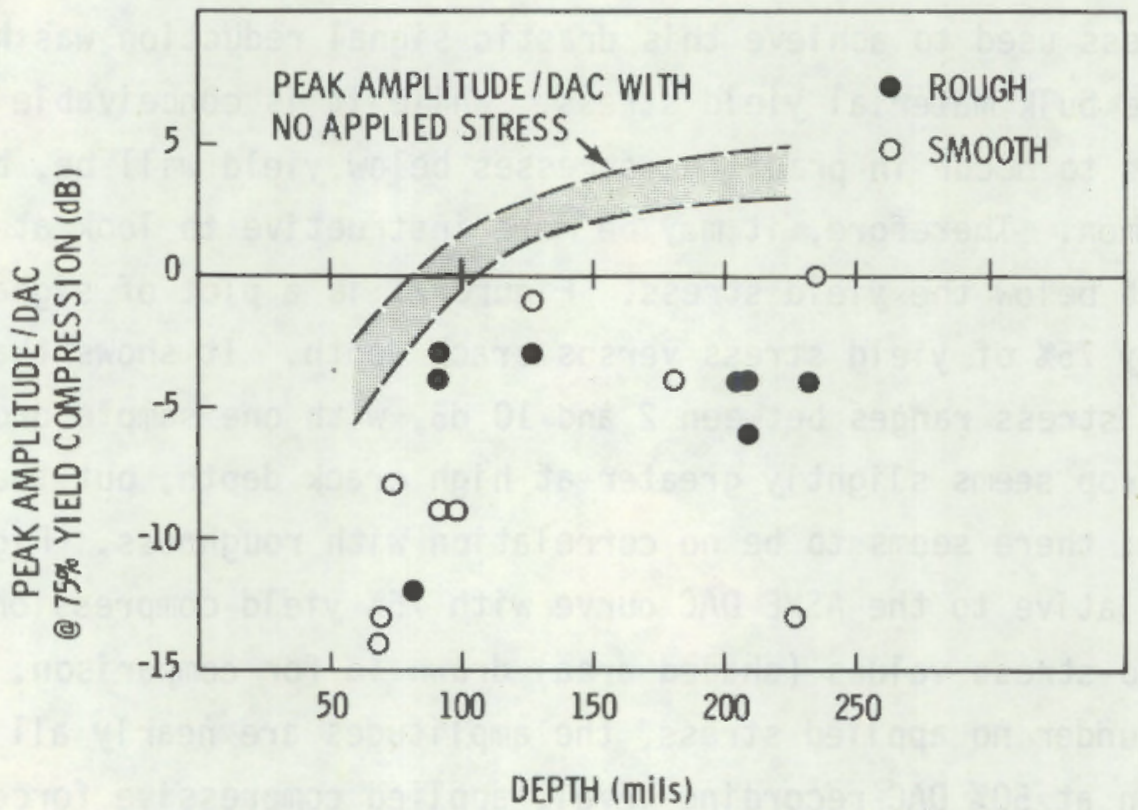

FIGURE 22. UTtrasonic Response of Bending Fatigue Cracks Compressed to $75 \%$ of Yield Stress 
According to the theoretical curve that predicted the observed very large drop in reflection coefficient as a crack tightens (Figure 16), the same effect will occur for a water-filled crack that is much less tight than our air-filled cracks. (Actually, our cracks probably fall between the air and water cases, because there will be oxides on the crack faces which will serve to transmit sound better than air would.) Several attempts were made to fill cracks with water, but with no success. No method was available to determine the degree of filling had we been able to get water inside. In the piping of nuclear plant, though, cracks could fill with water much more easily at the extant conditions of elevated temperature and pressure. If sufficiently tight cracks are being filled with water, then a detectability problem exists, for a crack on the lower plateau of signal versus tightness cannot be detected by a conventional ultrasonic inspection. Our air-filled cracks did not reach this lower plateau of ultrasonic response until a level of compression was imposed that is probably uncommon in reactor piping, but similar cracks filled with water may be on the lower plateau with much lower compression forces which are more prevalent, or perhaps with no compression at all, depending on initial crack tightness.

The compression-tension data described so far were taken from samples still in the cold-worked condition. Since reactor piping is annealed, the next step was to anneal six samples and perform the same tests to see if the pronounced effect of crack tightness would still be evident. Annealing did not significantly change the signal amplitude at zero applied stress; the maximum change was a $2 \mathrm{~dB}$ drop for one sample. Most were unchanged.

As before, putting tension on the crack did not change the signal. The annealed cracks were still fully open. There had been concern that the oxide film produced on the crack faces by annealing might reduce the signal by allowing transmission through the crack, but if th is had been the case, application of tension should have brought the signal back up again.

Compression-relaxation cycles again demonstrated a mechanical hysteres is, but there were differences from the behavior of the cold-worked samples. The differences were due both to the reduction of residual stresses and to the reduction of yield strength (Figures 23 and 24 ). 


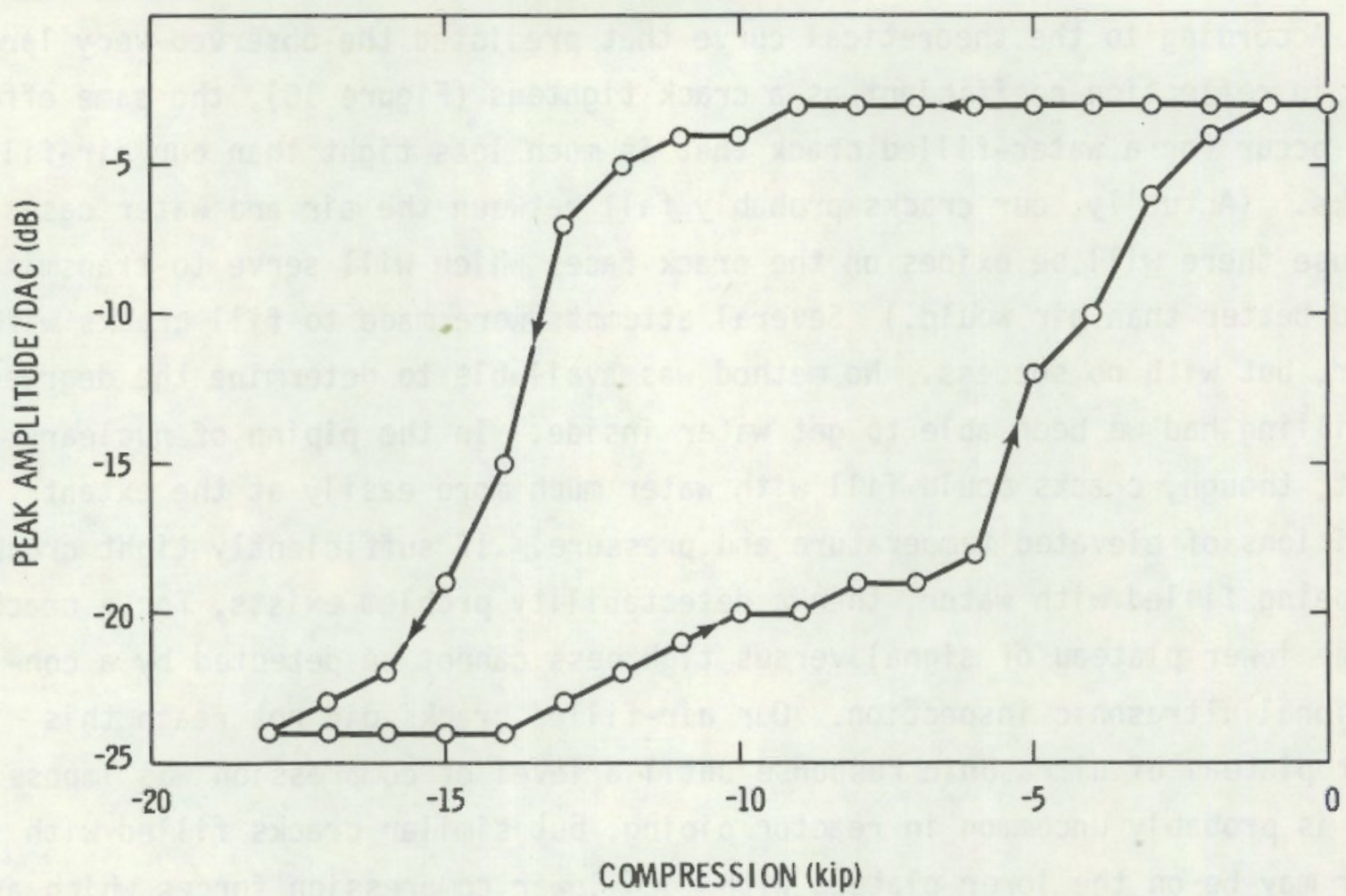

FIGURE 23. U1trasonic Response of Bending Fatigue Crack A155 (Annealed) with Varying Force Applied to Four-Point Bending Fixture

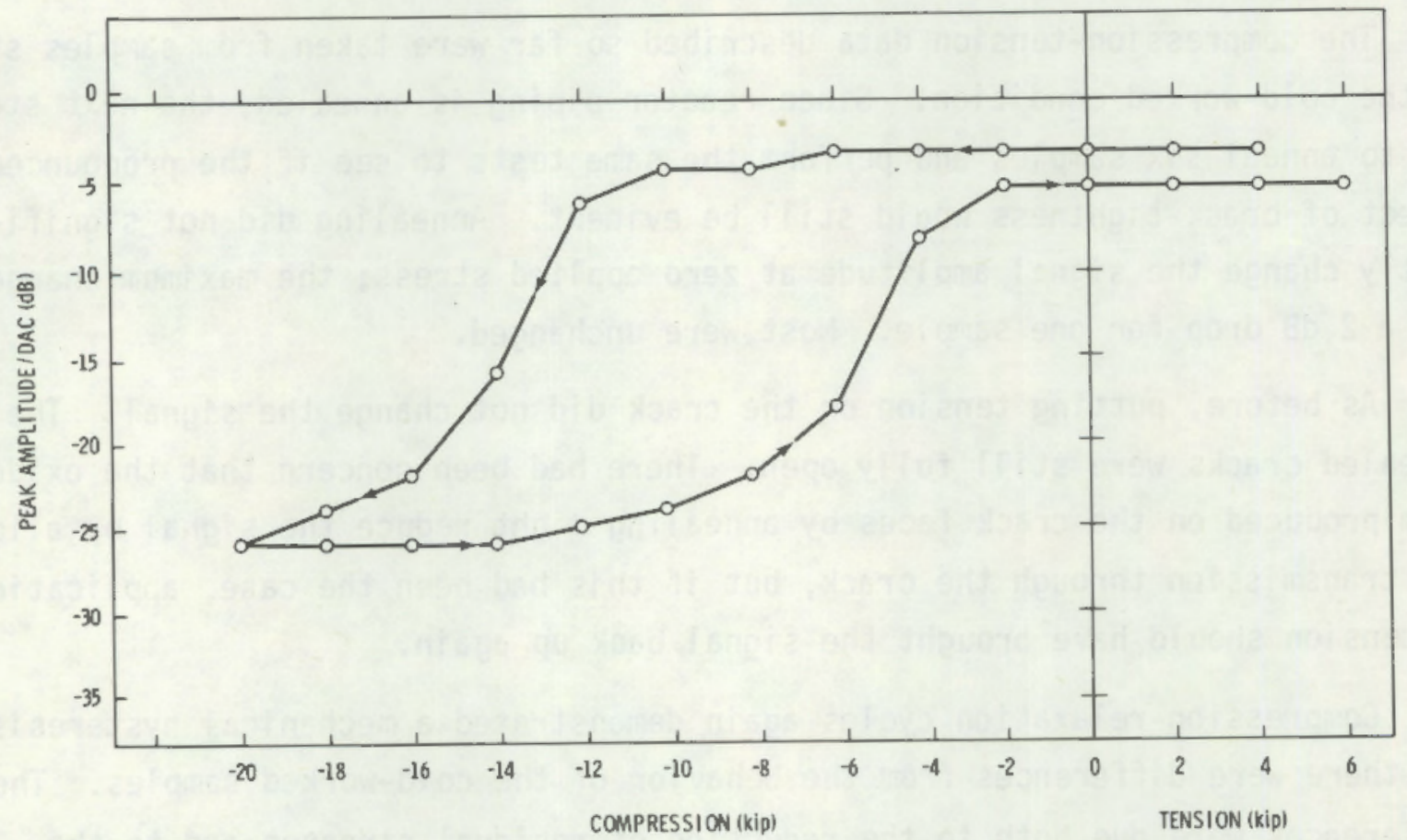

FIGURE 24. U1trasonic Response of Bending Fatigue Crack A156 (Annealed) with Varying Force Applied to Four-Point Bending Fixture 
Upon application of compressive force, the signal amplitude remained constant until a level of stress (at the crack face) of about $75 \%$ of the yield strength was reached. Then it fell rapidly to a lower plateau, which for all samples was 21-23 dB beneath the zero-stress amplitude. As the applied force was relaxed, the signal remained at the lower plateau until, at a force lower than that necessary for crack closure, it increased slowly and then rapidly to a value equal to or slightly less than the original. Application of tension at this point did not increase the signal further, regardless of whether it fully returned to the original value.

The rapid signal drop observed when compression was applied occurred as the stress reached the neighborhood of the yield strength for both the annealed and nonannealed samples. The reason that the annealed samples showed no gradual signal drop at lower stress was that, unlike the nonannealed samples, the crack tip was not under high residual compression. The drop was sudden because the crack closed all at once.

The total signal drop was only $22 \mathrm{~dB}$, compared to $32 \mathrm{~dB}$ for the coldworked specimens. This indicated that, while crack closure occured at the yield stress, the magitude of signal decrease that was eventually achieved depended on the amount of force on the crack faces. Much less force was available in the annealed samples because the yield strength was only half that of the cold-worked samples.

The previous comments on the effect of water intrusion into the crack apply equally here. While the signal drop occurred at a stress level that is probably unusual in the field, the drop might occur with little or no compression applied if the crack is filled with water. And though the drop is $10 \mathrm{~dB}$ smaller for annealed samples, it is still enough to reduce the reflection amplitude to the extent that an ultrasonic inspector would ignore it.

\section{THERMAL FATIGUE SAMPLE MEASUREMENT}

The thermal fatigue cracks are quite different from the bending fatigue flaws. They are much rougher in the macroscopic sense; they ripple, twist and change direction. One sample that was examined destructively had a crack that 
bent over so far that its deepest third was propagating parallel to the surface. These variable topographies make prediction and analys is of the cracks' ultrasonic behavior difficult, but they could also be beneficial in some circumstances. For example, a flat vertical flaw may be difficult to detect on some counterbores, but one of these thermal cracks in the same position could have areas with geometries favorable to detection.

$\underline{\text { Sizing }}$

None of the four sizing procedures employed produced consistent accuracy. The satellite pulse technique performed more poorly than it had for the bending fatigue cracks. No crack showed a recognizable satellite pulse, perhaps because the noise level was high. The high background noise was a result of the necessity for high gain in inspecting these flaws.

Echo amplitude also failed. The cracks were so tight that their echo amplitudes (with no applied stress) fell an average of $18 \mathrm{~dB}$ below DAC. No correlation was observed between amplitude and destructively determined depth. Another influence disruptive to echo amplitude sizing was the nonplanar shapes the cracks assumed. With so much variation in reflection geometry, echo amplitude will not be a simple function of throughwall penetration.

The influences of tightness and off-normal geometry on ERG depth measurement would seem to be in opposite directions. Extreme tightness would allow current flow across the crack face and the increased current flow indicates a smaller crack. Off-normal geometry causes the current to take a circuitous route around the crack, causing a large depth determination. Both effects are reflected in the data as shown below in Table 3 .

The ERG measurement was low for two of four samples and about right for a third sample; the sample for which the ERG measurement was far too high was that sample whose crack propagation direction was farthest from vertical. These two competing effects, either one of which could dominate and cause significant error for a particular flaw, make the ERG depth measurement unreliable for these flaws. 
TABLE 3. ERG Depth Measurement Performance on Thermal Fatigue Cracks

\begin{tabular}{|c|c|c|}
\hline $\begin{array}{c}\text { Sample } \\
\text { No } \\
\end{array}$ & $\begin{array}{l}\text { Actual } \\
\text { Depth }\end{array}$ & $\begin{array}{l}\text { ERG Depth } \\
\text { Measurement }\end{array}$ \\
\hline B101 & $250 \mathrm{mi}]$ & $135 \mathrm{mil}$ \\
\hline B103 & $193 \mathrm{mil}$ & $200 \mathrm{mil}$ \\
\hline B104 & $158 \mathrm{mil}$ & $400 \mathrm{mil}$ \\
\hline B114 & $147 \mathrm{mil}$ & $120 \mathrm{mil}$ \\
\hline
\end{tabular}

Probe motion measurements are taken from a trace of echo amplitude versus transducer position. For EDM slits and bending fatigue cracks, these curves are smooth and regular; but the traces obtained from thermal fatigue cracks are so irregular as to make measurements ambiguous or impossible. This is a result of variable off-normal crack geometry and (for through transmission) ultrasonic transmission through the crack.

\section{Detectability}

The detectability of these flaws depends heavily on externally applied stress. The bending fatigue flaws had this dependence, but it became significant only with considerable applied compressive stress. The thermal fatigue cracks, though, are highly sensitive to applied stresses in the neighborhood of zero. At zero applied stress, all 12 cracks would be undetectable with $50 \%$ DAC recording criterion. The echo amplitudes ranged from 9 to $27 \mathrm{~dB}$ below DAC; mean and standard deviation were $17.9 \pm 5.7 \mathrm{~dB}$. The destructively measured cracks were all rejectable according to the criteria of ASME Boiler and Pressure Vessel Code, Section XI, Table IWB-3514-3; their depths were 147, 158, 193 and 250 mils.

Through application of external stress, the thermal fatigue cracks also verify the theoretical behavior of reflection amplitude as a function of crack opening. A plateau of (comparatively) high-amplitude reflection occured with the crack in tension and a low-amplitude plateau was observed with the crack compressed. At rest (no externally applied stress), the cracks were in the lower part of the high-slope region between the plateaus and were therefore very sensitive to changes in crack face closure forces. 
The difference between the tension and compression plateaus ranged between 11 and $35 \mathrm{~dB}$. Most fell in the 28 to $35 \mathrm{~dB}$ range; the others were 11,14 and $20 \mathrm{~dB}$. The destructed samples included three with plateau separation of 11 , 14 and $28 \mathrm{~dB}$. The 11 and $14 \mathrm{~dB}$ cracks were much less planar than the $28 \mathrm{~dB}$ crack. This may mean that the nonplanar geometry of the cracks prevented their full closure, resulting in a high lower plateau. Both these nonplanar flaws were in nonannealed samples, as was the sample with $20 \mathrm{~dB}$ plateau separation (which was not examined destructively). This may indicate that the nonannealed samples are more likely to develop curving, nonplanar cracks.

Plots of signal amplitude versus tensile/compressive applied force reveal little or no mechanical hysteresis effect for the nonannealed samples (see Figures 25,26 ). This is because the hysteres is is a phenomenon of plastic strain and the plateaus are usually reached for these samples without exceeding the yield stress. Annealed samples do behave hysteretically, as shown in Figures 27 and 28. The upper reflectivity plateau is reached at approximately the the yield stress, which for these annealed samples corresponds to $11 \mathrm{ksi}$ load. Upon relaxation of the tensile load, the signal begins to drop just before full unloading and at zero load has dropped only a few $\mathrm{dB}$. At this point, the signal is 10 to $20 \mathrm{~dB}$ higher than the initial signal. A somewhat higher (compressive) load is required to reach the lower plateau. Relaxation to zero load brought the signal back up into the range of +3 to $-14 \mathrm{~dB}$ relative to the initial value.

Though these flaws are undetectable (50\% DAC çriterion) with no externally applied load, applying tension equal to the yield stress makes most of them detectable. Clearly, if cracks of this tightness occur in reactor piping, their detection will strongly depend on the stress condition at the crack under cold shutdown conditions. If the cracks fill with water, they may be undetectab le under any realistic stress condition. Also, if the stress values at a crack vary from one inservice inspection to the next, then meaningful interpretation of what is happening to the crack will be more difficult. 


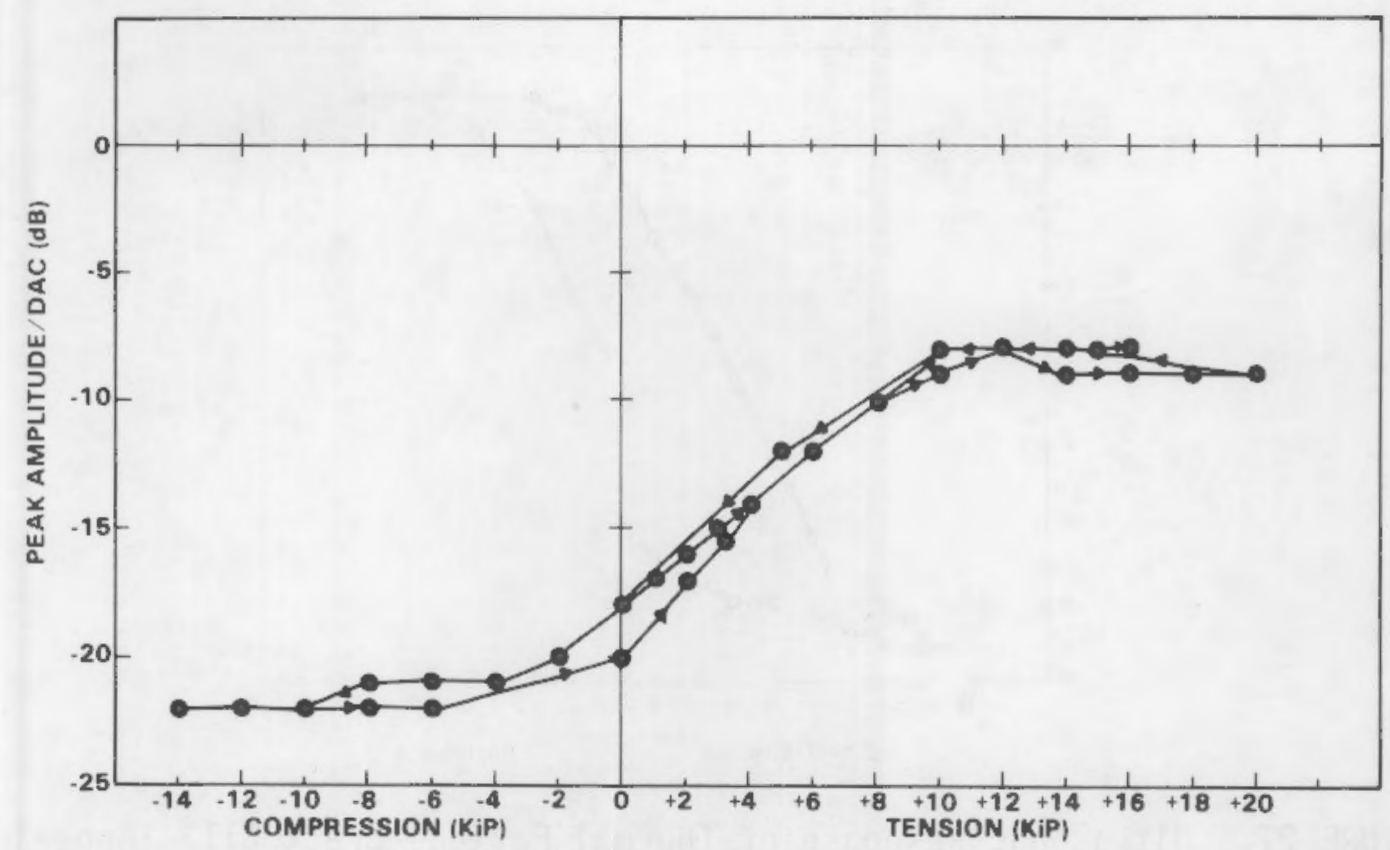

FIGURE 25. Ultrasonic Response of Thermal Fatigue Crack B103 with Varying Force Applied to Four-Point Bending Fixture.

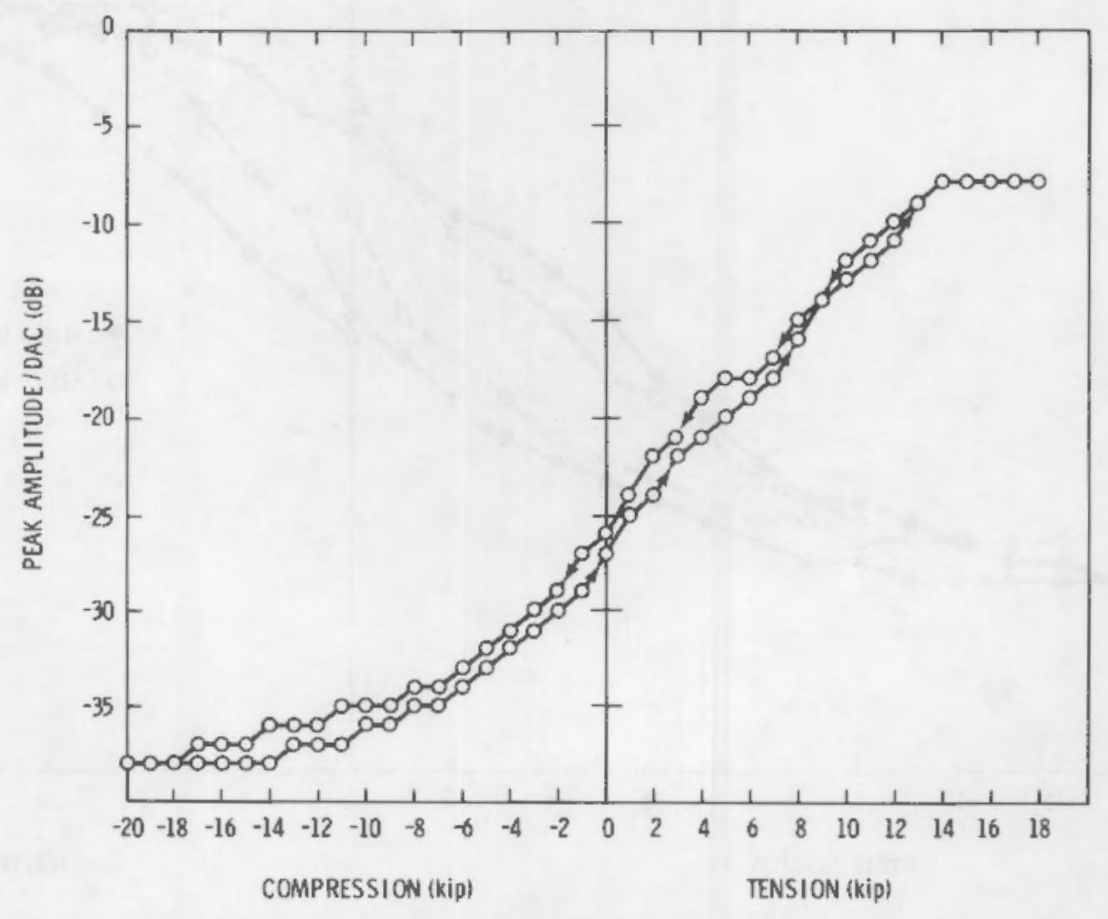

FIGURE 26. Ultrasonic Response of Thermal Fatigue Crack B105 with Varying Force Applied to Four-Point Bending Fixture. 


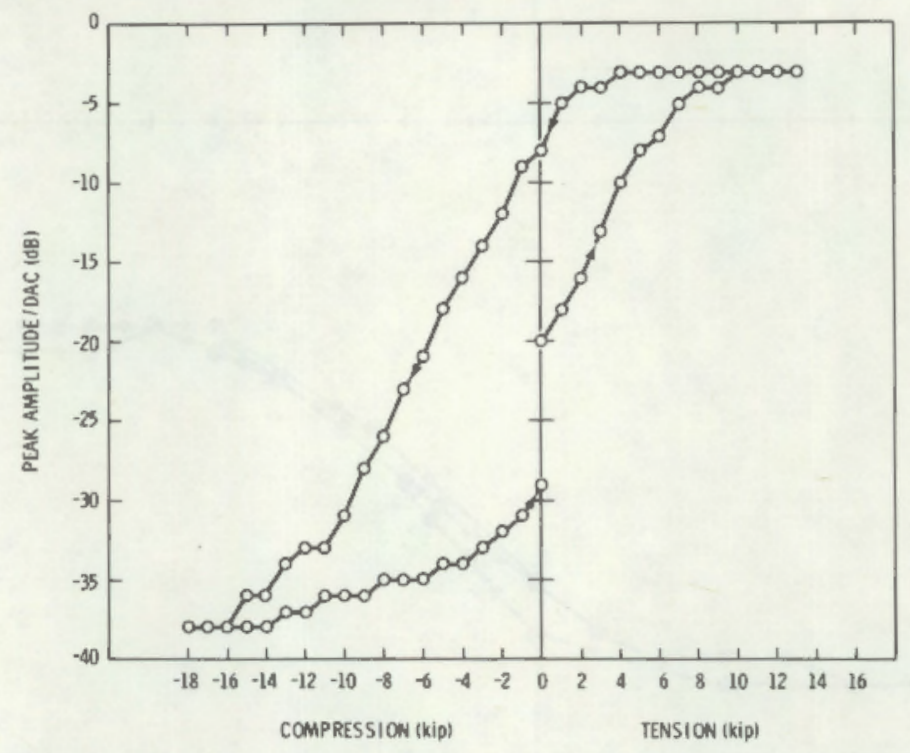

FIGURE 27. Ultrasonic Response of Thermal Fatigue Crack B113 (Annealed) with Varying Force Applied to Four-Point Bending Fixture.

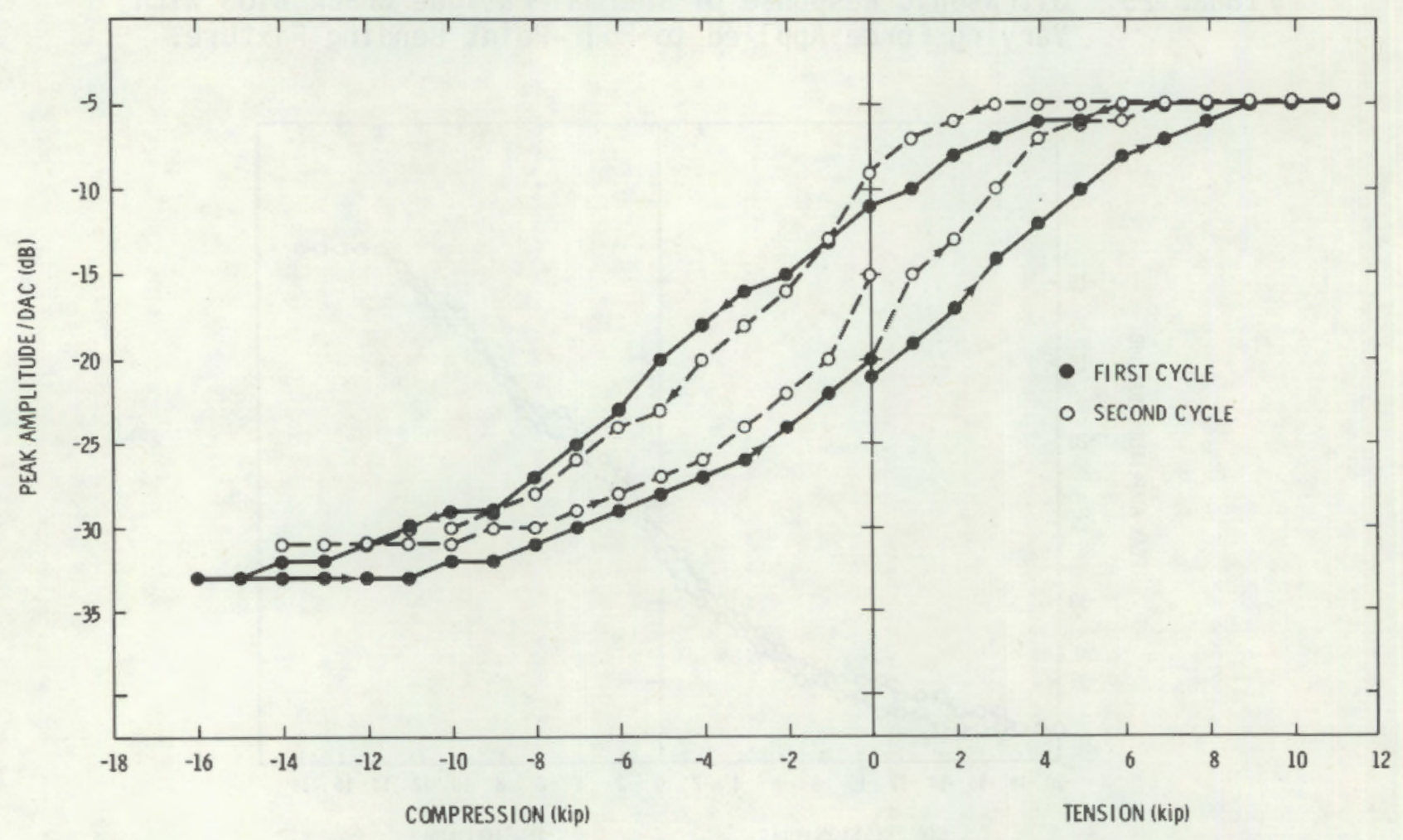

FIGURE 28. Ultrasonic Response of Thermal Fatigue Crack B116 (Annealed) with Varying Force Applied to Four-Point Bending Fixture. 


\section{FUTURE PLANS}

Plans for the coming quarter include completion of the topical report of Phase I, completion of the Phase II Analysis Before Test Document and preparations for the Phase II round robin test, including sample preparation and contractual agreements with ISI vendors. 


\section{REFERENCES}

Che11, G. G. 1979. "A Procedure for Incorporating Thermal and Residual Stresses into the Concept of a Failure Assessment Diagram." ASTM STP 668, American Society for Testing and Materials, pp. 581-605.

Combustion Engineering, Inc. 1977. Design Bas is in Pipe Breaks for the Combustion Engineering Two Loop Reactor Coolant System. CENPD-168-A.

Hooper, J. L., ed. 1979. Reactor Safety Research Programs Quarterly Report, Nuc lear April 1-June 30, 1979. NUREG/CR-0962, PNL-3040-2, prepared for the

Regulatory Commission by Pac if ic Northwest Laboratory, Richland, WA.

Paris, P. C., M. P. Gomez, H. Fada, and L. E. Baldini. 1979. "Fracture Proof Design." Presented at ASTM 12 th National Symposium on Fracture Mechanics, Washington University, St. Lou is, MO.

Paris, P., C., H. Fada, A. Zahoor, and H. Ernst. 1979. "The Theory of Insta668 , bility of the Tearing Mode of Elastic-Plastic Crack Growth." ASTM STP

American Society for Testing and Materials, pp. 5-36.

Fada, H., P. C. Par is M. P. Gomez, and R. Gamble. 1979. "A Stability Analys is of Circumferential Cracks for Reactor Piping Systems." Presented at ASTM 12 th National Symposium on Fracture Mechanics, Washington University, St. Lou is, MO. 
STEAM GENERATOR TUBE INTEGRITY(a)

R. A. Clark, Project Manager

V. F. FitzPatrick, Deputy Project Manager
J. M. Alzheimer
R. L. Burr
P. G. Doctor
G. H. Lyon
C. J. Morris
K. R. Wheeler

\section{INTRODUCTION}

The Steam Generator Tube Integrity Program is a multiphase, multitask laboratory program. The principle objective is to provide NRC with validated information on the remaining integrity of Pressurized Water Reactor (PWR) steam generator tubes where service induced degradation has been indicated. An additional objective is to evaluate nondestructive instrumentation/techniques with which to examine defects in piping that serves as the reactor primary system pressure boundary.

Initial program tasks included producing a matrix of steam generator tube specimens with mechanically or chemically induced flaws simulating defects found in nuclear steam generator service. These flawed specimens are then fully nondestructively characterized by means of positive replication and various NDT techniques, mainly eddy current testing. The tube specimens are next tested to failure at reactor operating temperatures. The failure strength, actual flaw dimensions, and NDTindicated flaw dimensions are utilized to derive mathematical relationships. These relationships are plotted to provide, within a statistical certainty band, the remaining mechanical integrity of a steam generator tube as a function of its flaw type and size as indicated by eddy current testing.

(a) RSR Fin. Budget No. B2097; RSR Contact: J. Muscara 
Early work showed that conventional, single-frequency, eddy current evaluation of steam generator tubes, as used for in-service inspections, could be improved. Thus, program efforts were expanded to include new eddy current measurement techniques, the effects of different calibration standards, and a more complex statistical analysis of NDT data.

The first two phases of the program involved the study of mechanically (Phase 1) and chemically (Phase 2) defected tubing. Phase 3 of the program includes correlating the mathematical models developed in Phases 1 and 2 with actual service-flawed tubing. Lack of suitable specimens led to the redirection of Phase 3 into the Surry Generator Program, a subprogram of the Steam Generator Tube Integrity Program. The Surry Generator Program is comprised of tasks to relocate a nuclear steam generator removed from service at Surry, Virginia to Hanford, Washington. Once at Hanford the steam generator will be housed in a specially designed facility to allow nondestructive as well as destructive examination of the unit. Research will be conducted in the areas of NDT technique verification and instrument development, defect matrix identification, profiling of defect types, extent and locations, identification of deposits and sources of corrosion, and health physics. The generator will also become a source of specimens with service-induced flaws for various NRC programs. Potential later research phases include simulated operation of a portion of the generator to assess long term effects on generator serviceability of chemical cleaning or decontamination procedures that may be proposed to NRC for licensing. Study of the recovery and reuse of materials in decommissioned reactor components is also a potential research task.

One further area of research involves primary system integrity in BWR piping. The 304 stainless steel alloy used in existing BWRs has exhibited stress corrosion cracking (SCC) in the heat-affected zone around welds. A principle concern is to monitor susceptible regions for crack initiation and growth. This will allow for timely repair at scheduled shutdowns. We are examining for NRC a monitoring device utilizing the principle of internal friction measurements. The device is attached to a specimen incorporated into a high-flow, water loop operated under BWR conditions. The specimen is cyclically loaded to failure while measurements are taken in an environment representative of field operating conditions. 


\section{TECHNICAL PROGRESS}

The following paragraphs detail progress in program tasks active this past quarter.

\section{STRESS CORROSION CRACKING OF INCONEL 600}

Phase 2 of the Steam Generator Tube Integrity Program required the manufacture and testing of specimens chemically defected to simulate conditions believed to exist in-reactor. Stress corrosion cracking of Inconel 600 tubing in a controlled manner was the final specimen preparation remaining. This past quarter saw completion of the required 63 specimens, plus a few spare samples. In addition, several samples were made to allow destructive assay during efforts to achieve a reliable nondestructive characterization of stress corrosion cracks in the tubes.

\section{STRESS CORROSION CRACKING OF 4-INCH DIAMETER, BWR PIPING}

An important aspect of the Steam Generator Tube Integrity program has been research related to nondestructive examination and characterization of flaws in tubing and piping. This pipe task is designed to assess the use of a nondestructive examination technique based on internal friction measurements for determining crack initiation and growth. Figure 1 shows the experimental configuration. A wave pattern is set-up in the pipe with a mechanical pinging device. Damping of the waveform is used to characterize defect initiation and growth in a pipe specimen.

Tests are conducted on 4" schedule 80 pipe. Reactor noise conditions are simulated by circulating water at $\sim 75 \mathrm{gpm}$ through the pipe. The water loop maintains the pipe sample at $550^{\circ} \mathrm{F}$. Pipe specimens are subject to cyclic loading by hydraulic rams positioned on either side (see previous quarterly report). The current series of tests is to establish baseline performance of the internal friction technique. Individual pipes are cyclically loaded to failure. Load and time to failure are compared to indications of crack initiation. We are attempting to establish if crack initiation as indicated by internal friction has a 
DAEDALEAN ASSOCIATES, Inc.

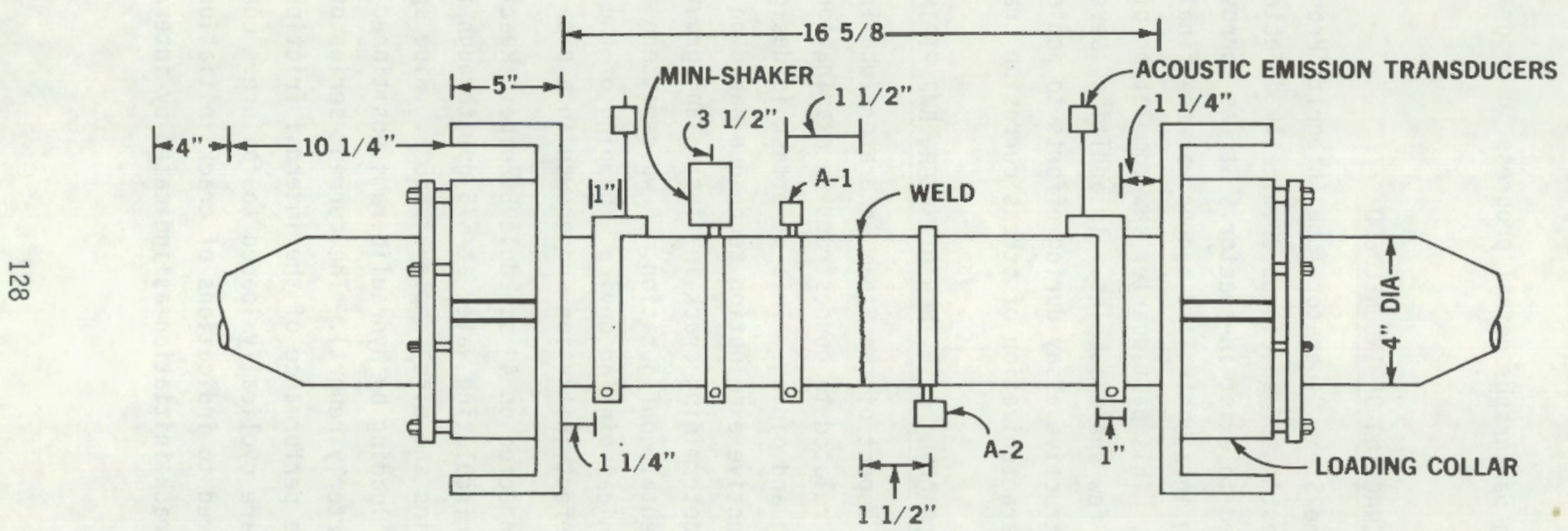

WATER FLOW

FIGURE 1. Experimental Configuration of Daedaleans Internal Friction Device 
constant relation to remaining pipe life. This quarter tests were completed on three specimens. Figure 2 shows the weld configuration used on all specimens. Table 1 lists the welding procedure for fabricating all specimens except the one tested in the previous quarter.

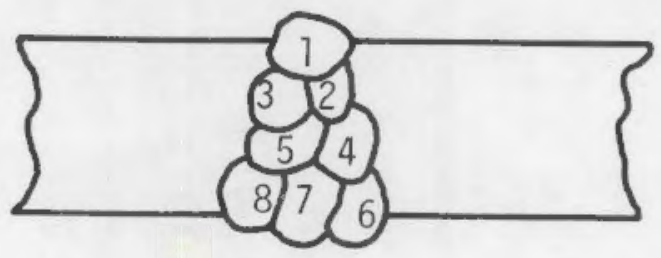

FIGURE 2. Weld Configuration of 4 "sch 80 Pipe Specimens

Specimen 2 was cyclically loaded to $135 \%$ of $550 \mathrm{~F}$ yield strength for 225 cycles. Loading was increased to $150 \%$ of yield until failure at load cycle 246 . Specimen 3 was cyclically loaded to $150 \%$ of yield strength and failed after 75 cycles. Specimen 4 was cyclically loaded to $136 \%$ of the yield strength and failed on cycle 163 . There were several features of note on the pipe failures. First there does not appear to be a constant correlation between cycles to failure and loading stress. Increased load does promote earlier failure but a wide scatter appears to exist on cycles to failure for specimens identically loaded. This observation agrees with information published by the General Electric pipe laboratory.

Data on indication of crack initiation versus load cycles and indication of crack initiation versus remaining pipe life to failure were gathered. These results are reported by Daedalean Associates under their contract with NRC. Daedalean staff instrumented the pipe tests with their internal friction measurement device. They are likewise responsible for data accumulation and interpretation. 


\section{TABLE 1. Pipe Weld Parameters}

Weld Process

Max. Interpass Temp.

GTA Electrode

Filler Metal Size

Polarity

Voltage

Amps

Travel Speed (IPM)

Torch Gas: Type/Flow, CFH

Gas Cup Size

I.D. Purge: Type/Flow, CFH

Weave Width

Purge Quality
PASS NO.

\begin{tabular}{|c|c|c|c|c|}
\hline Root & $\underline{2 n d}$ & 3rd & 4 th & Reminder \\
\hline GTA & GTA & SMA & SMA & SMA \\
\hline$<350^{\circ} \mathrm{F}$ & $<350^{\circ} \mathrm{F}$ & $<350^{\circ} \mathrm{F}$ & $<350^{\circ} \mathrm{F}$ & $<350^{\circ} \mathrm{F}$ \\
\hline $3 / 32^{\prime \prime} \emptyset$ & $3 / 32^{\prime \prime}$ & - & - & - \\
\hline $\begin{array}{l}1 / 16 \times 3 / 16^{\prime \prime} \\
\text { Grinnell Insert }\end{array}$ & $3 / 32^{\prime \prime} \emptyset$ & $1 / 8^{\prime \prime} \emptyset$ & $\begin{array}{l}\text { (Same } \\
\text { as }\end{array}$ & $\begin{array}{l}\text { Same } \\
\text { as }\end{array}$ \\
\hline DCSP & DCSP & DCRP & $3 r d)$ & $3 r d)$ \\
\hline $9-10$ & $9-10$ & $22-24$ & & \\
\hline $100 \pm 5$ & $100 \pm 5$ & $100 \pm 5$ & & \\
\hline 2.2 to 2.5 & 2.2 to 2.5 & 4 to 5 & & \\
\hline Argon $/ 6-8$ & Argon/15/18 & NA & NA & NA \\
\hline$\# 6-\# 8$ & $\# 6-\# 8$ & NA & NA & NA \\
\hline Argon/6-8 & Argon/6-8 & Not Required & Not Required & Not Required \\
\hline None & Across Groove & Across Groove & Across Groove & \\
\hline $2 \% \mathrm{O}_{2}$ Max. & $2 \% \mathrm{O}_{2}$ Max. & & & \\
\hline
\end{tabular}


Figures 3-7 illustrate typical pipe failures. Failure results from an overstress condition on remaining pipe ligament after considerable crack growth. Typical failure occurs instantaneously over 180 to $270^{\circ}$ of the pipe. Prior to this several cracks appear to grow together with perhaps 80 to. $90 \%$ of the pipe wall cracked (Figures 6 and 7 ). In no case did we observe a crack progressing through-wall, producing a leak, prior to the massive failure of the $4 "$ pipe. It should be pointed out that pipe loading was such that the force on the pipe per cycle remained constant. There was no constraint on movement (i.e., strain control) so that as a crack developed on one side of the pipe, this side still received the same applied loading per cycle. Thus, as cracking proceeded the stress in this area would increase on the remaining uncracked pipe cross section.

\section{NONDESTRUCTIVE TESTING}

Eddy current evaluation continued on Inconel 600 steam generator tubing exposed to our stress corrosion cracking procedure. We still lack a proven alternate nondestructive evaluation (NDE) technique for detecting stress corrosion cracks in relatively thin wall tubing. Several experiments were conducted to attempt to find a reliable means of independent verification of the eddy current data. Resistivity gauge measurements held some potential but were not entirely satisfactory. Crack depth information could be obtained for specimens with a single well defined crack. Branching or close-parallel cracks tended to give inconsistent results. There is also a fixture problem, the contact points on the gauge spread because of the large curvature on tube surfaces. This strongly influences resultant readings.

Lacking an independent ability to confirm eddy current SCC indications, one other possible approach would be obtaining an independent consensus from several parties conducting eddy current tests. In this vein we initiated a blind round robin eddy current test of ten specimens with stress corrosion cracks. We will seek between five and ten independent evaiuations during the next six months. If a pattern of agreement on defect morphology emerges, this would possibly be the best nondestructive analysis currently obtainable. 


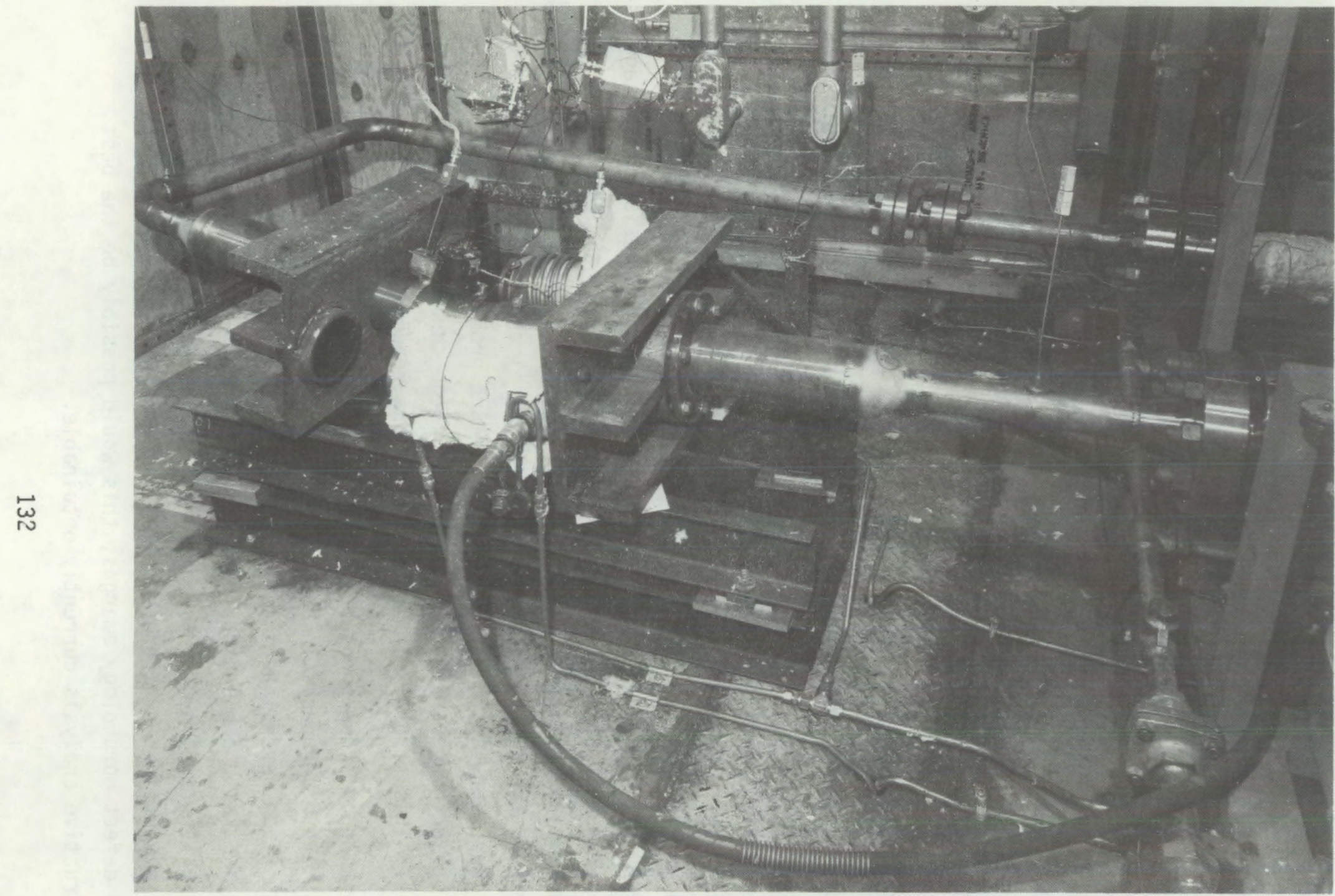

FIGURE 3. 4" Pipe Failure Showing Test Stand 


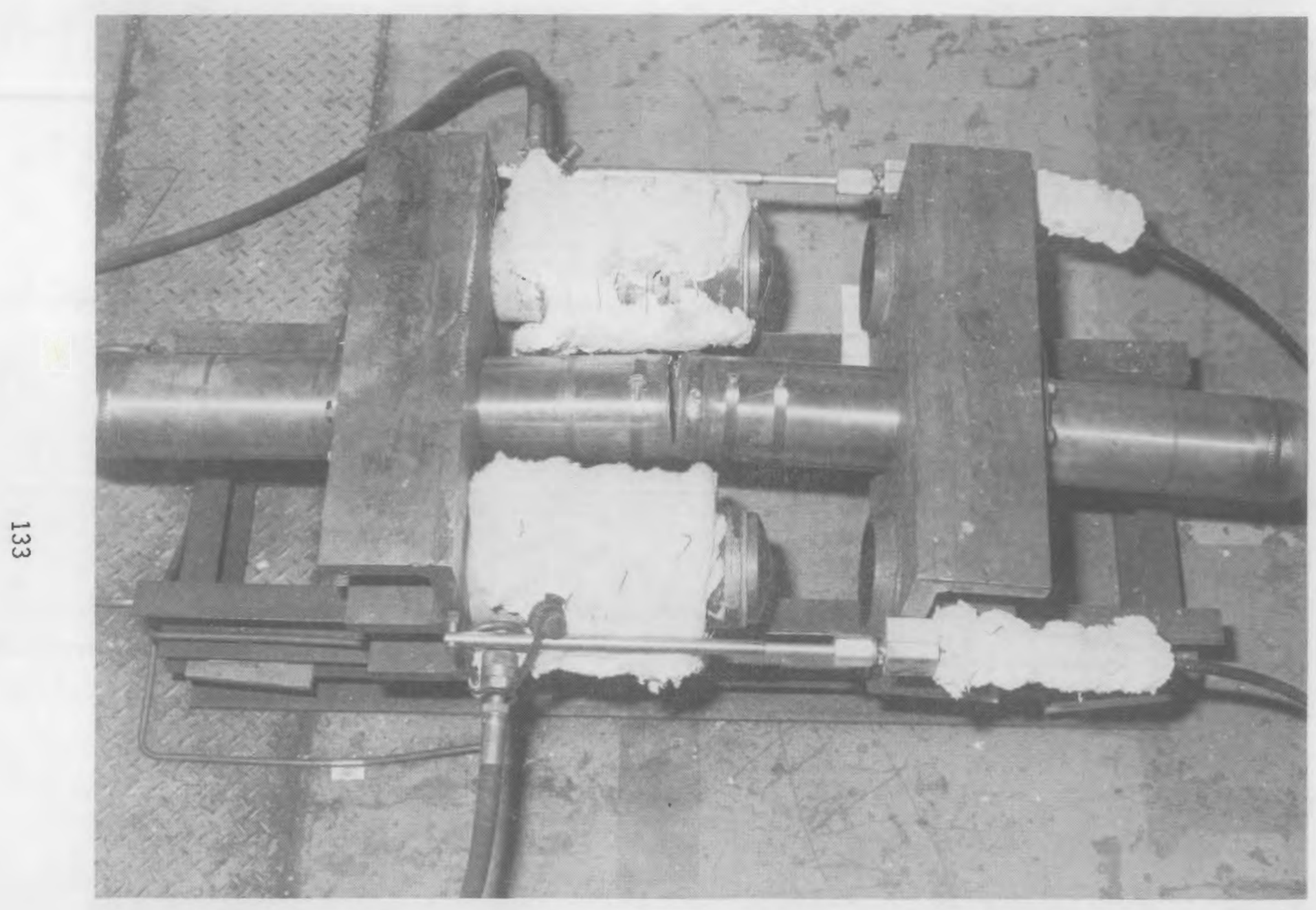

FIGURE 4. Pipe Failure with Loading Ram Detail 


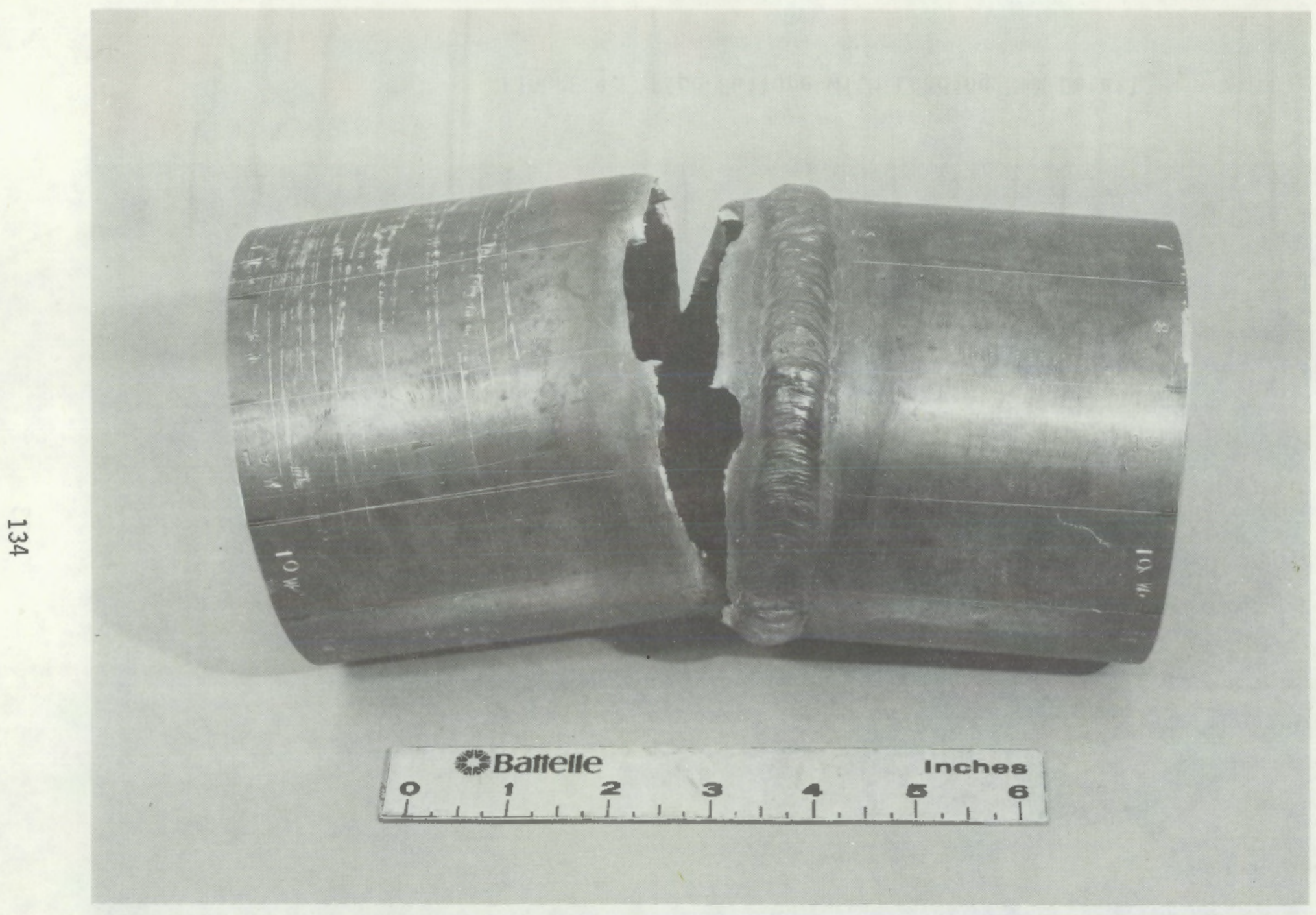

FIGURE 5. 4" Pipe Exhibiting Failure Mechanism of Several Cracks Growing Together. Also Apparent is the Large Extent of Failure 


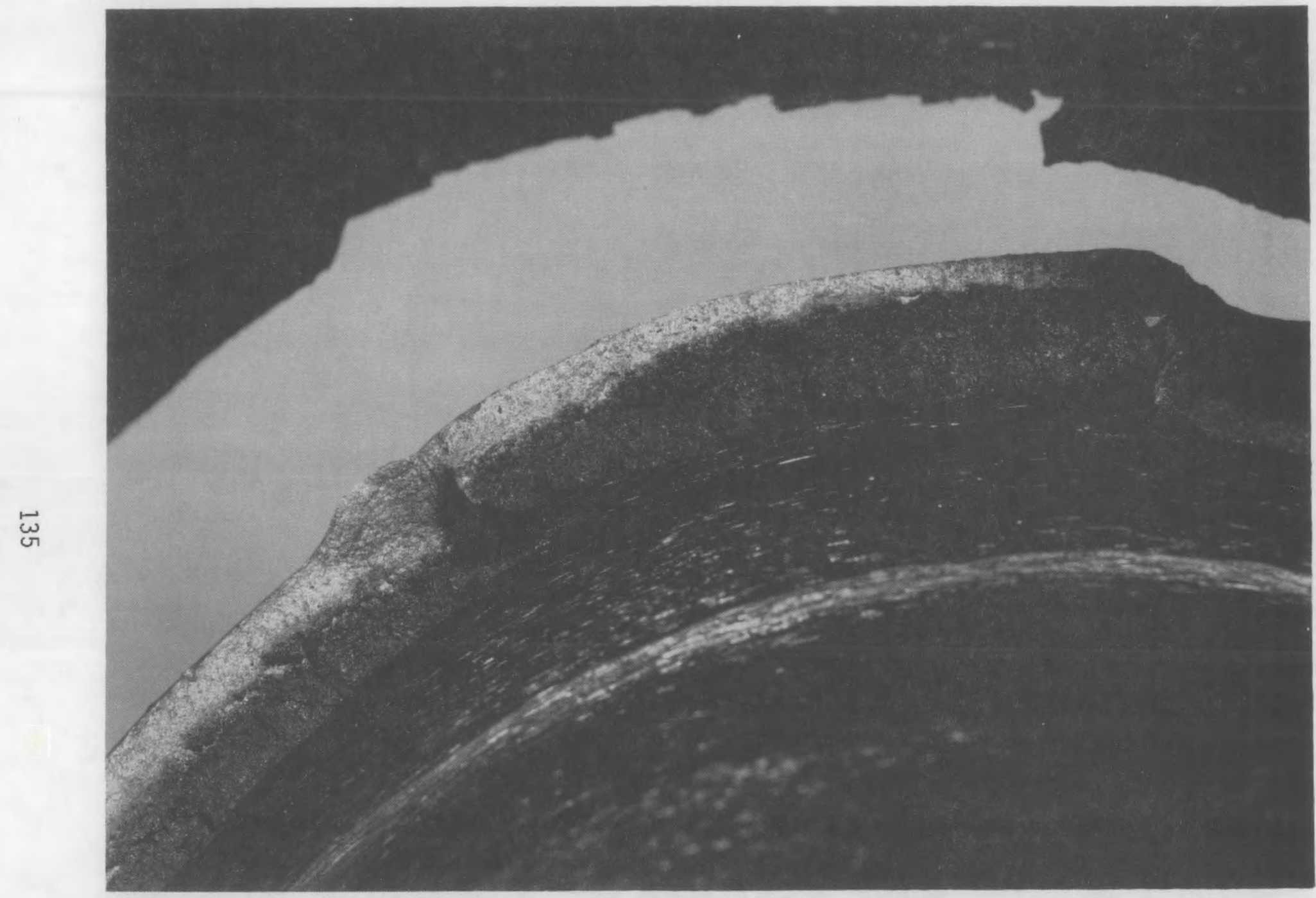

FIGURE 6. Details of the Fracture Surface of Specimen Shown in Figure 5 


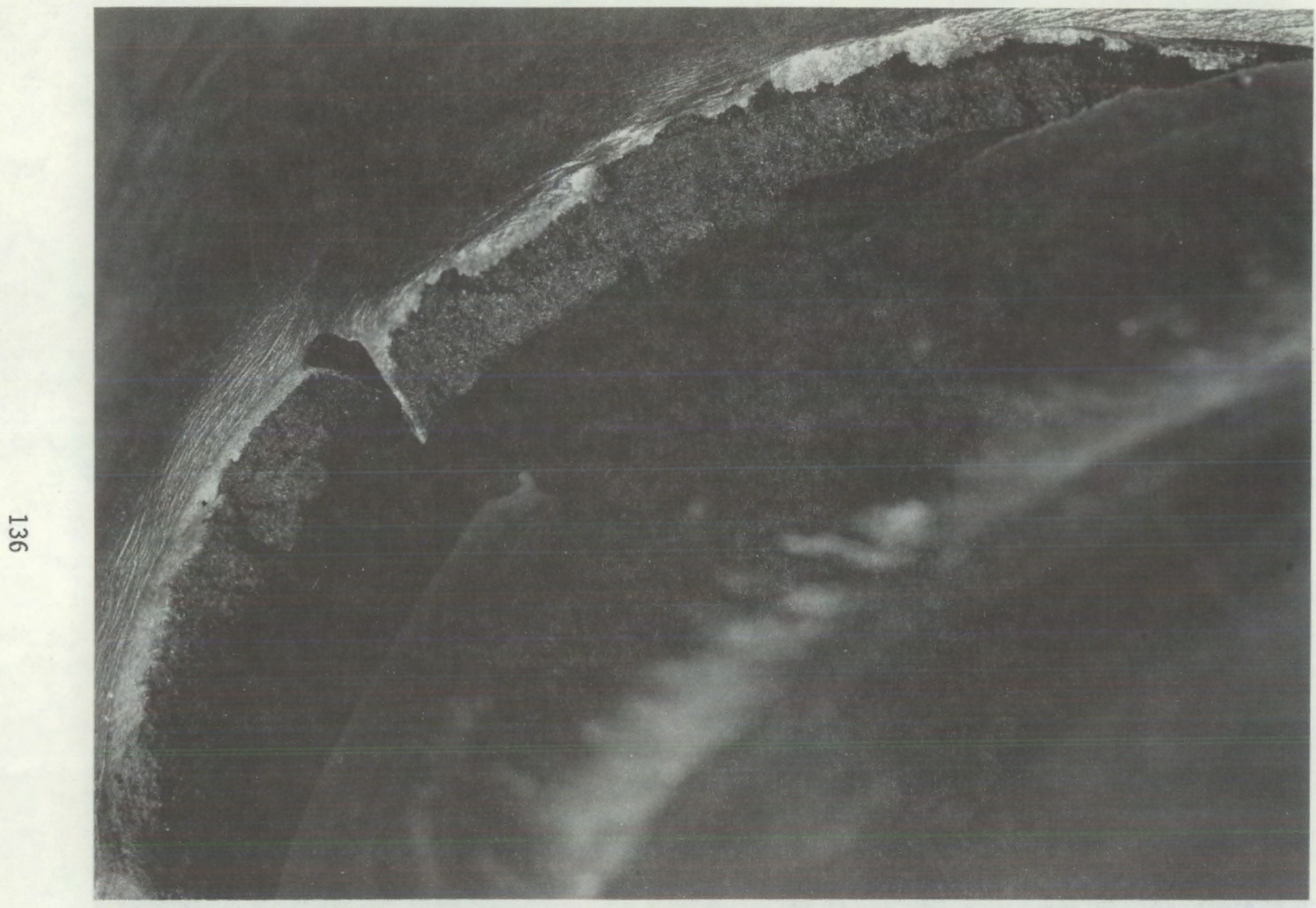

FIGURE 7. Details of Fracture Surface in Figure 5. Note the Dark Region Showing the Extent of Crack Growth Prior to Final Pipe Failure 
We also investigated the potential for crack definition after tube burst testing. Based on examination of the fracture surface, an attempt was made, via optical measurements, to calculate the initial crack depth. Figure 8 shows the fracture surfaces examined. Specimens fabricated with EDM notches in Phase I of the program were used. A range of crack depths was thus readily available. Also the EDM slot depths were accurately known from plastic replication of the specimens prior to burst testing. The conclusion from examining several fracture surfaces was that the initial crack depth could not be reliably determined in this manner. Plastic deformation resulting from the burst test thinned both the initial cracked area and the remaining tube ligament. Repeat specimens with identical EDM notches exhibited widely different thinning in the notched area ( $20 \%$ of tube wal1). This effect was accentuated by varying crack length which caused different bridging effects; shorter notches were more deformed than longer notches. Also initial EDM notch depth, for specimens notched less than 55\% through wall had no consistent effect on after burst indicated notch depth.

Efforts at crack characterization via $X$-ray tomography are continuing. One additional specimen has been forwarded to Los Alamos for examination.

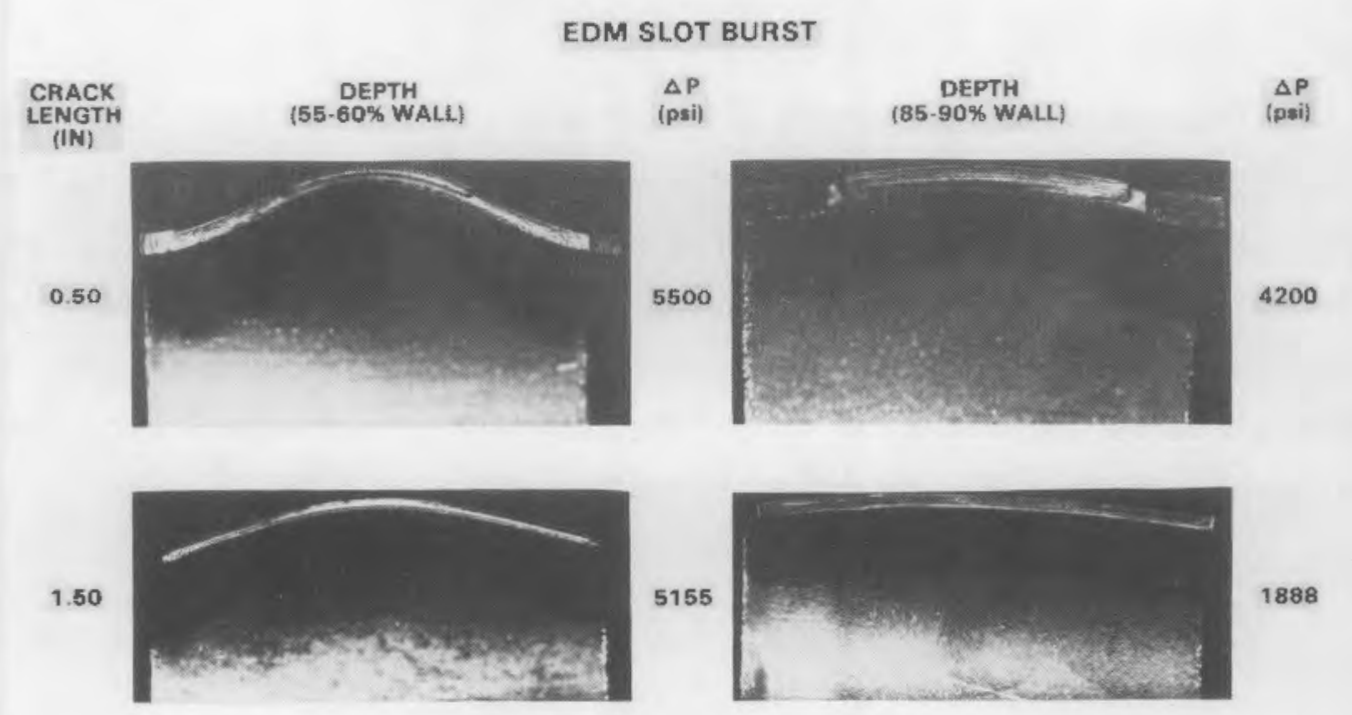

FIGURE 8. Typical EDM Notched Tubing Fracture Surfaces used to Evaluate use of Post Failure Crack Morphology to Determine Initial Crack Depth 


\section{BURST TESTING}

In conjunction with efforts to characterize stress corrosion cracks in tubing, a few SCC specimens were burst tested. The crack depth was characterized by eddy current techniques. Burst pressures versus indicated crack depth compared closely with burst data on EDM notched specimens. This implies that the eddy current evaluation of the stress corrosion cracking was accurate to within the Phase I derived curves of failure pressure as a function of defect depth.

Burst testing of stress corrosion cracked tubing produced an interesting observation on failure mode. Those specimens with $>50 \%$ through wall indicated cracking failed by propagation of the crack through the remainder of the tube wall. There was little or no discernible plastic deformation or bulging of the tube. This mode of failure would imply that a large leak would not be associated with through wall stress corrosion cracking. We are investigating to determine that the failure mode was not due to specimen preparation technique. Concentrated caustic remaining from the method used to generate stress corrosion cracks is the main concern.

\section{STATISTICAL ANALYSIS}

This past quarter Phase I and Phase II data on burst/collapse strength versus defect type and size were reexamined. The data were replotted with standard deviation bands added to tube strength versus defect size plots. Figures 9-14 show these results. All existing data from Phase II (chemically defected) specimens was incorporated. The constitutive equations on tube life developed in Phase I were not altered by the addition of these data points. 


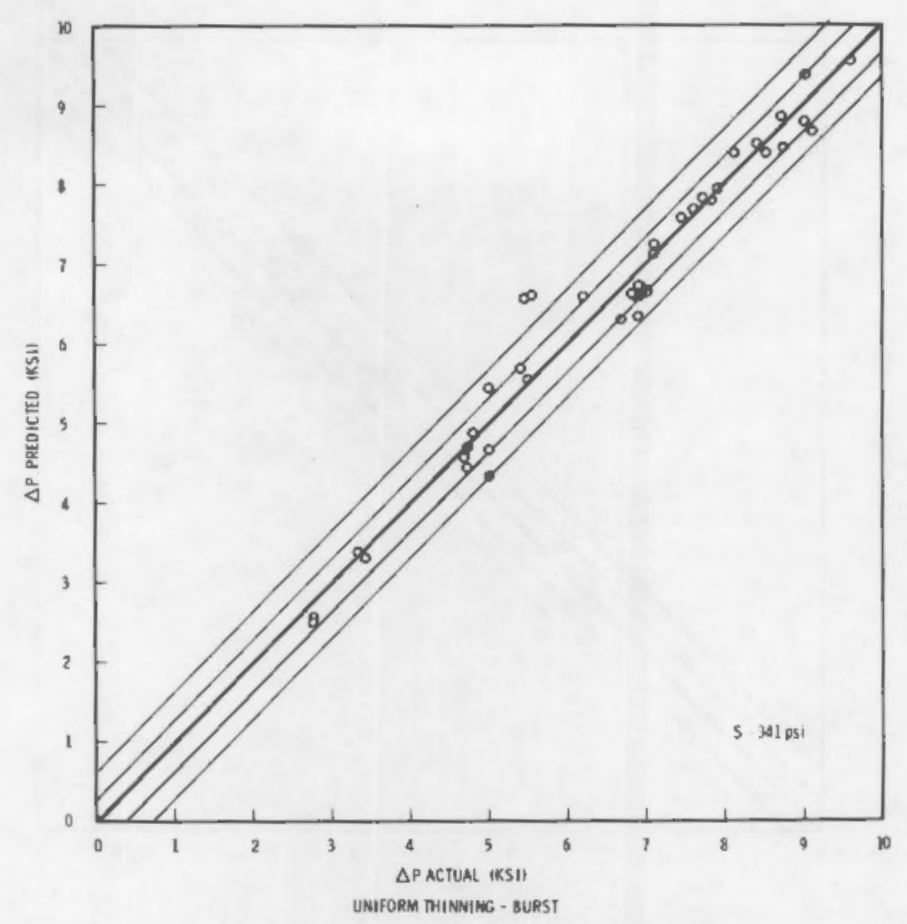

FIGURE 9. Standard Deviation Plot of Predictive Mathematical Model for Burst Pressure of Tubing with Uniform Thinning Defect

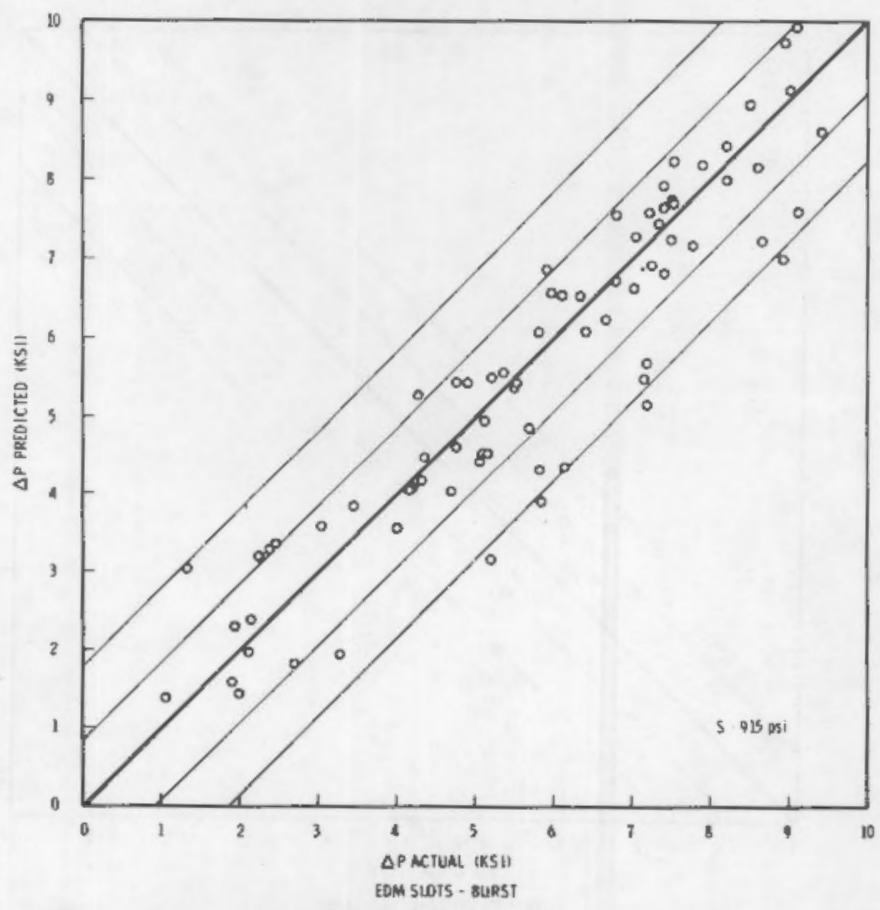

FIGURE 10. Standard Deviation Plot of Predictive Mathematical Model for Burst Pressure of Tubing with EDM Slot Defect 


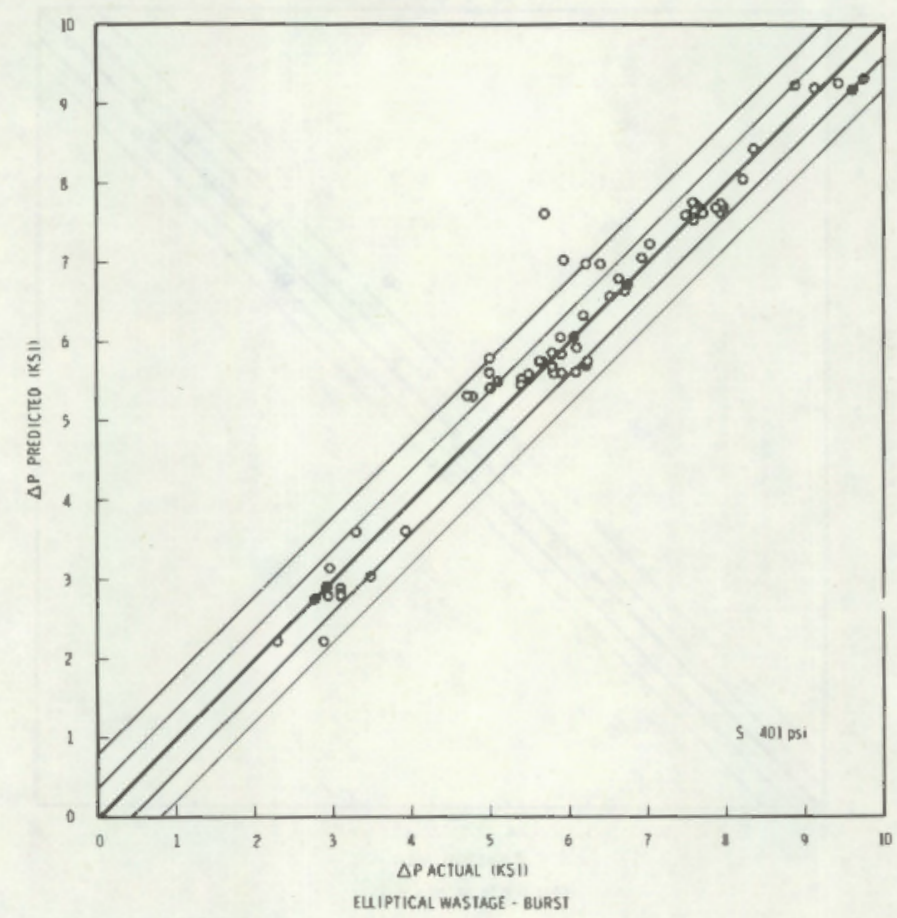

FIGURE 11. Standard Deviation Plot of Predictive Mathematical Model for Burst Pressure of Tubing with Elliptical Wastage Defect

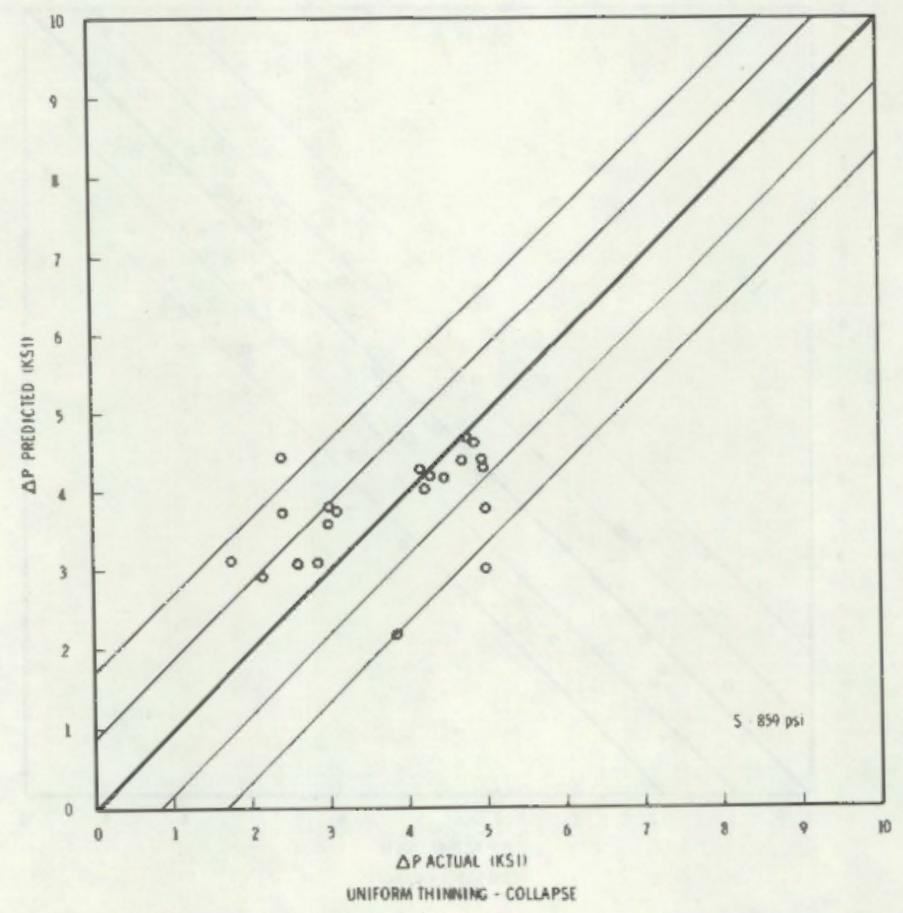

FIGURE 12. Standard Deviation Plot of Predictive Mathematical Model for Collapse Pressure of Tubing with Uniform Thinning Defect 


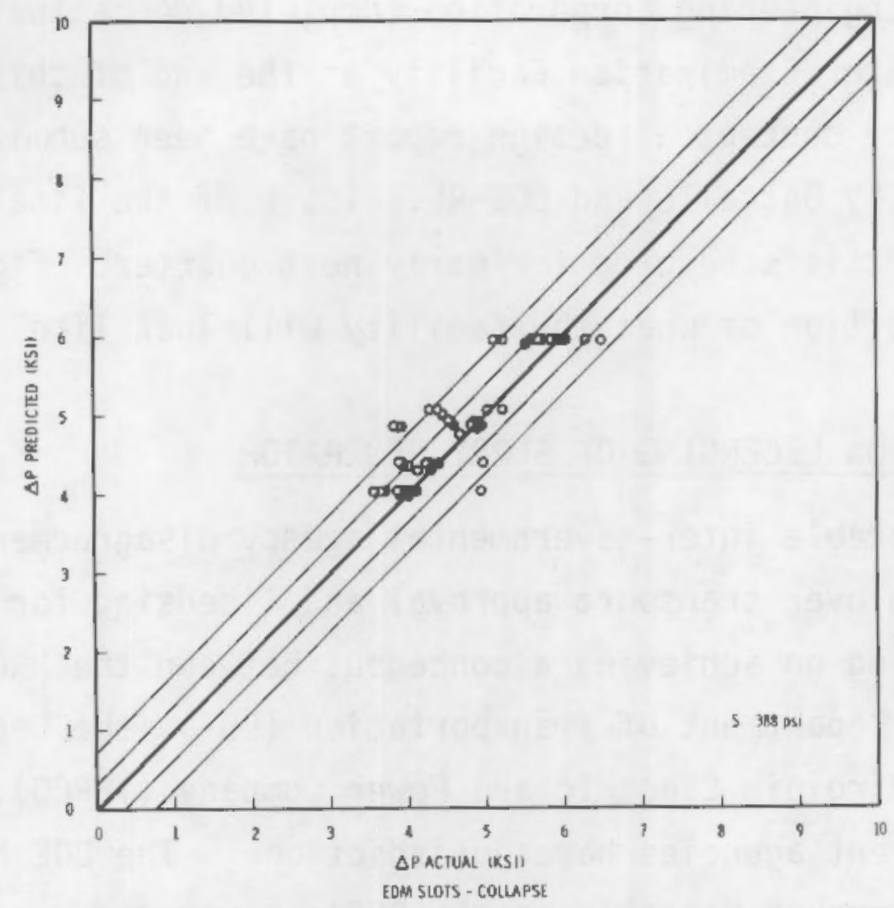

FIGURE 13. Standard Deviation Plot of Predictive Mathematical Model for Collapse Pressure of Tubing with EDM Slot Defect

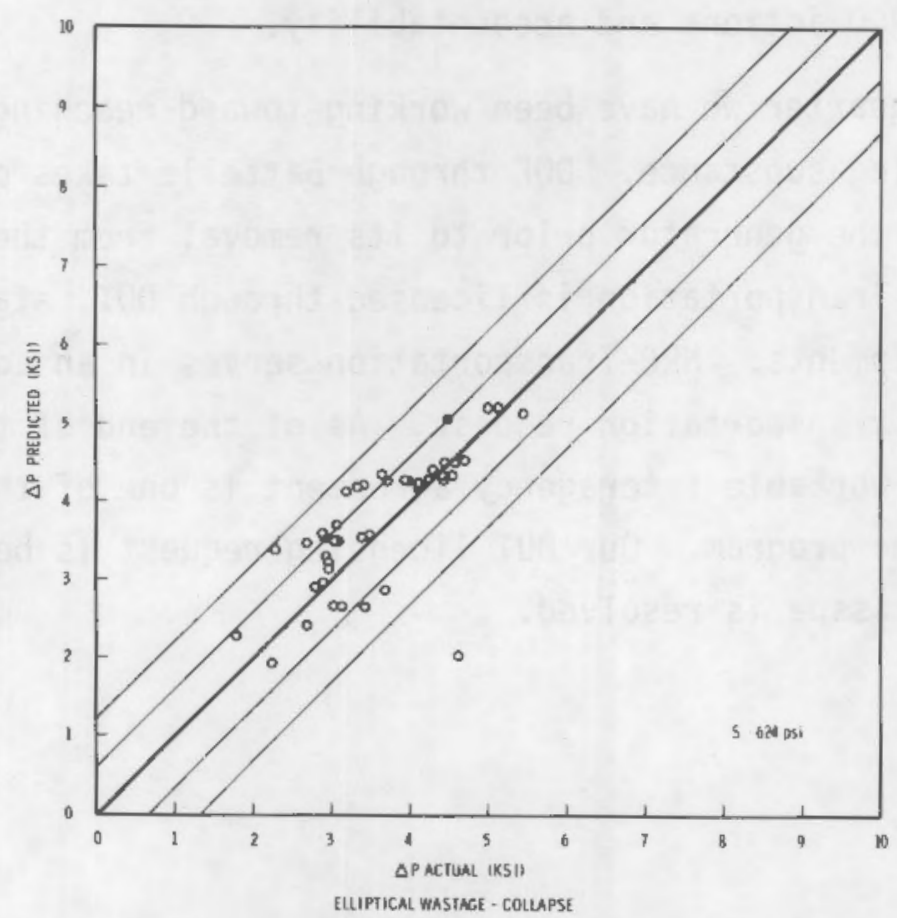

FIGURE 14. Standard Deviation Plot of Predictive Mathematical Model for Collapse Pressure of Tubing with Elliptical Wastage Defect 


\section{STEAM GENERATOR EXAMINATION FACILITY}

Vitro Engineering Corporation completed conceptual design of the Steam Generator Examination Facility at the end of this quarter. Draft copies of the conceptual design report have been submitted for review and comment by Battelle and DOE-RL. Issue of the final Conceptual Design Report is scheduled for early next quarter. Figure 15 is an artist's rendition of what the facility will look like.

\section{TRANSPORTATION LICENSING OF SURRY GENERATOR}

Considerable inter-governmental agency disagreement exists on jurisdiction over transport approval and licensing for the generator. We are working on achieving a concensus between the NRC-Transportation Branch, the Department of Transportation (DOT), the Department of Energy (DOE), and Virginia Electric and Power Company (VEPCO). At issue is where different agencies have jurisdiction. The DOE has agreed to take ownership, through Battelle as the DOE's contractor, at the Surry site. The Surry site is an NRC 1icensed reactor operation. However, NRC does not have jurisdiction over DOE. NRC can, through licensing jurisdiction, dictate VEPCO actions and accountability.

This quarter we have been working toward reaching an agreement of the following substance. DOE through Battelle takes ownership and possession of the generator prior to its removal from the storage facility at Surry. Transportation is 1 icensed through DOT, standard procedure for DOE shipments. NRC-Transportation serves in an advisory capacity to DOT on our transportation request. As of the end of this quarter, reaching a workable interagency agreement is one of the major hurdles faced by the program. Our DOT licensing request is being held up by DOT until this issue is resolved. 


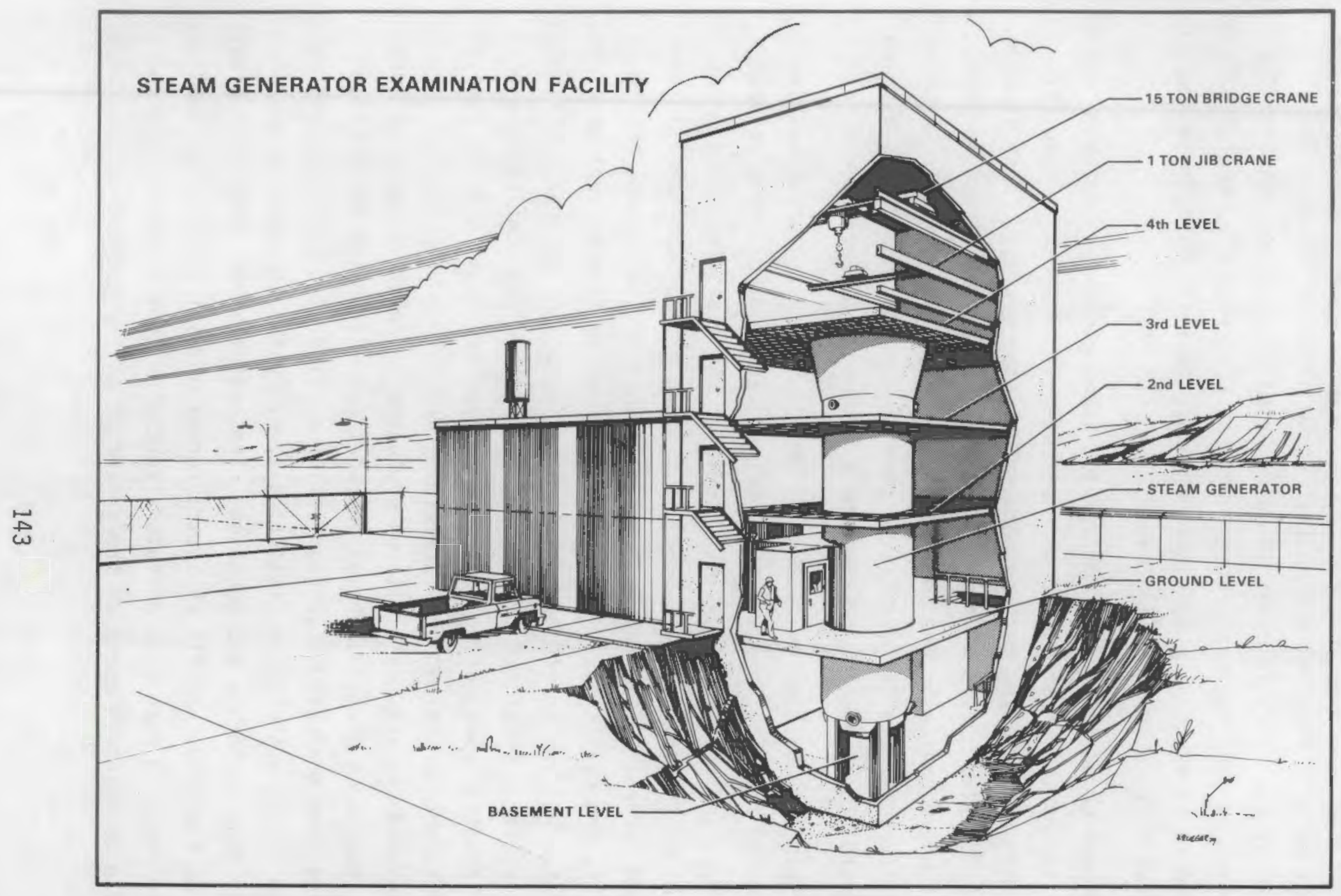

FIGURE 15. Artist's Rendition of Steam Generator Examination acility, Based on Conceptual Design 
SURRY GENERATOR PROJECT

This project, a subprogram of the Steam Generator Tube Integrity Program, was initiated with the FY 1979 Midyear Program Revision. The project entails retrieving a nuclear steam generator removed from service at the Surry II plant at Surry, Virginia and transporting the generator to Hanford, Washington. Once at Hanford the generator will be located in an especially designed temporary facility to allow nondestructive and destructive examination.

Research on a removed from service steam generator orginated out of Phase III of the Steam Generator Tube Integrity Program. Phase III involved obtaining and testing service defected tubing. These tests were to confirm models of remaining tube strength, developed in Phases I and II on mechanically and chemically simulated tube defects. An inability to obtain representative service defected tubing was a prime motivation for proposing research on a removed from service generator.

This past quarter an outline of proposed research areas was submitted for review. This outline together with comments from several sources, as discussed below, will serve as the basis for development of a detailed program plan and schedule. Areas of proposed investigation include nondestructive examination, materials and corrosion, health physics, and statistics. An extensive nondestructive evaluation of the generator will be the initial research effort. The generator will then be selectively sectioned to provide verification and confirmation of nondestructive examination techniques. Specimens will also be removed for destructive evaluation of remaining mechanical properties. Corrosion products and scale will be evaluated to relate effects of water constituents on steam generator degradation. Extensive information derived from nondestructive examination coupled with visual inspections during sectioning will be statistically evaluated to create a map of defect type, severity and location. The potential for material salvage will be explored. Health physics information will be obtained that will aid in reducing exposures on future generator repairs and maintenance. We plan to maintain parts of the generator as representative test beds 
for NRC. These could be used to assess new nondestructive testing techniques or to conduct research on long term effects of chemical cleaning or decontamination methods which may be proposed to NRC for 1 icensing.

\section{INSTITUTIONAL STRUCTURE}

The complexity and magnitude of the Surry Generator Program suggests that this may be a unique effort. Although the controlining research guidelines are to obtain information required by NRC, there are several areas where utilities and reactor vendors could benefit. In this vein we are attempting to establish a joint research program with the Electric Power Research Institute, EPRI, and other interested parties. Technical review of proposed research is to be by a committee of NRC and industry experts. This past quarter visits were conducted at Westinghouse, Babcock and Wilcox, and Combustion Engineering by the NRC and Battelle program managers. Also present was a representative of EPRI. At these meetings proposed research tasks were discussed, areas of vendor interest were established, and the guiding committee of technical experts in part established.

Most tasks on the Surry Steam Generator Program this past quarter involved establishing procedures and contracts for preparing and licensing the generator for shipment. These tasks are discussed below.

\section{TEMPORARY STORAGE}

The facility for destructive examination of the generator is scheduled to be available in 1981. A site has been secured for temporary storage of the generator until the examination facility is ready. The temporary storage site obtained is optimal because:

1. Electric power is close at hand, which will allow some early experiment access to the generator.

2. It is located within the existing security fence perimeter, therefore no additional security arrangements will be required.

3. Little daily personnel activity occurs in the storage area, minimizing radiation shielding requirements.

4. Temporary storage is very close to both the barge off-loading site and the location of the examination facility, minimizing transport expenses. 


\section{TRANSPORTATION PREPARATION OF THE SURRY GENERATOR}

At DOT-Richland's request, a management plan "For Acquisition, Preshipment Preparation and Transport of a Retired Nuclear Steam Generator" was prepared. The plan was submitted for DOE-RL review and approval after receiving Battelle Pacific Northwest Laboratory (PNL) management approval.

PNL has initiated work on obtaining all necessary subcontractors for preparation and shipment. Business and Engineering Consultants Incorporated has been contracted as marine consultants. In this capacity they will assist in developing loading and lashing requirements. A request for proposal (RFP) was issued to obtain a transport company to supply barging services. A sole source RFP was issued to Williams Crane and Rigging to prepare the generator for shipment at Surry, transport the generator from the Surry crypt to the barge, and load it onto the barge. Sole source procurement was used in this last case because Williams Crane and Rigging is on site for VEPCO, involved in the generator replacement project. Thus, equipment activation charges are minimized. Also Williams personnel have gone through necessary security and health physics clearances. Contract negotiations should be finalized this coming quarter.

\section{MILESTONES}

- Marine consultants are under contract.

- Conceptual design of the Steam Generator Examination Facility completed for review and comment.

- Draft Statement of Work for architect-engineering services - Steam Generator Examination Facility. Submitted to DOE.

- Fabrication of all stress corrosion cracked tubing samples for Phase II program requirements was completed. 


\section{PROBLEMS}

- Jurisdictional issues between the several government agencies involved in licensing transport of the generator must be resolved.

- Characterization of stress corrosion cracks in Inconel 600 tubing has not yet been achieved. This continues to prevent completion of Phase II mechanical properties testing. 

No. of

Copies

\section{OFFSITE}

\section{A. A. Churm}

DOE. Patent Division

9800 S. Cass Avenue

Argonne, IL 60439

600

U.S. Nuclear Regulatory Cormission

Division of Technical Information and Document Control

7920 Norfolk Avenue

Bethesda, MD 20014

2 DOE Technical Information Center

R. F. Abbey, Jr.

Reactor Safety Research Division

Nuclear Regulatory Commission

Washington, DC 20555

S. Fabric

Reactor Safety Research Division

Nuclear Regulatory Commission

Washington, DC 20555

D. A. Hoatson

Reactor Safety Research Division Nuclear Regulatory Commission

Washington, DC 20555

W. V. Johnston

Reactor Safety Research Division

Nuclear Regulatory Commiss ion

Washington, DC 20555

10 J. Muscara

Reactor Safety Research Division Nuclear Regulatory Commission Washington, DC 20555
No. of

Copies

R. D. Schamberger

Reactor Safety Research Division

Nuclear Regulatory Commiss ion

Washington, DC 20555

H. H. Scott

Reactor Safety Research Division

Nuclear Regulatory Commission

Washington, DC 20555

R. Van Houton

Reactor Safety Research Divis ion

Nuclear Regulatory Commiss ion

Washington, DC 20555

M. A. Wolf

Department of Atmospheric

Sciences

Oregon State University

Corvallis, OR 97330

L. Agee

Electric Power Research

Institute

$3212 \mathrm{Hillview}$ Avenue

P. 0. Box 10412

Palo Alto, CA 94304

B. R. Sehgal

Electric Power Research Institute

3212 Hillview Avenue

P. 0. Box 10412

Palo Alto, CA 94304

F. Shak ir

Department of Metallurgy

Association of American

Railroads

3140 S. Federal

Chicago, IL 60616 
No. of

Copies

SM-ALC/MMET

Attn: Capt. John Rodgers

McClellan AFB, CA 95652

Dr. Sotirios, J. Vahaviolos

Western Electric, ERC

P. 0. Box 900

Princeton, NJ 08540

Mr. Jerry Whittaker

Union Carbide Company

Oak Ridge National Laboratories

$\mathrm{Y}-12$

Oak Ridge, TN 37830

Mr. L. J. Anderson, 82402

Dow Chemical Company

Texas Division

P. 0. Drawer K

Freeport TX 77541

Mr. M. C. Jon

Western Electric, ERC

P. 0. Box 900

Princeton, NJ 08540

P. Causs in

Vincotte

1640 Rhode-Saint-Genese

Belgium

ACE Sinclair

Research Division

Berkeley Nuclear Laboratories

Berkeley

Gloucestershire, GL 139 PB

U.K.

203 U.S. Acoust ic Emission Work ing

Group Membership (GS Code)

Don Birchon

Admiralty Materials Laboratory

Holton Health Poole

Dorser, England

020-122-2711
No. of

Copies

W. L. Pearl

Nuclear Water \& Waste Technology

P. 0. Box 6406

San Jose, CA 95150

\section{ONSITE}

51 Pacific Northwest Laboratory

M. C. Bampton

F. L. Becker

T. D. Chikalla

R. A. Clark

E. L. Courtright

M. E. Cunn inghan

J. M. Cuta

J. F. Dawson

R. L. Dillion

C. W. Dotson

C. E. Elderk in

R. K. Hadlock

C. R. Hann

A. J. Haverfield

J. L. Hooper

P. H. Hutton

J. M. Kelly

R. J. Kurtz

P. T. Lands iede 1

D. D. Lanning

R. P. Marsha11

C. L. Mohr (3)

W. C. Morgan

C. J. Morr is

P. W. Nickola

C. A. Novich

L. T. Pedersen

G. J. Posakony

R. E. Schreiber

E. B. Schwenk

G. P. Selby

J. R. Skorpik

A. M. Sutey

M. J. Thurgood

G. L. Tingey

D. S. Trent

C. L. Wheeler

R. E. Williford

Technical Information (5)

Publishing Coordination $\mathrm{E}_{i}$ 